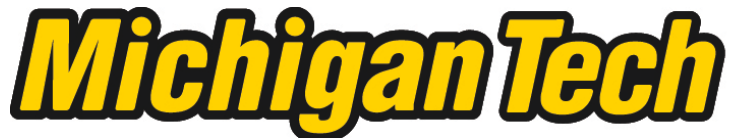 \\ Michigan Technological University Create the Future Digital Commons @ Michigan Tech
}

\section{Study of the effect of biodiesel fuel on passive oxidation in a catalyzed particulate filter}

Kenneth L. Shiel

Michigan Technological University

Follow this and additional works at: https://digitalcommons.mtu.edu/etds

Part of the Mechanical Engineering Commons

Copyright 2012 Kenneth L. Shiel

\section{Recommended Citation}

Shiel, Kenneth L., "Study of the effect of biodiesel fuel on passive oxidation in a catalyzed particulate filter", Master's Thesis, Michigan Technological University, 2012.

https://doi.org/10.37099/mtu.dc.etds/406

Follow this and additional works at: https://digitalcommons.mtu.edu/etds

Part of the Mechanical Engineering Commons 


\title{
A STUDY OF THE EFFECT OF BIODIESEL FUEL ON PASSIVE OXIDATION
} IN A CATALYZED PARTICULATE FILTER

\author{
By \\ Kenneth L. Shiel \\ A THESIS \\ Submitted in partial fulfillment of the requirements for the degree of \\ MASTER OF SCIENCE \\ (Mechanical Engineering)
}

MICHIGAN TECHNOLOGICAL UNIVERSITY

2012

(C) 2012 Kenneth L. Shiel 
This thesis, "A Study of the Effect of Biodiesel Fuel on Passive Oxidation in a Catalyzed Particulate Filter," is hereby approved in partial fulfillment of the requirements for the Degree of MASTER OF SCIENCE IN MECHANICAL ENGINEERING.

Department of Mechanical Engineering - Engineering Mechanics

Signatures:

Thesis Co-Advisor

John H. Johnson

Thesis Co-Advisor

Jeffrey D. Naber

Department Chair

William W. Predebon

Date 


\section{Table of Contents}

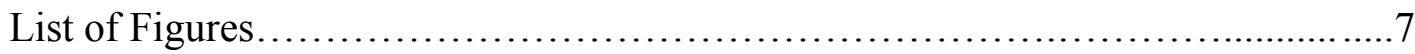

List of Tables............................................................... 10

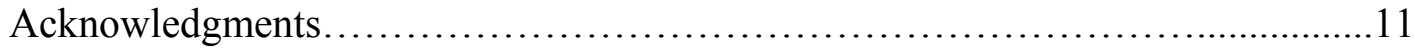

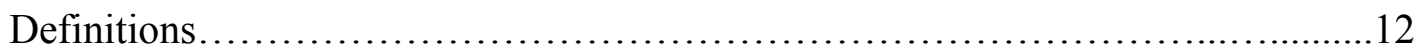

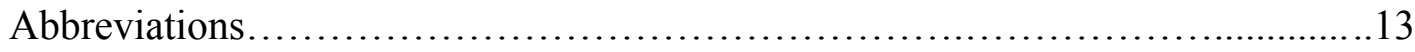

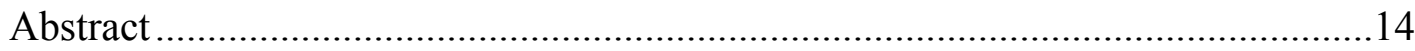

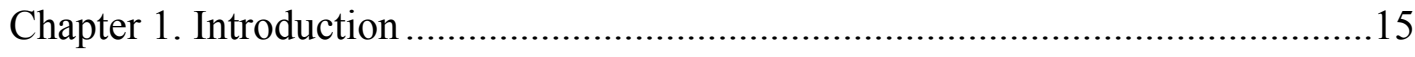

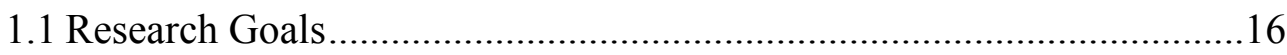

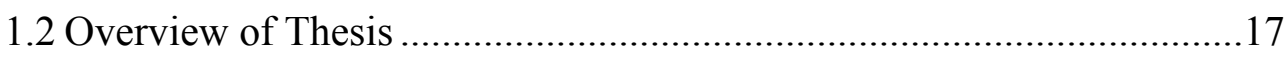

Chapter 2. Background and Literature Review......................................................18

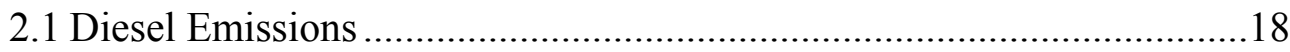

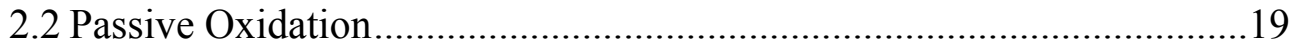

2.3 ULSD Compared to Biodiesel Emissions .............................................22

2.4 Catalyst Aging and Effect of Aging......................................................23

2.5 Modeling of the CPF Pressure Drop .........................................................23

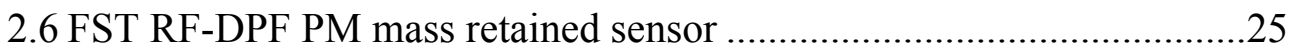

2.7 Pegasor Particle Sensor (PPS)...........................................................26

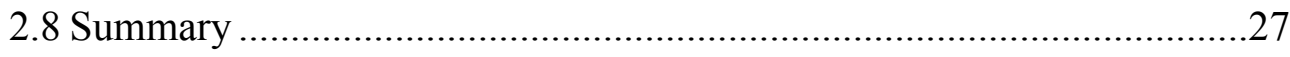

Chapter 3. Experimental Setup, Test Procedures.....................................................28

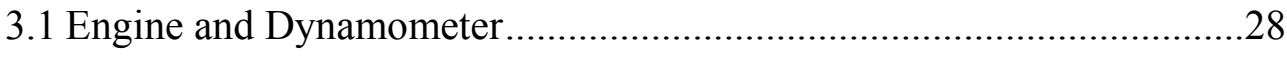

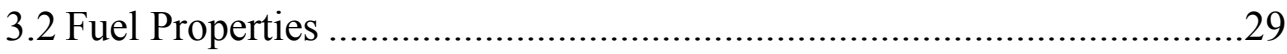

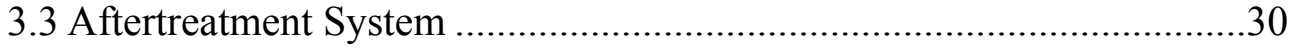

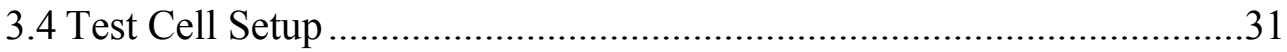

3.4.1 Data Acquisition .........................................................................32 
3.4.2 Temperature 32

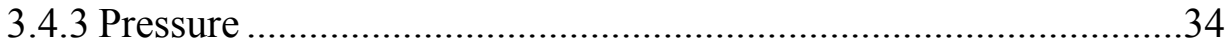

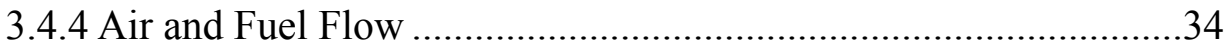

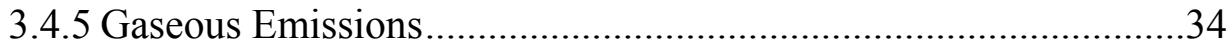

3.4.6 Particulate Matter Concentration ......................................................

3.4.7 Particle Size Distribution .............................................................35

3.4.8 PM Mass Retained in the Catalyzed Particulate Filter ...................35

3.5 Experimental Particulate Matter Sensors ..................................................38

3.5.1 FST RF-DPF Mass Retained Sensors …………………………......38

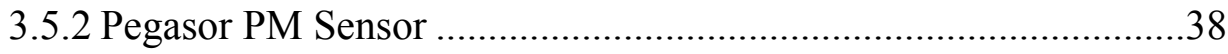

3.6 Passive Oxidation Test Procedure..............................................................38

3.6.1 Catalyzed Particulate Filter Clean out …………………………....39

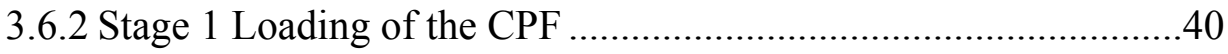

3.6.3 Stage 2 Loading of the CPF .......................................................42

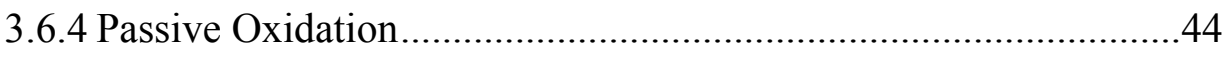

3.6.5 Stage 3 Loading of the CPF .............................................................45

3.7 Modified Test Procedure.......................................................................46

3.7.1 Temperature Ramp-up ...............................................................47

3.7.2 Stage 4 Loading of the CPF...........................................................48

3.7.3 Loading Time Prediction ...............................................................49

3.8 Passive Oxidation Test Matrix .............................................................50

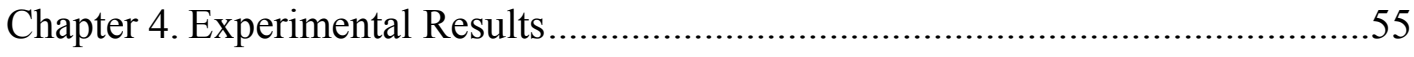

4.1 Test Procedure Comparison ...................................................................55

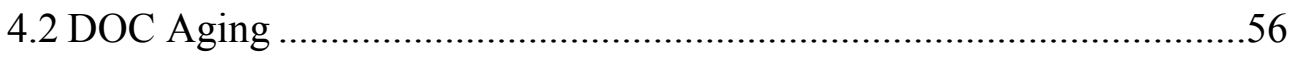

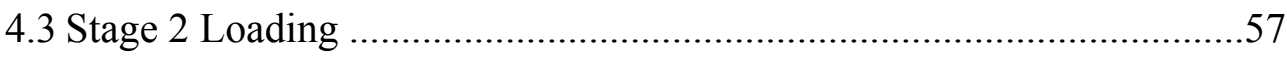




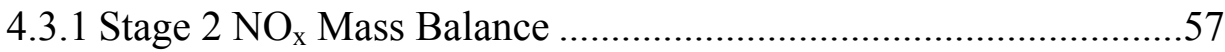

4.3.2 Stage 2 Gaseous Emissions...........................................................58

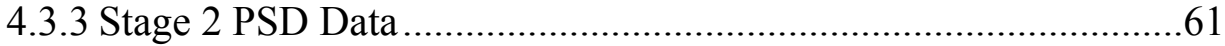

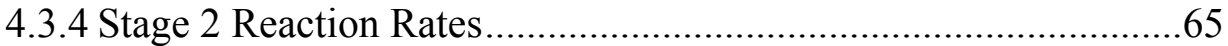

4.3.5 Stage 2 Differential Pressure Drop Profile …………………….....67

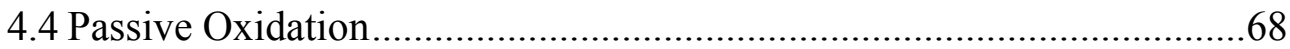

4.4.1 Passive Oxidation $\mathrm{NO}_{\mathrm{x}}$ Mass Balance ...........................................69

4.4.2 Passive Oxidation PSD Data ........................................................73

4.4.3 Passive Oxidation Reaction Rates................................................77

4.4.4 Passive Oxidation Differential Pressure Drop Profile ....................78

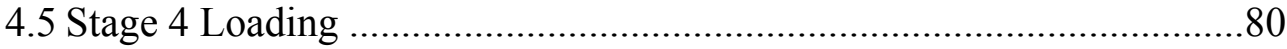

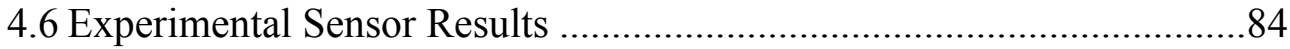

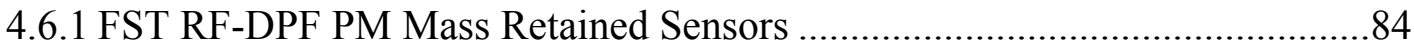

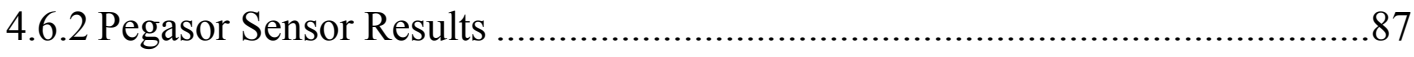

4.7 CPF Resistance Analysis …………………………….........................90

Chapter 5. Summary and Conclusions .....................................................................97

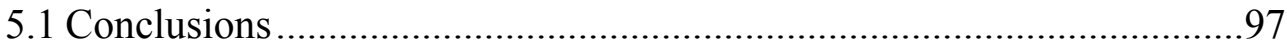

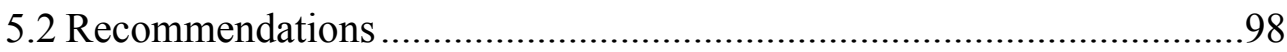

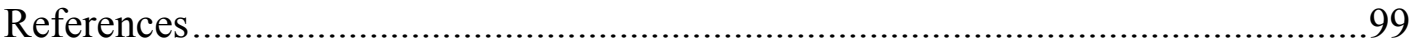

Appendix A $\quad$ CPF Thermocouple Layout prior to ISL 365 Test 10............................... 103

Appendix B PM Sample Filter Preparation ……………………………………........ 104

Appendix C PSD Sample Collection and Dilution Ratio Data Collection ..................... 105

Appendix D CPF Weighing Procedure ……………………………………………..... 107

Appendix E PM Mass Balance Calculations for Stage 1............................................ 109

Appendix F Filtration Efficiency during First Twenty Minutes of Loading ................. 113 


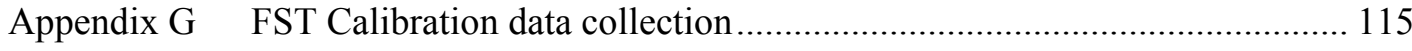

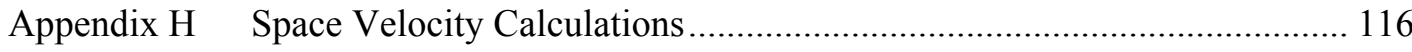

Appendix I Temperature Comparison between Original and Modified Procedure..... 117

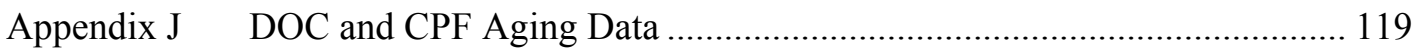

Appendix K Complete Emissions Summaries ........................................................... 121

Appendix L Stage 2 Loading PSD Data Separated by Test ...................................... 136

Appendix M PSD Data Collected at the End of Stage 2 and Passive Oxidation........... 145

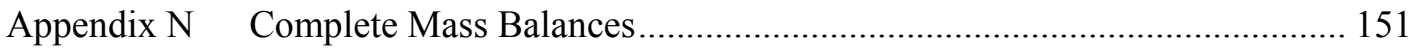

Appendix O Statistical Analysis of Stage 2 Loading Reaction Rates.......................... 160

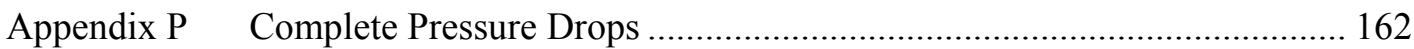

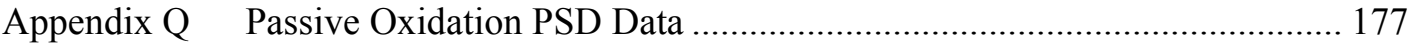

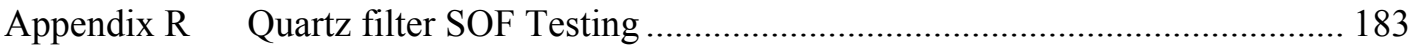

Appendix S Passive Oxidation $\mathrm{NO}$ to $\mathrm{NO}_{2}$ Conversion Efficiencies .......................... 184

Appendix T Permissions to Use Copyrighted Material ............................................. 185 


\section{List of Figures}

Figure 2.1: Filter resonance curves and response of RF signal to PM [30] .................... 26

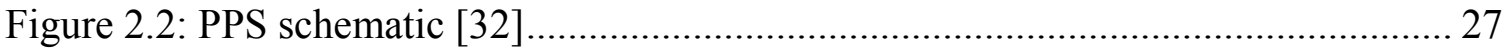

Figure 3.1: Schematic of test cell set up on Cummins 2007 ISL .................................. 32

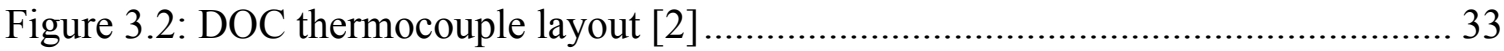

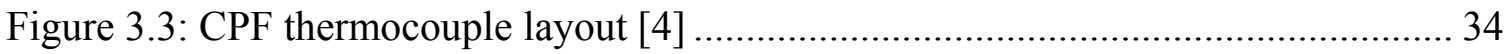

Figure 3.4: Gaseous emissions sampling strategy for Stage 1..................................... 41

Figure 3.5: Gaseous emissions sampling strategy for Stage 2 loading phase.................. 43

Figure 3.6: Gaseous emissions and PSD sampling strategy for P.O .............................. 45

Figure 3.7: Typical pressure drop profile of modified test procedure ............................. 47

Figure 3.8: Absolute humidity vs. PM concentration during loading............................ 49

Figure 4.1: Pressure drop profiles for original and modified test procedure ...................56

Figure 4.2: DOC NO to $\mathrm{NO}_{2}$ conversion efficiency during Stage 2.............................. 57

Figure 4.3: Average Stage $2 \mathrm{NO}$ to $\mathrm{NO}_{2}$ conversion efficiency .................................... 58

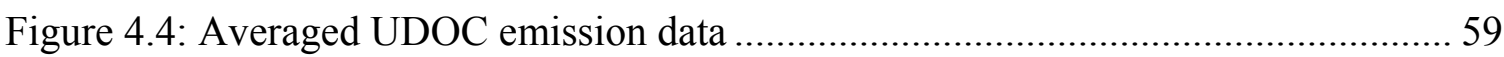

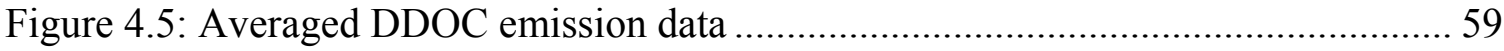

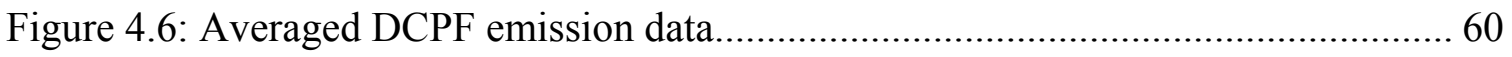

Figure 4.7: PSD data collected UDOC at the beginning of Stage 2 during each test ....... 62

Figure 4.8: PSD data collected DDOC at the beginning of Stage 2 during each test ....... 63

Figure 4.9: PSD data collected DCPF at the beginning of Stage 2 during each test ........ 64

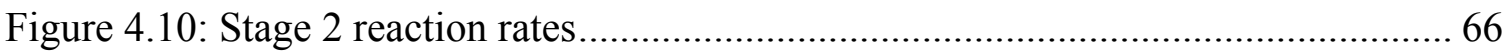

Figure 4.11: Pressure drop profile across CPF at end of loading vs. CPF loading........... 67

Figure 4.12: $\mathrm{NO}_{2}$ consumption rate vs. average $\mathrm{CPF}$ temperature for p.o ..................... 71

Figure 4.13: $\mathrm{NO}_{2}$ production rate vs. average $\mathrm{CPF}$ temperature for p.o........................ 72

Figure 4.14: $\mathrm{NO}_{2}$ consumption / $\mathrm{NO}_{2}$ available at inlet CPF vs. average CPF temp ....... 73

Figure 4.15: PSD data collected UDOC at the beginning of Passive Oxidation .............. 74

Figure 4.16: PSD data collected DDOC at the beginning of Passive Oxidation ............. 75

Figure 4.17: PSD data collected DCPF at the beginning of Passive Oxidation .............. 76

Figure 4.18: Log scale reaction rates Passive Oxidation vs. 1000 / average CPF temp... 77

Figure 4.19: Differential pressure drop across the CPF during point A ......................... 79

Figure 4.20: Differential pressure drop across the CPF during point F .......................... 79

Figure 4.21: Differential pressure drop across the CPF during point $\mathrm{H}$.......................... 80

Figure 4.22: ISL loading reaction rate comparison for Point A tests ............................ 81

Figure 4.23: ISL loading reaction rate comparison for Point $\mathrm{F}$ tests .............................. 81

Figure 4.24: ISL loading reaction rate comparison for Point $F$ tests .............................. 82

Figure 4.25: Example RF sensor calibration used to correlate RF output ....................... 85

Figure 4.26: Comparison of RF output with gravimetric measurements [30] ................. 86

Figure 4.27: Raw RF output during passive oxidation testing. [30] .............................. 86

Figure 4.28: PSD data by number and by volume for the three loading parts of the test. 89 
Figure 4.29: Pressure drop across the CPF and Pegasor sensor output during testing ..... 89

Figure 4.30: PM concentration by mass vs. PM concentration by Pegasor sensor .......... 90

Figure 4.31: CPF resistance during Test 11 Point A with B20 ..................................... 91

Figure 4.32: CPF resistance during Test 12 Point F with B20 .................................... 92

Figure 4.33: CPF resistance during Test 13 Point H with B20...................................... 92

Figure 4.34: CPF resistance during Test 14 Point A with B10 ..................................... 93

Figure 4.35: CPF resistance during Test 15 Point $F$ with B10 ................................... 93

Figure 4.36: CPF resistance during Test 16 Point $\mathrm{H}$ with B10...................................... 94

Figure 4.37: CPF resistance during Test 17 Point F with B10 ..................................... 94

Figure 4.38: CPF resistance during Test 18 Point A with B20...................................... 95

Figure 4.39: CPF corrected resistance during Test 11 Point A with B20........................ 96

Figure 4.40: CPF corrected resistance during Test 18 Point A with B20........................ 96

Figure C.1: Copper dilution line connected from the heated filter to dilution box ........ 105

Figure C.2: PSD sample line connected to the DDOC gaseous emissions port ............. 106

Figure F. 1: Filtration efficiency calculated from PSD data after clean out of CPF....... 114

Figure G. 1: Pressure drop profile FST calibration data collection .............................. 115

Figure L. 1: ISL 365 B20 Test 11 beginning Stage 2 loading PSD data ....................... 136

Figure L. 2: ISL 365 B20 Test 11 end Stage 2 loading PSD data ............................... 136

Figure L. 3: ISL 365 B20 Test 12 beginning Stage 2 loading PSD data ....................... 137

Figure L. 4: ISL 365 B20 Test 12 end Stage 2 loading PSD data ............................... 137

Figure L. 5: ISL 365 B20 Test 13 beginning Stage 2 loading PSD data ....................... 138

Figure L. 6: ISL 365 B20 Test 13 end Stage 2 loading PSD data .............................. 138

Figure L. 7: ISL 365 B10 Test 14 beginning Stage 2 loading PSD data ....................... 139

Figure L. 8: ISL 365 B10 Test 14 end Stage 2 loading PSD data ................................ 139

Figure L. 9: ISL 365 B10 Test 15 beginning Stage 2 loading PSD data ....................... 140

Figure L. 10: ISL 365 B10 Test 15 end Stage 2 loading PSD data .............................. 140

Figure L. 11: ISL 365 B10 Test 16 beginning Stage 2 loading PSD data ..................... 141

Figure L. 12: ISL 365 B10 Test 16 end Stage 2 loading PSD data .............................. 141

Figure L. 13: ISL 365 B10 Test 17 beginning Stage 2 loading PSD data ..................... 142

Figure L. 14: ISL 365 B10 Test 17 end Stage 2 loading PSD data ............................. 142

Figure L. 15: ISL 365 B20 Test 18 beginning Stage 2 loading PSD data ..................... 143

Figure L. 16: ISL 365 B20 Test 18 end Stage 2 loading PSD data ............................. 143

Figure L. 17: ISL 425 Test 1 beginning Stage 2 loading PSD data.............................. 144

Figure L. 18: ISL 425 Test 1 end Stage 2 loading PSD data ....................................... 144

Figure M. 1: End of Stage 2 loading UDOC PSD by number....................................... 145

Figure M. 2: End of Stage 2 loading DDOC PSD by number...................................... 146

Figure M. 3: End of Stage 2 loading DCPF PSD by number ..................................... 147

Figure M. 4: End of Passive Oxidation UDOC PSD by number................................. 148

Figure M. 5: End of Passive Oxidation DDOC PSD by number.................................. 149

Figure M. 6: End of Passive Oxidation DCPF PSD by number .................................. 150 
Figure P. 1: Pressure drop across CPF ISL 365 Test 6 ULSD ...................................... 162

Figure P. 2: Pressure drop across CPF ISL 365 Test 7 ULSD ..................................... 163

Figure P. 3: Pressure drop across CPF ISL 365 Test 8 ULSD ...................................... 164

Figure P. 4: Pressure drop across CPF ISL 365 Test 9 ULSD ...................................... 165

Figure P. 5: Pressure drop across CPF ISL 365 Test 10 ULSD ..................................... 166

Figure P. 6: Pressure drop across CPF ISL 365 Test 11 B20 ..................................... 167

Figure P. 7: Pressure drop across CPF ISL 365 Test 12 B20 ....................................... 168

Figure P. 8: Pressure drop across CPF ISL 365 Test 13 B20 ..................................... 169

Figure P. 9: Pressure drop across CPF ISL 365 Test 14 B10 .................................... 170

Figure P. 10: Pressure drop across CPF ISL 365 Test 15 B10 …………………........ 171

Figure P. 11: Pressure drop across CPF ISL 365 Test 16 B10 ..................................... 172

Figure P. 12: Pressure drop across CPF ISL 365 Test 17 B10 ………......................... 173

Figure P. 13: Pressure drop across CPF ISL 365 Test 18 B20 .................................... 174

Figure P. 14: Pressure drop across CPF ISL 365 Test 19 ULSD ................................. 175

Figure P. 15: Pressure drop across CPF ISL 425 Test 1 ULSD .................................... 176

Figure S. 1: Passive oxidation $\mathrm{NO}$ to $\mathrm{NO}_{2}$ conversion efficiencies [2] .......................... 184 


\section{List of Tables}

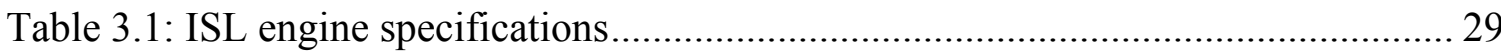

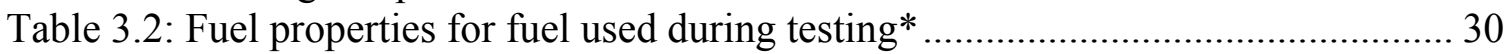

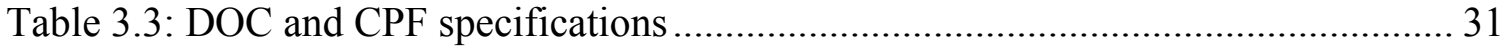

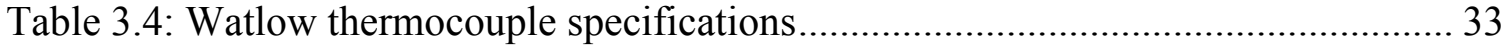

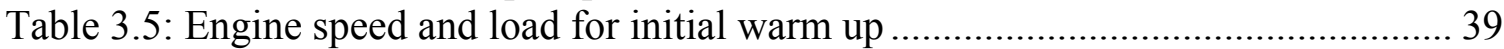

Table 3.6: Engine speed and load for Stage 2 engine warm up ................................... 42

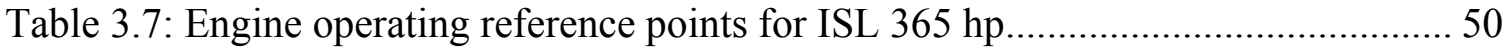

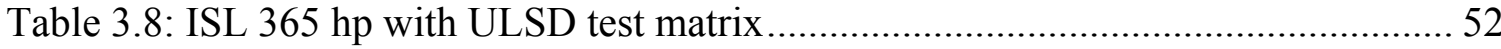

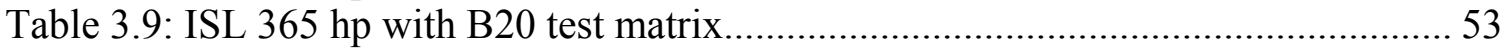

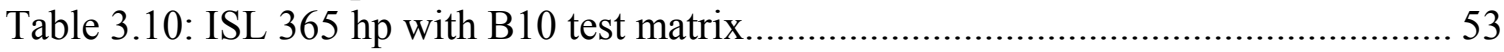

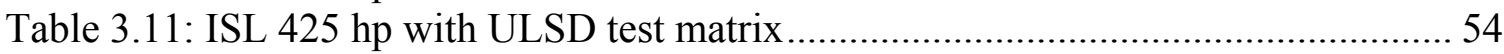

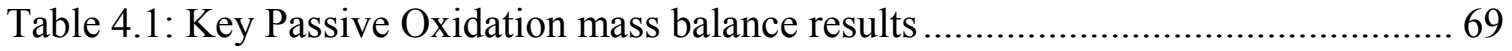

Table 4.2: $\mathrm{NO}_{\mathrm{x}}$ mass balance for Passive Oxidation ................................................. 70

Table 4.3: Stage 2 and Stage 4 reaction rates, volume ave. CPF temp, and mass added . 83

Table 4.4: Processed values of temperature, flow rate, and PM concentration ................ 88

Table K. 1: ISL 365 Test 6 with ULSD emission summary ...................................... 121

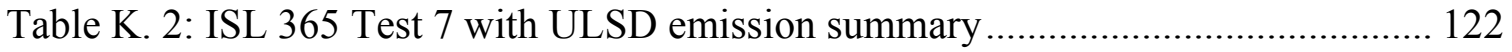

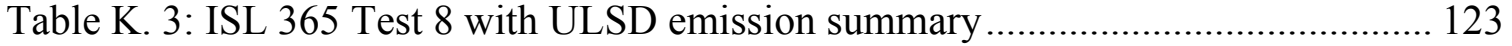

Table K. 4: ISL 365 Test 9 with ULSD emissions summary ..................................... 124

Table K. 5: ISL 365 Test 10 with ULSD emission summary ..................................... 125

Table K. 6: ISL 365 Test 19 with ULSD emissions summary ................................... 126

Table K. 7: ISL 365 Test 11 with B20 emissions summary ...................................... 127

Table K. 8: ISL 365 Test 12 with B20 emissions summary ...................................... 128

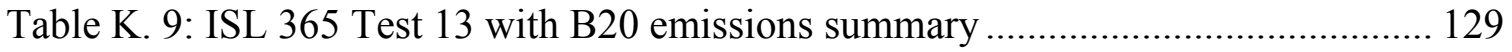

Table K. 10: ISL 365 Test 14 with B10 emissions summary .................................... 130

Table K. 11: ISL 365 Test 15 with B10 emissions summary .................................... 131

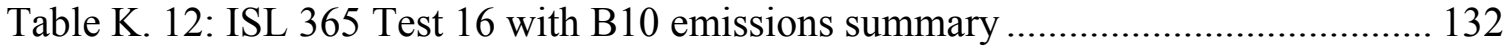

Table K. 13: ISL 365 Test 17 with B10 emissions summary .................................... 133

Table K. 14: ISL 365 Test 18 with B20 emissions summary .................................... 134

Table K. 15: ISL 425 Test 1 with ULSD emissions summary ................................... 135

Table N. 1: Key results for passive oxidation during Stage 2 .................................. 151

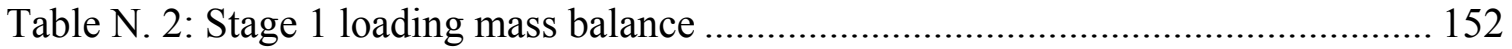

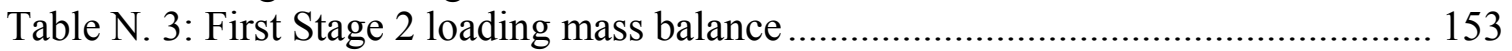

Table N. 4: Second Stage 2 loading mass balance (when necessary)........................... 154

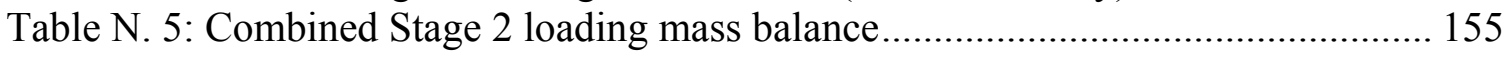

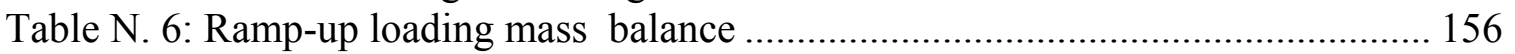

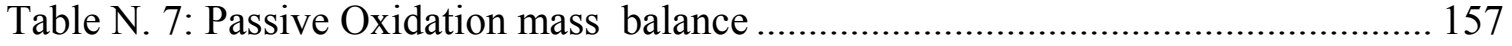

Table N. 8: Stage 3 loading mass balance ............................................................... 158

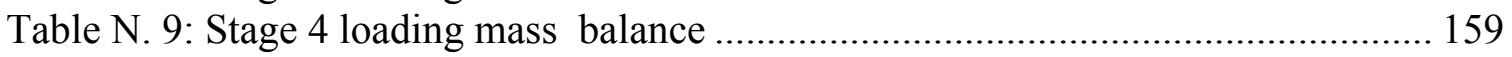




\section{Acknowledgements}

There are many individuals and organizations responsible for my ability to complete this work. I would like to thank everyone who assisted me in any way to complete this thesis.

I would like to thank my advisors Dr. John Johnson and Dr. Jeff Naber for giving me the opportunity to participate in this research project and for their guidance along the way. I would like to thank every professor which taught a class in which I attended. Without the knowledge I gained in my course work I would have been lost. I would like to thank Dr. Jason Keith for taking time out of his busy schedule to be on my defense committee. I would like to thank the team at Cummins whom have provided valuable answers and assistance when needed. This team includes but is not limited to; Joe Brault, Krishna Chilumukuru, Tamas Szailer, Abhijeet Nande, Ravi Venkata, and Ross Berryhill. Again the assistance was appreciated. I would like to thank the Heavy Duty Diesel group team members, past and present, which have aided in performing these tests and analyzing the data. This includes Chris Hutton, James Pidgeon, Harsha Surenahalli, Xiaobo Song, Ryan Foley, Caleb Bauer, and Matt Heath. Special thanks go to Chris Hutton for the excellent test cell setup which was used for all of the tests performed in this thesis. I would also like to thank the MTU staff members who work here every day. Without their direction and support I would not have been able to complete this work.

Personally I would like to thank my friends and family for supporting me when it got tough. Without you this would not be worth it.

For financial support I would like to thank Cummins Inc. for the fellowship funding I received and the engine and aftertreatment systems they provided. This material is based upon work supported by the Department of Energy National Energy Technology Laboratory under Award Number DE-EE0000204.

This paper was prepared as an account of work sponsored by an agency of the United States Government. Neither the United States Government nor any agency thereof, nor any of their employees, makes any warranty, express or implied, or assumes any legal liability or responsibility for the accuracy, completeness, or usefulness of any information, apparatus, product, or process disclosed, or represents that its use would not infringe privately owned rights. Reference herein to any specific commercial product, process, or service by trade name, trademark, manufacturer, or otherwise does not necessarily constitute or imply its endorsement, recommendation, or favoring by the United States Government or any agency thereof. The views and opinions of authors expressed herein do not necessarily state or reflect those of the United States Government or any agency thereof. 


\section{Definitions}

active regeneration.

B10.

B20.

ISL 365 tests.

ISL 425 tests.

passive oxidation.

Passive Oxidation.
Active regeneration is the thermal oxidation of particulate matter within the catalyzed particulate filter by injecting fuel prior to the aftertreatment system. This is accomplished with an auxiliary fuel doser mounted in the exhaust or by late in-cylinder fuel injection.

B10 fuel is ultra low sulfur diesel fuel blended with $10 \%$, by volume, soy based methyl ester biodiesel fuel.

B20 fuel is ultra low sulfur diesel fuel blended with $20 \%$, by volume, soy based methyl ester biodiesel fuel.

Tests conducted with the 2007 Cummins ISL engine rated at $272 \mathrm{~kW}(365 \mathrm{hp})$

Tests conducted with the 2007 Cummins ISL engine rated at $317 \mathrm{~kW}$ (425 hp)

Passive oxidation is the oxidation of particulate matter without an external energy source within the catalyzed particulate filter by engine exhaust by-products.

Passive Oxidation, signified by capitals in this thesis, represents the stage of the test with engine operating conditions which result in decreasing the loading of the CPF 


\section{Abbreviations}

A

$\mathrm{CO}$

$\mathrm{CO}_{2}$

$\mathrm{CPF}$

$\mathrm{D}$

DOC

$\mathrm{E}_{\mathrm{a}}$

ECU

EGR

FST

$\mathrm{HC}$

$\mathrm{L}$

$\mathrm{m}_{\text {add_S3 }}$

$\mathrm{m}_{\mathrm{c}}$

$\mathrm{m}_{\text {Predicted }}$

$\mathrm{m}_{\text {Ret_PO }}$

met_S1

$\mathrm{m}_{\text {Ret_S2 }}$

met_S3

met_S4

$m_{\text {Ret_RU }}$

$\mathrm{m}_{\mathrm{RU}}$

$\mathrm{m}_{\text {Start }}$

$\mathrm{m}_{\text {Stop }}$

$\mathrm{m}_{\mathrm{S} 1}$

$\mathrm{m}_{\mathrm{S} 2}$

$\mathrm{m}_{\mathrm{S} 3}$

$\mathrm{m}_{\mathrm{S} 4}$

$\mathrm{NO}$

$\mathrm{NO}_{2}$

$\mathrm{NO}_{\mathrm{X}}$

$\mathrm{O}_{2}$

OEM

Qexh

RF-DPF

$\mathrm{RR}_{0}$

$\mathrm{scm}$

$t_{\text {eff }}$

time $_{\mathrm{S} 2}$

time $_{\text {stage }}$

$\mathrm{V}$

f

Pre-exponential factor, (1/s)

Carbon Monoxide

Carbon Dioxide

Catalyzed Particulate Filter

Mass diffusion coefficient 5.1E-6 used [1]

Diesel Oxidation Catalyst

Activation energy, $(\mathrm{J} / \mathrm{gmol})$

Engine Control Unit

Exhaust Gas Recirculation

Filter Sensing Technologies

Hydrocarbons

Characteristic length, thickness of PM cake layer, constant 3E-7 used [1]

Predicted PM mass retained in the CPF during Stage 3 loading

Calculated clean mass of the $\mathrm{CPF}$

Predicted masses retained during Stage 1, Ramp-up, and Stage 3

Calculated total PM mass retained in the CPF after Passive Oxidation

Predicted PM mass retained in the CPF after Stage 1 loading

Calculated total PM mass retained in the CPF after Stage 2 loading

Calculated total PM mass retained in the CPF after Stage 3 loading

Calculated total PM mass retained in the CPF after Stage 4 loading

Calculated total PM mass retained in the CPF after Ramp-up

Predicted PM mass retained in the CPF during Ramp-up

PM mass retained at the beginning of stage

PM mass retained at the end of stage

Measured CPF mass after Stage 1 loading

Measured mass of the CPF after nominal loading of $2.2 \mathrm{~g} / 1$ is achieved

Measured CPF mass after Stage 3 loading

Measured CPF mass after Stage 4 loading

Nitrogen Monoxide

Nitrogen Dioxide

The sum of Nitrogen Monoxide and Nitrogen Dioxide

Oxygen

Original equipment manufacturer

Exhaust volumetric flow rate, $(\mathrm{scm} / \mathrm{sec})$

Radio frequency diesel particulate filter

Global reaction rate, $\left(\mathrm{s}^{-1}\right)$

Standard cubic meters

Time of stage calculating reaction rate for, (s)

Length of Stage 2 in minutes

Length of stage calculating predicted mass retained for

Wall velocity

Filtration efficiency of the CPF 


\section{Abstract}

A 2007 Cummins ISL 8.9L direct-injection common rail diesel engine rated at $272 \mathrm{~kW}$ ( $365 \mathrm{hp}$ ) and $317 \mathrm{~kW}(425 \mathrm{hp}$ ) was used to load the filter to $2.2 \mathrm{~g} / \mathrm{L}$ and passively oxidize particulate matter (PM) within an aftertreatment system consisting of a diesel oxidation catalyst (DOC) and catalyzed particulate filter (CPF). The tests conducted with the engine rated at $365 \mathrm{hp}$ used a $2007 \mathrm{DOC}$ and CPF. The tests conducted with the engine rated at $425 \mathrm{hp}$ used a $2010 \mathrm{DOC}$ and $2007 \mathrm{CPF}$. Understanding the passive $\mathrm{NO}_{2}$ oxidation kinetics of PM within the CPF allows for reducing the frequency of active regenerations (hydrocarbon injection) and the associated fuel penalties.

Modeling the passive oxidation of accumulated PM in the CPF will lead to creating accurate state estimation strategies. The MTU 1-D CPF model will be used to simulate data collected from this study to examine differences in the PM oxidation kinetics when soy methyl ester (SME) biodiesel is used as the source of fuel for the engine, and when the engine is operated at a higher power rating.

A test procedure developed by Hutton et al. [1,2] was modified to improve the ability to model the experimental data and provide additional insight into passively oxidized PM in a partially regenerated $\mathrm{CPF}$. A test procedure was developed to allow PM oxidation rates by $\mathrm{NO}_{2}$ to be determined from engine test cell data. An experimental matrix consisting of $\mathrm{CPF}$ inlet temperatures from 250 to $450{ }^{\circ} \mathrm{C}$ with varying $\mathrm{NO}_{\mathrm{X}} / \mathrm{PM}$ from 25 to 583 and $\mathrm{NO}_{2} / \mathrm{PM}$ ratios from 5 to 240 was used.

SME biodiesel was volumetrically blended with ULSD in 10\% (B10) and 20\% (B20) portions. This blended fuel was then used to evaluate the effect of biodiesel on passive oxidation rates. Four tests were performed with B10 and four tests with B20. Gathering data to determine the effect of fuel type (ULSD and biodiesel blends) on PM oxidation is the primary goal.

The engine used for this testing was then configured to a higher power rating and one of the tests planned was performed. Additional testing is scheduled to take place with ULSD fuel to determine the affect the engine rating has on the PM oxidation.

The experimental reaction rates during passive oxidation varied based upon the average CPF temperature, $\mathrm{NO}_{2}$ concentrations, and the $\mathrm{NO}_{\mathrm{X}} / \mathrm{PM}$ ratios for each engine rating and with all fuels. The data analysis requires a high fidelity model that includes $\mathrm{NO}_{2}$ and thermal oxidation mechanisms and back diffusion to determine the details of the PM oxidation process. 


\section{Chapter 1. Introduction}

The diesel engine has become popular globally for the use in mobile and stationary applications due to its high thermodynamic efficiency. Environmental protection agencies around the world have been developing stringent emissions regulations reducing the levels of nitrogen oxides $\left(\mathrm{NO}_{\mathrm{x}}\right)$ and particulate matter $(\mathrm{PM})$ in both on and off highway engines. The U.S. has been working to decrease exhaust emissions and increase fuel efficiency of its vehicles, and also to decrease its dependence on foreign oil.

One type of aftertreatment system is the use of a diesel oxidation catalyst (DOC) and a catalyzed particulate filter (CPF) in line with each other. Each component contains a catalyst to assist in the oxidation of exhaust gases. The DOC is a flow through element, and as the exhaust passes over the platinum based wash coat, carbon monoxide (CO), hydrocarbons $(\mathrm{HC})$, and nitric oxide $(\mathrm{NO})$ are each oxidized to carbon dioxide $\left(\mathrm{CO}_{2}\right)$, water $\left(\mathrm{H}_{2} \mathrm{O}\right)$, and nitrogen dioxide $\left(\mathrm{NO}_{2}\right)$. The exhaust gasses then travel to the $\mathrm{CPF}$ which is a wall flow device. As the exhaust passes through the CPF, PM becomes trapped in the wall and on the cake layer. The use of a diesel oxidation catalyst (DOC) and a catalyzed particulate filter (CPF) as an aftertreatment system has reduced vehicle exhaust emission levels in the diesel engine, but it has also introduced control strategy challenges.

Trapped PM increases the filtration efficiency of the CPF by building a "cake" layer and by blocking passages in the wall. This also causes increased back pressure on the engine which reduces fuel efficiency. In order to reduce this backpressure, and improve performance, the PM retained in the CPF must be removed. To accomplish this, one method used is to perform an active regeneration which consists of injecting (dosing) additional fuel into the exhaust system either by late in-cylinder injection or by an auxiliary fuel injector mounted in the exhaust stream after the turbo charger. This fuel is then partially oxidized in the exhaust, and further oxidized by the DOC, which creates an exotherm in the CPF. This process is termed $\mathrm{HC}$ dosing. The temperature increase oxidizes the PM retained in the CPF. While this method is effective at oxidizing the PM retained in the $\mathrm{CPF}$, the fuel used during the process does not produce useful work hence reducing engine efficiency.

Passive oxidation consists of using engine exhaust by-products, such as $\mathrm{NO}_{2}$ and exhaust temperatures, rather than additional fuel to oxidize the PM within the CPF. This method is preferred because it reduces the need of $\mathrm{HC}$ dosing.

Additional renewable fuel resources are being developed in order to decrease U.S. dependence on foreign oil. Biodiesel consists of long-chain alkyl (methyl, propyl or ethyl) esters derived from vegetable oil or animal fat (lipids). Biodiesel is made by chemically reacting lipids with an alcohol. The use of $20 \%$ biodiesel fuel volumetrically blended with ULSD fuel may be used in late model engines as long as the fuel meets ASTM D7467 specification requirements [3]. The effect biodiesel blended fuel has on the engine and aftertreatment performance is not fully known at this time. 
Sensor development is being performed in industry in an attempt to optimize the control strategies used for diesel engines. PM concentration and CPF PM mass retained sensors are being developed to more accurately determine internal CPF states. This technology in conjunction with control systems will result in reduced use of fuel for active regeneration and additional passive oxidation of PM in the CPF during normal vehicle operation.

The following thesis will describe work performed to quantify the effect biodiesel fuel has on the passive oxidation of PM within a CPF. This work is part of a DOE project and most of the passive oxidation results have also been published in a 2012 SAE technical paper [4]. The paper being published by SAE compares results from this work with B10 and B20 fuels to work performed by Hutton et al. [1, 2] with ULSD fuel. Tests described in this thesis were performed with a range of fuels using the PM sensors and an engine configured at two ratings.

\subsection{Research Goals}

The main goals of this research were to further develop the procedure used by Hutton et al. [1] and to use this procedure to collect and analyze the PM oxidation data when operating a 2007 Cummins ISL engine and aftertreatment system with methyl-ester biodiesel blended fuel. This procedure was then used to determine how the same engine rated at different power outputs impacted the passive oxidation of particulate matter. The research objectives used to meet these goals are listed below.

1. Modify the test procedure used to collect passive oxidation data in order to develop more repeatable test data that will better support the modeling and analysis effort

2. Quantify the effect on passive oxidation of PM produced by a Cummins 2007 ISL rated at $272 \mathrm{~kW}$ (365 hp) while operating with B10 and B20 fuels

3. Quantify the effect on passive oxidation of PM produced by the Cummins 2007 ISL when the turbocharger and ECU are changed to produce $317 \mathrm{~kW}$ (425 hp) rating

4. Collect data that can be used with the MTU 1-D CPF model to determine the $\mathrm{NO}_{2}$ assisted PM oxidation kinetics

The modeling effort, as described in goal 4 above, is proceeding in parallel with the experimental work to develop and calibrate a 1-D CPF simulation model. The goal of this research as it pertains to modeling was to compile the data in such a way as to assist in the modeling effort. Emissions, temperature, PM loading, exhaust flow rate, and PM concentration data has been compiled and processed for each stage of each test performed. The MTU 1-D CPF simulation has been calibrated and used to determine oxidation kinetics during passive oxidation of PM within the CPF used for each test. This research will be published in a 2013 SAE paper and is not presented in this thesis. 


\subsection{Overview of Thesis}

This chapter provides a brief description of the material covered in this thesis. The introduction section has familiarized the reader with the DOC/CPF aftertreatment system used for this study as well as methods used to oxidize the PM retained within the CPF. Quantification of the effect biodiesel blended fuels has on this aftertreatment system and its performance is the primary desired result of this work.

Chapter 2 is a background and literature review section that will give the reader vital information to understanding the topics covered in latter chapters. Information from prior research conducted at Michigan Technological University along with technical papers from other organizations relating to relevant topics is summarized.

Chapter 3 describes the test cell and specific instruments used to gather temperature, pressure, CPF weight, and gaseous concentration data for each test. The engine used, results of fuel sample testing, and the aftertreatment system specifications are detailed. Tests conducted with experimental sensors are described. The procedure used to collect passive oxidation data was changed in order to stabilize the CPF temperatures during passive oxidation portions of the test and to gather additional data after partially regenerating the $\mathrm{CPF}$. These changes in the test procedure are presented and engine operating conditions used for each test is shown.

Chapter 4 shows the experimental results of testing. The test procedures are analyzed to determine the effects. A temperature analysis is used to explain why the modified procedure resulted in increased repeatability of the pressure drop across the CPF during passive oxidation. An additional test was performed validating the assumption peak filtration efficiency within the first minute of CPF loading. Stage 2 and Passive Oxidation gaseous emissions, differential pressure drops, particle size data (PSD), and reaction rates are presented and discussed. Sensor testing results and CPF resistance plots for ISL 365 $\mathrm{B} 10$ and B20 tests are shown.

Chapter 5 provides a summary of the results of passive oxidation with biodiesel blended fuel and tests conducted with the ISL rated at $425 \mathrm{hp}$. DOC aging had a significant impact on the loading stages and may be the primary source of discrepancy when comparing biodiesel blended fuel tests to ULSD tests. Recommendations for future testing and possible test repetition along with supporting arguments are given. 


\section{Chapter 2. Background and Literature Review}

A brief of the literature covered in this thesis will be presented in this chapter. Information regarding passive oxidation, diesel emissions with ULSD and biodiesel blended fuels, DOC performance after being aged, and background literature on PM sensors will also be summarized. After reviewing this chapter, the reader will be able to understand some of the challenges manufacturers contend with when trying to meet emissions regulations and still produce an efficient and reliable diesel engine. The complicated nature of passive oxidation and the mechanisms by which this process occurs will be detailed, and the method used to calculate the reaction rate will be given. The use of biodiesel blended fuels can result in different emissions concentrations, PM structure and content, and $\mathrm{HC}$ speciation. A diesel oxidation catalyst (DOC) may become aged over time reducing the efficiency of the aftertreatment system and this aging may be accelerated by biodiesel fuel use. Low emissions regulations and the desire of consumers and the federal government to decrease fuel consumption have lead to the search for exhaust emissions sensing technology that will improve control strategies. Two PM sensor types will be described.

\subsection{Diesel Emissions}

As the diesel engine has been developed over the past 40 years, regulations limiting the $\mathrm{PM}$ emissions and gaseous emissions levels of $\mathrm{CO}, \mathrm{HC}$, and $\mathrm{NO}_{\mathrm{x}}$ have become more restrictive over time. The technology used on this engine has constantly changed to maintain efficiency and to decrease the regulated emissions. Beginning in 2010 the EPA heavy duty diesel emissions standards are $0.2 \mathrm{~g} / \mathrm{bhp}-\mathrm{h}$ for $\mathrm{NO}_{\mathrm{x}}, 0.14 \mathrm{~g} / \mathrm{bhp}$-h for nonmethane HC, and $15.5 \mathrm{~g} / \mathrm{bhp}-\mathrm{h}$ for CO. Since 2007 the standard for PM emissions has been $0.01 \mathrm{~g} / \mathrm{bhp}-\mathrm{h}$.

There is a trade off in designing a diesel engine between $\mathrm{NO}_{\mathrm{x}}$ and $\mathrm{PM}$ emissions without

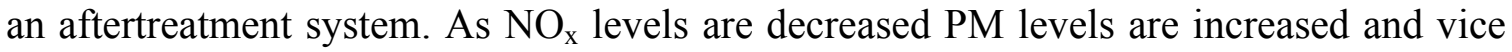
versa. In addition, by increasing $\mathrm{NO}_{\mathrm{x}}$ and decreasing PM the efficiency of the engine is increased but the available power is decreased and vice versa. Looking to the future, emissions standards will remain the same but the combined efficiency of the fleet of vehicles on the road will be required to achieve 35 mile per gallon. In order to achieve near zero emission levels manufacturers have used an aftertreatment system to meet $\mathrm{NO}_{\mathrm{x}}$ and PM emissions standards. The use of a DOC and a CPF primarily traps and oxidizes PM emissions from a diesel engine. The use of this system and additional components along with engine tuning will be optimized in order to achieve increased fuel efficiency while maintaining emissions standards.

Emissions of $\mathrm{CO}, \mathrm{HC}$, and $\mathrm{NO}_{\mathrm{x}}$ are compounds that are not in their lowest energy state. By passing these emissions through a DOC, each may be oxidized to form other compounds. $\mathrm{CO}$ is oxidized to $\mathrm{CO}_{2}$. $\mathrm{HC}$ oxidize to water and $\mathrm{CO}_{2}$. $\mathrm{NO}$ oxidizes to $\mathrm{NO}_{2}$ and $\mathrm{NO}_{\mathrm{x}}$ emissions reduce to $\mathrm{N}_{2}$ and $\mathrm{O}_{2}$ in the atmosphere. $\mathrm{NO}_{2}$ is more toxic than $\mathrm{NO}$, however $\mathrm{NO}_{2}$ is a more favorable reductant of $\mathrm{PM}$ in the $\mathrm{CPF}$. 
The DOC begins the reactions required for the aftertreatment system to be effective. Very small particles such as PM have been shown to increase heath risks. For the heavy duty system used in this study the exhaust gasses then flow to the CPF which is a wall flow device. As the exhaust passes through the CPF, PM becomes trapped in the wall and on the cake layer. The CPF has been shown to be very effective at removing PM emissions from the exhaust. From literature, the CPF and can achieve filtration efficiencies over 99\% [5]. Trapped PM increases the filtration efficiency of the CPF, but this also causes increased back pressure on the engine which reduces fuel efficiency. Active regeneration oxidizes the PM retained in the CPF, but results in a fuel penalty.

\subsection{Passive Oxidation}

The additional fuel injected during an active regeneration of the CPF does not produce useful work, and thus increases the overall fuel consumption of the engine. The use of passive oxidation which refers to oxidation of PM in the CPF using the gaseous $\mathrm{NO}_{2}$ concentration present in the exhaust can decrease the need for active regenerations. The oxidation kinetics of PM within the CPF is not fully known. The temperature of the exhaust has the strongest effect on the passive oxidation within the CPF. Passive oxidation of $\mathrm{PM}$ is dominant between $250-400{ }^{\circ} \mathrm{C}$ [6]. At higher temperatures above $400{ }^{\circ} \mathrm{C}$ thermal $\left(\mathrm{O}_{2}\right)$ oxidation becomes primary.

Depending on the engine combustion fundamentals, fuel used, and conditions the engine is operated and the PM structure can vary. Work performed by Yang et al. [7] showed that the PM exiting the engine can vary based on the amount of soluble organic fraction adsorbed on the particles. This work was performed by using a dilution tunnel. Work performed by Strzelec el al. [8] shows that dilute exhaust particulate samples may not give accurate particulate properties needed for the modeling effort. This work found that DPF particulate may have higher fractions of heavy paraffin and aromatics when compared to dilute samples. These differences may lead to different oxidation characteristics.

Passive oxidation takes place as a localized reaction as gaseous $\mathrm{NO}_{2}$ travels into the PM cake and wall layers. Because the flow through the CPF can be affected by maldistribution of PM which can lead to heterogeneous PM distributions [8, 10]. As the cake and wall layers become un-evenly distributed, the flow of $\mathrm{NO}_{2}$ can become un-even as well. There is a possibility that $\mathrm{NO}_{2}$ can diffuse from high concentration areas to low concentration areas.

This flow of $\mathrm{NO}_{2}$ can occur against the flow of exhaust and is termed back diffusion of $\mathrm{NO}_{2}$. This diffusion is dependent on a mass diffusion coefficient, PM cake layer thickness, and wall velocity of the exhaust stream. Each of these values is difficult to determine, however the likely hood of diffusion can be found by determining the Péclet number $[11,12]$. The Péclet number is a dimensionless parameter which relates the rate of advection to the rate of diffusion of a substance which is driven by a concentration gradient. Equation 1 shows the Péclet number calculation. 


$$
P e_{L}=\frac{L \times V}{D}
$$

$\mathrm{L}=$ Characteristic length, thickness of PM cake layer

$\mathrm{D}=$ Mass diffusion coefficient

$\mathrm{V}=$ Wall velocity

Prior work by Hutton et al. [1] has shown that the $\mathrm{NO}_{2}$ available both into the CPF and from back diffusion is the primary reductant of PM in the CPF when operating below 400 ${ }^{\circ} \mathrm{C}$ with ULSD fuel. Modeled reaction rates more closely matched the experimental rates when back diffusion was included. The parameters used for $\mathrm{L}$ and $\mathrm{D}$ were $3 \mathrm{E}-7$ and 5.1E6 respectively [1]. The modeling effort will take the data collected by this work and attempt to determine the details of the transition from $\mathrm{NO}_{2}$ oxidation to $\mathrm{O}_{2}$ oxidation in the CPF.

Oxidation of PM within the CPF can occur from contributions of gaseous concentrations other than $\mathrm{NO}_{2}$. Gaseous concentrations of $\mathrm{CO}$ and $\mathrm{HC}$ can contribute to the oxidation of $\mathrm{PM}$ within the $\mathrm{CPF}$. Due to the $\mathrm{DOC}, \mathrm{CO}$ concentrations into the $\mathrm{CPF}$ are typically zero and $\mathrm{HC}$ concentrations are minimal and provide no significant contribution [13]. The $\mathrm{O}_{2}$ concentration has been found to be a critical factor. Experiments conducted at $300{ }^{\circ} \mathrm{C}$ with a reaction atmosphere containing $10 \% \mathrm{O}_{2}$ was found to oxidize PM twice as fast when compared to experiments conducted with no $\mathrm{O}_{2}$ in the reaction atmosphere[13]. This result is not due to the oxygen reacting directly with the $\mathrm{PM}$ as $300{ }^{\circ} \mathrm{C}$ is below the minimum temperature required for thermal PM oxidation to occur. At this temperature $\mathrm{O}_{2}$ is important in the formation of $\mathrm{NO}_{2}$. This additional $\mathrm{NO}_{2}$ formation then reacts with the $\mathrm{PM}$ in the $\mathrm{CPF}$.

Work performed by Konstandopoulos et al. [14] has shown that physical contact of PM with the catalyst coating is just as important as the type of coating used in reference to oxidation. The geometry of both the CPF substrate and the PM itself are then critical factors in the rate of PM oxidation.

Goals of this research include quantification of the effect fuel and engine rating has on the passive oxidation of PM in the CPF. To quantify the oxidation rate during passive oxidation and loading stages of each test equation 2 was used. This equation comes from work in reference [15], and is the solution of equation 3. Equation 2 has inputs of mass, filtration efficiency, PM concentration, and time. Each input is assumed constant during the stage being calculated. This equation does not allow for the separation of $\mathrm{NO}_{2}$ and thermal $\left(\mathrm{O}_{2}\right)$ oxidation, but includes both. Due to this, the activation energy and preexponential factors in Equations 4 and 5 must be found with the MTU 1-D model. Equation 4 represents the reaction rate constant of PM oxidation due to $\mathrm{NO}_{\mathrm{x}}$ concentrations which is the primary reductant below $400{ }^{\circ} \mathrm{C}$. Equation 5 represents the reaction rate constant of thermal $\left(\mathrm{O}_{2}\right)$ oxidation which is the primary reductant above 400 ${ }^{\circ} \mathrm{C}$. 


$$
\mathrm{m}_{\mathrm{Stop}}=\frac{\mathrm{Q}_{\mathrm{exh}}{ }^{*} \mathrm{C}_{\mathrm{in}} * \eta_{\mathrm{f}}}{\mathrm{RR}_{0} * 1000}\left[1-\mathrm{e}^{\left(-\mathrm{RR}_{\mathrm{o}} * \mathrm{t}_{\mathrm{eff}}\right)}\right]+\mathrm{m}_{\mathrm{Start}} * \mathrm{e}^{\left(-\mathrm{RR}_{\mathrm{o}} * \mathrm{t}_{\mathrm{eff}}\right)}
$$

$\mathrm{RR}_{0} \quad=$ Reaction Rate, $(1 / \mathrm{s})$

$\mathrm{f} \quad=$ filtration efficiency of the filter

$\mathrm{C}_{\mathrm{in}}=$ particulate matter concentration in the exhaust, $(\mathrm{mg} / \mathrm{scm})$

$\mathrm{Q}_{\text {exh }}=$ standard volumetric flow rate of exhaust, $(\mathrm{scm} / \mathrm{sec})$

$\mathrm{t}_{\mathrm{eff}}=$ time of stage calculating reaction rate for, $(\mathrm{s})$

$\mathrm{m}_{\text {Stop }}=\mathrm{PM}$ mass retained in the CPF at the end of the stage, $(\mathrm{g})$

$\mathrm{m}_{\text {Start }}=\mathrm{PM}$ mass retained in the CPF at the beginning of the stage, $(\mathrm{g})$

$$
0=\frac{d m}{d t}+R R_{0} m-\eta_{\mathrm{f}} \mathrm{C}_{\mathrm{in}} \mathrm{Q}_{\mathrm{exh}}
$$

$\frac{d m}{d t} \quad=$ change of mass over time, $(\mathrm{g} / \mathrm{sec})$

$\mathrm{RR}_{0}=$ Reaction Rate, $(1 / \mathrm{s})$

$\mathrm{m} \quad=$ mass in the filter

$\mathrm{f} \quad=$ filtration efficiency of the filter

$\mathrm{C}_{\text {in }}=$ particulate matter concentration in the exhaust, $(\mathrm{mg} / \mathrm{scm})$

$\mathrm{Q}_{\text {exh }}=$ standard volumetric flow rate of exhaust, $(\mathrm{scm} / \mathrm{sec})$

$$
\begin{gathered}
R R_{O, N O 2-N O}=f\left([N O],\left[N O_{2}\right]\right) * A * e^{\left(-\frac{E a}{R T_{R}}\right)} \\
R R_{O, O 2}=\left[O_{2}\right] A * e^{\left(-\frac{E_{a}}{R T_{R}}\right)}
\end{gathered}
$$

$\left[\mathrm{NO}_{2}\right]=\mathrm{NO}_{2}$ concentration, $(\mathrm{ppm})$

[NO] = NO concentration, $(\mathrm{ppm})$

$\left[\mathrm{O}_{2}\right]=\mathrm{O}_{2}$ concentration, $(\mathrm{ppm})$

A $=$ pre-exponential factor, $(1 / \mathrm{s})$

$\mathrm{E}_{\mathrm{a}} \quad=$ activation energy, $(\mathrm{J} / \mathrm{gmol})$

$\mathrm{R}=$ universal gas constant, $(\mathrm{J} / \mathrm{gmolK})$

$\mathrm{T}_{\mathrm{R}}=$ average $\mathrm{CPF}$ temperature, $(\mathrm{K})$ 


\subsection{ULSD Compared to Biodiesel Emissions}

Work continues to understand the passive oxidation of PM within the CPF in order to optimize control strategies and increase fuel efficiency while adhering to emissions regulations. Studies have been conducted showing that the use of B20 fuel may increase engine out $\mathrm{NO}_{\mathrm{x}}$ formation and decrease engine out total $\mathrm{HC}$ (THC), CO, and PM levels [16 - 18]. Tinsdale et al. [16] performed work with fatty acid methyl ester (FAME) biodiesel, and theorized that the likely explanation for increased $\mathrm{NO}_{\mathrm{x}}$ is due to additional NO produced by the Zeldovich and/or Fenimore mechanism due to an increased adiabatic flame temperature.

Other studies have shown that these changes are not statistically different leading to the conclusion that engine design and control strategies seem to be important factors $[19,20]$. Eckerle et al. [19] showed that for biodiesel blends of $20 \%$ or less the difference in $\mathrm{NO}_{\mathrm{x}}$ emissions between the base fuel and a biodiesel blended fuel was less than may be seen between two commercial fuels.

Studies performed by Eckerle et al. [19] have shown that there are two ways in which the diesel fuel properties can affect the $\mathrm{NO}_{\mathrm{x}}$ emissions. The flame temperature within the cylinder is affected by fuel chemistry. Increased flame temperature results in higher $\mathrm{NO}_{\mathrm{x}}$ formation. The methyl ester compounds in biodiesel have more double bonds and these double bonds may increase the flame temperature $[19,20]$. At the same time, biodiesel fuel has lower aromatic content than ULSD fuel. Flame temperatures are lower during combustion dominated by diffusion burning (higher load operation) with lower aromatic content. The second way in which diesel fuel properties may affect the $\mathrm{NO}_{\mathrm{x}}$ emissions is through ignition delay [19]. At lower engine loadings decreased aromatics, which may be found with biodiesel, cause shorter ignition delay. This shorter ignition delay results in higher engine out $\mathrm{NO}_{\mathrm{x}}$ emissions.

Biodiesel PM may have a higher degree of structure disorder and oxygen content when compared to ULSD PM, and each of these factors results in greater reactivity when in the presence of reductants $[8,21$ - 23]. Detailed chemical and spectroscopic characterization results by Williams et al. [21] point to a higher degree of PM structure disorder and oxygen content as being responsible for higher passive oxidation rates when biodiesel blended fuel is used. Northrop et al. [24] showed that unburned methyl esters from combustion of biodiesel have low volatility and are more susceptible to form PM in the atmosphere. This would result in PM emissions that may not be detected in the exhaust stream being formed in the atmosphere.

The HC and PM species present in the engine out exhaust stream while operating with biodiesel blended fuel may be different than with ULSD [20, 24]. Northrop et al. [24] showed that the shorter ignition delay caused by lower aromatic content of biodiesel blended fuels, and biodiesel fuel oxygen content, resulted in lower engine out THC emissions. This study also showed a significant increase $(0.9 \mathrm{~g} / \mathrm{kg}-\mathrm{ULSD} 1.1 \mathrm{~g} / \mathrm{kg}-\mathrm{B} 100)$ of engine out ethylene $\left(\mathrm{C}_{2} \mathrm{H}_{4}\right)$ emissions with B100 measured using an FT-IR analyzer. This indicates that biodiesel may lead to an increase of partially burned products 
compared to ULSD, but this increase of partially burned products is off- set by the decrease in unburned HC. Maricq et al. [20] showed that there were 2-3 times lower PM concentration over a range of medium load steady state points, but there was no impact on the semi-volatile PM emissions with B20 fuel. Reduction in PM concentration in this work with B20 fuel is larger than some other studies partially due to the use of $200{ }^{\circ} \mathrm{C} \mathrm{N}$ dilution. This heated dilution may suppress nucleation and condensation of semi-volatile exhaust species [20]. Slower CPF loading was also noticed in this study with B20 fuel when compared to ULSD.

The conclusion of nucleation and condensation of semi-volatiles on PM samples in the study conducted by Maricq et al. [20] was affirmed by work performed by Northrop et al. [24]. In this study engine out PM measurements taken by a smoke meter showed a decrease in PM with the use of B100 compared to ULSD. The mass of PM determined by taking a cold dilution tunnel PM sample at $47{ }^{\circ} \mathrm{C}$ was over ten times greater for B100 than ULSD. Additional analysis of the PM samples in this study showed that the total organic fraction calculated for B100 was $99 \%$ compared to $86 \%$ for ULSD, and conversion of this organic fraction across the DOC was significantly lower for B100 indicating that semi-volatiles were dominant [24].

\subsection{Catalyst Aging and Effect of Aging}

Catalyst aging refers to catalyst sites within an aftertreatment system becoming in-active over time. Causes of this aging may be due to ash coating the catalyst, chemical poisoning, or physical loss of catalyst.

Studies have shown that $\mathrm{CO}$ and $\mathrm{HC}$ emissions reduce $\mathrm{NO}_{2}$ creating $\mathrm{NO}$ before the $\mathrm{NO}$ is oxidized to $\mathrm{NO}_{2}$ across the DOC, and the later reaction may become less prevalent as the DOC is aged [25 -27]. This causes $\mathrm{NO}_{2}$ consumption across the DOC and decreases the amount of $\mathrm{NO}_{2}$ available for passive oxidization in the CPF. Studies conducted by Katare et al. [25] with an aged DOC suggest that $\mathrm{CO}$ oxidation takes place before $\mathrm{HC}$ oxidation, and that $\mathrm{NO}$ oxidation is limited by kinetics at temperatures below $350{ }^{\circ} \mathrm{C}$ and by thermodynamics above. Another conclusion from work performed by Katare et al. [25] is that the $\mathrm{NO}_{2}$ reduction may happen at the front section of the DOC, and may not be space velocity dependent.

Biodiesel fuel use can result in doubling of the ash exposure resulting in decreased DOC activity, higher $\mathrm{HC}$ slip across the DOC, and reduced $\mathrm{NO}_{2}$ formation out of the $\mathrm{DOC}$ due to impurities [28]. The increased impurities and ash present in biodiesel may cause $\mathrm{NO}_{2}$ consumption across $\mathrm{CPF}$ as well. This $\mathrm{NO}_{2}$ consumption would cause decreasing passive oxidation reaction rates over time [28]. Studies have shown that the use of B20 fuel has little effect on the differential pressure drop characteristic of the CPF [23].

\subsection{Modeling of the CPF Pressure Drop}

Diesel engine manufacturers have used the differential pressure drop across the CPF to predict the proper timing of active regenerations. The pressure drop is dependent on 
characteristics of the $\mathrm{CPF}$, temperature, pressure, exhaust flow rate, and the changing PM mass retained in the $\mathrm{CPF}$. The pressure drop across the $\mathrm{CPF}$ is related to a changing resistance to the flow. As PM mass is retained in the wall and cake layers of the CPF, resistance through the $\mathrm{CPF}$ is increased. This increased resistance increases the differential pressure drop across the CPF. As the pressure drop increases the back pressure encountered by the engine increases as well. Modeling efforts work to capture a full description of the diesel particulate filter state during loading and regeneration. This requires consideration of changing filtration efficiency, mass and energy balances, and the resulting pressure drop. As described in paragraph 2.2, the distribution of PM mass can change during passive oxidation. Maldistribution of PM from temperature gradients results in un-even exhaust flow through the CPF.

Equation 6 represents the differential pressure across the CPF as reported by Kladopoupou et al. [29]. By dividing the differential pressure across the $\mathrm{CPF}(\Delta \mathrm{P})$ by the actual volumetric flow rate of the exhaust gasses $\left(\mathrm{Q}_{\mathrm{exh}}\right)$, the changing resistance through the CPF as it is loaded or oxidized can be calculated. The terms and variables on the right hand side of this equation represent CPF dimensional characteristics and PM mass and permeability responsible for the resistance of the CPF. The resistance of exhaust gasses through the CPF is dependent on temperature, pressure, PM mass retained, and the exhaust gas viscosity.

$$
\frac{\Delta P}{Q_{\text {exh }}}=\frac{\mu}{2 V_{\text {trap }}}(\alpha+w)^{2}\left[\begin{array}{l}
\frac{w}{k_{0} \alpha}+\frac{1}{2 k_{\text {soot }}} \ln \left(\frac{\alpha}{\alpha-2 w_{s}}\right) \\
+\frac{4 F L^{2}}{3}\left(\frac{1}{\left(\alpha-2 w_{s}\right)^{4}}+\frac{1}{\alpha^{4}}\right)
\end{array}\right]
$$

$$
\begin{array}{ll}
\Delta \mathrm{P} & =\text { pressure drop across CPF } \\
\mathrm{Q}_{\text {exh }} & =\text { standard volumetric flow rate of exhaust, }(\mathrm{scm} / \mathrm{sec}) \\
\mu & =\text { exhaust dynamic viscosity } \\
\mathrm{V}_{\text {trap }} & =\text { total filter volume } \\
\alpha & =\text { filter cell width } \\
\mathrm{W} & =\text { filter wall thickness } \\
\mathrm{w}_{\mathrm{s}} & =\text { particulate matter layer thickness } \\
\mathrm{k}_{0} & =\text { clean filter wall permeability } \\
\mathrm{k}_{\mathrm{soot}} & =\text { particulate layer permeability } \\
\mathrm{F} & =\text { factor equal to } 28.454 \\
\mathrm{~L} & =\text { filter length }
\end{array}
$$




\subsection{FST RF-DPF PM mass retained sensor}

The Filter Sensing Technologies (FST) radio frequency diesel particulate filter (RF-DPF) PM mass retained sensor used during testing utilizes radio frequencies in the microwave range to monitor the amount, type, and spatial distribution of material accumulated in a CPF. The FST RF-DPF sensor measures PM and ash accumulation in the CPF directly. The sensor functions by transmitting an RF signal through the CPF housing over a broad frequency range. Two antennas are used, one for transmission of the RF signal, and the second for signal detection. Figure 2.1 presents the response of the raw (unprocessed) RF signal and a schematic showing the location of the antennas in the filter housing.

Sweeping the RF signal over an appropriate frequency range results in resonant modes being generated in the CPF housing, which functions as a microwave cavity. As PM accumulates in the CPF, the resonant modes are affected. Physically, each resonant mode corresponds to different regions of high electric field strength within the CPF. These modes are most sensitive to detect PM and ash accumulation in the regions of the filter corresponding to areas of high electric field.

Work performed by Sappok et al. [31] showed that while the RF system is affected by temperature it is not affected by exhaust flow rate like pressure drop profiles are. A tapered element oscillating microbalance (TEOM), traditional diluted gravimetric sampling, and a Dekati DMM were used to determine PM concentrations during this study. PM concentrations and differential pressure drop profiles were compared to the RF system outputs during steady state and transient engine operating conditions. In this study the RF sensor tested showed repeatability during steady state loading conditions of a diesel particulate filter (DPF), and remained stable during low PM emissions events while displaying rapid response to high PM emissions events. 


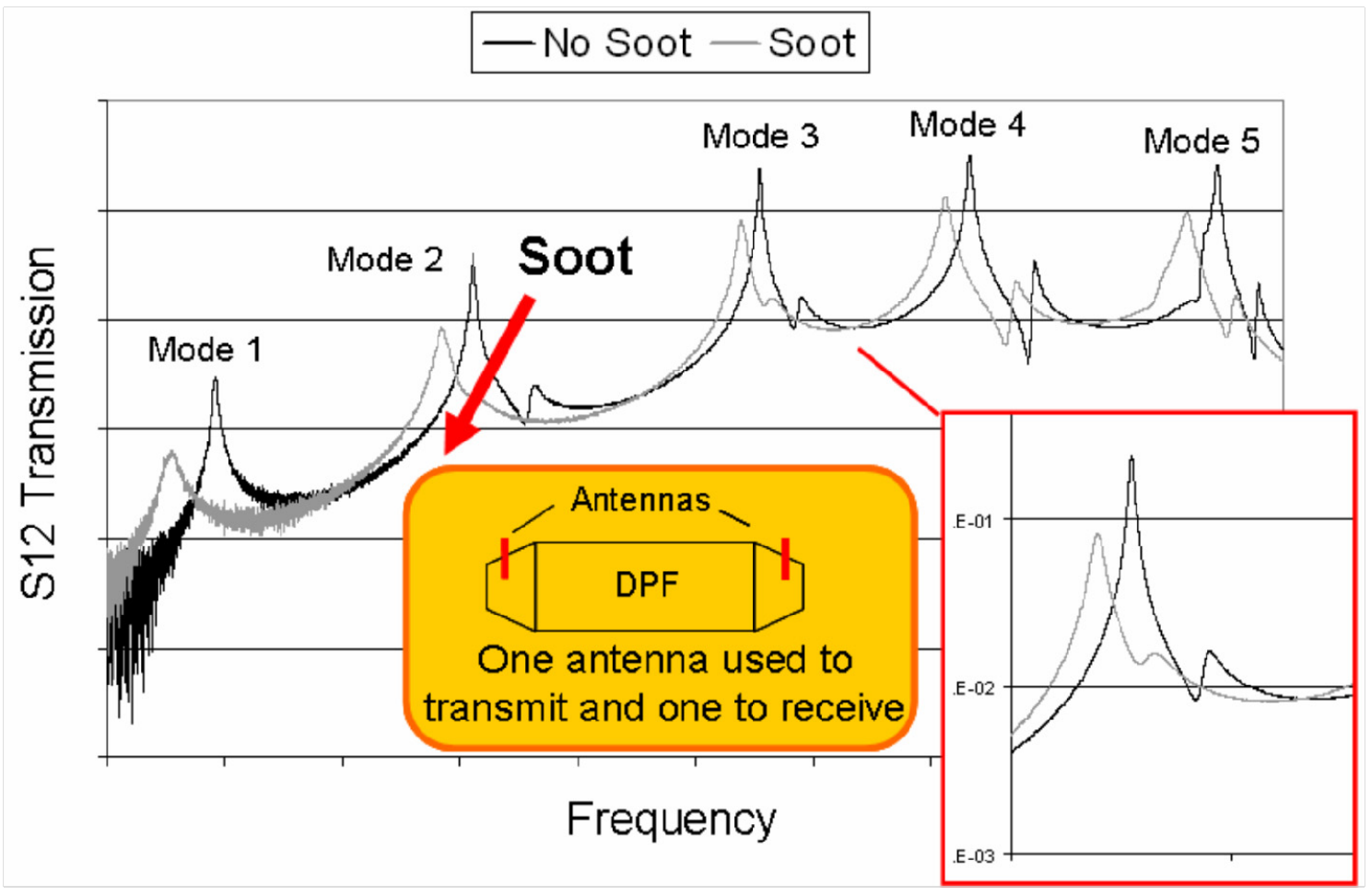

Figure 2.1: Filter resonance curves and response of RF signal to PM accumulation in the CPF [30]

\subsection{Pegasor Particle Sensor (PPS)}

The Pegasor particle sensor (PPS) is shown in Figure 2.2. Clean dried pressurized air is used to carry a corona discharge of positive ions through the sensor. This air draws PM matter into the sensor by Venturi effect. The ions attach to the PM and leave the sensor as the PM leaves. The change in voltage potential due to the lost ions is proportional to the total surface area of the PM that passes through the sensor. Knowledge of the PM average midpoint diameter and density is used to convert this data to mass, volume, or number readings. 


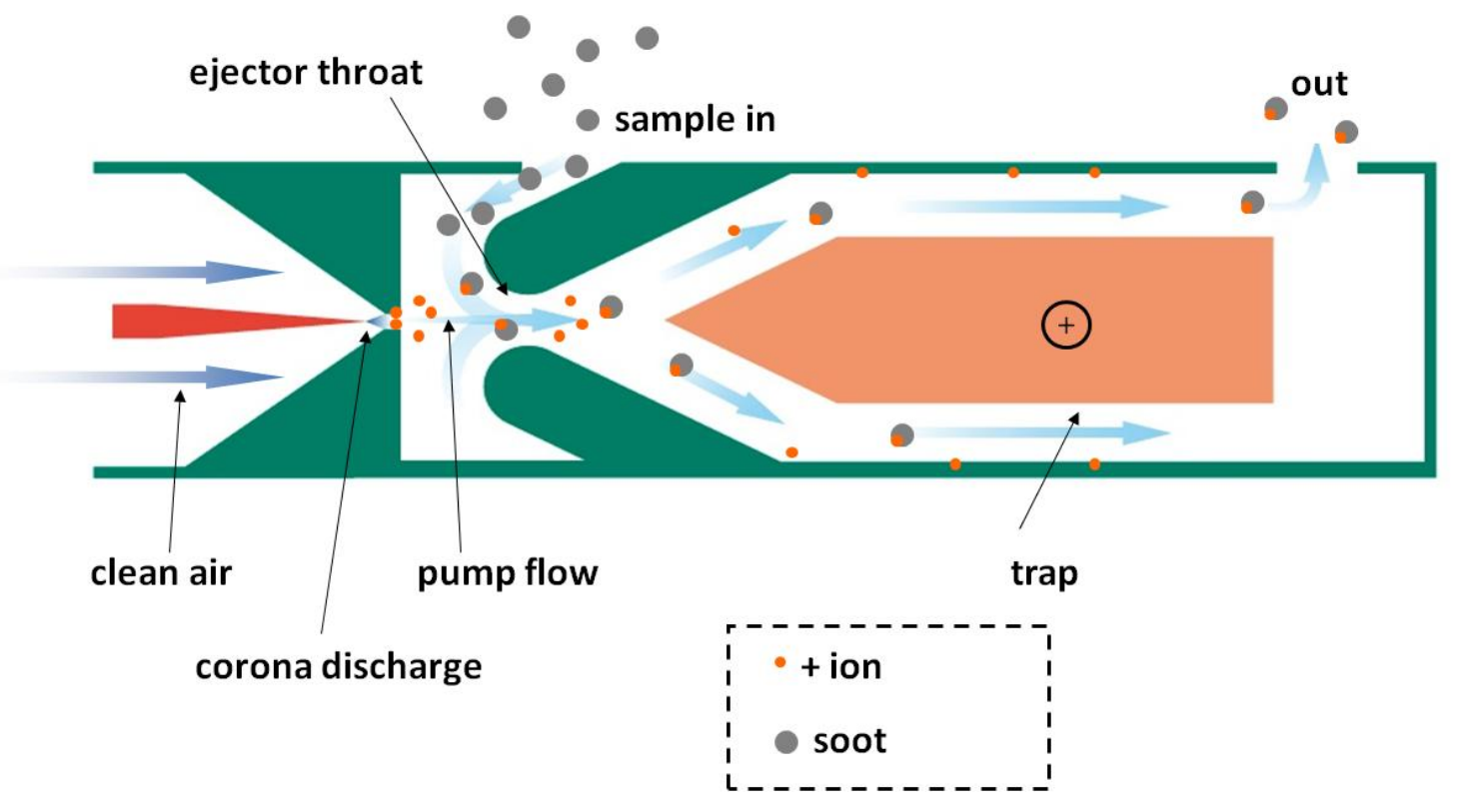

Figure 2.2: PPS schematic [32]

Work performed by Ntziachristos et al. [32] showed that a sensor of this type could be used downstream of a DPF to detect decreased filtration efficiency of a damaged filter. Engine testing was conducted with a functional DPF with $1 \mathrm{mg} / \mathrm{km}$ of PM emissions out of the DPF and a damaged DPF with $6 \mathrm{mg} / \mathrm{km}$ PM emissions out of the DPF. These DPF out PM emission values were determined with an AVL Smokemeter 415S.

\subsection{Summary}

The diesel engine in a dependable power plant that may be used in many ways. Strict emissions regulations have made the use of aftertreatment systems and complicated control strategies common. The use of biodiesel in order to reduce US dependency on foreign oil requires research into the impact biodiesel fuel has on the engine and aftertreatment systems. Biodiesel has been shown to possibly increase engine out $\mathrm{NO}_{\mathrm{x}}$ while reducing $\mathrm{CO}, \mathrm{THC}$, and $\mathrm{PM}$ emissions depending on the engine control strategies and design [16-20]. One clear difference in emissions when operating with biodiesel is the structure and content of the THC and PM out of the engine.

Catalyst aging in the DOC can affect the gaseous concentrations into the $\mathrm{CPF} . \mathrm{NO}_{2}$ may be reduced to NO rather than NO being oxidized across an aged DOC [25 - 27]. This reduces the $\mathrm{NO}_{2}$ concentration into the CPF and may decrease the reaction rate of PM in the CPF. This aging may be accelerated by a doubling in ash content when operating with biodiesel fuels [28].

Two sensor types have been described which may lead to improved control strategies based on their output. Knowing the precise amount of PM mass retained in the CPF, or the amount of PM entering the CPF can lead to better state estimation of the CPF as it is used over a transient cycle in a vehicle. 


\section{Chapter 3. Experimental Setup, Test Procedures}

A 2007 Cummins 8.9 L ISL engine was used at two different power ratings. Fourteen experiments were conducted at $272 \mathrm{~kW}(365 \mathrm{hp})$. Four tests were conducted with B10 fuel and four with B20 fuel to quantify the effect of methyl-ester biodiesel blended fuel on the passive oxidation in the CPF when compared to ULSD. The remainder of the 272 $\mathrm{kW}$ (365 hp) rating tests were conducted with ULSD fuel. After completion of the fourteen tests the ISL was fitted with a larger variable geometry turbo and a new engine control unit (ECU) to increase the power rating to $317 \mathrm{~kW}(425 \mathrm{hp})$. A single test was performed at this rating at the time of completion of this thesis. Five additional tests will be conducted with this engine at this rating with ULSD to determine the effect on passive oxidation of PM in the CPF and to evaluate the performance of an experimental CPF PM mass retained sensor.

Engine manufacturers often build a single base engine and offer a range of optional equipment to give the engine a different set of performance characteristics. Adding a turbo charger, or replacing the existing turbo with one capable of higher boost pressures, will increase power output and may increase fuel efficiency during the same drive cycle. An engine with the same base structure may be offered at multiple power ratings. Studies have shown that PM emissions are reduced and $\mathrm{NO}_{\mathrm{x}}$ emissions are increased when boost pressure is increased [33, 34].

\subsection{Engine and Dynamometer}

The engine specifications for the 2007 Cummins ISL engine used for this testing are shown in Table 3.1. A Dyne Systems Dynamatic model 8121 wet gap / low inertia eddy current dynamometer was used for this testing. A Digalog Model 1022A dynamometer controller with two operating modes (speed, load) was used to regulate engine speed and load. This controller was operated in the "speed" mode for all passive oxidation tests. 
Table 3.1:

ISL engine specifications

\begin{tabular}{|l|l|}
\hline Model & $\begin{array}{l}\text { Cummins ISL }-272 \mathrm{~kW}(365 \mathrm{hp}) \\
\text { and } 317 \mathrm{~kW}(425 \mathrm{hp})^{*}\end{array}$ \\
\hline Year of Manufacture & 2007 \\
\hline Cylinders & 6, inline \\
\hline Bore \& Stroke & 114 X $114.5 \mathrm{~mm}$ \\
\hline Displacement & $8.9 \mathrm{~L}$ \\
\hline Aspiration & Turbo Charged \\
\hline After cooling & Cummins Charge Air Cooler \\
\hline Turbocharger & Variable Geometry Turbine (Holset VGT) \\
\hline Rated Speed and Power & 2100 rpm and 272 kW \\
\hline Peak Torque & 1695 Nm @ 1400 rpm \\
\hline Common Rail Pressure (Peak) & 160 MPa \\
\hline EGR system & Electronically Controlled and Cooled \\
\hline
\end{tabular}

* Different turbocharger and ECU

\subsection{Fuel Properties}

The fuel used during testing was chemically tested to determine properties. The properties of each batch of fuel used for testing are shown in Table 3.2. ULSD-1 is the batch of fuel used for ULSD tests performed on the ISL at $272 \mathrm{~kW}$ (365 hp) rating. ULSD-2 is the batch of fuel used for ULSD tests performed on the ISL at $317 \mathrm{~kW}$ (425 hp) rating. A single batch of B10 and B20 were used for biodiesel testing. 
Table 3.2:

Fuel properties for fuel used during testing*

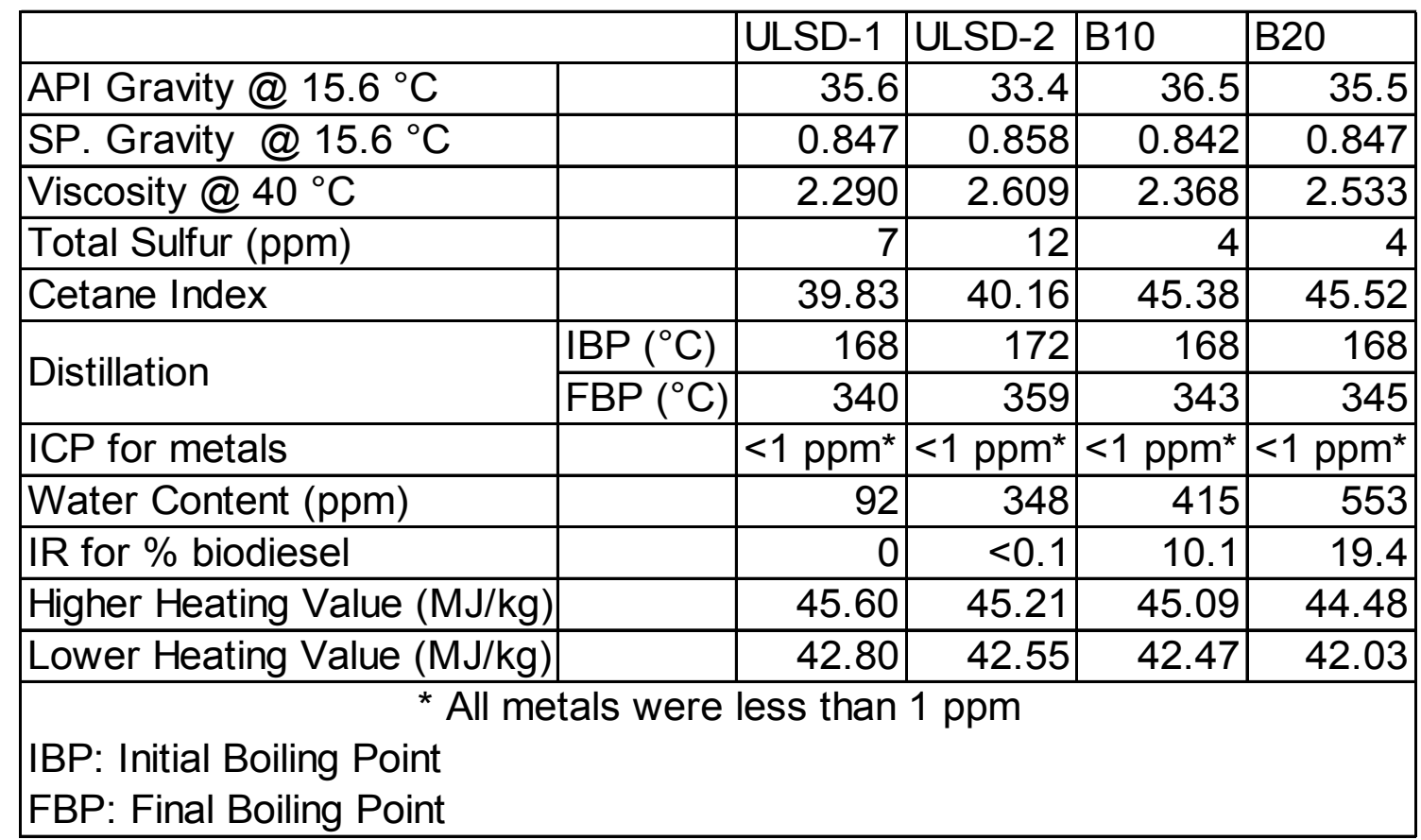

* Fuel analyzed by Cummins lab

\subsection{Aftertreatment System}

A Cummins 2007 aftertreatment system consisting of a diesel oxidation catalyst (DOC) and a catalyzed particulate filter (CPF) was used for passive oxidation tests conducted at the $272 \mathrm{~kW}$ (365 hp) rating. A Cummins 2010 DOC and new Cummins $2007 \mathrm{CPF}$, of the same model number, was used for passive oxidation tests conducted at $317 \mathrm{~kW}$ (425 hp) rating. The part numbers and specifications for the DOC's and CPF's used for this study are shown in Table 3.3. 
Table 3.3:

DOC and CPF specifications

\begin{tabular}{|l|c|c|}
\hline Specification & DOC & CPF \\
\hline Part \# & $\begin{array}{l}\text { EPN Q621300 (ISL 365) } \\
\text { EPN Q629360-10 (ISL 425) }\end{array}$ & $\begin{array}{l}\text { EPN Q623316 (ISL 365) } \\
\text { Same EPN for ISL 425 }\end{array}$ \\
\hline Substrate & Cordierite & Cordierite \\
\hline Cell Geometry & Square & Square \\
\hline Diameter (mm) & 267 & 267 \\
\hline Length (mm) & 102 & 305 \\
\hline Total Volume (L) & 5.7 & 17.1 \\
\hline $\begin{array}{l}\text { Cell Density } \\
\left.\text { (cells/cm }{ }^{2} \text { cells/in }{ }^{2}\right)\end{array}$ & $62,(400)$ & $31,(200)$ \\
\hline Cell Width (mm) & 1.09 & 1.49 \\
\hline Frontal Area (\%) & 81 & 69 \\
\hline $\begin{array}{l}\text { Channel Wall Thickness } \\
\text { (mm) }\end{array}$ & 0.114 & 0.305 \\
\hline Wall Density (g/cc) & N/A & 0.45 \\
\hline Specific Heat (J/kg K) & N/A & 891 \\
\hline $\begin{array}{l}\text { Thermal Conductivity } \\
\text { (W/m K) }\end{array}$ & N/A & 0.84 \\
\hline Porosity (\%) & 35 & 52 \\
\hline Mean Pore Size (micron) & N/A & 13 \\
\hline
\end{tabular}

\subsection{Test Cell Setup}

The layout of the exhaust system is shown in Figure 3.1. The exhaust system includes two routes for the exhaust to flow through. The advantage of using two routes for the exhaust gas is to increase the control of the exhaust gas to the aftertreatment system. This provides the ability to immediately start or stop a stage of the testing without adverse effects on the engine or exhaust system. The route flowing through the aftertreatment system is designated the trap line, and the route that goes to the building exhaust is designated the baseline. Pneumatic valves are used for controlling the exhaust flow path. More information on the use of pneumatic valves to control the flow of exhaust can be found in a prior study performed by Chilumukuru et al. [35]. While warming up the system to a specified engine speed and load, defined by the stage of the test, the exhaust is diverted to the baseline. Once speed, load, and turbo-out exhaust temperature of the engine have stabilized, the exhaust gas is diverted to the trap line. This provides a consistent flow of the exhaust through the aftertreatment system, and a clear beginning of the test stage. 


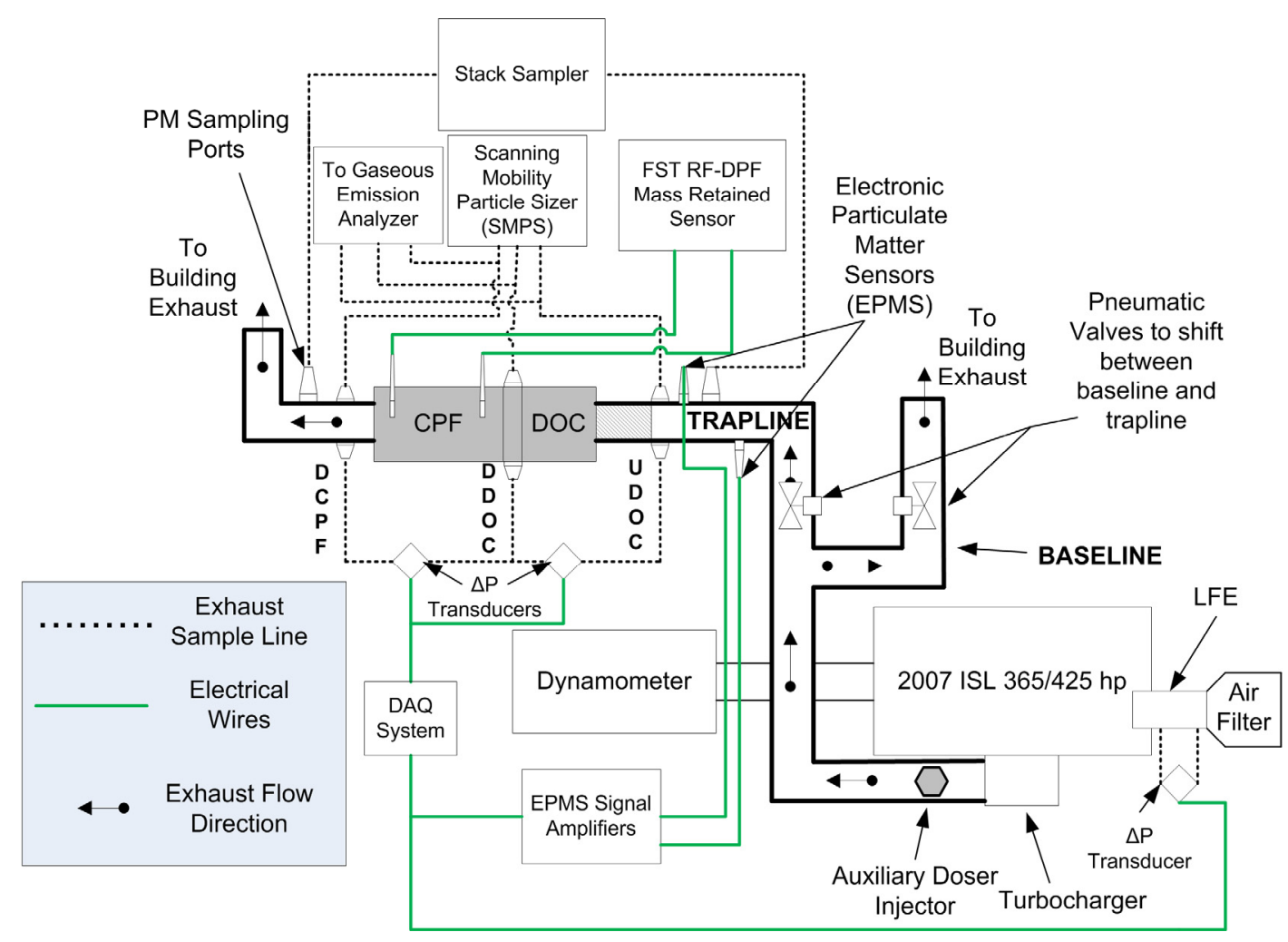

Figure 3.1: Schematic of test cell set up on Cummins 2007 ISL

\subsubsection{Data Acquisition}

A National Instruments data acquisition system was used to monitor and record temperature and pressure throughout the aftertreatment system. Data were recorded at 1 $\mathrm{Hz}$ for ISL $272 \mathrm{~kW}(365 \mathrm{hp})$ tests $6-9$ and at $5 \mathrm{~Hz}$ for ISL $272 \mathrm{~kW}(365 \mathrm{hp})$ tests $10-$ 19 and all ISL $317 \mathrm{~kW}(425 \mathrm{hp})$ tests. The tests conducted with the ISL rated at $272 \mathrm{~kW}$ (365 hp) will be referred to as ISL 365 tests and tests conducted with the ISL rated at 317 $\mathrm{kW}$ (425 hp) will be referred to as ISL 425 tests throughout this thesis.

\subsubsection{Temperature}

The temperature within the test cell was measured for each test. Three different diameter ungrounded type $\mathrm{K}$ thermocouples were used to measure temperatures within the aftertreatment system. The diameter of thermocouple used depended of the location being measured. Thermocouple locations, part numbers, and descriptions are shown in Table 3.4. Gaseous temperatures were measured with $3.175 \mathrm{~mm}(0.125 \mathrm{in}$. $)$ diameter thermocouples. The DOC had $0.508 \mathrm{~mm}(0.020$ in.) diameter thermocouples within the substrate. The CPF had $0.8128 \mathrm{~mm}$ (0.032 in.) diameter thermocouples within the substrate. The thermocouple layout used within the DOC for testing on the ISL is shown in Figure 3.2. 
Table 3.4:

Watlow thermocouple specifications

\begin{tabular}{|c|c|c|c|l|l|}
\hline Location & Type & Diameter & Length(s) & Watlow part number & Body Material \\
\hline DOC & $\mathrm{K}$ & $0.020^{\prime \prime}$ & $12^{\prime \prime}, 17^{\prime \prime}$ & AX1078701, PT-227664-001 & Inconel \\
\hline CPF & $\mathrm{K}$ & $0.032^{\prime \prime}$ & $12^{\prime \prime}, 17^{\prime \prime}$ & AX1078801, Special Order & Inconel \\
\hline Engine exhaust & $\mathrm{K}$ & $0.125^{\prime \prime}$ & $6^{\prime \prime}$ & ACGF00Q060U40000 & Inconel \\
\hline
\end{tabular}

Exhaust FIow
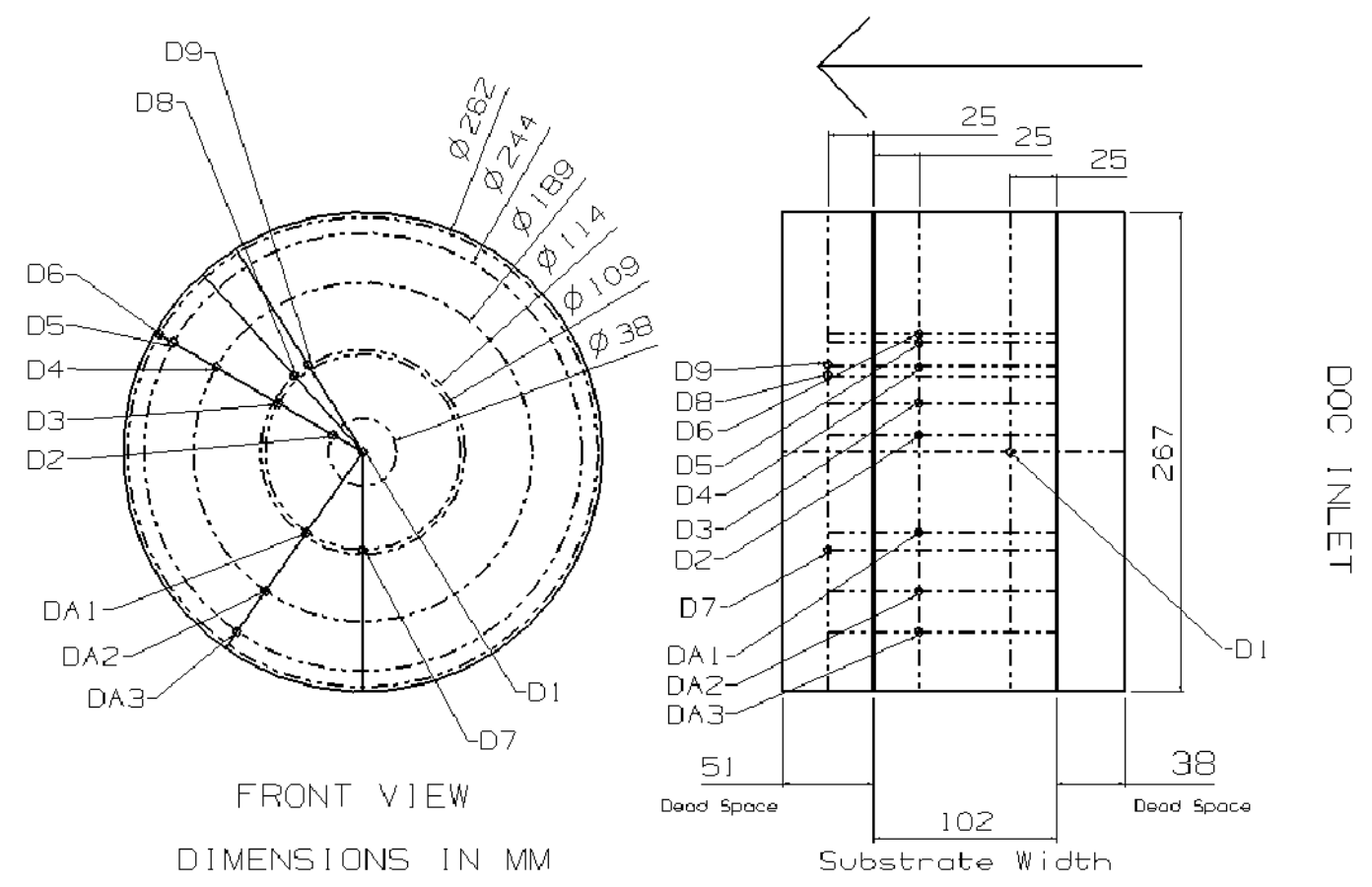

\section{Figure 3.2: DOC thermocouple layout [2]}

The thermocouple layout used for ISL $272 \mathrm{~kW}(365 \mathrm{hp})$ tests $10-19$ is shown in Figure 3.3. ISL $317 \mathrm{~kW}$ (425 hp) test 1 was completed without thermocouples, emissions probe, or differential pressure probe in place. The CPF thermocouple layout was modified slightly before ISL test 10 to more accurately capture radial temperature gradients. The CPF thermocouple layout used for ISL tests 6 - 9 can be found in Appendix A. During the separate portions of the test, the average CPF temperature was calculated. The volume averaged CPF temperature was found by averaging thermocouples placed at the 110,190 , and $244 \mathrm{~mm}$ diameter locations. The thermocouples used to find the volume averaged CPF temperature for each set of testing had approximately the same placement. More information pertaining to the volume averaged CPF temperature may be found in reference [2]. 


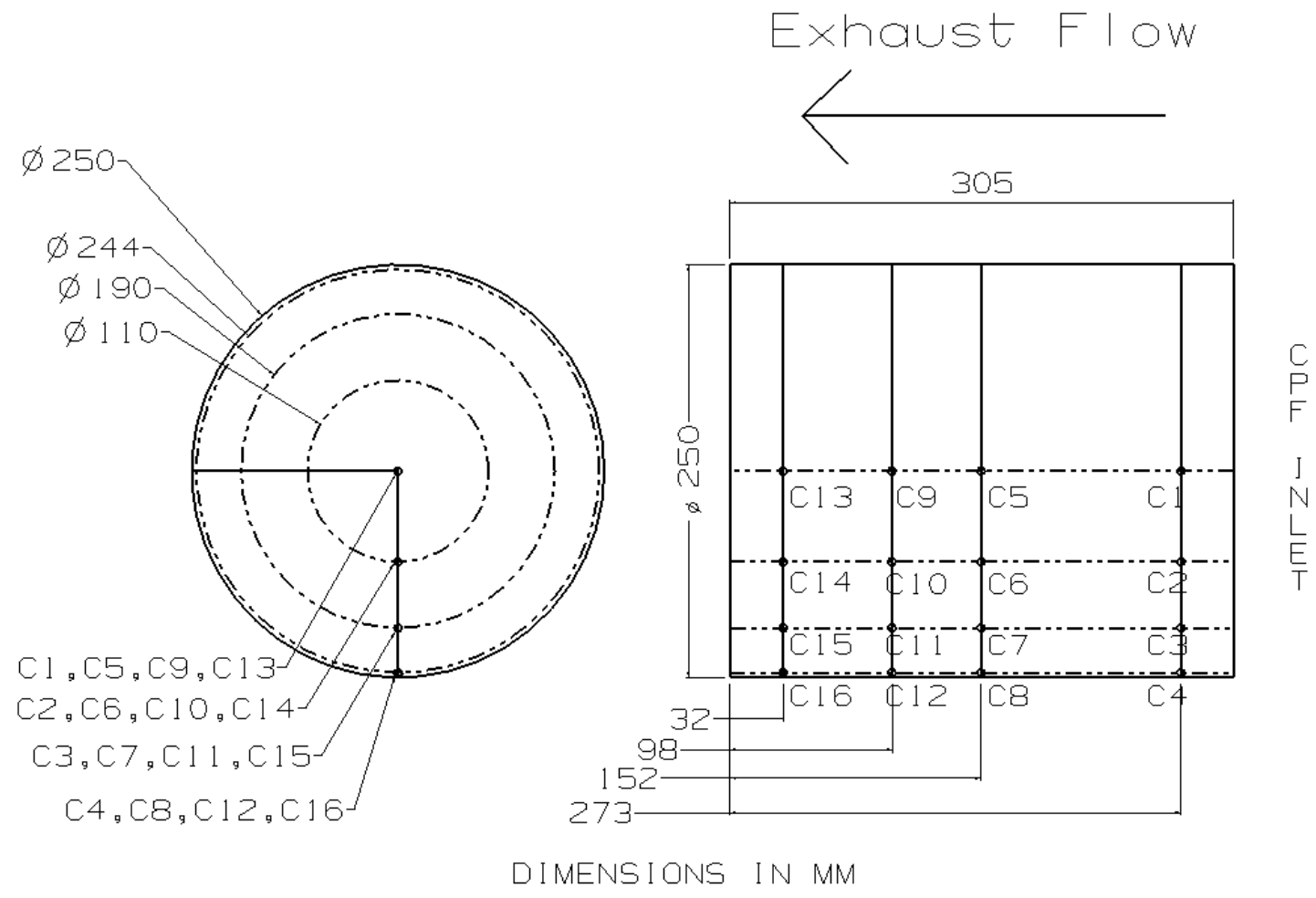

Figure 3.3: CPF thermocouple layout [4]

\subsubsection{Pressure}

The pressure measurements were obtained by four different sensors during each test. Differential pressure across the DOC, CPF, and laminar flow element (LFE) were measured by three of the sensors. The fourth sensor measured barometric pressure in the test cell at the LFE. The test cell relative humidity was recorded for each test at the LFE as well. The test cell temperature, barometric pressure, and relative humidity were used to find density and viscosity adjustments for the air mass flow rates before beginning each test.

\subsubsection{Air and Fuel Flow}

The LFE, manufactured by Meriam Instruments (Cleveland, Ohio), was used for air flow measurements. This instrument paired with a $3.45 \mathrm{kPa}(0.5 \mathrm{psid})$ differential pressure transducer determined the air mass flow rate into the engine. The exhaust mass flow rate is then calculated by adding the fuel mass flow rate to the air flow rate. A fuel mass balance, manufactured by AVL (Plymouth, MI) with a manufacturer part number of $703 \mathrm{G}$, was used to measure fuel flow rate.

\subsubsection{Gaseous Emissions}

Experiments performed on the 2007 Cummins 8.9 L ISL used a Pierburg AMA 4000 emissions bench manufactured by AVL North America (Plymouth, MI). This emissions 
bench measures hydrocarbons $(\mathrm{HC}), \mathrm{NO}_{\mathrm{x}}\left(\mathrm{NO}_{2}+\mathrm{NO}\right), \mathrm{NO}, \mathrm{CO}, \mathrm{CO}_{2}$, and $\mathrm{O}_{2}$. Gaseous emissions testing on the ISL consisted of sampling raw exhaust gas from three locations in the aftertreatment system. The sampling locations are upstream of the diesel oxidation catalyst (UDOC), downstream the diesel oxidation catalyst (DDOC), and downstream the catalyzed particulate filter (DCPF). The exhaust gas passes through a filter that is maintained at $185^{\circ} \mathrm{C}$ and then flows to the analyzer through a sample line maintained at $185^{\circ} \mathrm{C}$.

\subsubsection{Particulate Matter Concentration}

A manual sampling train from Andersen Instruments Inc. (Smyrna, GA) was used to obtain particulate matter (PM) samples. Raw, heated $\left(260-480^{\circ} \mathrm{C}\right)$ exhaust was drawn through a Pall Corporation (Ann Arbor, MI) type A/E $47 \mathrm{~mm}$ glass fiber filter type. Additional information is available in research performed by Lakkireddy et al. [37]. This was done multiple times over the course of each test to gain an average PM concentration during loading and passive oxidation portions of the experiments. The particulate matter concentrations were measured in the same manner on both ISL $365 \mathrm{hp}$ tests and ISL 425 $\mathrm{hp}$ tests. The two sampling locations used for this measurement were UDOC and DCPF. The DCPF PM sample was collected during Stage 2 of each test and was used to determine the filtration efficiency of the CPF. Additional details of the PM sample filter preparation, sample collection, and sample processing is shown in Appendix B.

\subsubsection{Particle Size Distribution}

Particle size distribution (PSD) data were collected during loading and passive oxidation portions of both ISL $272 \mathrm{~kW}(365 \mathrm{hp})$ tests and ISL $317 \mathrm{~kW}(425 \mathrm{hp})$ tests. A detailed description of the procedure used to collect particle size distribution data can be found in Appendix C. Measurements were performed using a set of four instruments from TSI Inc. (Shoreview, MN). The four instruments are collectively termed Scanning Mobility Particle Sizing System (SMPS) system. The first of the four instruments is a mini dilution system and was manufactured in-house at MTU and uses filtered, compressed air heated to a temperature of $200{ }^{\circ} \mathrm{C}$ to condition the exhaust gas. Dilution ratios were found to depend on the pressure drop across the aftertreatment components and the compressed air pressure. Three sampling locations used for this measurement were UDOC, DDOC, and DCPF. Each of these locations presents a different exhaust pressure which needs to be considered in the sampling and compensated for. The compressed air pressure was maintained at a gauge pressure of $30 \mathrm{psi}$ and the dilution ratio for each engine operating condition and at each sampling location was compensated for during post processing of the PSD data.

\subsubsection{PM Mass Retained in the Catalyzed Particulate Filter}

The diesel oxidation catalyst (DOC) and catalyzed particulate filter (CPF) were mounted in a stainless steel "can" that could easily be removed from the exhaust line for weighing. The scale used for the mass measurement of the CPF during the performed testing was an Ohaus Ranger model 35LM with a readability of $0.1 \mathrm{~g}$, and a repeatability of $\pm 0.3 \mathrm{~g}$. 
From experimentation and analysis performed in Austin et al. [22, 36], it has been shown that the mass of the CPF can be heavily influenced by the temperature that it is weighed at. Due to this, great care was taken to ensure that the CPF was weighed at approximately the same temperature during each stage of the test. To ensure that the CPF is weighed at the same temperature throughout the test process, temperature measurements are recorded prior to weighing at each of the locations shown in Figure 3.3. The individually measured substrate temperatures within the CPF can vary widely. As an example, measured temperatures within the CPF at a given time after operating the ISL at $365 \mathrm{hp}$ at a speed of $2100 \mathrm{rpm}$ and a load of $195 \mathrm{Nm}$ can range from 180 to $290^{\circ} \mathrm{C}$. Due to the temperature gradients, it is not practical to specify an average CPF temperature at which weighing occurs for every test. The preferred approach is to ensure that the individual temperature measurements vary by no more than $\pm 15^{\circ} \mathrm{C}$ during the weighting for the different portions of the test. The detailed mass measurement procedure can be found in Appendix D. Additional information on the CPF weighing procedure can be found in references $[2,30]$. An axial flow exhaust gas mixer (Emitec Inc., MI) was mounted in the exhaust just before the inlet of the DOC.

The mass retained during Stage 1, ramp-up, and Stage 3 cannot be determined from direct mass measurement such as with Stage 2 and Stage 4. The mass deposited during these stages must be determined by calculation. The method used to calculate the mass retained during Stage 1, Ramp-up, and Stage 3 is detailed, but a final mass balance will be performed by the modeling effort. The method of calculation assumes that the rate of mass deposition from Stage 2 is constant during ramp-up loading (equation 7) and the rate of mass deposition from Stage 4 (if used) is constant during Stage 3 (equation 8). Equation 9 is used to determine Stage 1 mass retained. The assumption of Stage 2 filtration efficiency used in this equation results in the same value that would be obtained by assuming Stage 1 loading rate is the same as Stage 2. Details on the derivation of this equation can be found in Appendix E. The MTU 1-D model will be used to account for differences in exhaust gas concentrations and temperature for each stage. The MTU 1-D model will be calibrated and used to complete the final mass balance for these tests, but equations 7 - 9 will be used for the mass balances within this thesis. If Stage 4 was not performed for a test the mass deposition from Stage 2 is assumed constant for Stage 3. The filtration efficiency is determined by taking a single downstream PM sample during Stage 2 and this filtration efficiency is assumed constant through the entire test. The mass out of the CPF for each stage is calculated with this filtration efficiency. The remainder of the engine out PM mass is assumed to be oxidized. 


$$
m_{a d d_{-} R U}=\left(\frac{m_{S 1}-m_{S 2}}{\text { time }_{S 2}}\right) \times \text { time }_{\text {stage }}
$$

$$
\begin{aligned}
& \mathrm{m}_{\mathrm{add} \_\mathrm{RU}}=\quad \text { Predicted PM mass retained in the CPF during Ramp-up, [g] } \\
& \mathrm{m}_{\mathrm{S} 1}=\text { Measured mass of the CPF at end of Stage 1 loading, [g] } \\
& \mathrm{m}_{\mathrm{S} 2}=\text { Measured mass of the CPF at end of Stage 2 loading, [g] } \\
& \text { time }_{\mathrm{S} 2}=\text { Time of Stage } 2 \text { loading, [min.] } \\
& \text { time }_{\mathrm{RU}}=\text { Time of Ramp-up, [min.] }
\end{aligned}
$$

$$
m_{\text {add_S3 }}=\left(\frac{m_{S 3}-m_{S 4}}{\text { time }_{S 4}}\right) \times \text { time } e_{\text {stage } 3}
$$

$$
\begin{aligned}
& \mathrm{m}_{\mathrm{add} \_} \mathrm{S} 3=\text { Predicted PM mass retained in the CPF during Stage 3, [g] } \\
& \mathrm{m}_{\mathrm{S} 3}=\text { Measured mass of the CPF at end of Stage } 3 \text { loading, }[\mathrm{g}] \\
& \mathrm{m}_{\mathrm{S} 4}=\text { Measured mass of the CPF at end of Stage } 4 \text { loading, }[\mathrm{g}] \\
& \text { time } 44_{\mathrm{S} 4}=\text { Time of Stage } 4 \text { loading, }[\mathrm{min} .] \\
& \text { time }_{\text {stage3 }}=\text { Time of Stage } 3,[\mathrm{~min} .]
\end{aligned}
$$

$$
m_{a d d \_S 1}=\eta_{S 1} m_{i n, S 1}-\left(\eta_{S 2}-\frac{m_{S 2}-m_{S 1}}{m_{i n, S 2}}\right) m_{i n, S 1}
$$

$$
\begin{aligned}
& \mathrm{m}_{\text {add_s } 1}=\text { Predicted PM mass retained in the CPF during Stage 1, [g] } \\
& \text { S1 }=\text { Average filtration efficiency of the CPF during Stage 1, [.] } \\
& \text { S2 }=\text { Average filtration efficiency of the CPF during Stage 2, [.] } \\
& \mathrm{m}_{\mathrm{S} 1}=\quad \text { Measured mass of the CPF at end of Stage } 1 \text { loading, [g] } \\
& \mathrm{m}_{\mathrm{S} 2}=\quad \text { Measured mass of the CPF at end of Stage } 2 \text { loading, [g] } \\
& \mathrm{m}_{\mathrm{in}, \mathrm{S} 1}=\text { PM mass into the CPF during Stage 1, [g] } \\
& \mathrm{m}_{\mathrm{in}, \mathrm{S} 2}=\quad \mathrm{PM} \text { mass into the CPF during Stage 2, [g] }
\end{aligned}
$$


In order to assume that the rate of mass deposition remains constant many associated factors must be assumed constant as well; the exhaust mass flow rate and temperature through the CPF are maintained at a similar value for all loading stages during each test, the PM concentration remains consistent over the course of each test, and the filtration efficiency during each stage is constant. The average filtration efficiency during Stage 1 was needed, and the time required for filtration efficiency to reach steady filtration efficiency was unknown. Appendix F describes a test conducted to determine the time required to achieve steady particle size distribution filtration efficiency is minimal and therefore constant filtration efficiency similar to Stage 2 may be assumed during Stage 1 loading.

\subsection{Experimental Particulate Matter Sensors}

Testing was performed in parallel and during passive oxidation testing in order to assist in the development of PM concentration sensors and CPF PM mass retained sensors for research related to improving OBD algorithms used for estimating the internal states of the CPF. These sensors may be used as inputs to the CPF model in the short term to increase accuracy of the model. Long term, these sensors may become OEM standard sensors used in the engine and aftertreatment control strategies either in the lab or in vehicles or both.

\subsubsection{FST RF-DPF Mass Retained Sensors}

Multiple generations of FST RF-DPF PM mass retained sensors were tested. Interference of electrical conducting elements made it difficult to create calibration which maintained repeatability from test to test. Details on the calibration data collection process is shown in Appendix G. Testing is being conducted on the ISL rated at $425 \mathrm{hp}$ without conducting elements placed into the CPF while using the RF-DPF sensors in an attempt to eliminate interference. These sensors may be used to determine the instantaneous PM loading of a CPF or DPF resulting in improved modeling and on the road control strategies.

\subsubsection{Pegasor PM Sensor}

Testing was performed on the 2007 Cummins ISL engine rated at $425 \mathrm{hp}$ in order to evaluate a Pegasor PM sensor. The sensor was setup to collect particulate matter (PM) concentration data upstream of the aftertreatment system. An initial calibration was used which provided for an output from the Pegasor sensor in units of $\mathrm{mg} / \mathrm{m}^{3}$ during the course of testing. Engine operating conditions designated as "loading" conditions were used to compare readings from the sensor to the PM mass concentrations measured via MTU's hot sampling method.

\subsection{Passive Oxidation Test Procedure}

The original test procedure developed and used by Hutton et al. [1, 2] will be described in full detail. The differences between the modified test procedure and the original test procedure will be highlighted. All other steps are the same for both test procedures. 
Prior to the start of each test, fourteen Pall Corporation (Ann Arbor, MI) type A/E $47 \mathrm{~mm}$ glass fiber filters must be prepared at least 24 hours before the test is to begin. The procedure for preparing PM sample filters can be found in Appendix C. The engine is operated at loading and passive oxidation conditions before testing. The speed and load is adjusted to achieve the desired temperature and flow rate values specified for the test. The experimentally determined speed and load values are then used for loading and passive oxidation conditions of the test.

For the initial engine start up at the beginning of a test, the engine is started and brought to idle using MTU Heavy Duty Engine standard operating procedure SOP-S1. This can be found in the control room of the MTU diesel engine test bed, S010 in the MEEM building.

The exhaust is routed through the trap line which includes the aftertreatment system $(\mathrm{DOC}+\mathrm{CPF})$; this allows the aftertreatment system to warm up thoroughly to reduce the thermal shock to the system during the initial warm up process.

The engine's warm up process can be seen in Table 3.5. The final engine operating condition is held until a stable DOC inlet temperature of $380^{\circ} \mathrm{C} \pm 10^{\circ} \mathrm{C}$ is observed.

Table 3.5:

Engine speed and load for initial warm up

\begin{tabular}{|c|c|c|}
\hline $\begin{array}{c}\text { Engine } \\
\text { Speed }\end{array}$ & $\begin{array}{c}\text { Engine } \\
\text { Load }\end{array}$ & Time \\
\hline$[$ RPM] & {$[\mathrm{Nm}]$} & {$[\mathrm{min}]$} \\
\hline 750 & 0 & 1 \\
\hline 1200 & 220 & 5 \\
\hline 1800 & 220 & 5 \\
\hline 2100 & 440 & 5 \\
\hline 2100 & 840 & 5 \\
\hline
\end{tabular}

\subsubsection{Catalyzed Particulate Filter Clean out}

After the engine is brought to $2100 \mathrm{RPM}$ and $840 \mathrm{Nm}$, and the DOC inlet temperature has stabilized at $380^{\circ} \mathrm{C} \pm 10^{\circ} \mathrm{C}$, the auxiliary fuel dosing injector is turned on and the duty cycle is adjusted until a CPF inlet temperature of $600{ }^{\circ} \mathrm{C}$ is achieved. Once a CPF inlet temperature of $600^{\circ} \mathrm{C}$ is achieved, it is maintained until a constant pressure drop profile across the $\mathrm{CPF}$ is observed. This process typically requires fifteen minutes at 600 ${ }^{\circ} \mathrm{C}$. Once the pressure drop profile is stable, the dosing injector is turned off and the transition is made to Stage 1 loading. After the dosing injector is turned off, the CPF pressure drop profile is allowed to stabilize before proceeding. 


\subsubsection{Stage 1 Loading of the CPF}

The engine is switched to loading conditions, with a DOC inlet temperature of $265^{\circ} \mathrm{C} \pm$ $10^{\circ} \mathrm{C}$ for Stage 1 loading of the CPF. Loading conditions were typically $2100 \mathrm{rpm}$ and $195 \mathrm{Nm}$ for the ISL rated at $365 \mathrm{hp}$, and $2090 \mathrm{rpm}$ and $255 \mathrm{Nm}$ for the ISL rated at 425 $\mathrm{hp}$. The engine is allowed to run at the loading condition for approximately thirty minutes to allow the temperature of the $\mathrm{CPF}$ to stabilize. By weighing the $\mathrm{CPF}$ at a similar temperature during all portions of the test, the buoyancy effect that results from the thermal mass of the CPF is maintained at a constant level. Ultimately, this technique reduces variability between $\mathrm{CPF}$ weight measurements from different stages in the experiment.

During Stage 1 loading, gaseous emissions are sampled constantly and samples are taken downstream of the catalyzed particulate filter (DCPF), downstream of the diesel oxidation catalyst (DDOC), and upstream of the diesel oxidation catalyst (UDOC), in that order. Figure 3.4 is a visual representation of the gaseous emissions sampling strategy for Stage 1 loading. This strategy was chosen because sampling gaseous emissions at locations of high $\mathrm{HC}$ concentrations (UDOC or DDOC) and transitioning to a location of low $\mathrm{HC}$ concentration (DCPF) provides the opportunity for analyzer hang up. This hang up can also be attributed to the length of sample line used within the test cell but has the same end result which is artificial inflation of the measured $\mathrm{HC}$ concentrations.

One PM sample is collected UDOC for five minutes during Stage 1 loading along with the continuous monitoring of temperature, exhaust flow, fuel flow, and pressure drop profiles across the DOC and CPF.

After thirty minutes of Stage 1 loading, the engine out exhaust is switched to the bypass line which diverts the exhaust around the aftertreatment system and the engine is shut down. Once the engine is shut down, the aftertreatment system is disassembled to allow the weighing of the $\mathrm{CPF}$. The $\mathrm{CPF}$ weighing procedure is explained in detail in Appendix D. 


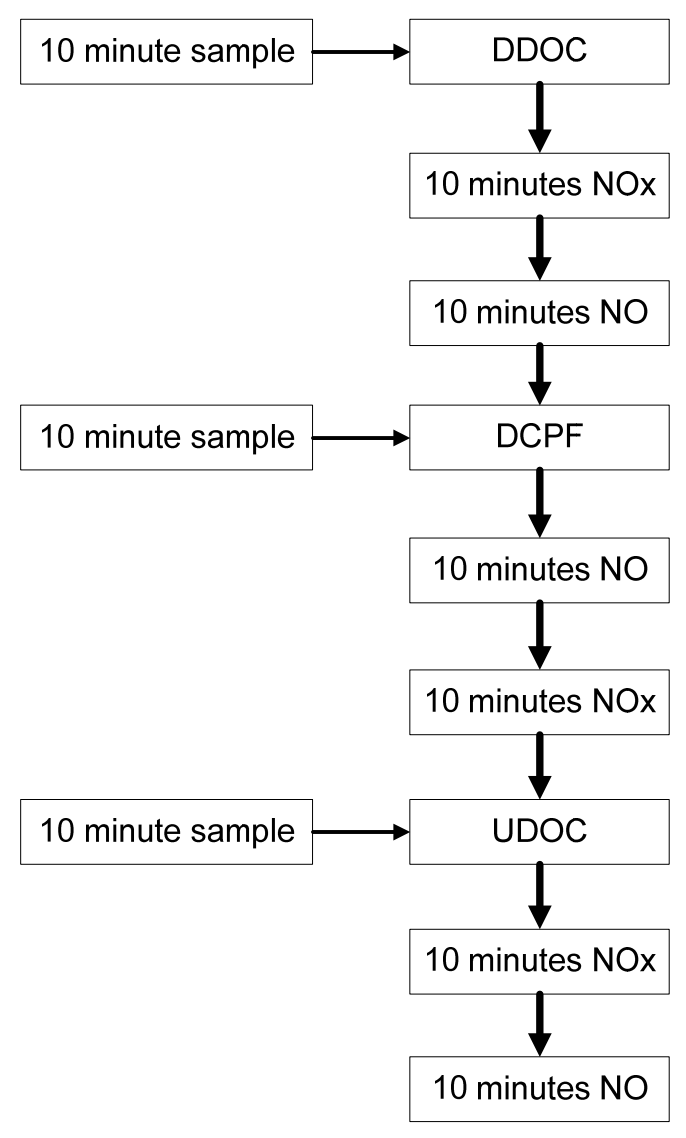

Figure 3.4: Gaseous emissions sampling strategy for Stage 1

The weighing of the CPF provides for the mass measurement $m_{\mathrm{S} 1}$ which is used with $\mathrm{m}_{\text {addt-s1 }}$ to determine the clean weight of the filter $\left(\mathrm{m}_{\mathrm{c}}\right)$ using equation 10 . The value $\mathrm{m}_{\text {add- }}$ $\mathrm{s} 1$ is obtained twice, once prior to the start of the experiment using preliminary test data. This value is used to predict the CPF PM loading during the test. After the test has been completed, the rate of mass deposition from Stage 2 is assumed to be constant for Stage 1 and Ramp-up and Stage 4 is constant from Stage 3 and a more accurate value of loading is calculated for Stage 1, Ramp-up, and Stage 3. Once the MTU 1-D model is calibrated, the data will be re-run using the experimental gaseous and PM concentrations in order to provide the most accurate mass estimate to be used in the final mass balance.

$$
\mathbf{m}_{\mathbf{c}}=\mathbf{m}_{\mathbf{s} \mathbf{1}}-\mathbf{m}_{\text {add_s1 }}
$$

$$
\begin{aligned}
& \mathrm{m}_{c} \quad=\text { Calculated clean weight of the CPF, }[\mathrm{g}] \\
& \mathrm{m}_{\mathrm{S} 1} \quad=\text { Measured mass of the CPF after Stage } 1 \text { loading, }[\mathrm{g}] \\
& \mathrm{m}_{\text {add_s1 }}=\text { Predicted PM added during Stage } 1 \text { loading, }[\mathrm{g}]
\end{aligned}
$$




\subsubsection{Stage 2 Loading of the CPF}

The aftertreatment system is reassembled and installed in the exhaust system. While the exhaust is still routed through the baseline, the engine is started and brought to idle. Table 3.6 shows the warm up procedure, and warm up is complete when a steady exhaust manifold temperature is achieved.

Table 3.6:

Engine speed and load for Stage 2 engine warm up

\begin{tabular}{|c|c|c|}
\hline $\begin{array}{c}\text { Engine } \\
\text { Speed }\end{array}$ & $\begin{array}{c}\text { Engine } \\
\text { Load }\end{array}$ & Time \\
\hline$[$ RPM] & {$[\mathrm{Nm}]$} & {$[\mathrm{min}]$} \\
\hline 750 & 0 & 1 \\
\hline 1200 & 195 & 5 \\
\hline 1800 & 195 & 5 \\
\hline 2100 & 195 & 5 \\
\hline
\end{tabular}

Once the exhaust manifold temperature has stabilized, the exhaust is switched to the trap line which marks the beginning of Stage 2 loading.

Stage 2 loading takes place at the same loading conditions used for Stage 1, with a DOC inlet temperature of $265^{\circ} \mathrm{C} \pm 10^{\circ} \mathrm{C}$. The time of Stage 2 loading is based on preliminary data, and has been shown to vary based upon test cell humidity affecting the engine out PM concentration.

The same measurements and samples that were taken during Stage 1 are also taken during Stage 2. The strategy for gaseous sampling is modified from Stage 1 loading with initial sampling occurring DDOC. This location was given first priority in order to facilitate the modeling effort as it was deemed important from a modeling perspective to record the $\mathrm{CPF}$ inlet concentrations during the start of Stage 2 loading. The second sampling location is DCPF with the final location being UDOC. Gaseous sampling is cycled through these locations during the test with the time at each location split equally dependent upon the predicted length of the stage.

Figure 3.5 is the visual representation of the gaseous emissions sampling strategy for Stage 2 loading. Sample time at each location may be adjusted depending of the total length of the loading stage. 


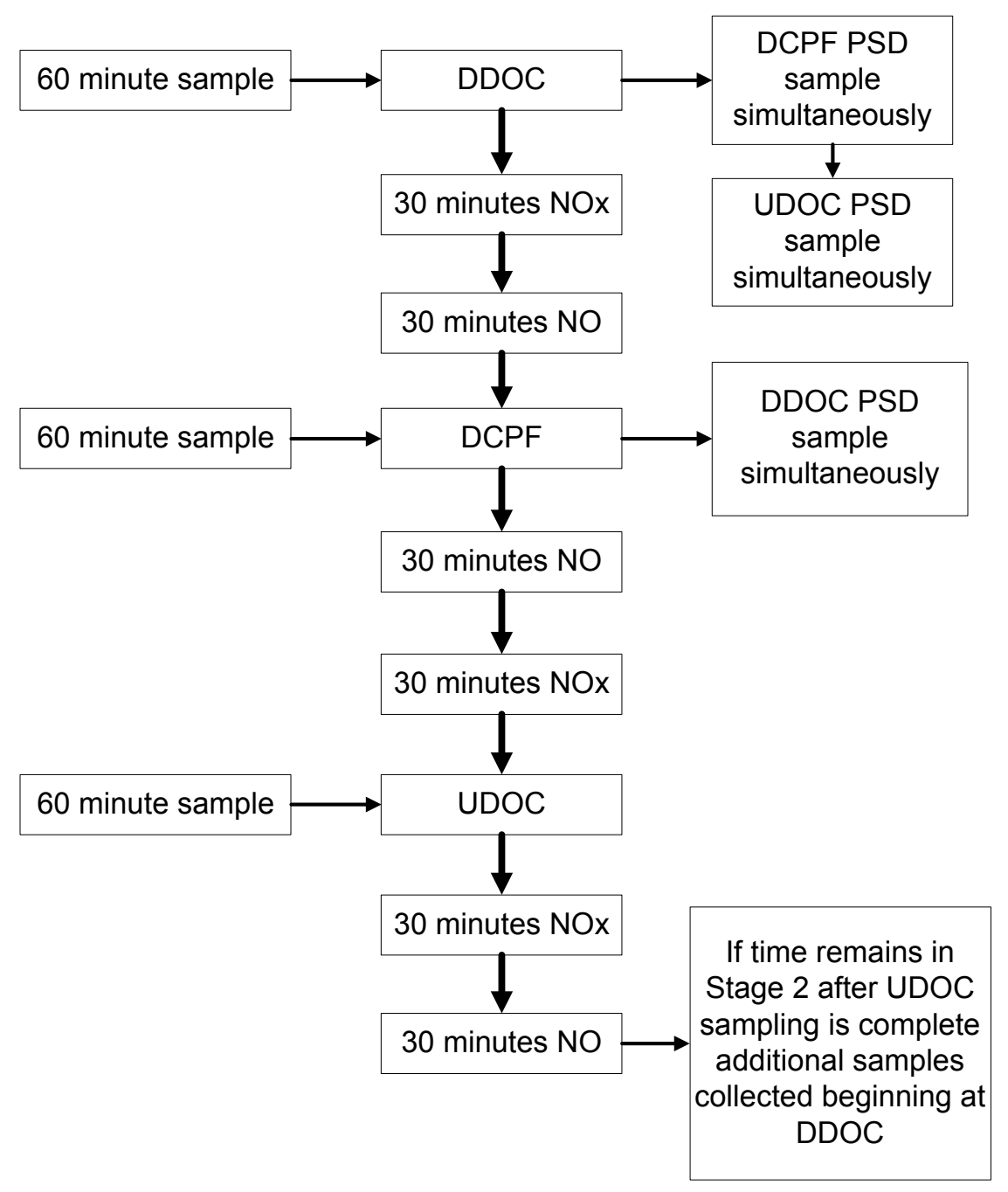

Figure 3.5: Gaseous emissions sampling strategy for Stage 2 loading phase

Exhaust particle size distribution (PSD) samples are also collected DCPF, DDOC, and UDOC. One sample at each location is taken at the beginning of Stage 2 and one sample at each location at the end of Stage 2. The PSD is set to perform three scans at each point requiring seven minutes per point. The PSD samples must be taken at a different location than the gaseous emissions to allow each analyzer to receive the full exhaust sample at that location. For example, if gaseous emissions are being sampled DCPF, PSD must be sampled UDOC or DDOC until the DCPF gaseous emissions sampling has been completed.

Four PM samples are collected UDOC and one PM sample is taken DCPF during Stage 2 loading. One hour is required to collect a measurable amount of PM DCPF. The sample time for the UDOC PM samples is five minutes, which is the same strategy that was used during Stage 1 loading.

After a predetermined amount of loading time has passed, and by observation of the pressure drop profile, the exhaust is diverted through the bypass line and the engine is 
brought to idle and shut down. The aftertreatment system is removed from the exhaust system and then disassembled for CPF weighing. The weighing of the CPF provides for the mass measurement $\mathrm{m}_{\mathrm{S} 2}$ which is used with $\mathrm{m}_{\mathrm{c}}$ in equation 11 to determine $\mathrm{m}_{\text {Ret-S2}}$, the PM mass retained in the CPF after Stage 2.

$$
m_{R e t} S 2=m_{S 2}-m_{c}
$$

$$
\begin{aligned}
& \mathrm{m}_{\text {Ret-S2 }}=\text { Calculated PM mass retained in the CPF at end of Stage } 2 \text { loading, }[\mathrm{g}] \\
& \mathrm{m}_{\mathrm{S} 2}=\text { Measured mass of the CPF at end of Stage } 2,[\mathrm{~g}] \\
& \mathrm{m}_{\mathrm{c}} \quad=\text { Calculated clean weight of the CPF, from Eqn. } 3,[\mathrm{~g}]
\end{aligned}
$$

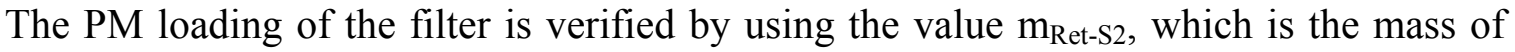
the accumulated PM in the filter, and dividing this mass value by the volume of the CPF, $17.1 \mathrm{~L}$. If $2.2 \pm 0.2 \mathrm{~g} / \mathrm{L}$ has not been achieved, the aftertreatment system must be reinstalled in the exhaust system and additional loading will be required.

After verifying that the CPF loading of $2.2 \pm 0.2 \mathrm{~g} / 1$ has been achieved, the aftertreatment system is reassembled and reinstalled into the exhaust system and subsequently, Stage 2 loading has been completed.

\subsubsection{Passive Oxidation}

The aftertreatment system is reassembled and installed in the exhaust system. While the exhaust is still routed through the baseline, the engine is started and brought to idle. The warm up procedure is similar to the procedure described in Table 3.6 with an adjustment made to the final speed and load. The final speed and load is that of the pre-determined passive oxidation conditions. Warm up is complete when a steady exhaust manifold temperature is achieved.

Gaseous emissions during passive oxidation are collected using the same procedure as was used in Stage 2 loading. Time spent at each measurement location is split evenly and is adjusted according to the expected length of the passive oxidation portion of the test.

Exhaust PSD samples are also collected DCPF, DDOC, and UDOC. If time allows, one sample at each measurment location is taken at the beginning of passive oxidation and one sample at each location at the end of passive oxidation. The PSD is set to perform three scans at each point requiring seven minutes per point. The PSD samples must be taken at a different location than the gaseous emissions to allow each analyzer to receive the full exhaust sample at that location. For example, if gaseous emissions are being sampled DCPF, PSD must be sampled UDOC or DDOC until the DCPF gaseous emissions sampling has been finished. Figure 3.6 is the visual representation for gaseous and PSD sampling during the passive oxidation phase. 


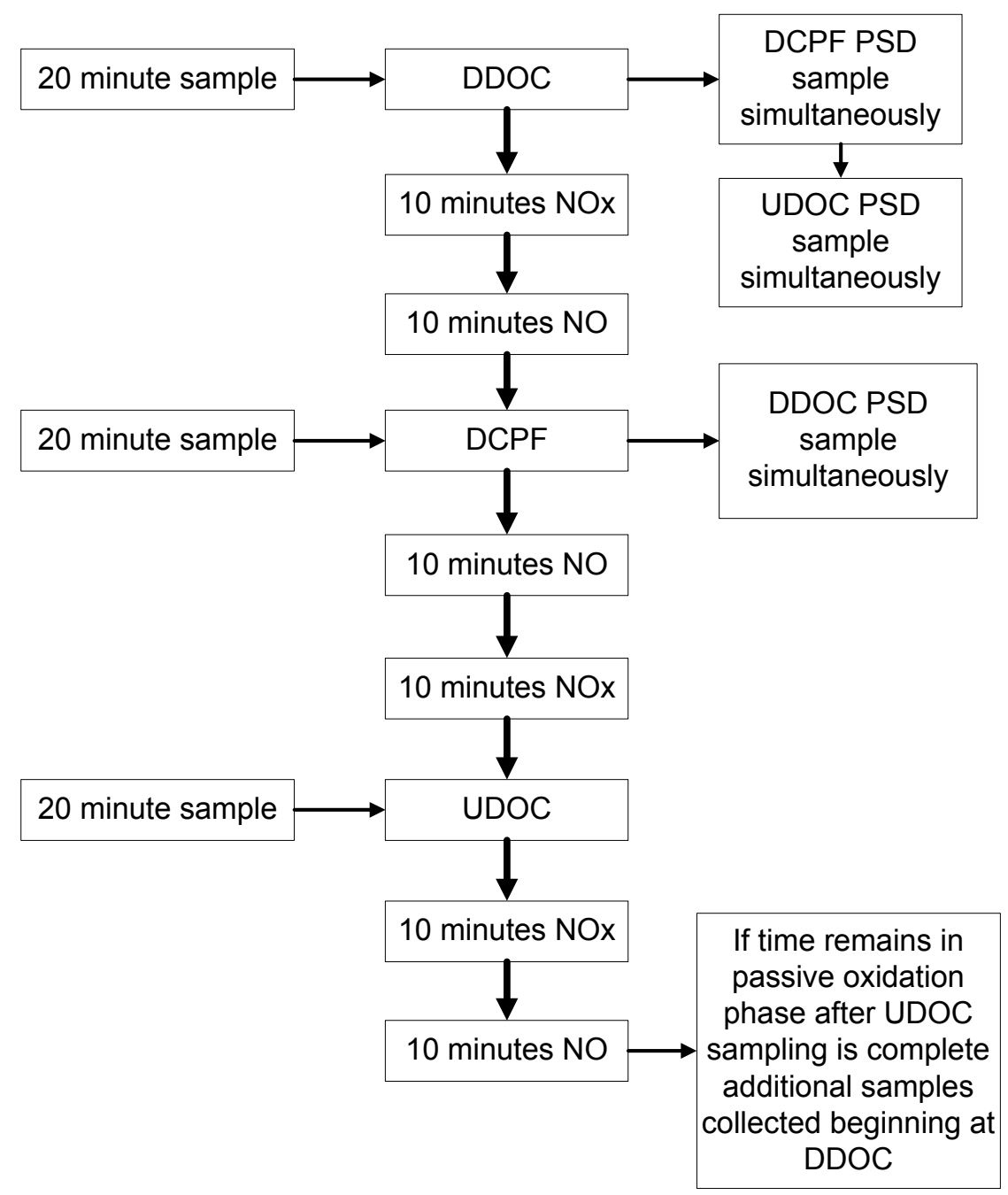

Figure 3.6: Gaseous emissions and PSD sampling strategy for Passive Oxidation phase

After a predetermined amount of time, or if the slope of the pressure drop profile across the CPF decreases significantly, the passive oxidation portion of the experiment is halted and the transition is made to Stage 3 loading. The times used for passive oxidation portions with ULSD tests conducted by Hutton et al. [1, 2] were used for the tests performed at the same engine operating conditions in this thesis. For example, the passive oxidation portion of Test 3 consisting of $365^{\circ} \mathrm{C}$ average $\mathrm{CPF}$ temperature and an exhaust mass flow rate of $7.4 \mathrm{~kg} / \mathrm{min}$ conducted by Hutton et al. [2] was ran for 81.2 minutes. A time of 81.2 minutes was then targeted for passive oxidation tests conducted at similar engine operating conditions.

\subsubsection{Stage 3 Loading of the CPF}

After the passive oxidation portion of the test is concluded, the transition to Stage 3 loading begins. The engine is brought to the same engine conditions used during Stage 1 and 2 loading, with a DOC inlet temperature of $265^{\circ} \mathrm{C} \pm 10^{\circ} \mathrm{C}$. 
The collection of experimental data occurs in the same manner as the Stage 1 loading portion of the experiment. Stage 3 loading is thirty minutes long which allows the temperature of the CPF to stabilize to the values that were experienced in Stage 1 and Stage 2 loading, allowing for the best calculation of total PM oxidized during passive oxidation.

After thirty minutes of operating in Stage 3 loading, the exhaust is switched to the bypass line and the engine is brought to idle and shut down. The aftertreatment system is removed from the exhaust system and disassembled for weighing of the CPF.

The weighing of the CPF provides for the mass measurement $m_{\mathrm{S} 3}$ which is used with $\mathrm{m}_{\mathrm{c}}$ in equation 12 to determine the remaining amount of PM mass in the filter $\left(\mathrm{m}_{\text {Ret-S3 }}\right)$.

$$
\mathbf{m}_{\text {Ret_S3 }}=\mathbf{m}_{\mathrm{s} 3}-\mathbf{m}_{\mathbf{c}}
$$

$\mathrm{m}_{\text {Ret_S3 }}=$ Calculated PM mass retained in the CPF after Stage 3 loading, [g]

$\mathrm{m}_{\mathrm{S} 3}=$ Measured mass of the CPF after stage 3 loading, [g]

$\mathrm{m}_{\mathrm{c}} \quad=$ Calculated clean weight of the CPF, from eqn. $1,[\mathrm{~g}]$

In order to determine the amount of PM mass present in the filter after the passive oxidation portion of the experiment, equations 7 - 9 are used along with the assumption of constant rate of mass deposition during Stage 3 and Stage 4. Equation 8 is used to calculate the amount of PM mass that is added during stage 3 loading $\left(\mathrm{m}_{\text {add- } \mathrm{s} 3}\right)$ which is used with equation 13 to determine the amount of PM present in the filter $\left(\mathrm{m}_{\text {Ret-PO }}\right)$ after the passive oxidation portion of the experiment.

$$
\mathbf{m}_{\text {Ret_Po }}=\mathbf{m}_{\text {Ret_S3 }}-\mathbf{m}_{\text {add_S3 }}
$$

$\mathrm{m}_{\text {Ret_PO }}=$ Calculated PM mass retained in the CPF after passive oxidation, [g]

$\mathrm{m}_{\text {Ret_S3 }}=$ Measured PM mass retained in the CPF after Stage 3 loading, [g]

$\mathrm{m}_{\text {add_S3 }} \quad=$ Predicted PM mass added to the CPF during Stage 3 loading, $[\mathrm{g}]$

After the CPF has been weighed, the aftertreatment system is reassembled and installed in the exhaust system.

\subsection{Modified Test Procedure}

The test procedure used by Hutton et al. [1,2] was modified to limit temperature gradients experienced by the CPF during the passive oxidation portion, and to capture additional post oxidation loading data. A temperature Ramp-up period consisting of operating the engine at loading conditions in the trap line for fifteen minutes reduced the 
amount of time required for the $\mathrm{CPF}$ to reach stable temperature. After passively oxidizing the $\mathrm{CPF}$, the PM structure and dispersion within the CPF may change. In order to capture additional loading data after passively oxidizing the CPF, Stage 4 consisting of loading conditions for one hour was added after Stage 3 weighing. This test procedure was used for all of the ISL $272 \mathrm{~kW}(365 \mathrm{hp}$ ) biodiesel, and $317 \mathrm{~kW}$ (425 hp) testing. A pressure drop profile of a typical test performed with the modified test procedure is shown in Figure 3.7 with the measured and calculated PM mass loadings on the alternate y-axis. A dashed line is used to signify breaks between each stage, and each stage is labeled.

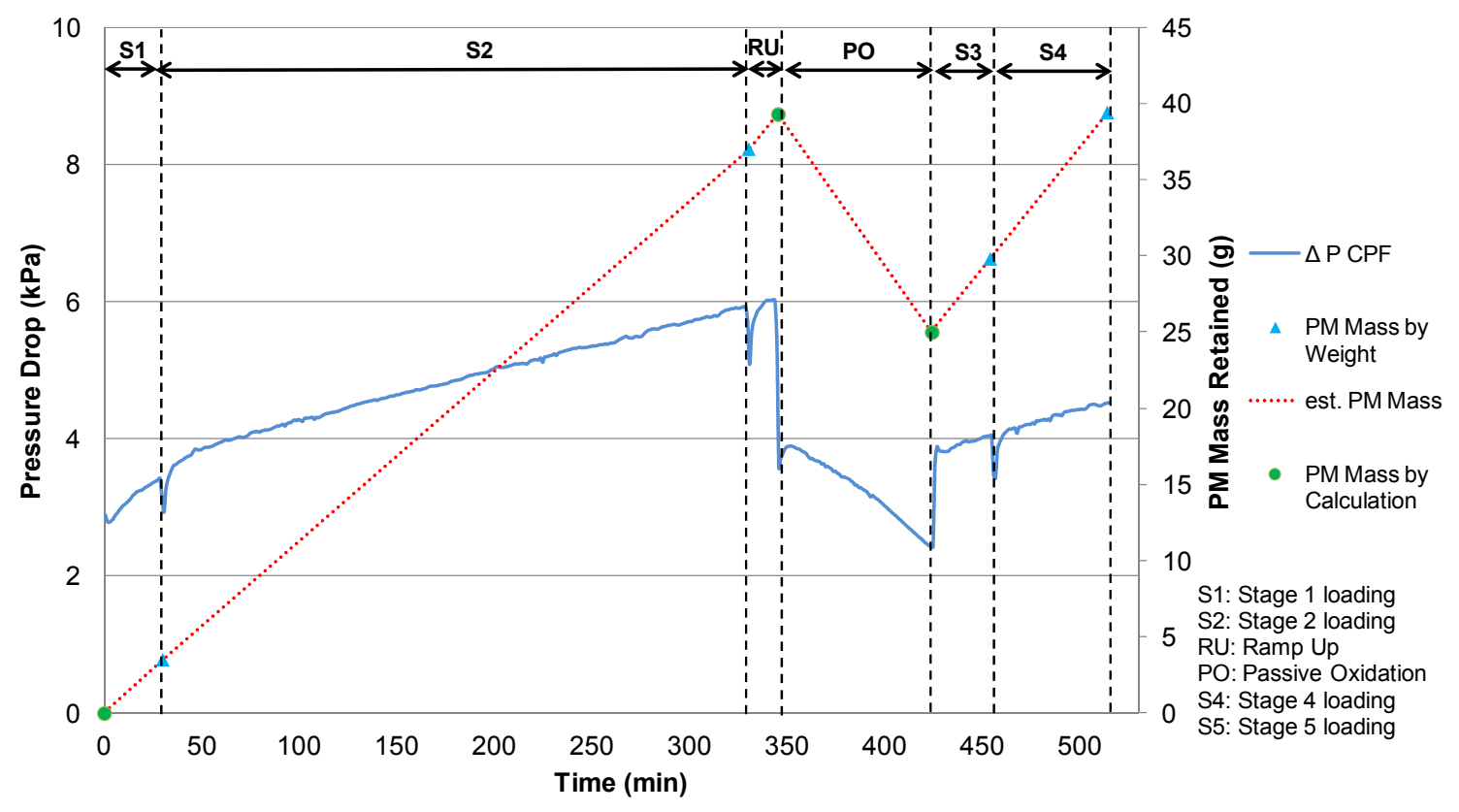

Figure 3.7: Typical pressure drop profile of modified test procedure

\subsubsection{Temperature Ramp-up}

During disassembly and weighing, the temperature of the CPF and DOC is reduced due to heat transfer to the test cell. Prior to the passive oxidation portion of the test, the engine is operated at loading conditions which allows the system to reach temperatures similar to Stage 2 loading. While the exhaust is still routed through the baseline, the engine is started and brought to idle. Table 3.6 shows the engine operating conditions used for warm up. The warm up is complete when a steady exhaust manifold temperature is achieved. Once the exhaust manifold temperature has stabilized, the exhaust is switched to the trap-line and the aftertreatment system is allowed to warm up at the loading condition for approximately 15 minutes or until the DOC inlet temperature has stabilized at $265^{\circ} \mathrm{C} \pm 10^{\circ} \mathrm{C}$.

In order to determine the amount of PM mass present in the filter before the Passive Oxidation portion of the experiment, equation 7 is used to calculate the amount of PM mass that is added during Ramp-up loading ( $\left.m_{\text {add_RU }}\right)$ which is used with equation 14. 


$$
\mathbf{m}_{\text {Ret_RU }}=\mathbf{m}_{\text {Ret_S2 }}+\mathbf{m}_{\text {add_RU }}
$$

$\mathrm{m}_{\text {Ret_RU }}=$ Calculated PM mass retained in the CPF before passive oxidation, [g]

$\mathrm{m}_{\text {Ret_ } \mathrm{S} 2}=$ Calculated PM mass retained in the CPF at end of Stage 2 loading, $[\mathrm{g}]$

$\mathrm{m}_{\text {add } \_ \text {RU }}=$ Predicted PM mass added to the CPF during Stage 3, $[\mathrm{g}]$

\subsubsection{Stage 4 Loading of the CPF}

After the aftertreatment system is reassembled and installed in the exhaust system, and while the exhaust is still routed through the baseline, the engine is started and brought to idle. Table 3.6 shows the warm up procedure, and warm up is complete when a steady exhaust manifold temperature is achieved.

Once the exhaust manifold temperature has stabilized, the exhaust is switched to the trapline which marks the beginning of Stage 4 loading.

Stage 4 loading takes place at loading conditions, with a DOC inlet temperature of $265^{\circ} \mathrm{C}$ $\pm 10^{\circ} \mathrm{C}$, which is the same operating condition as the Stage 1 loading. Stage 4 loading is sixty minutes long and allows the performance of the CPF to be evaluated after a partial regeneration.

The collection of experimental data occurs in the same manner as the Stage 1 portion of the experiment, with the only differences being that three UDOC PM samples are collected and the total length of Stage 4 loading.

After sixty minutes of operating in Stage 4 loading, the exhaust is switched to the bypass line and the engine is brought to idle and shut down. The aftertreatment system is removed from the exhaust system and disassembled for weighing of the CPF.

The weighing of the CPF provides for the mass measurement $m_{\mathrm{S} 4}$ which is used with $\mathrm{m}_{\mathrm{c}}$ in equation 15 to determine the remaining amount of PM mass in the filter ( $\left.\mathrm{m}_{\text {Ret- } \mathrm{S} 4}\right)$.

$$
\mathbf{m}_{\text {Ret_s4 }}=\mathbf{m}_{\mathrm{S} 4}-\mathbf{m}_{\mathbf{c}}
$$

$$
\begin{aligned}
& \mathrm{m}_{\text {Ret_ } \mathrm{S} 4}=\text { Calculated PM mass retained in the CPF after Stage } 4 \text { loading, }[\mathrm{g}] \\
& \mathrm{m}_{\mathrm{S} 4} \quad=\text { Measured mass of the CPF after Stage } 4 \text { loading, }[\mathrm{g}] \\
& \mathrm{m}_{\mathrm{c}} \quad=\text { Calculated clean weight of the CPF, from eqn. } 1,[\mathrm{~g}]
\end{aligned}
$$


After the mass retained in the CPF after Stage 4 is determined, the experiment has concluded.

\subsubsection{Loading Time Prediction}

Loading times have been found to vary based on test cell absolute humidity which appears to increase the PM concentration with increasing humidity. The relative humidity and temperature are recorded at the beginning of every test to determine the absolute humidity for the day. The absolute humidity is then compared to prior test loadings to approximate the amount of time required to load up to $2.2 \mathrm{~g} / \mathrm{L}$ in the CPF. Figure 3.8 shows the PM concentration $(\mathrm{mg} / \mathrm{scm})$ versus the absolute humidity for the performed tests. Data labels represent total loading times.

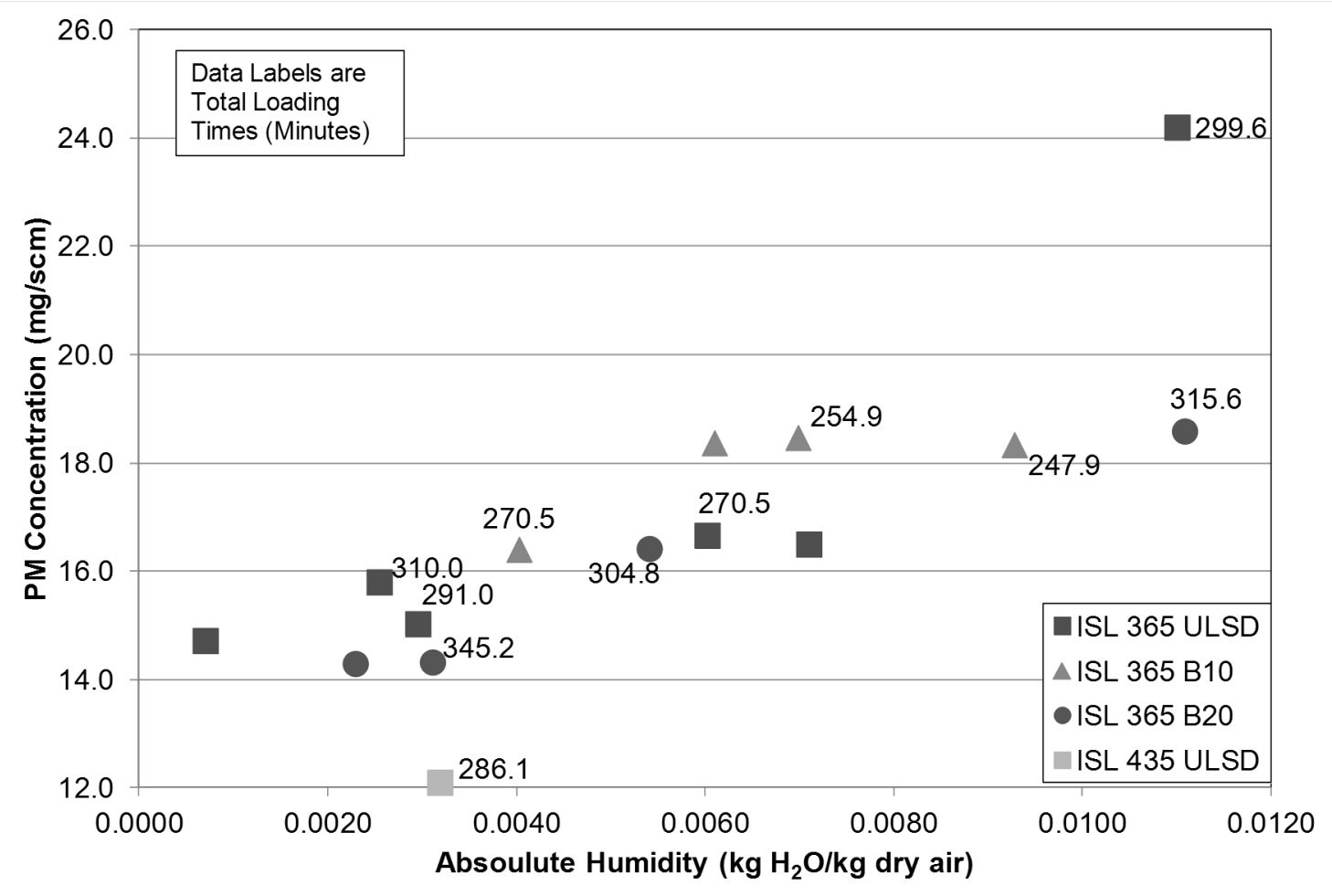

Figure 3.8: Absolute humidity vs. PM concentration during loading, used to determine loading times

Loading times for B20 tests were typically longer when compared to ULSD tests with similar humidity. ISL 425 Test 1 with ULSD showed a lower PM concentration when compared to ISL 365 tests at similar absolute humidity of $0.003 \pm .0005 \mathrm{~kg} / \mathrm{kg}$. Despite this, the loading time was comparable to ISL 365 tests with ULSD at this absolute humidity. Differences may be due to changes in exhaust emissions composition due to the increased boost pressures [31, 34]. 


\subsection{Passive Oxidation Test Matrix}

For each engine rating and fuel, a test matrix was created consisting of engine operating points chosen to provide a range of temperatures, exhaust mass flow rates, $\mathrm{NO}_{2} / \mathrm{PM}$ ratios, and $\mathrm{NO}_{\mathrm{x}} / \mathrm{PM}$ ratios. Each test point is given a letter and represents an exhaust mass flow rate and DOC inlet temperature. Despite engine rating or fuel being used for each test, exhaust mass flow rates and DOC inlet temperatures were targeted corresponding to the test point used for the test. Performing tests by this method resulted in comparable average CPF temperatures for each test point and repeatable passive oxidation results. Table 3.7 shows the reference points used for all testing and the speed and torque used with the ISL rated at $365 \mathrm{hp}$ to achieve desired temperatures and exhaust mass flow rates.

Table 3.7:

\section{Engine operating reference points for ISL $365 \mathrm{hp}$}

\begin{tabular}{|c|c|c|c|c|c|c|}
\hline שֶ & 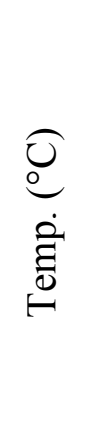 & 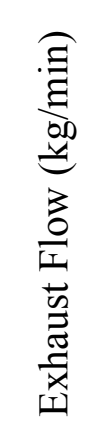 & 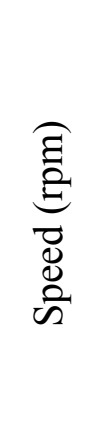 & 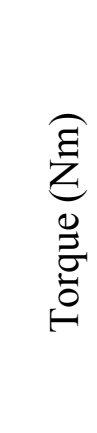 & 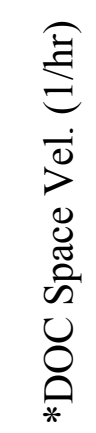 & 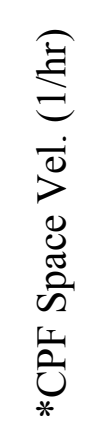 \\
\hline A & 254 & 5.8 & 1230 & 290 & $115 \mathrm{k}$ & $84 \mathrm{k}$ \\
\hline B & 265 & 13.1 & 2100 & 200 & $259 \mathrm{k}$ & $193 \mathrm{k}$ \\
\hline Z & 287 & 6.6 & 1100 & 435 & $138 \mathrm{k}$ & $102 \mathrm{k}$ \\
\hline $\mathrm{F}$ & 357 & 7.8 & 1290 & 545 & $183 \mathrm{k}$ & $135 \mathrm{k}$ \\
\hline $\mathrm{H}$ & 408 & 15.4 & 1500 & 1090 & $385 \mathrm{k}$ & $288 \mathrm{k}$ \\
\hline $\mathrm{J}$ & 482 & 17.2 & 1650 & 1250 & $440 \mathrm{k}$ & $335 \mathrm{k}$ \\
\hline
\end{tabular}

The test matrix completed by Hutton et al. [1,2] was expanded on. Tests 8 and 9 were compared to prior tests at the similar operating conditions to determine that each $\mathrm{CPF}$ used during ISL and ISM testing was comparable. For CPF test comparison results see reference $[1,4]$. Tests 6 and 7 were completed without the DOC in place during the passive oxidation portions in order to further quantify the DOC effect. Test 10 was performed to obtain data at $290{ }^{\circ} \mathrm{C} \mathrm{CPF}$ temperature. Test 19 was performed with the 
modified test procedure and ULSD fuel to determine the effect the procedure had on the passive oxidation portion of the test. Table 3.8 shows the engine speed (rpm), engine load $(\mathrm{Nm}), \mathrm{CPF}$ loading at the end of the stage $(\mathrm{g} / \mathrm{L})$, exhaust flow rates $(\mathrm{kg} / \mathrm{min}), \mathrm{DOC}$ and CPF space velocity $(1 / \mathrm{hr})$, engine out PM concentration $(\mathrm{mg} / \mathrm{scm})$, and a $\mathrm{NO}_{\mathrm{x}}$ mass balance for Stage 2 and the passive oxidation portions of each test performed on the ISL rated at $365 \mathrm{hp}$ with ULSD fuel.

Three passive oxidation operating test conditions were chosen from prior ULSD testing to be performed with B10 fuel and B20 fuel. One test point was then repeated with each fuel to determine test repeatability. Test point $\mathrm{F}$ was chosen to repeat with B10 fuel. Table 3.10 shows the engine speed (rpm), engine load (Nm), CPF loading at the end of the stage $(\mathrm{g} / \mathrm{L})$, exhaust flow rates $(\mathrm{kg} / \mathrm{min})$, DOC and CPF space velocity $(1 / \mathrm{hr})$, engine out PM concentration $(\mathrm{mg} / \mathrm{scm})$, and a $\mathrm{NO}_{\mathrm{x}}$ mass balance for Stage 2 and passive oxidation portions of each test performed on the ISL rated at $365 \mathrm{hp}$ with B10 fuel.

Test point A was chosen to repeat with B20 fuel. Table 3.9 shows the engine speed $(\mathrm{rpm})$, engine load $(\mathrm{Nm}), \mathrm{CPF}$ loading at the end of the stage $(\mathrm{g} / \mathrm{L})$, exhaust flow rates $(\mathrm{kg} / \mathrm{min})$, DOC and CPF space velocity $(1 / \mathrm{hr})$, engine out PM concentration $(\mathrm{mg} / \mathrm{scm})$, and a $\mathrm{NO}_{\mathrm{x}}$ mass balance for Stage 2 and passive oxidation portions of each test performed on the ISL rated at $365 \mathrm{hp}$ with B20 fuel.

Three test point conditions were chosen from prior testing for ISL 425 testing. The test points were chosen to match DOC inlet temperatures and mass flow rates of prior USLD, B10 and B20 testing for comparison. Table 3.7 shows the DOC inlet temperatures and mass flow rates for each reference point along with the speed and load required for the ISL at $365 \mathrm{hp}$ rating to achieve these values. Each of the test points will be performed twice. The first round of testing will be performed with the DOC and CPF thermocouples, emissions probe, and differential probe removed. Differential pressure and DDOC emissions were taken at the surface of the DOC can. Temperatures were recorded by OEM thermistors. This setup was used in order to eliminate signal variation observed during RF-DPF PM loading sensor testing in order to improve the quality of the $\mathrm{PM}$ mass retained data.

A second round of testing will be performed with thermocouples and probes in place. Table 3.11 shows the engine speed (rpm), engine load (Nm), CPF loading at the end of the stage $(\mathrm{g} / \mathrm{L})$, exhaust flow rates $(\mathrm{kg} / \mathrm{min})$, DOC and CPF space velocity $(1 / \mathrm{hr})$, engine out PM concentration $(\mathrm{mg} / \mathrm{scm})$, and a $\mathrm{NO}_{\mathrm{x}}$ mass balance for Stage 2 and Passive Oxidation portions of ISL 425 Test 1. 


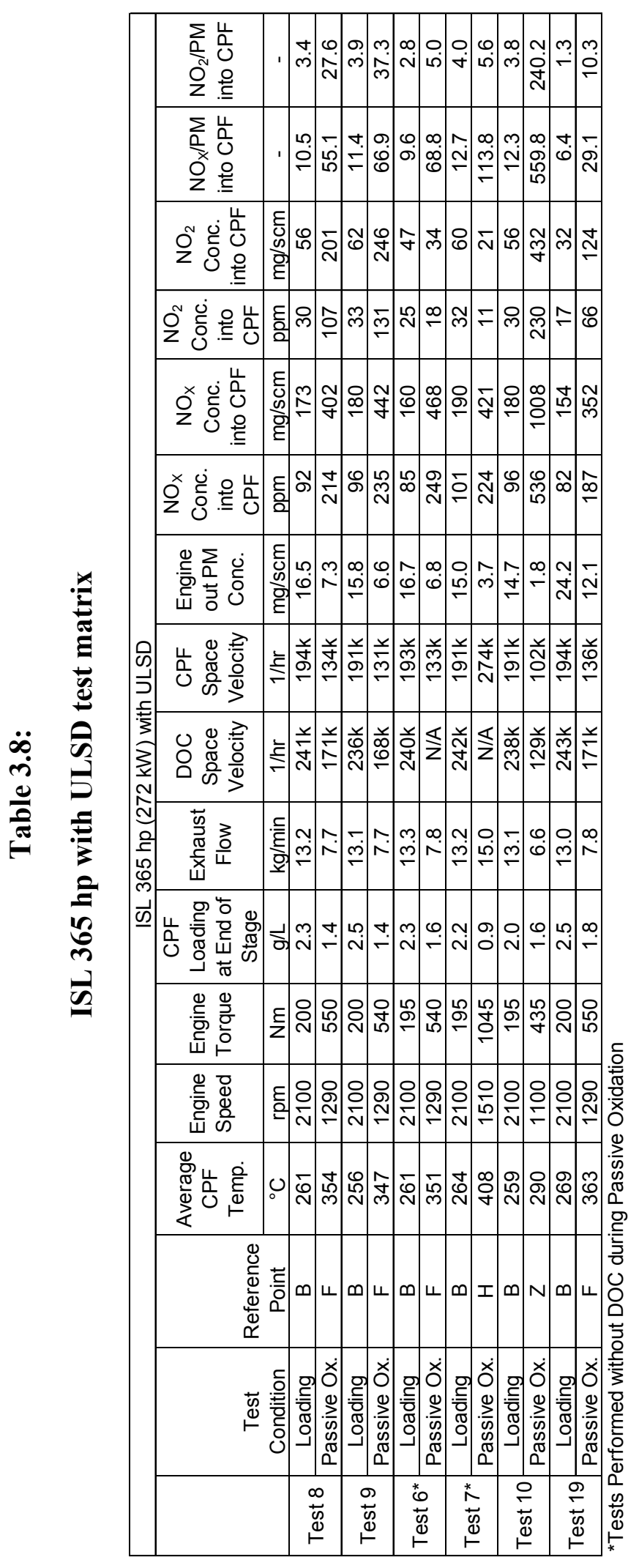




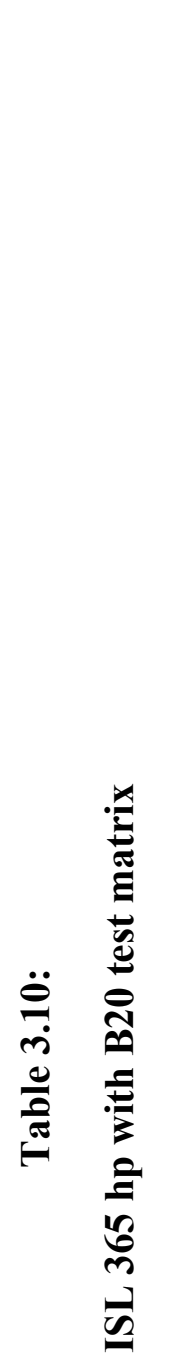

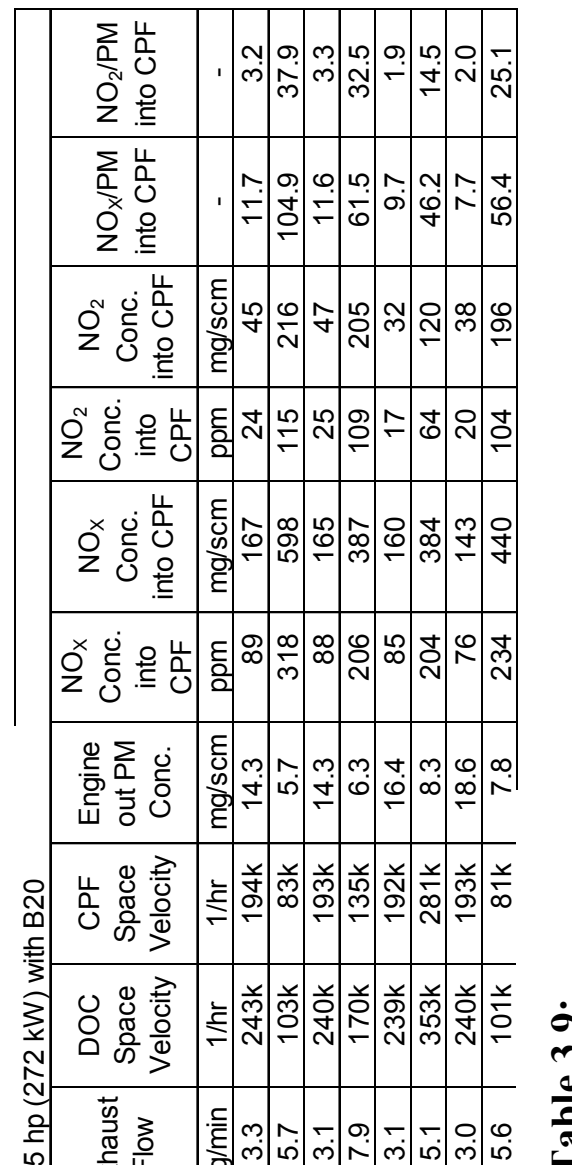

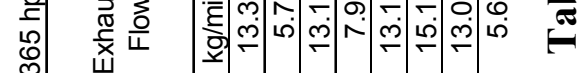

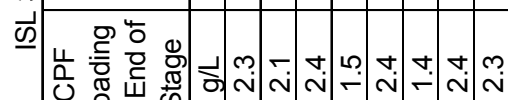

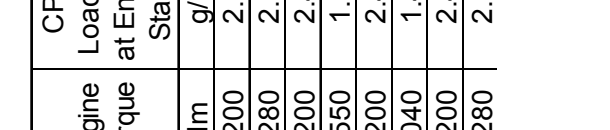

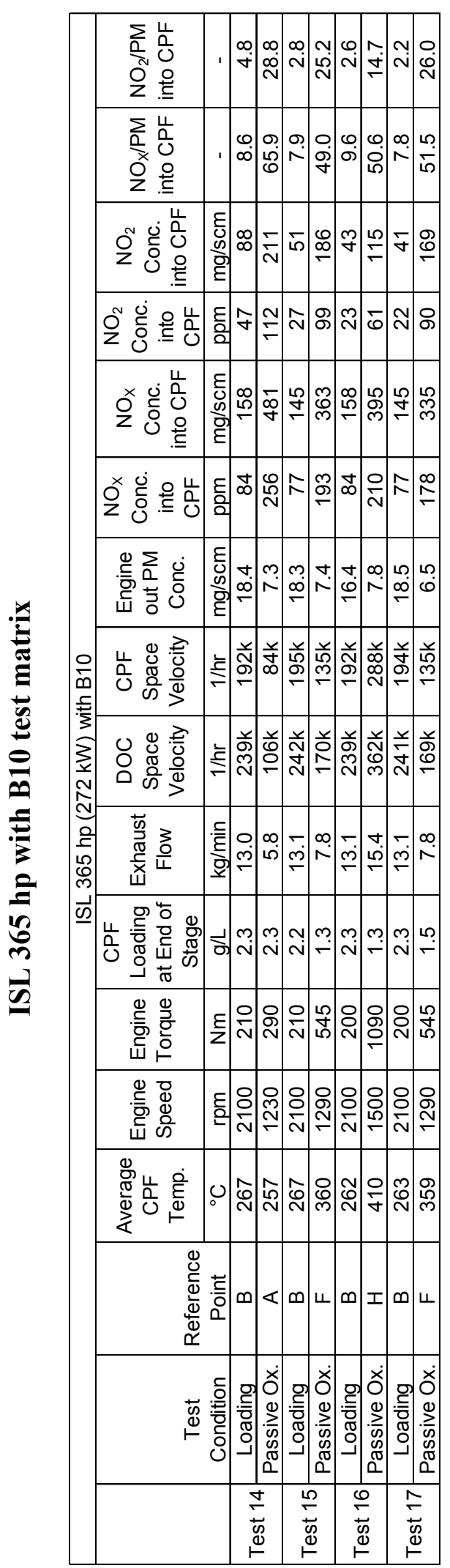




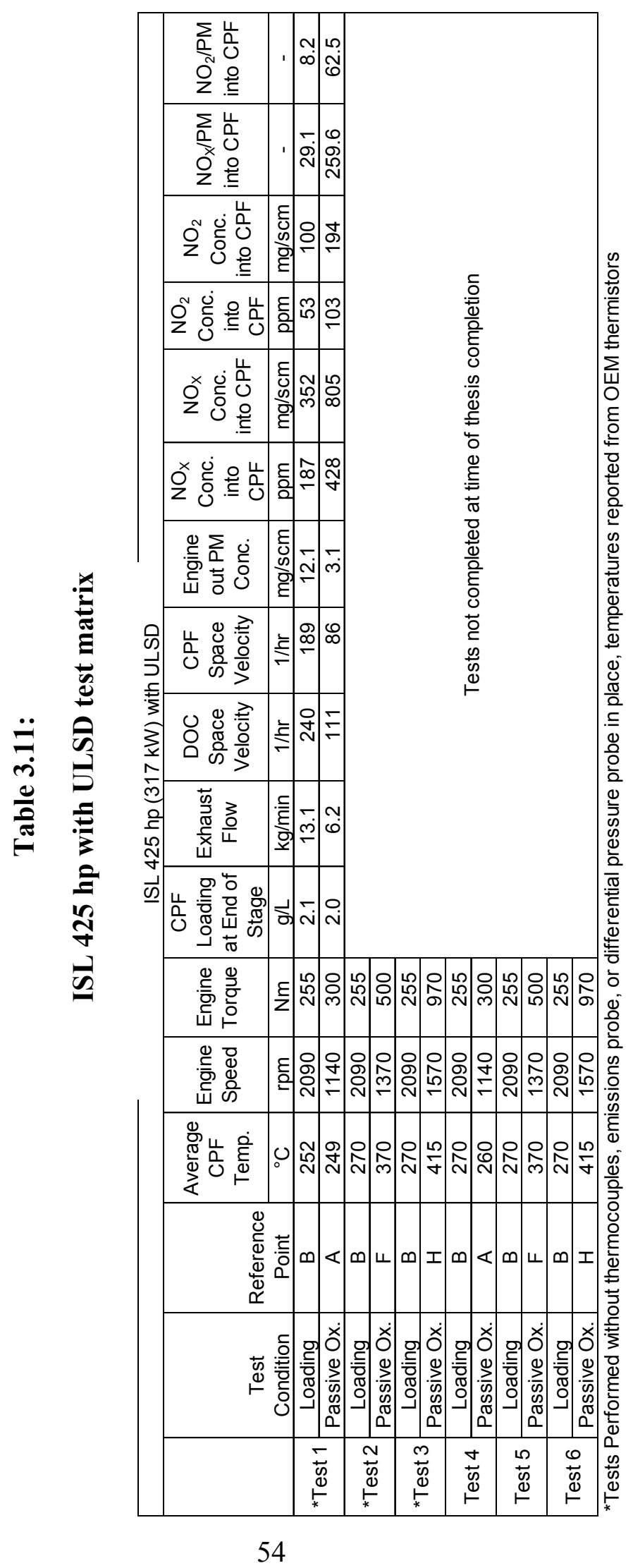




\section{Chapter 4. Experimental Results}

The test procedure was modified prior to performing most of the tests for this thesis. The next section will discuss the result of modifying the procedure. The affect will be shown by comparing temperature and differential pressure profiles of a test performed with each method. Section 4.2 will detail the DOC aging and its affect on biodiesel testing. Section 4.3 will discuss Stage 2 loading results including emissions data, PSD data, reaction rates, and the differential pressure drop across the CPF. Section 4.4 will show Passive Oxidation results including a detailed $\mathrm{NO}_{\mathrm{x}}$ mass balance discussing consumption and back diffusion, PSD data, reaction rates, and differential pressure drop profiles. Section 4.5 will discuss Stage 4 loading. Section 4.6 will detail results from experimental sensor testing. Section 4.7 will show results of CPF resistance analysis. ULSD passive oxidation testing with the ISL rated at $425 \mathrm{hp}$ began in parallel with the writing of this thesis. A summary of the results from completed tests will be presented for each section.

\subsection{Test Procedure Comparison}

The test procedure used for ISL 365 tests 1-10 did not include the Ramp-up or Stage 4. The ramp-up portion increased and stabilized CPF temperatures before changing to the passive oxidation operating condition. Appendix I shows results of test procedure comparison and how the ramp-up reduces temperature gradients in the CPF during passive oxidation.

The stabilization and increase of CPF temperatures before beginning passive oxidation made the pressure drop profile more repeatable. Figure 4.1 shows passive oxidation point $\mathrm{F}$ pressure drops. The un-modified test procedure shows variation in peak, shape, and slope. The modified test procedure shows consistent pressure drop profile peak and shape. The slope of the modified test procedure is similar as well with approximately $0.02 \mathrm{kPa} /$ minute slopes for each test performed at point $\mathrm{F}$ conditions. The pressure drop difference between tests performed with the modified test procedure and point $\mathrm{F}$ passive oxidation conditions is $0.5 \mathrm{kPa}$ after 80 minutes. This difference in pressure drop for the modified test procedure with different fuels may be due to the fuel being used during each test and the resulting oxidation of the PM in the cake and wall. The tests with the steepest slope during passive oxidation were with B20 fuel followed by B10 fuel. This indicates an increased biodiesel PM oxidation rate. 


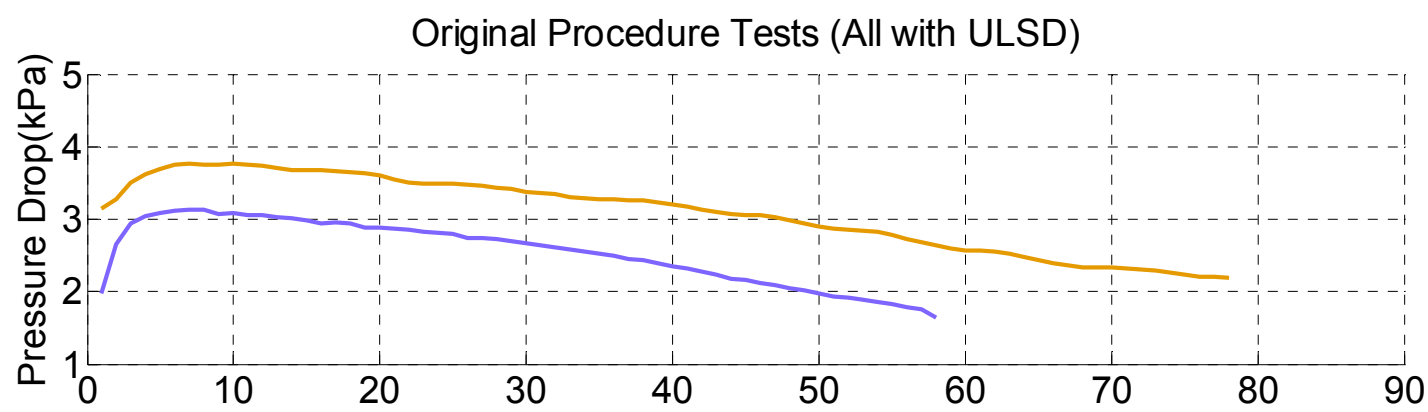

Modified Procedure Tests

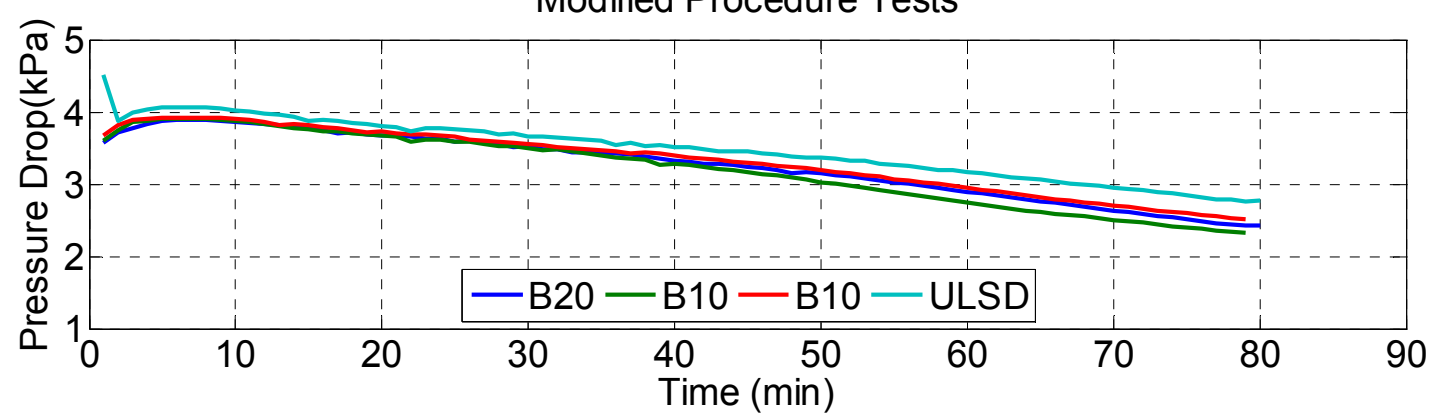

Figure 4.1: Pressure drop profiles during Point F Passive Oxidation portions for original test procedure and modified test procedure

\subsection{DOC Aging}

During B10 and B20 testing, a negative $\mathrm{NO}$ to $\mathrm{NO}_{2}$ conversion efficiency was present during the loading stages. In order to verify whether the negative $\mathrm{NO}$ to $\mathrm{NO}_{2}$ conversion efficiency was due to biodiesel fuel being used, or DOC aging, test 19 was completed with ULSD fuel. The emissions data was examined from this test and negative NO to $\mathrm{NO}_{2}$ conversion efficiency across the DOC during loading stages was present. This leads to the conclusion that the $\mathrm{DOC}$ had been affected by aging and $\mathrm{NO}_{2}$ consumption across the DOC was not directly due to the fuel being used during the test. DOC aging has been shown to accelerate due to biodiesel use [28]. The $\mathrm{NO}$ to $\mathrm{NO}_{2}$ conversion efficiency for Stage 2 loading of each passive oxidation test plotted in the order the test was performed is shown in Figure 4.2. A downward slope in the $\mathrm{NO}$ to $\mathrm{NO}_{2}$ conversion efficiency can be noticed beginning at the fourth performed ULSD test (Test 9). Testing performed by Hutton et al. [1] prior to this testing with ULSD fuel and the same engine and aftertreatment system averaged $10 \% \mathrm{NO}$ to $\mathrm{NO}_{2}$ conversion efficiency. Additional data suggesting DOC aging of the DOC used for ISL 365 tests is shown in Appendix J. Included in this appendix is the CPF $\mathrm{NO}$ to $\mathrm{NO}_{2}$ conversion efficiency during Stage 2. This plot did not show any evidence of CPF aging. Complete emissions summaries of each test may be found in Appendix K. 


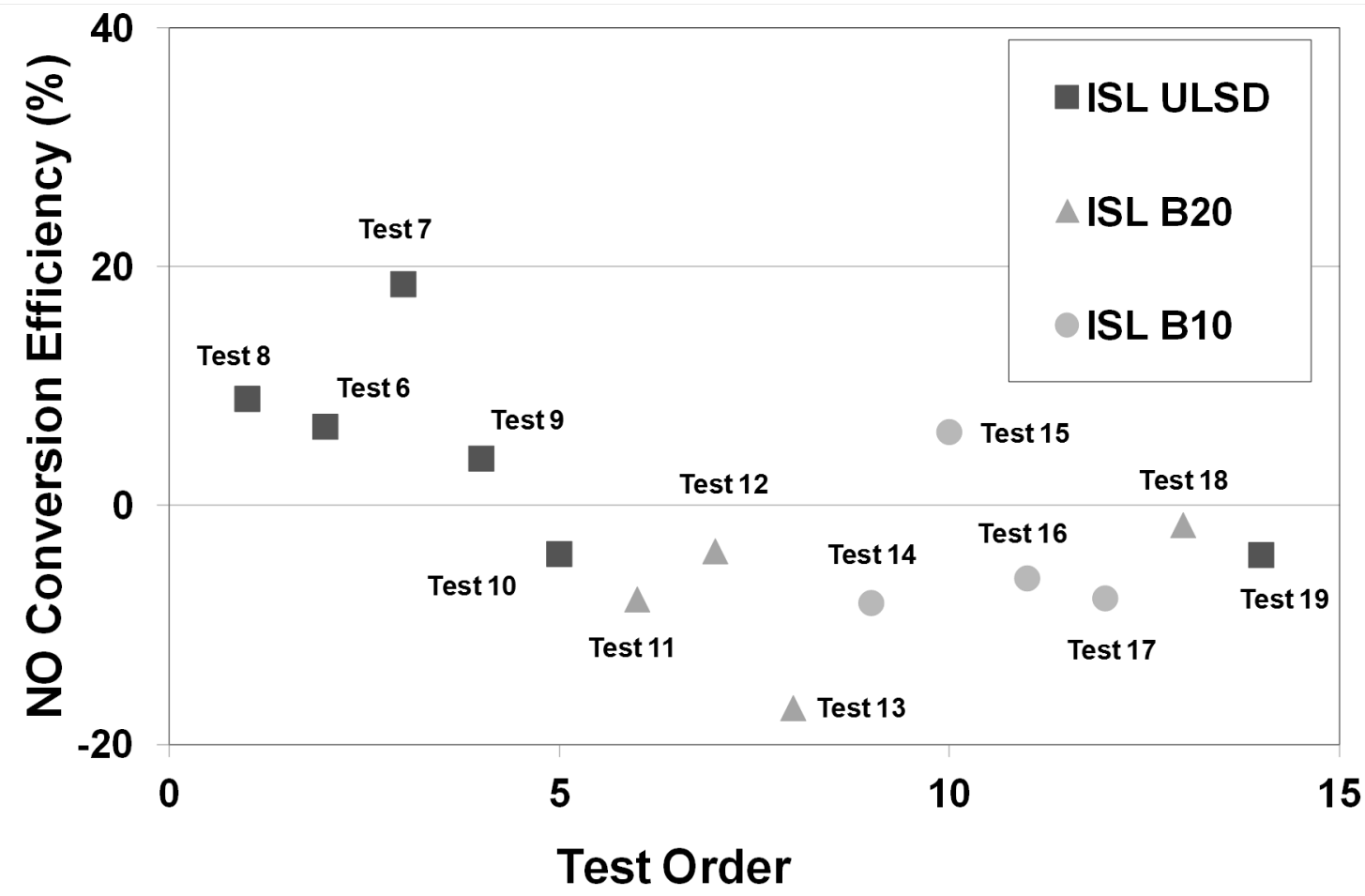

Figure 4.2: DOC NO to $\mathrm{NO}_{2}$ conversion efficiency during Stage 2 of ISL 365 passive oxidation tests, plotted in chronological order of test

\subsection{Stage 2 Loading}

Stage 2 loading consists of operating the engine at an exhaust mass flow rate of $13 \pm 0.3$ $\mathrm{kg} / \mathrm{min}$ resulting in an average CPF temperature of $265 \pm 6{ }^{\circ} \mathrm{C}$ during the stage until a loading of $2.2 \pm 0.2 \mathrm{~g} / \mathrm{L}$ is achieved (Table $3.8-3.11$ ). For the ISL at $365 \mathrm{hp}$ rating, a speed of $2100 \pm 5 \mathrm{rpm}$ and a load of $200 \pm 10 \mathrm{Nm}$ were used. For the ISL at $425 \mathrm{hp}$ rating, a speed of $2090 \mathrm{rpm}$ and a load of $255 \mathrm{Nm}$ were used. For both engine ratings and all fuels the speed and load used to achieve the desired temperature and flow rates depended on the test cell conditions for the day. The speed and load was adjusted during pre-testing to achieve desired temperatures and flow rates for the test. A direct mass measurement of the CPF was performed before and after Stage 2. Gaseous emissions, PSD data, and PM samples to be used to determine PM concentration were taken during Stage 2 and the Passive Oxidation portion of every test.

\subsubsection{Stage $2 \mathrm{NO}_{\mathrm{x}}$ Mass Balance}

$\mathrm{NO}$ and $\mathrm{NO}_{2}$ concentrations present into the CPF were found to be critical factors in the passive oxidation of PM within the CPF. A mass balance of $\mathrm{NO}_{\mathrm{x}}$ was performed for Stage 2 and the Passive Oxidation portion of each test. The conversion efficiency of NO to $\mathrm{NO}_{2}$ across the DOC became negative during biodiesel loading stages. From Chapter 4.2 this was found to be due to DOC aging. The average conversion efficiency of NO to 
$\mathrm{NO}_{2}$ across the DOC for each fuel and engine rating tested is shown in Figure 4.3. NO to $\mathrm{NO}_{2}$ conversion efficiencies from testing completed by Hutton et al. [1] are included in the average for ISL 365 ULSD tests. Data labels indicate DOC space velocity. ISL 425 Test 1 shows the $\mathrm{NO}$ to $\mathrm{NO}_{2}$ conversion efficiency expected from an un-aged but degreened DOC (the DOC was new for the $425 \mathrm{hp}$ tests since the DOC for the $365 \mathrm{hp}$ tests showed aging effects).

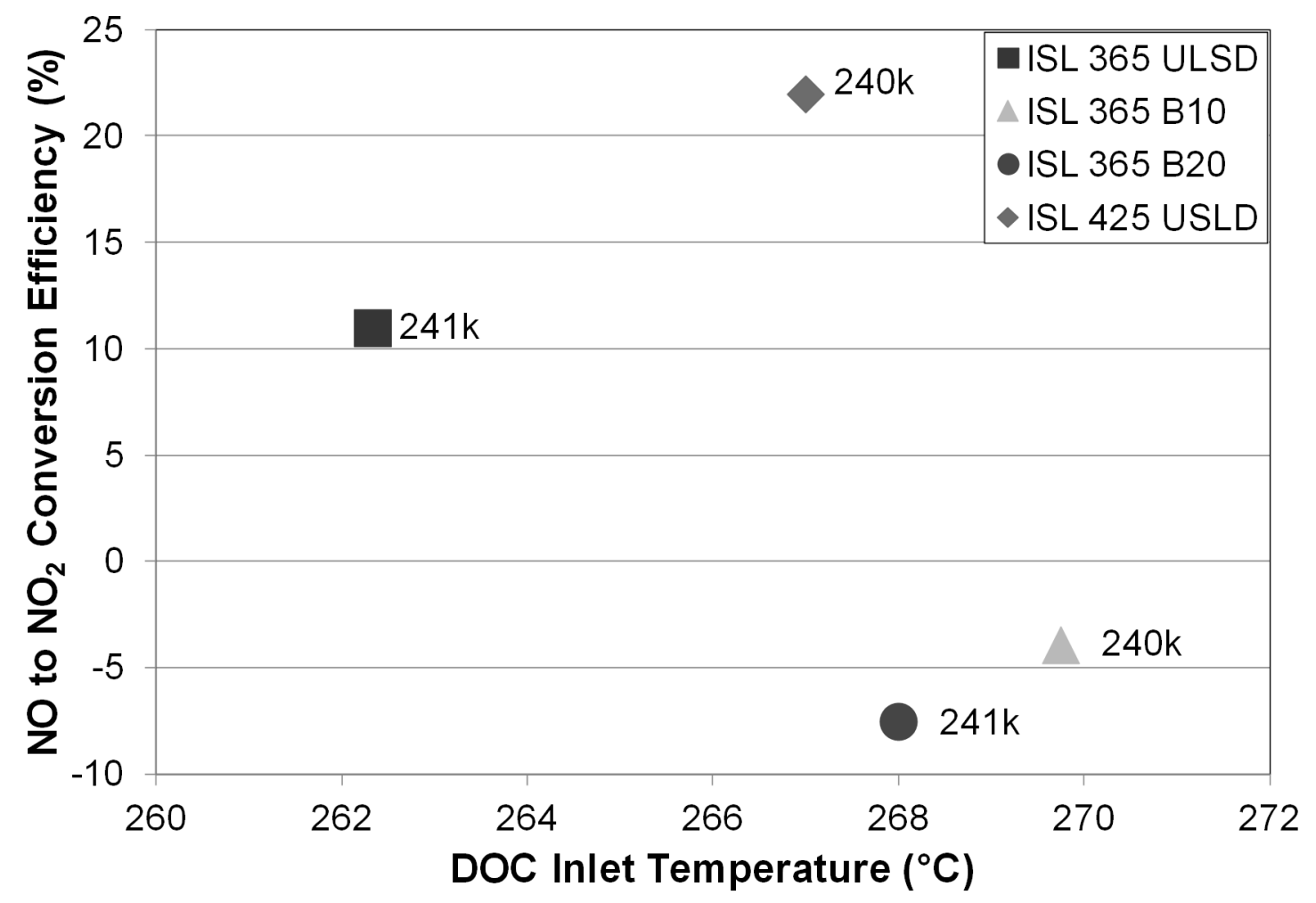

Figure 4.3: Average Stage $2 \mathrm{NO}$ to $\mathrm{NO}_{2}$ conversion efficiency for ULSD, B10, and B20 tests, ISL 425 indicated by single test

\subsubsection{Stage 2 Gaseous Emissions}

Gaseous emissions were collected in three locations (UDOC, DDOC, and DCPF) during each passive oxidation test. The gaseous concentrations are shown for each location in Figure 4.4-4.6. The concentrations are separated by engine or fuel type for each location. The error bars represent standard deviation between tests. ISL 425 emissions data is represented by a single test. Before beginning B10 testing, the Flame Ionization Detector (FID) within the emissions bench failed. Modeling efforts determined that $\mathrm{HC}$ oxidation of PM is minimal so Tests 14-18 were completed without the FID. To supplement the data, the ISL was run at the same operating conditions with B10 to obtain HC emissions data after the FID was repaired. This data are included in Figure 4.4-4.6. 


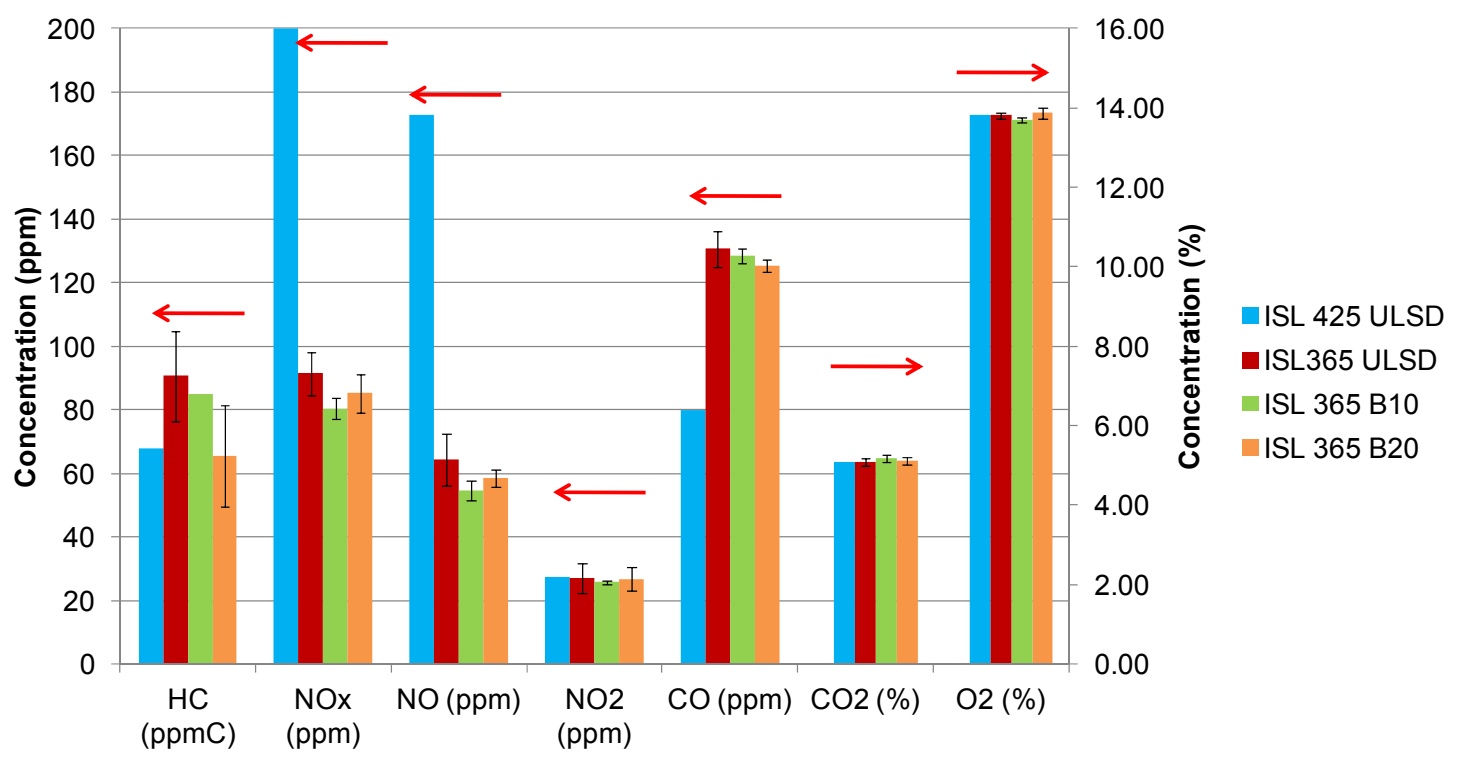

Figure 4.4: Averaged UDOC emission data

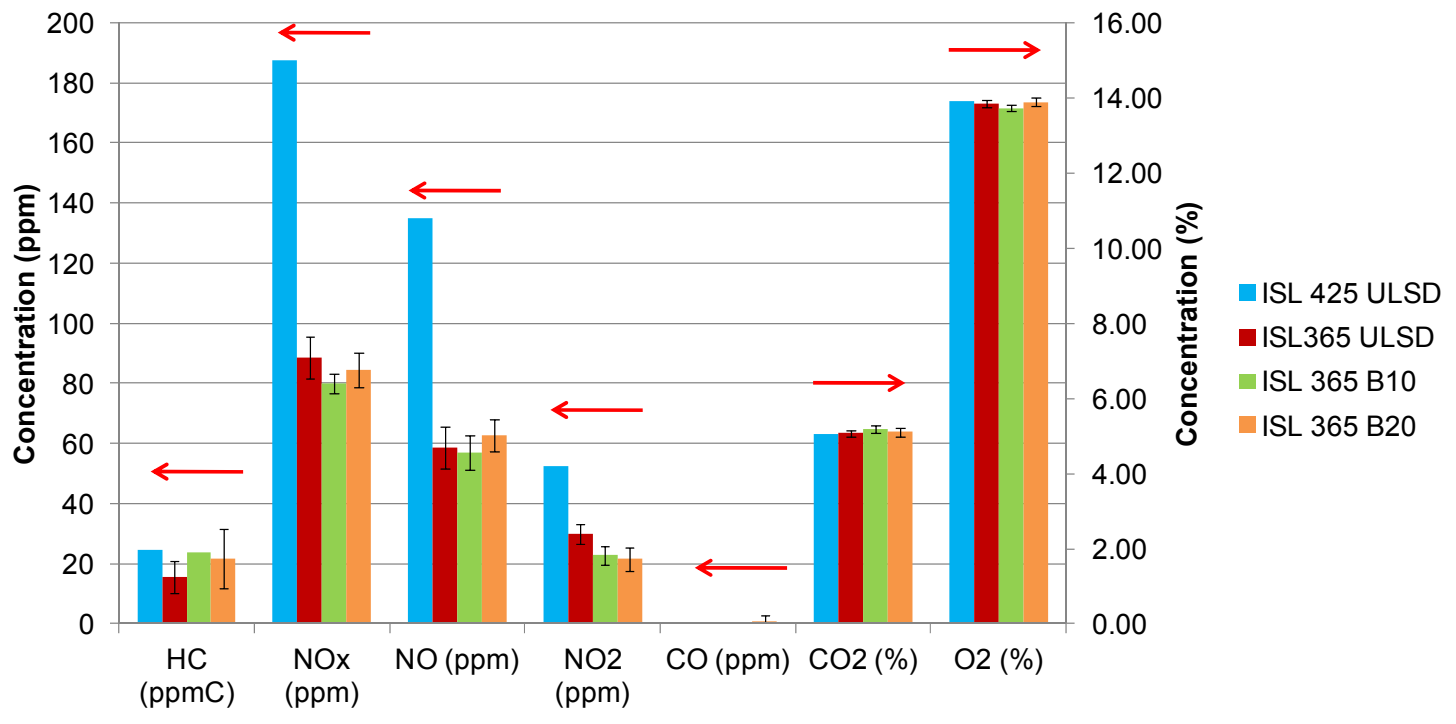

Figure 4.5: Averaged DDOC emission data 


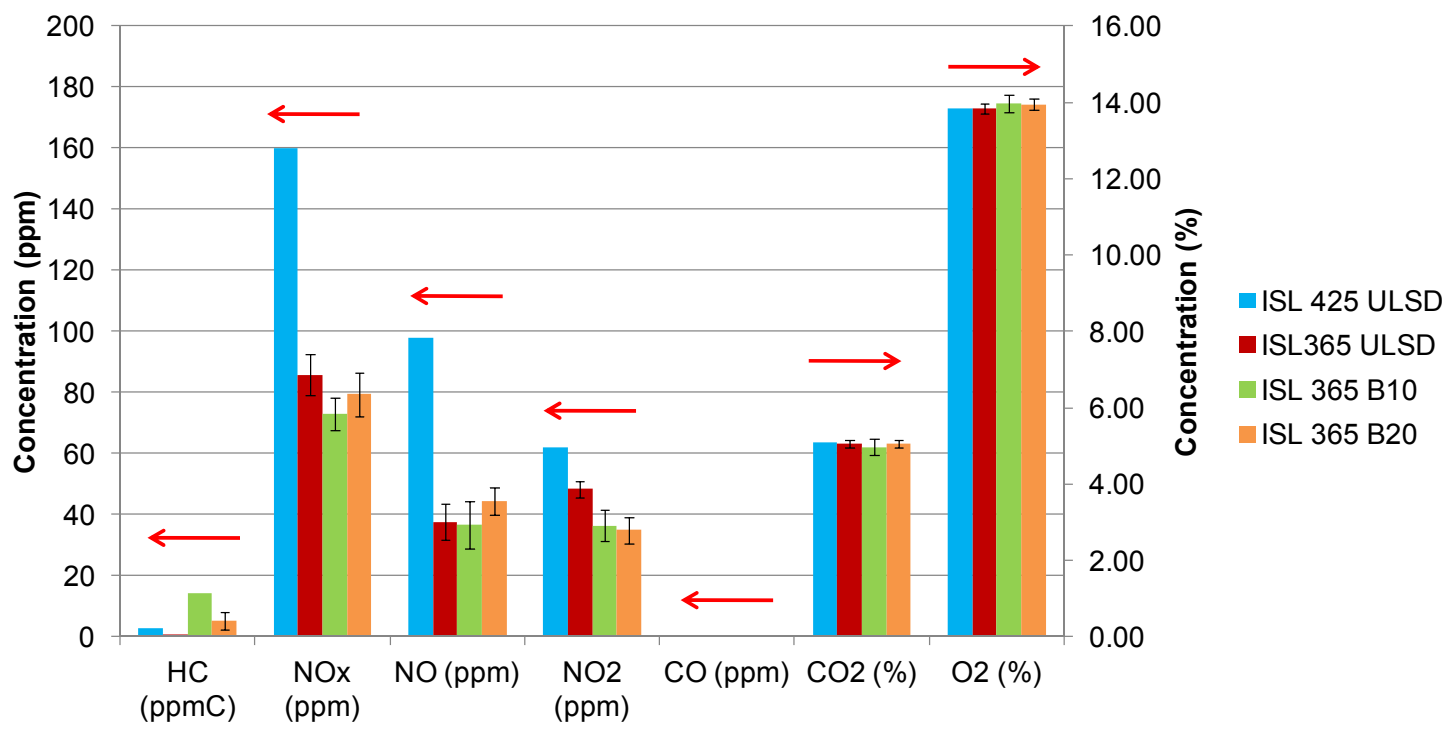

Figure 4.6: Averaged DCPF emission data

The engine out HC emissions was similar for the ISL 365 with all fuels ( $77 \pm 13$ ppmC). B20 HC emissions averaged the lowest ( 65 ppmC). Overlapping standard deviation error bars indicate that this may be insignificant difference. Work performed by Northrop et al. [24] showed that compositional differences may lead to different oxidation mechanisms of HC species when using biodiesel fuel. This is something that may need to be accounted for during simulation of the data and when preparing for reactor tests. Engine out $\mathrm{HC}$ emissions for the ISL 425 Test 1 was $68 \mathrm{ppmC}$. This value is similar to the average ISL 365 B20 value of 65 ppmC, but additional tests should be performed before conclusions are made.

The engine out $\mathrm{NO}_{2}$ concentration was similar for the ISL 365 with all fuels $(26.5 \pm .5$ ppm). $\mathrm{NO}_{\mathrm{x}}$ values recorded during ISL 425 tests were more than two times greater than the $\mathrm{NO}_{\mathrm{x}}$ emissions during ISL tests with all fuels. An increase in $\mathrm{NO}_{\mathrm{x}}$ and a decrease in PM emissions when increasing boost pressures are consistent findings from the literature $[29,34]$. The engine out $\mathrm{NO}_{\mathrm{x}}$ emissions for the ISL with ULSD, B10, and B20 are comparable ( $86 \pm 6 \mathrm{ppm})$. This finding is consistent with the results of Maricq et al. [20]. Complete emissions summaries can be found in Appendix $\mathrm{K}$ for each test. The increased engine out $\mathrm{NO}_{\mathrm{x}}$ concentration during ISL 425 Test 1 resulted in a higher concentration of $\mathrm{NO}_{2}$ entering the CPF (53 ppm compared to 26.5 ppm for ISL 365 tests).

The engine out CO concentration was similar for the ISL 365 with all fuels $(128 \pm 3$ ppm). The CO concentration for ISL 425 Test 1 was 80 ppm. This value is 48 ppm lower than ISL 365 tests. The CO concentrations were consumed across the DOC for ISL 365 and ISL 425 tests. 


\subsubsection{Stage 2 PSD Data}

Particle size distribution (PSD) data were collected during Stage 2 and passive oxidation during each of the performed passive oxidation tests. ISL 365 Test 11 with B20 fuel PSD data shows significant and unexplained variation from data collected during the other tests, as such the data are not included in this analysis. Figure $4.7-4.9$ corresponds to the UDOC, DDOC, and DCPF particle size distribution data taken at the beginning of Stage 2 for ISL 365 B10 and B20 tests, and ISL 425 Test 1. Appendix L shows the PSD data, collected during Stage 2 loading, separated by each test with PSD filtration efficiency. During biodiesel testing PSD data was collected twice during Stage 2 and twice during passive oxidation if time allowed, and these data are shown in Appendix Q.

B10 tests signified by a ' + ' symbol show a marginally higher particle concentration at the $11 \mathrm{~nm}$ particle diameter than B20 tests. From Figure 4.9 showing PSD data from the DCPF location it can be seen that B20 tests signified by a 'o' symbol have a particle number peak at a larger particle diameter when compared to B10 tests. These shifts in peak particle diameter may indicate changes in PM structure and HC species due to biodiesel content.

ISL 425 Test 1 signified by an ' $x$ ' symbol shows a significantly lower particle concentration and a larger peak particle diameter at each point data. This is consistent with decreasing PM concentrations and changing emissions composition due to higher in cylinder flame temperatures found in the literature [29, 34]. ISL 425 Test 1 and ISL 365 Test 9 average cylinder temperatures during loading were $351{ }^{\circ} \mathrm{C}$ suggesting similar flame temperatures. Additional data will be collected in order to perform a more complete comparison. 


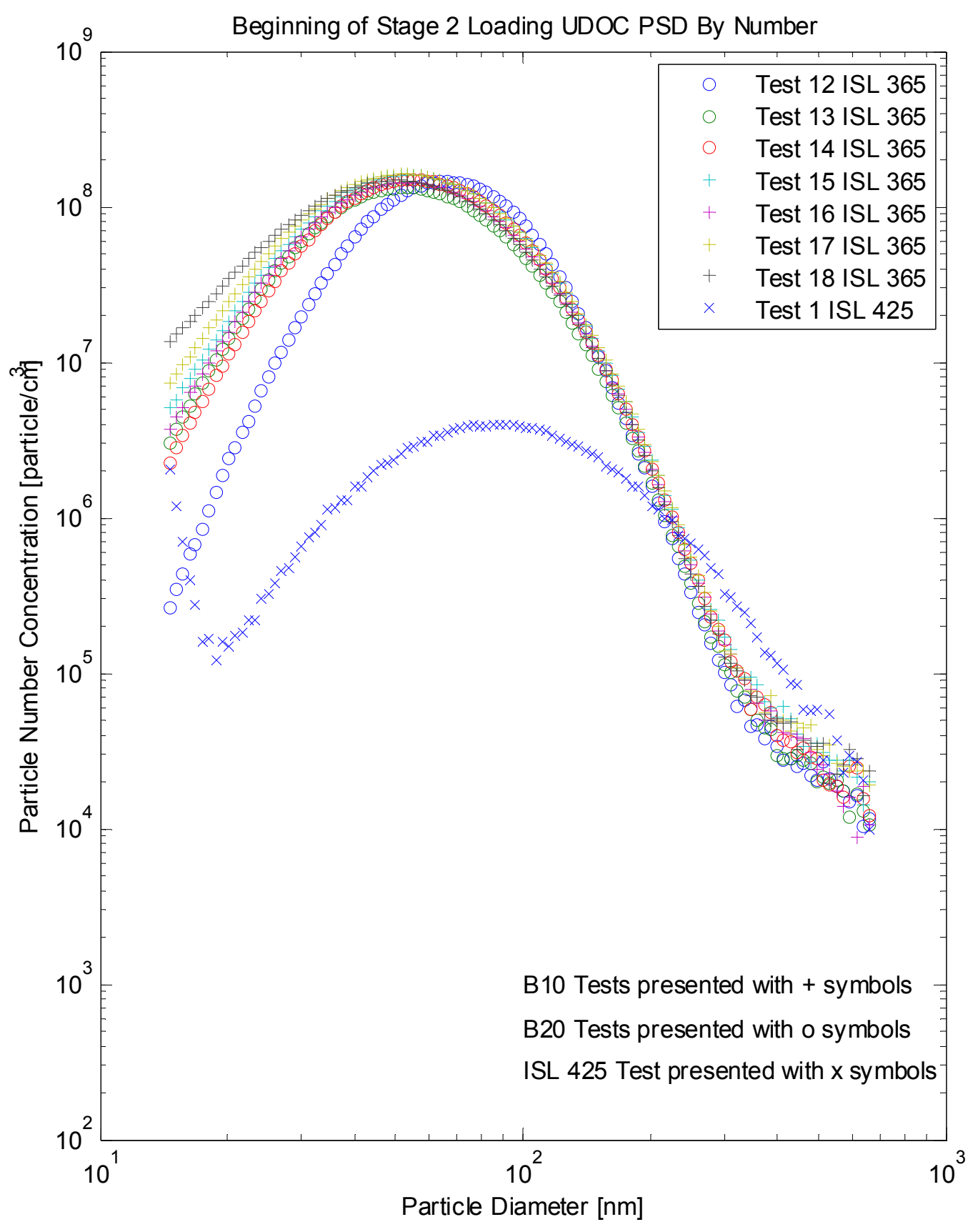

Figure 4.7: PSD data collected UDOC at the beginning of Stage 2 during each test 


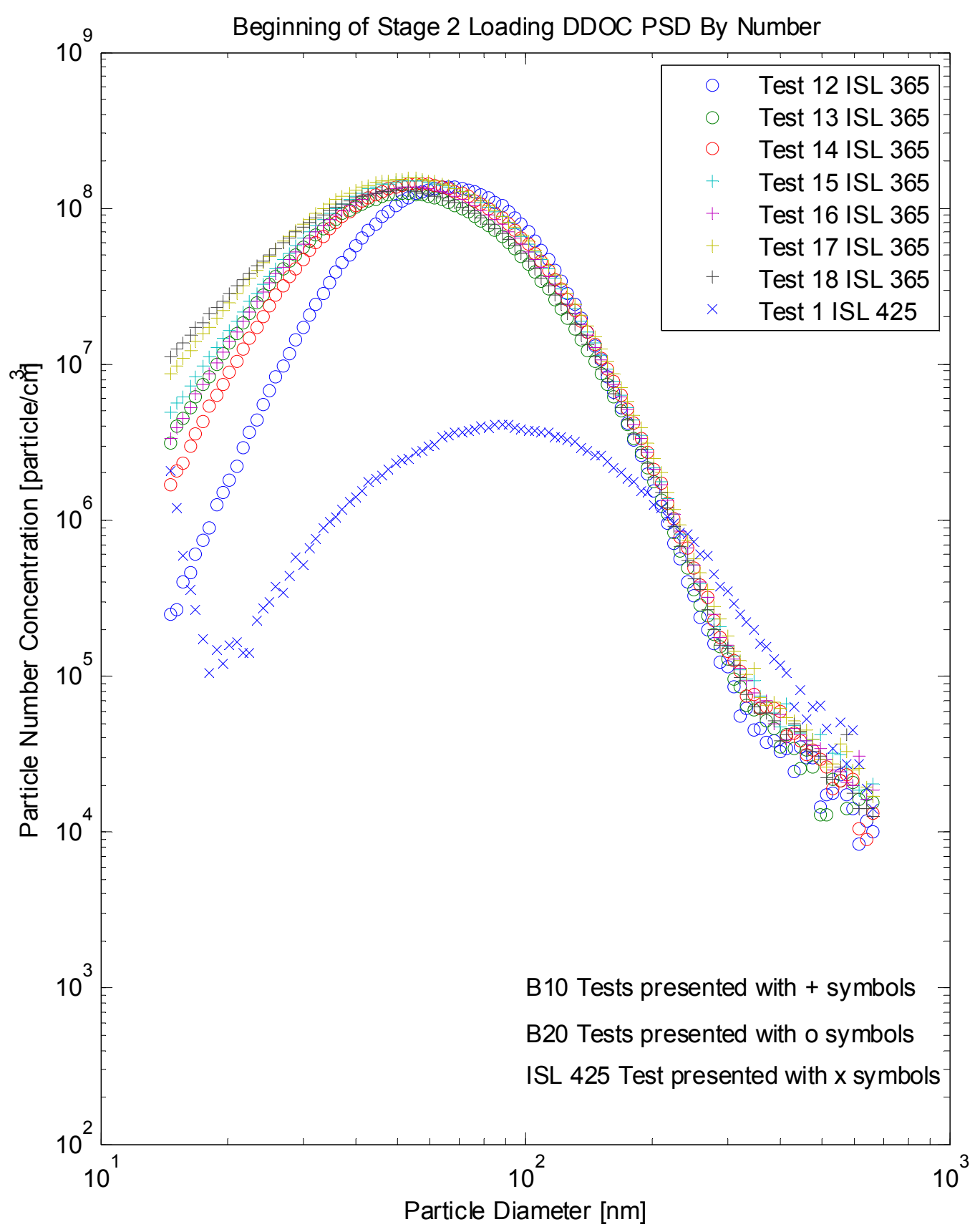

Figure 4.8: PSD data collected DDOC at the beginning of Stage 2 during each test 


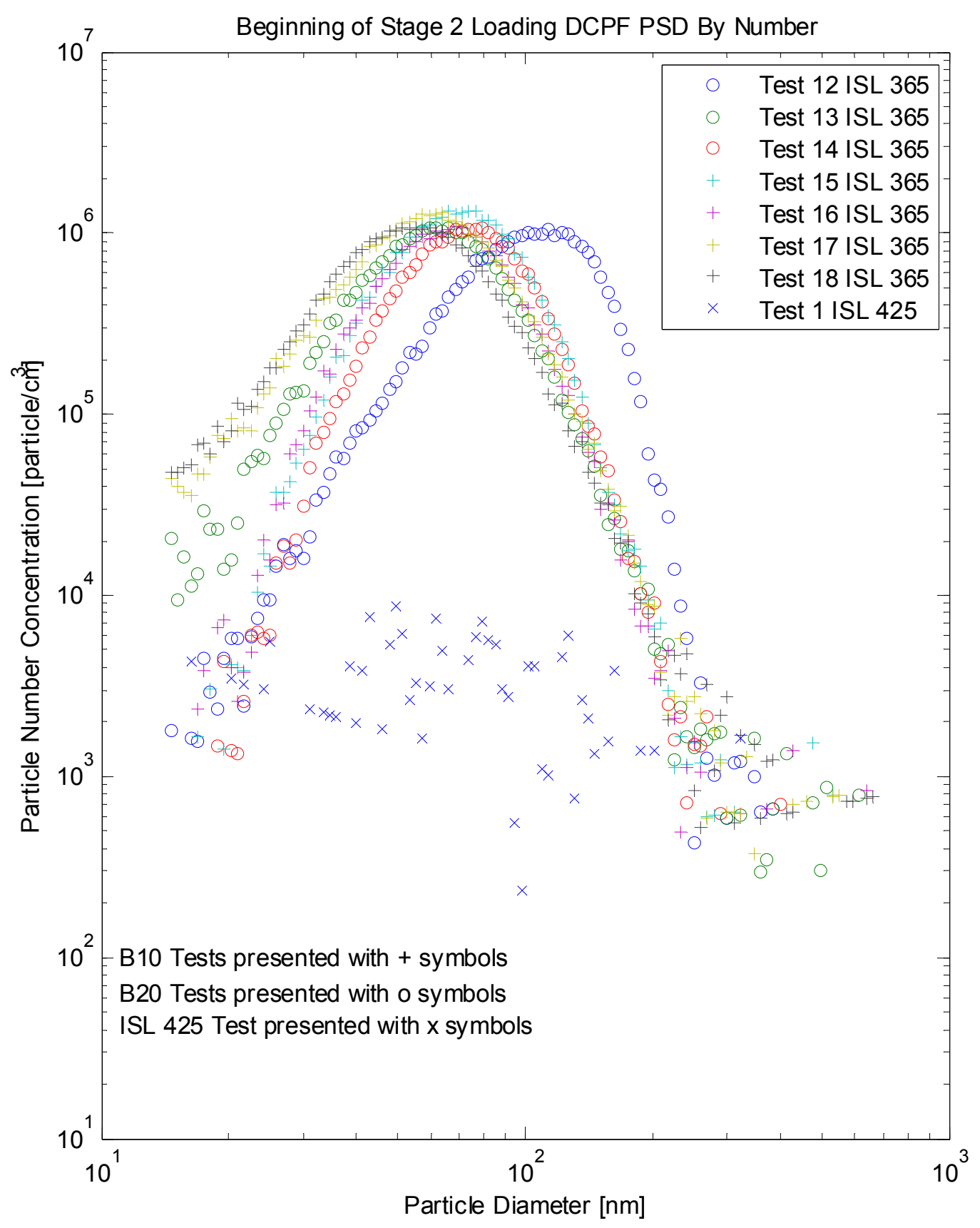

Figure 4.9: PSD data collected DCPF at the beginning of Stage 2 during each test 


\subsubsection{Stage 2 Reaction Rates}

Equation 2 was used to calculate the reaction rate during Stage 2 and Passive Oxidation. This equation has inputs of mass, filtration efficiency, PM concentration, and time. Each input is assumed constant during the stage being calculated. This equation does not allow for the separation of $\mathrm{NO}_{2}$ and thermal $\left(\mathrm{O}_{2}\right)$ oxidation, but includes both.

Figure 4.10 shows the calculated reaction rates plotted versus 1000/average CPF temperature $(\mathrm{K})$. The reaction rates are labeled by fuel and engine rating, and an average of each group with multiple points is also shown with standard deviation error bars.

An important input to Equation 2 in the beginning and ending PM mass retained within the CPF. A mass balance is performed for each test. The rate of mass added during Stage 1 and Ramp-up is assumed to be the same as during Stage 2. The rate of mass added during Stage 3 is assumed to be the same as during Stage 4. The filtration efficiency is determined by taking a single downstream PM sample during Stage 2 and this filtration efficiency is assumed constant through the entire test. The mass out of the CPF for each stage is calculated with this filtration efficiency. The remainder of the engine out PM mass is assumed to be oxidized. An example calculation, using values for ISL Test 14 with B10 fuel, is shown by equation 16 . The method used to iterate this equation may result in a slight variation, so Matlab was used for all calculations.

$$
\begin{gathered}
36.8=\frac{0.179 * 18.4 * 0.96}{\mathrm{RR}_{0} * 1000}\left[1-\mathrm{e}^{\left(-\mathrm{RR}_{\mathrm{o}}^{*}\left(223.8^{*} 60\right)\right)}\right]+4.6 * \mathrm{e}^{\left(-\mathrm{RR}_{\mathrm{o}}^{*}(223.8 * 60)\right)} \quad \text { Eqn. } 16 \\
\text { Solving iteratively, } \mathrm{RR}_{0}=3.56 \mathrm{E}-5
\end{gathered}
$$

ISL 365 Test 19 with ULSD fuel encountered an engine fault code during the first half of Stage 2 loading causing the EGR to remain closed. The engine fault code was removed allowing normal operation of the EGR during the second half of Stage 2 loading of this test. The reaction rate calculated in Figure 4.10 for Test 19 Stage 2 is calculated from the second half of Stage 2 loading. This reaction rate is significantly higher. The increased reaction rate may be due to different PM structure and content of the PM retained during the first half of Stage 2 loading. Complete mass balances and further comparison of key Stage 2 loading variables can be seen in Appendix N. 


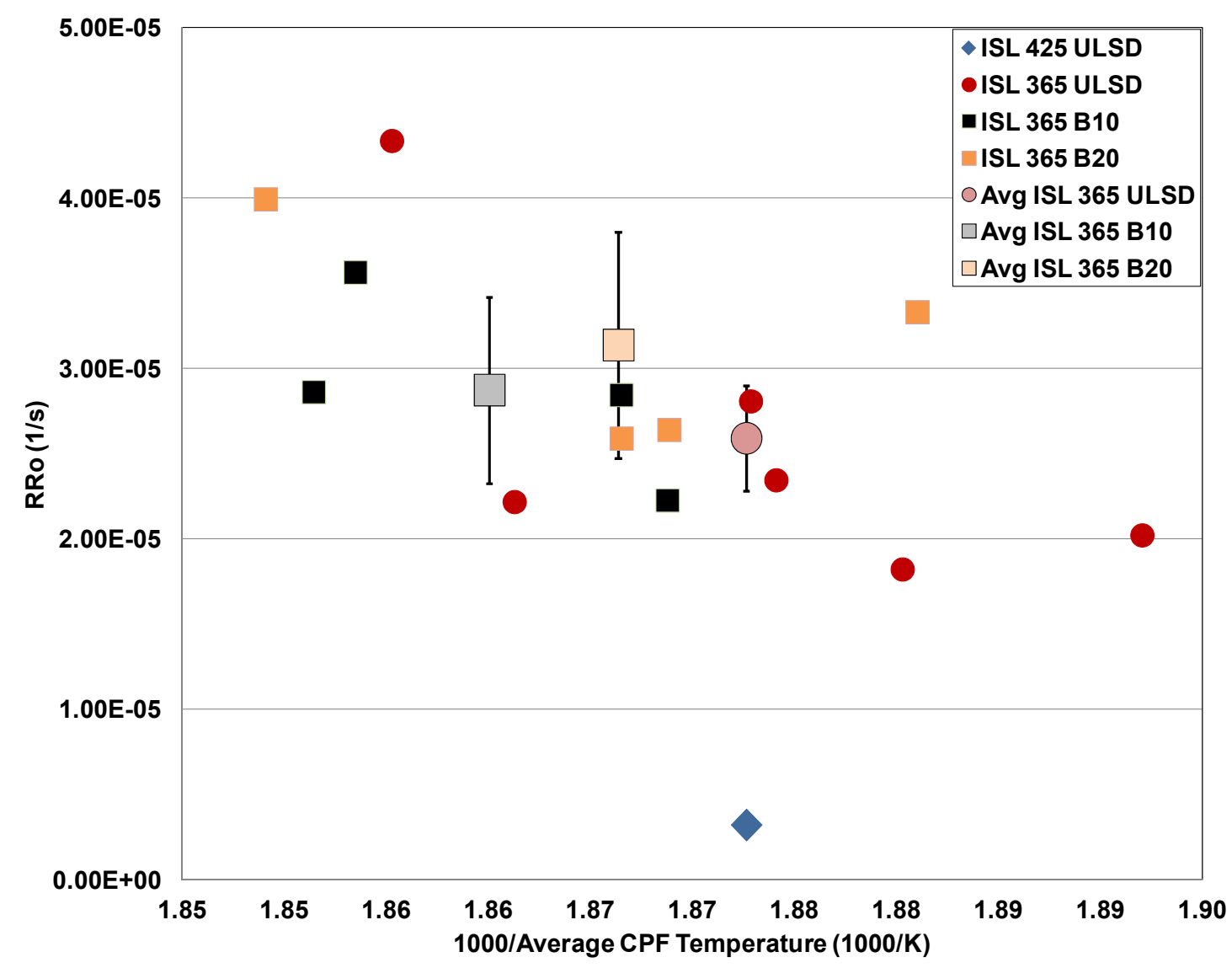

Figure 4.10: Stage 2 reaction rates

Loading times were longer with B20 fuel than with ULSD fuel with a similar absolute humidity. Despite this, the overlapping standard deviation error bars of ISL 365 tests suggest that each fuel loaded the CPF in a similar manor. ISL 425 Test 1 had a lower reaction rate than ISL 365 tests. This may be due to changes in the exhaust emissions composition and concentrations. A statistical analysis was performed with and without ISL 365 Test 19 data determining that there is no proof to support that the reaction rates are different between ISL 365 tests with each fuel and results are shown in Appendix O. Due to only one test being completed with the ISL at $425 \mathrm{hp}$ rating it is not included in the statistical analysis. The reaction rate for ISL 425 Test 1 shown in Figure 4.10 by a blue diamond symbol is nearly a factor lower than ISL 365 tests (3.23E-6 versus 2.84E5). ISL 425 Test 1 has a higher concentration of $\mathrm{NO}_{2}$ into the $\mathrm{CPF}$ (53 ppm compared to $26.5 \mathrm{ppm}$ for ISL 365 tests) which should have resulted in a higher reaction rate. The decreased reaction rate may be due to changes in soot structure due to increased boost pressure on the ISL $425 \mathrm{hp}$ rating. 


\subsubsection{Stage 2 Differential Pressure Drop Profile}

The CPF loading before transitioning to passive oxidation conditions versus the differential pressure drop across the CPF at that time is shown in Figure 4.11 for ISL 365 Tests $6-19$ and ISL 425 Test 1 . From this plot it can be seen that a $6 \mathrm{kPa}$ pressure drop across the CPF corresponded to approximately $2.3 \mathrm{~g} / \mathrm{L}$ nominal loading for ISL 365 tests. This consistent CPF loading versus CPF pressure drop is an additional benefit to the procedure used for this testing. ISL 425 Test 1 has both a lower loading and a lower pressure drop prior to beginning passive oxidation. Additional testing will be required in order to make a comparison between engine ratings and CPFs used for ISL 365 and 425 testing. Appendix $\mathrm{P}$ shows the complete pressure drop profiles for each test.

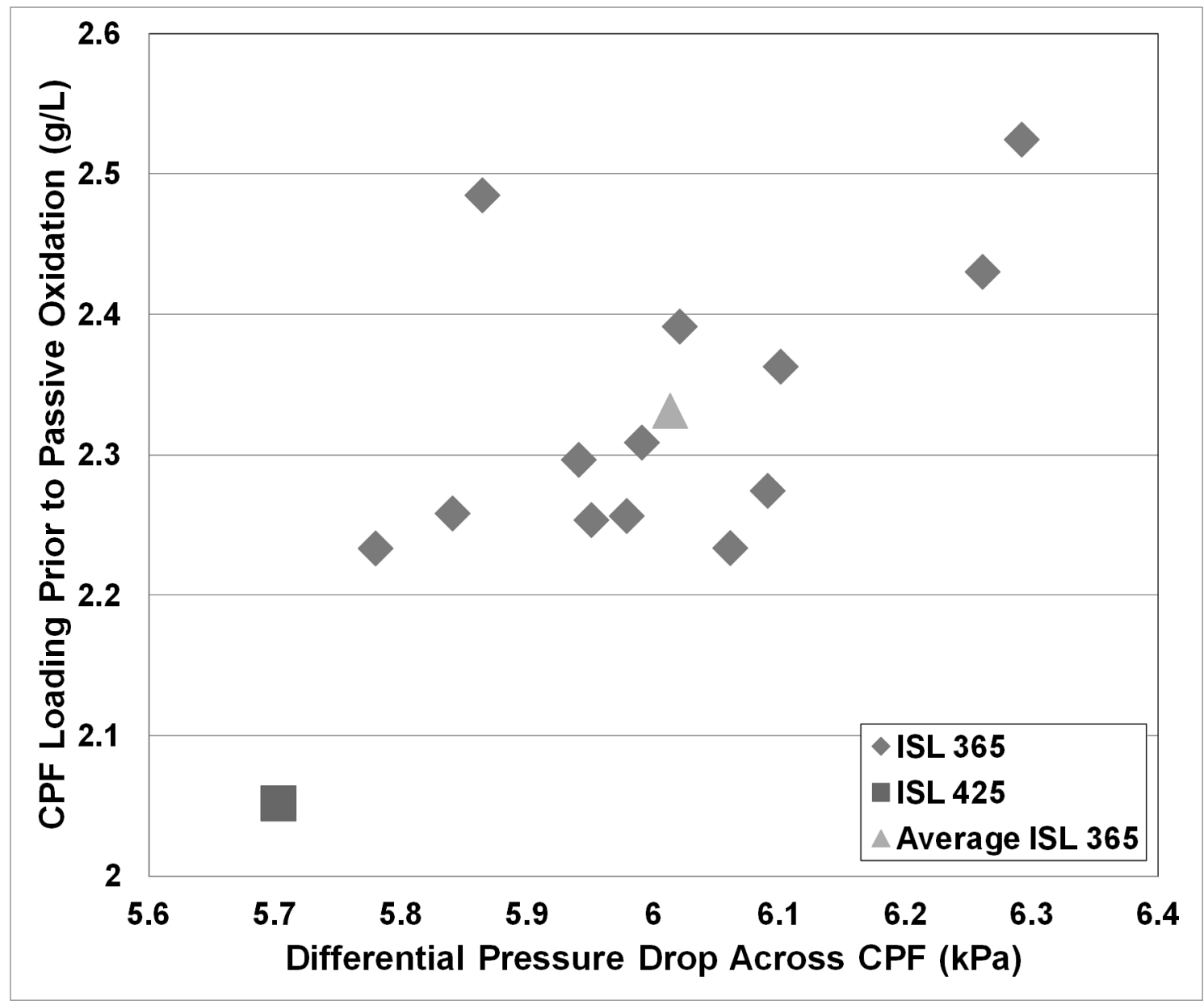

Figure 4.11: Pressure drop profile across CPF at end of loading vs. CPF loading prior to switching to passive oxidation conditions 


\subsection{Passive Oxidation}

The passive oxidation portion of the test consisted of operating the engine at one of four engine operating conditions. These conditions were chosen to provide a range of temperatures from 260 to $410{ }^{\circ} \mathrm{C}$, a range of $\mathrm{NO}_{2} / \mathrm{PM}$ ratios from 5 to 240 , and a range of $\mathrm{NO}_{\mathrm{x}} / \mathrm{PM}$ ratios from 25 to 583 .

During ISL 365 tests 11 and 18 the exhaust valve to the baseline stuck open slightly after the Stage 2 loading. During ISL 365 Test 17 the valve to the baseline stuck open during Stage 4 . The valve being stuck open allowed exhaust to flow around the aftertreatment system to the base line. This changed the actual volumetric flow rate of exhaust flowing through the aftertreatment system. The loss associated with this has been determined in two ways; the fraction of the differential pressure drop lost during the loading stage was calculated, the second method used changes in the $\Delta \mathrm{P} / \mathrm{Q}$ plot to determine the fraction of exhaust flow lost.

The differential pressure drop across the CPF is expected to return to a similar value from Stage 1 to Stage 2 to Ramp-up, and from Stage 3 to Stage 4. The fraction of pressure drop across the CPF from the prior loading stage when compared to the current loading stage represents the fraction of exhaust diverted to the baseline. The $\Delta \mathrm{P} / \mathrm{Q}$ plots, which will be detailed in section 4.7 , can be adjusted by changing the actual volumetric flow rate (Q) directly. Each method for adjusting the flow resulted in approximately $13 \%$ of the engine out exhaust volumetric flow rate being diverted to the baseline when the valve was stuck during loading stages. During Test 11 and 18 additional volumetric flow rate adjustments was made during Passive Oxidation. The passive oxidation portions of these tests were performed at a lower flow rate condition than during loading. This low flow rate would have generated a different pressure between the baseline and trap lines. Additional exhaust flow is believed to have been allowed to be diverted to the baseline during passive oxidation. These values were used to compensate for the actual volumetric flow in the reaction rate calculations. During ISL 365 Test 11 the pressure drop across the DOC was noticed to increase during the course of the test indicating that PM was being retained on the face of the DOC. This is termed 'DOC face plugging'. The amount of PM retained on the DOC during this test cannot be accounted for.

Table 4.1 shows key variables during Passive Oxidation to facilitate discussion. The PM mass retained in the CPF during loading on the ISL 365 with B10 and B20 testing was consistent as shown by standard deviations below 1. Test 9 and Test 19 on the ISL 365 with ULSD had high loadings prior to Passive Oxidation resulting in a standard deviation of 3.2. The decrease of PM mass in the CPF and resulting percent PM oxidized were low for tests conducted at Point A conditions consisting of an average CPF temperature of $250.5 \pm 6.5^{\circ} \mathrm{C}$ and an exhaust mass flow rate of $5.9 \pm 0.3 \mathrm{~kg} / \mathrm{min}$ (ISL 365 Tests 11,14 , 18 and ISL 425 Test 1). This engine operating point provides conditions within the CPF in which the rate of PM oxidized by the CPF is close to the rate at which PM enters the $\mathrm{CPF}$. The total mass oxidized during ISL 425 Test 1 was not high enough to expect a reasonably accurate reaction rate $(1.7 \mathrm{~g})$ due to mass measurement error of .3 grams. 
Table 4.1:

Key Passive Oxidation mass balance results

\begin{tabular}{|c|c|c|c|c|c|c|c|c|c|c|c|c|c|}
\hline & Variable & $\begin{array}{c}\text { Average } \\
\text { CPF } \\
\text { temp. }\end{array}$ & \begin{tabular}{|c|} 
Exhaust \\
Volumetric \\
flow rate
\end{tabular} & $\begin{array}{c}\text { Exhaust } \\
\text { Mass flow } \\
\text { rate }\end{array}$ & $\begin{array}{l}\text { Engine } \\
\text { out PM } \\
\text { Conc. }\end{array}$ & $\begin{array}{c}\text { Engine } \\
\text { out PM } \\
\text { mass } \\
\text { During } \\
\text { Passive } \\
\text { Ox. }\end{array}$ & $\begin{array}{c}\text { PM mass } \\
\text { retained } \\
\text { in } \mathrm{CPF} \\
\text { During } \\
\text { Loading }\end{array}$ & $\begin{array}{c}\text { Decrease } \\
\text { of PM } \\
\text { Mass in } \\
\text { CPF }\end{array}$ & $\begin{array}{c}\text { PM mass } \\
\text { retained } \\
\text { in } \mathrm{CPF}\end{array}$ & $\begin{array}{c}\text { Total } \\
\text { Mass } \\
\text { Available } \\
\text { for OX. }\end{array}$ & $\begin{array}{c}\text { Total } \\
\text { Mass of } \\
\text { PM } \\
\text { Oxidized }\end{array}$ & $\begin{array}{l}\text { Percent } \\
\text { PM } \\
\text { oxidized }\end{array}$ & Mass Out \\
\hline Engine & Test/Units & ${ }^{\circ} \mathrm{C}$ & $\mathrm{scm} / \mathrm{sec}$ & $\mathrm{kg} / \mathrm{min}$ & $\mathrm{mg} / \mathrm{scm}$ & $\mathrm{g}$ & $\mathrm{g}$ & $\mathrm{g}$ & $\mathrm{g}$ & $\mathrm{g}$ & $\mathrm{g}$ & $\%$ & $\mathrm{~g}$ \\
\hline \multirow{6}{*}{ ISL 365 ULSD } & Test 6 & *344 & 0.106 & 7.8 & 6.8 & 5.2 & 38.6 & 10.1 & 28.5 & 43.8 & 15.2 & 35 & 0.1 \\
\hline & Test 7 & *391 & 0.202 & 15.0 & 3.7 & 5.4 & 38.3 & 21.9 & 16.4 & 43.7 & 27.2 & 62 & 0.1 \\
\hline & Test 8 & 351 & 0.104 & 7.7 & 7.3 & 2.7 & 38.9 & 14.3 & 24.6 & 41.6 & 16.9 & 41 & 0.1 \\
\hline & Test 9 & 338 & 0.104 & 7.7 & 6.6 & 3.3 & 42.5 & 18.0 & 24.5 & 45.8 & 21.3 & 46 & 0.1 \\
\hline & Test 10 & 287 & 0.090 & 6.6 & 1.8 & 0.6 & 34.4 & 5.5 & 28.9 & 35.0 & 6.1 & 17 & 0.0 \\
\hline & Test 19 & 363 & 0.106 & 7.8 & 12.1 & 6.2 & 43.2 & 14.1 & 29.1 & 49.4 & 20.1 & 41 & 0.2 \\
\hline & & & & & \multicolumn{2}{|c|}{ Average } & 39.3 & 14.0 & 25.3 & 43.2 & 17.8 & 40.3 & 0.1 \\
\hline & & & & & \multicolumn{2}{|c|}{ Standard Dev. } & 3.2 & 5.8 & 4.9 & 4.8 & 7.1 & 14.7 & 0.1 \\
\hline \multirow{4}{*}{ ISL 365 B20 } & Test 11 & 254 & 0.067 & 5.7 & 5.7 & 2.7 & 39.5 & 0.4 & 39.1 & 42.2 & 3.0 & 7 & 0.1 \\
\hline & Test 12 & 351 & 0.107 & 7.9 & 6.3 & 3.2 & 40.9 & 16.1 & 24.8 & 44.1 & 19.3 & 44 & 0.0 \\
\hline & Test 13 & 405 & 0.203 & 15.1 & 8.3 & 4.3 & 40.5 & 17.8 & 22.7 & 44.8 & 21.9 & 49 & 0.2 \\
\hline & Test 18 & 251 & 0.067 & 5.6 & 7.8 & 3.7 & 41.5 & 0.7 & 40.8 & 45.2 & 4.2 & 9 & 0.2 \\
\hline & & & & & \multicolumn{2}{|c|}{ Average } & 40.6 & 8.8 & 31.9 & 44.1 & 12.1 & 27.3 & 0.1 \\
\hline & & & & & \multicolumn{2}{|c|}{ Standard Dev. } & 0.8 & 9.5 & 9.4 & 1.3 & 9.9 & 22.1 & 0.1 \\
\hline \multirow{4}{*}{ ISL 365 B10 } & Test 14 & 254 & 0.079 & 5.8 & 7.3 & 3.5 & 38.5 & -0.3 & 38.8 & 42.0 & 3.1 & 7 & 0.1 \\
\hline & Test 15 & 357 & 0.106 & 7.8 & 7.4 & 3.8 & 38.2 & 16.2 & 22.0 & 42.0 & 19.9 & 47 & 0.1 \\
\hline & Test 16 & 408 & 0.207 & 15.4 & 7.8 & 4.2 & 38.7 & 17.3 & 21.4 & 42.9 & 21.3 & 50 & 0.1 \\
\hline & Test 17 & 356 & 0.105 & 7.8 & 6.5 & 3.3 & 39.3 & 13.7 & 25.6 & 42.6 & 16.8 & 40 & 0.2 \\
\hline & & & & & \multicolumn{2}{|c|}{ Average } & 38.7 & 11.7 & 27.0 & 42.4 & 15.3 & 36.0 & 0.1 \\
\hline & & & & & \multicolumn{2}{|c|}{ Standard Dev. } & 0.5 & 8.2 & 8.1 & 0.4 & 8.3 & 19.6 & 0.0 \\
\hline ISL 425 ULSD & Test 1 & **249 & 0.085 & 6.2 & 3.1 & 1.6 & 35.1 & 0.2 & 34.9 & 36.7 & 1.7 & 5 & 0.1 \\
\hline
\end{tabular}

This conclusion suggests that tests performed on the ISL rated at $425 \mathrm{hp}$ should use a longer passive oxidation time than testing performed on the ISL rated at $365 \mathrm{hp}$ under similar engine operating conditions in order to achieve measurable PM mass retained changes. The engine operating points chosen to be used during passive oxidation provided a range of $\mathrm{NO}_{\mathrm{x}}, \mathrm{NO}_{2}$, and $\mathrm{PM}$ outputs. While the resulting temperature of the $\mathrm{CPF}$ has been found to have the greatest effect on the oxidation of PM within the CPF, the concentration of $\mathrm{NO}_{2}$ into the $\mathrm{CPF}$ has been found to be critical as well. From analysis performed by Hutton et al. $[1,2]$ the $\mathrm{NO}_{2}$ available at the inlet does not account for all of the PM mass oxidized during the passive oxidation stage. $\mathrm{NO}_{2}$ back diffusion has been found to explain the extra mass oxidized.

\subsubsection{Passive Oxidation $\mathrm{NO}_{\mathrm{x}}$ Mass Balance}

In order to understand more about back diffusion, a careful $\mathrm{NO}_{\mathrm{x}}$ mass balance was performed. All PM oxidized is assumed to be $\mathrm{NO}_{2}$ related oxidation resulting in a value of $\mathrm{NO}_{2}$ consumed. Subtracting the $\mathrm{NO}_{2}$ consumed by the $\mathrm{NO}_{2}$ available at the inlet results in an approximation of the $\mathrm{NO}_{2}$ that back diffused from downstream within the $\mathrm{CPF}$. Table 4.2 shows the $\mathrm{NO}_{\mathrm{x}}$ mass balance for all the tests. Péclet numbers shown are dimensionless parameters which signify the likelihood of back diffusion occurring. More information regarding the calculation of Péclet numbers may be found in references [1, 2]. 


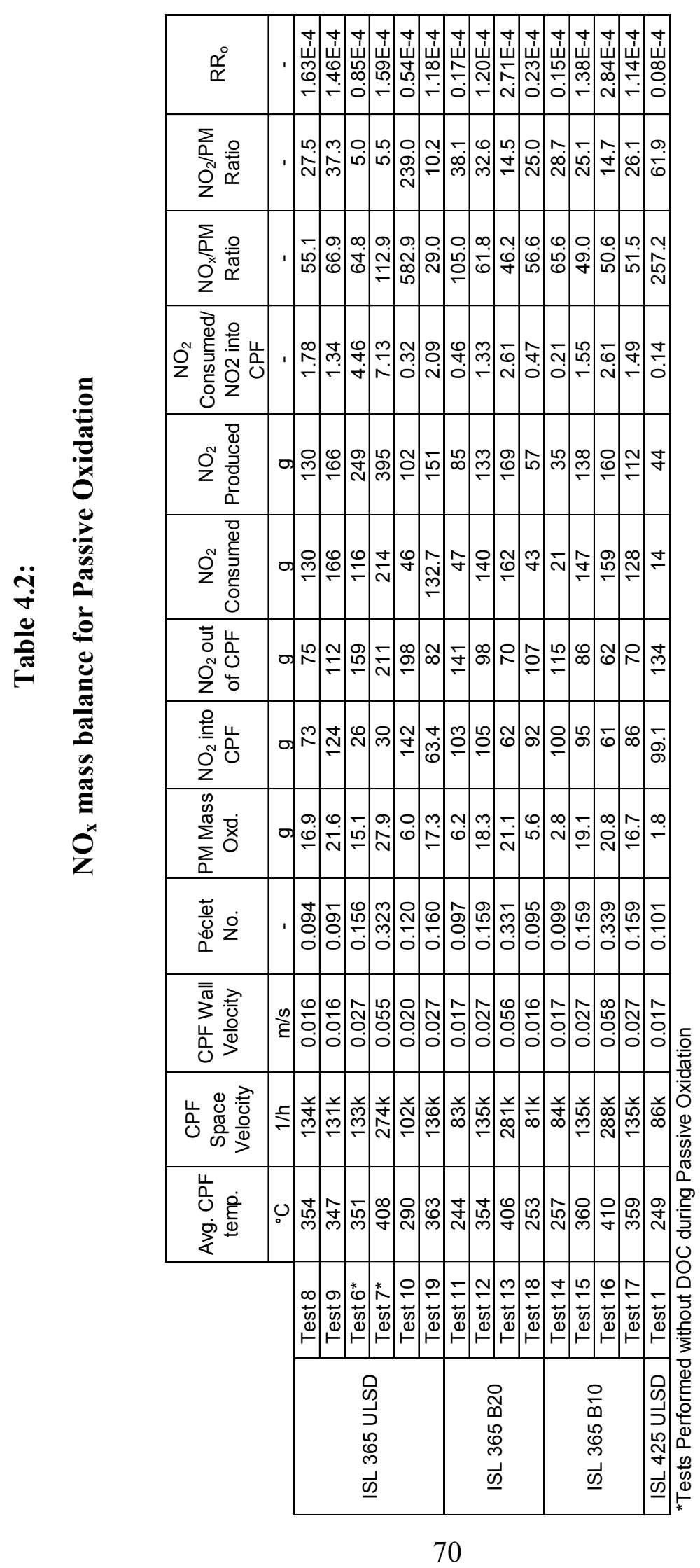


The PM oxidized is assumed to be due to $\mathrm{NO}_{2}$ oxidation. This assumption neglects thermal $\left(\mathrm{O}_{2}\right)$ oxidation. The MTU 1-D model must be used to more accurately determine oxidation kinetics and oxidation mechanisms taking place during the passive oxidation of $\mathrm{PM}$ in the CPF. This assumption allows for the relative analysis of gaseous emission and back diffusion data. The $\mathrm{NO}_{2}$ consumption plotted versus the average CPF temperature during passive oxidation is shown in Figure 4.12.

The $\mathrm{NO}_{2}$ available at the inlet of the $\mathrm{CPF}$ is subtracted from the $\mathrm{NO}_{2}$ consumed during passive oxidation. The remainder of the $\mathrm{NO}_{2}$ consumed is assumed to come from back diffusion. The calculated $\mathrm{NO}_{2}$ produced by back diffusion for each passive oxidation test is shown in Figure 4.13.

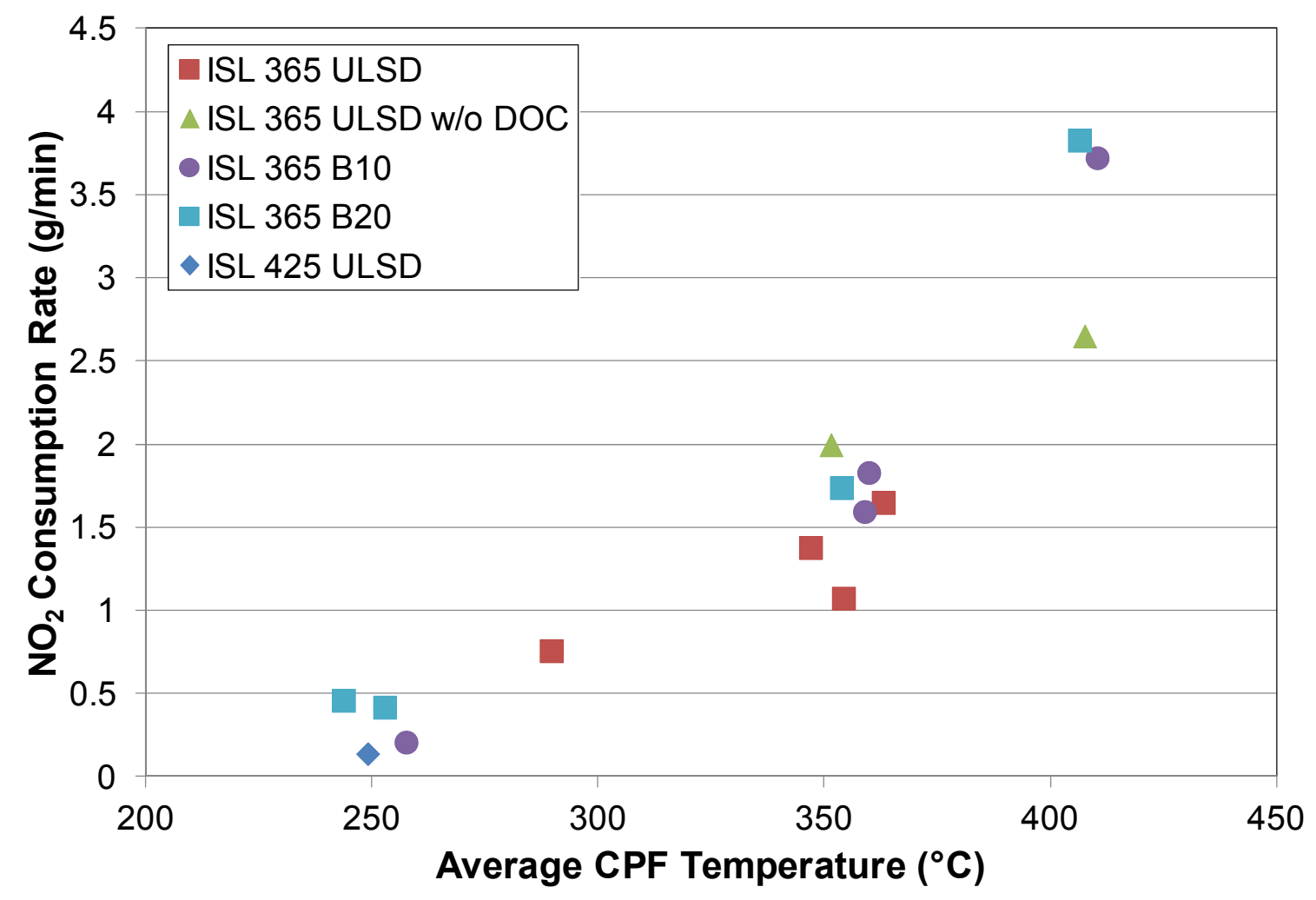

Figure 4.12: $\mathrm{NO}_{2}$ consumption rate vs. average $\mathrm{CPF}$ temperature for passive oxidation tests 


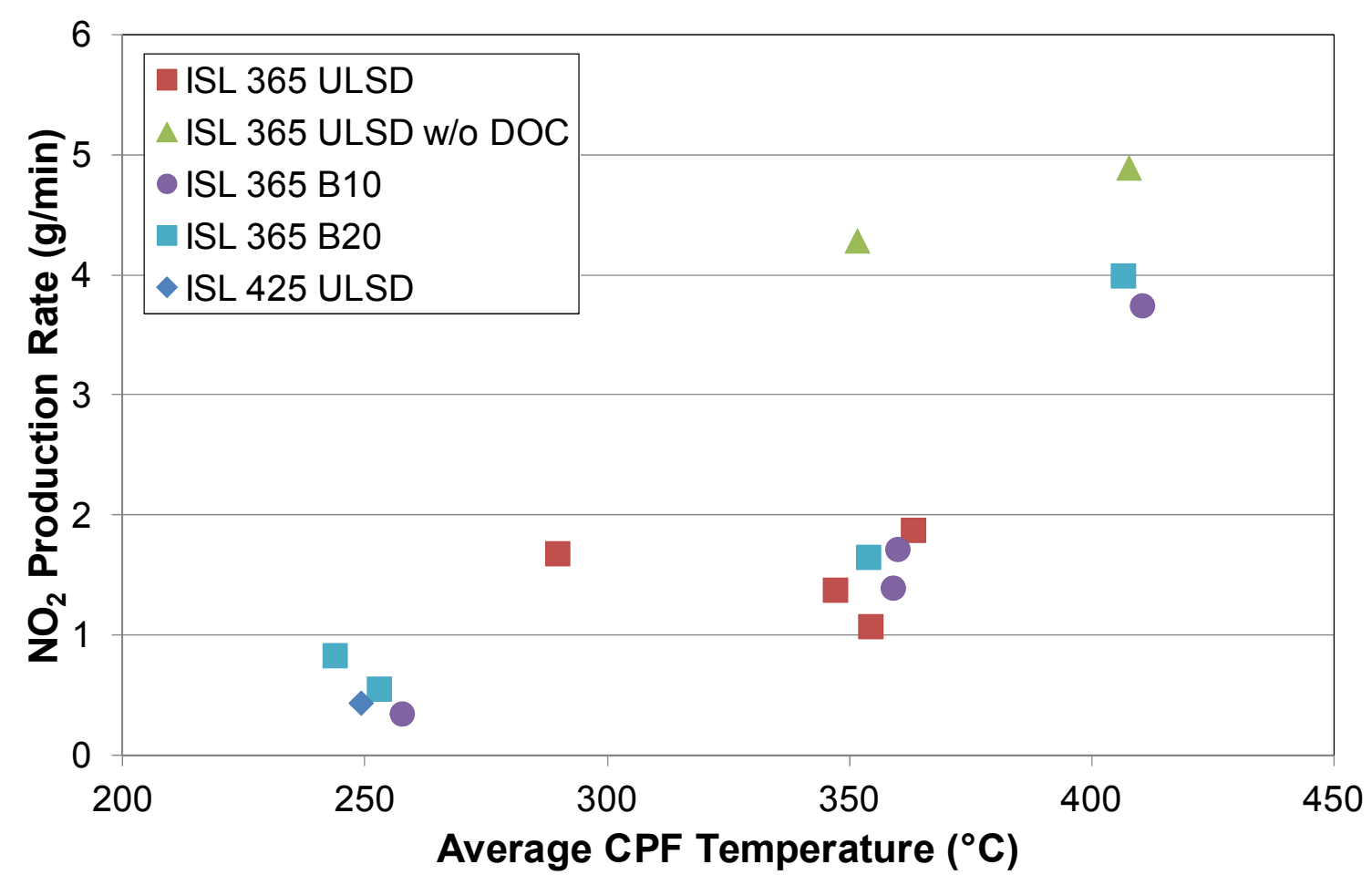

Figure 4.13: $\mathrm{NO}_{2}$ production rate vs. average $\mathrm{CPF}$ temperature for passive oxidation tests

As stated, the $\mathrm{NO}_{2}$ oxidation of PM does not occur alone and thermal $\left(\mathrm{O}_{2}\right)$ oxidation mechanisms are present. Figure 4.14 shows that the $\mathrm{NO}_{2}$ consumption/ $\mathrm{NO}_{2}$ available ratio increases with temperature. Values greater than 1 indicate that more $\mathrm{NO}_{2}$ than is available at the CPF inlet is required to oxidize the amount of PM lost during passive oxidation. This is based on the assumption that $\mathrm{NO}_{2}$ is the only oxidizer. $\mathrm{NO}$ may oxidize $\mathrm{PM}$ as well and there is a thermal $\left(\mathrm{O}_{2}\right)$ mechanism transition present above $400{ }^{\circ} \mathrm{C}$ that will have to be accounted for by the modeling effort. ISL 365 tests performed without the DOC during passive oxidation have a higher $\mathrm{NO}_{2}$ consumption / $\mathrm{NO}_{2}$ into the CPF ratio. This may be due to the increased $\mathrm{NO}$ at the CPF inlet being converted to $\mathrm{NO}_{2}$ by the CPF. This $\mathrm{NO}_{2}$ would then oxidize the PM in the CPF. 


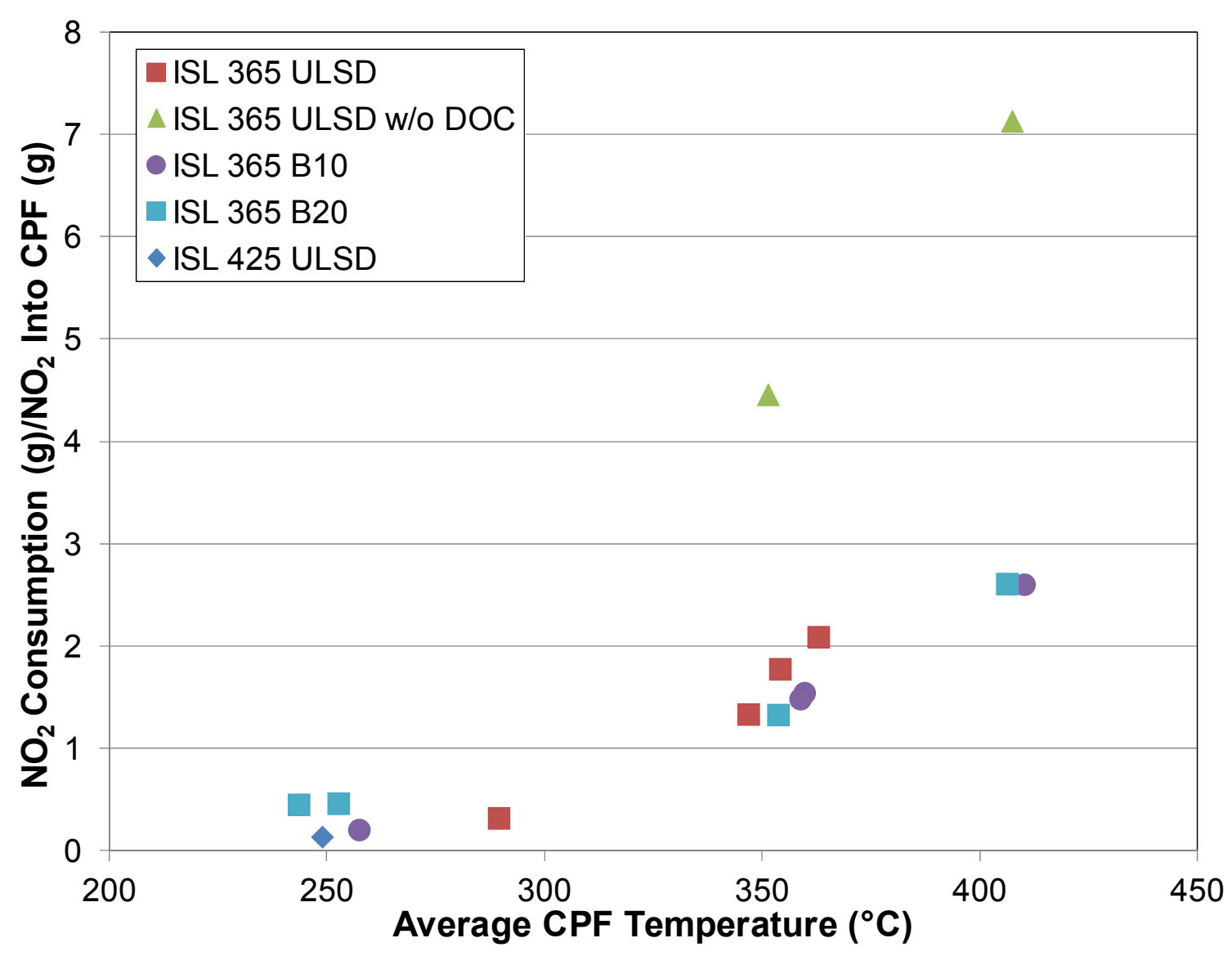

Figure 4.14: $\mathrm{NO}_{2}$ consumption / $\mathrm{NO}_{2}$ available at the inlet of the CPF vs. average CPF temperature

\subsubsection{Passive Oxidation PSD Data}

Particle size distribution (PSD) data was collected during Stage 2 and Passive Oxidation during each of the performed passive oxidation tests. Figure $4.15-4.17$ corresponds to the UDOC, DDOC, and DCPF particle size distribution data collected at the beginning of Passive Oxidation for all of the tests. Test 11 PSD data shows significant and unexplained variation from data collected during the other tests, as such the data is not included in this analysis. Appendix Q shows the PSD data collected during Passive Oxidation separated by each test with PSD filtration efficiency. During biodiesel testing, PSD data was collected twice during Passive Oxidation if time allowed and this data is in Appendix M. 


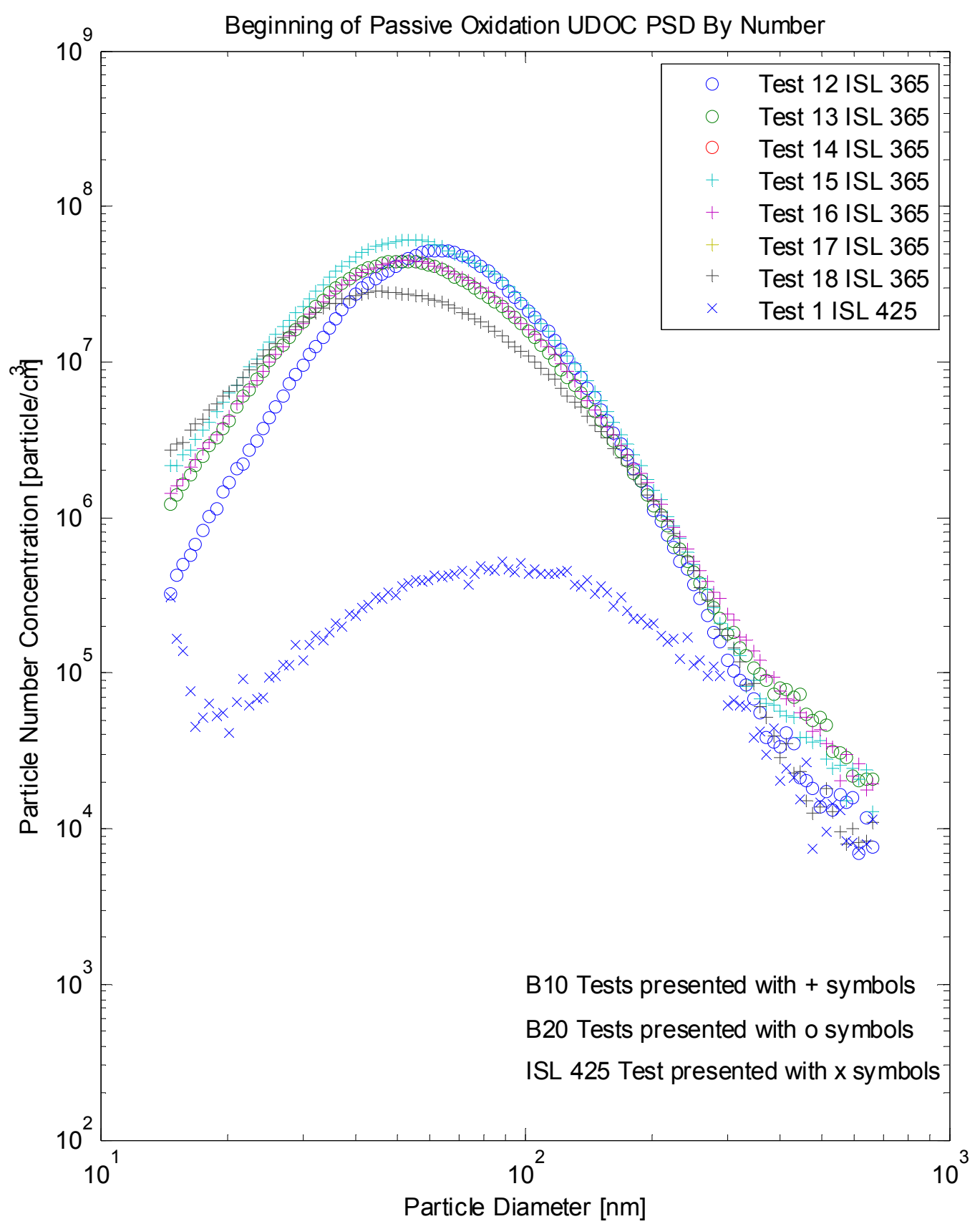

Figure 4.15: PSD data collected UDOC at the beginning of Passive Oxidation during each test 


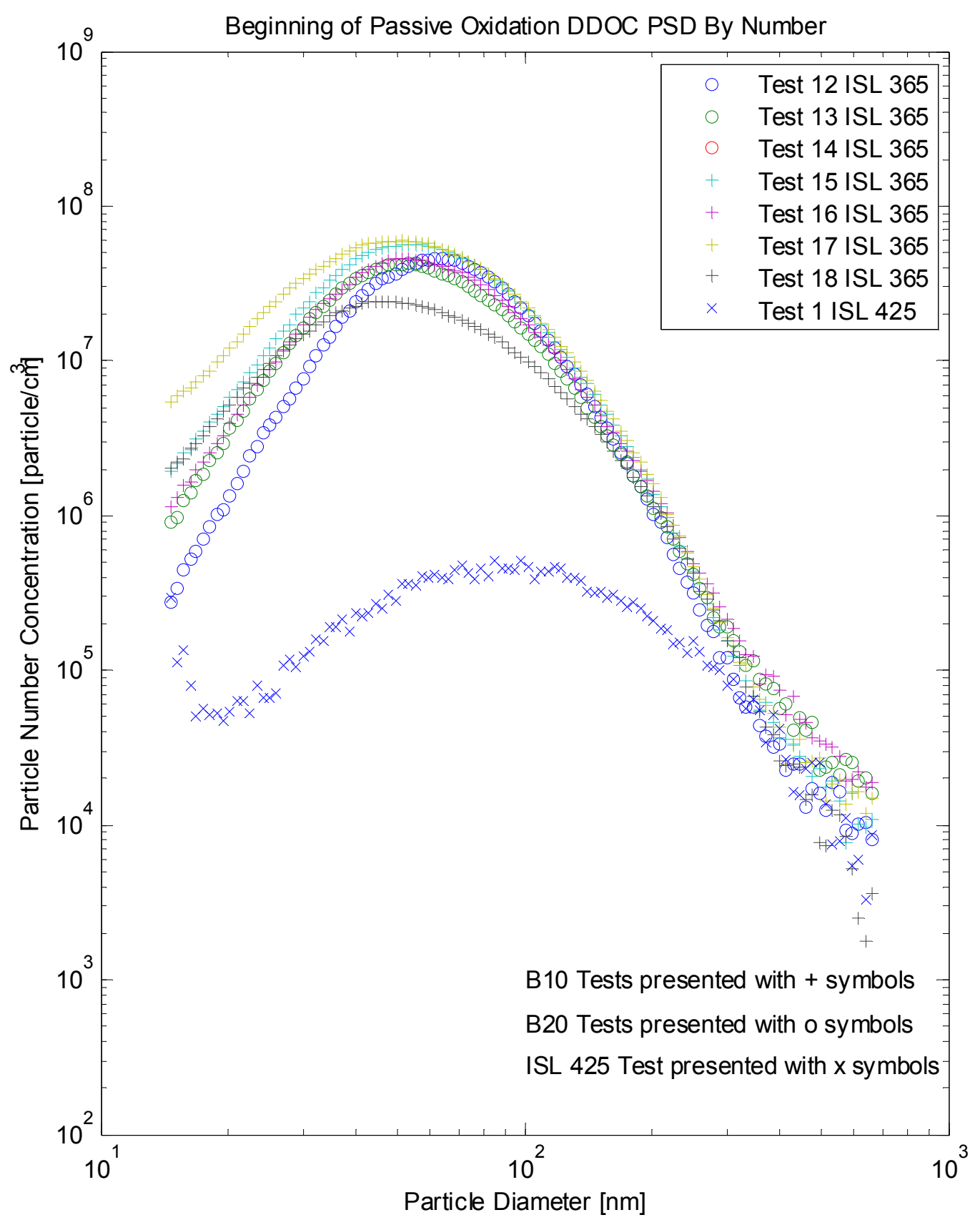

Figure 4.16: PSD data collected DDOC at the beginning of Passive Oxidation during each test 


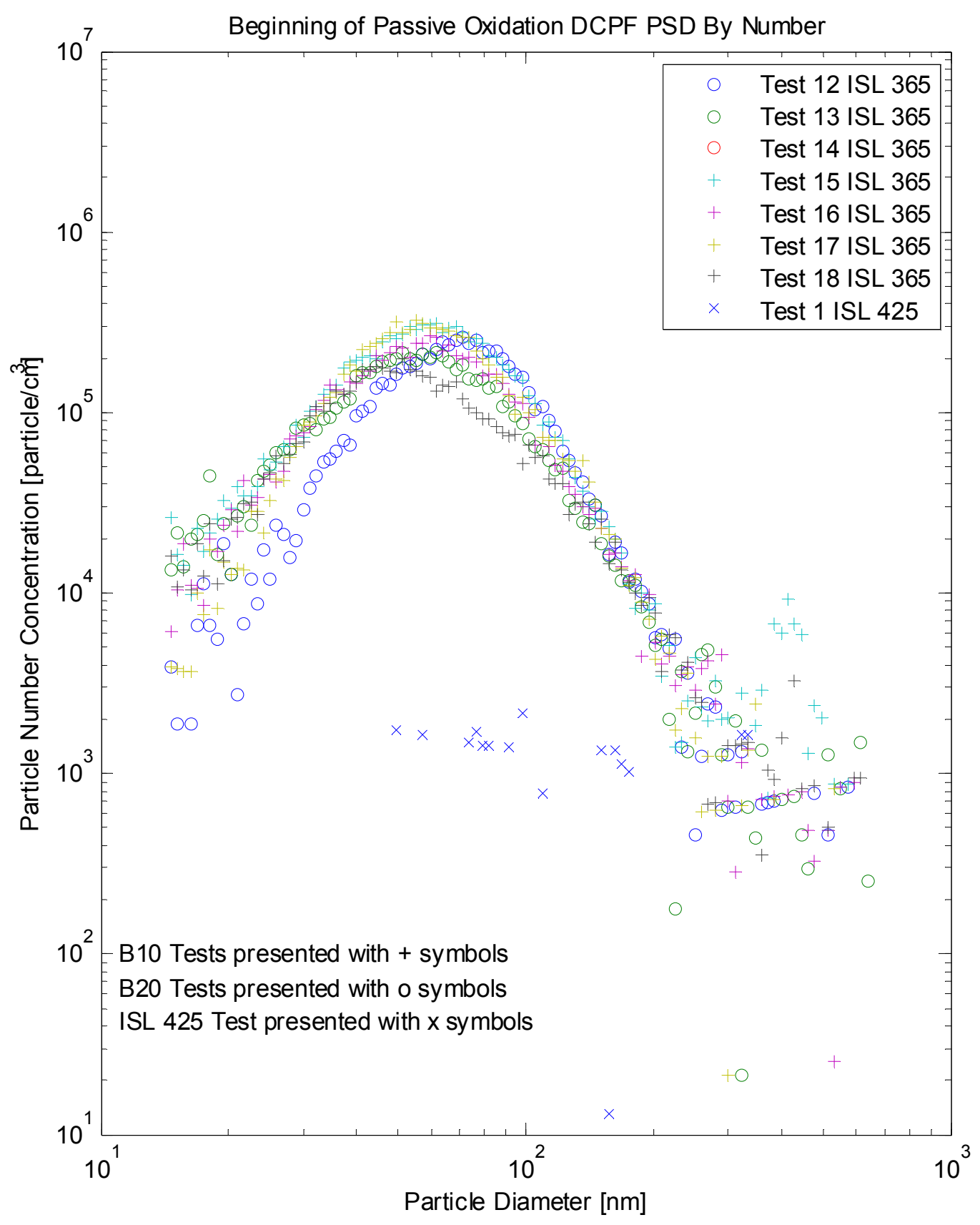

Figure 4.17: PSD data collected DCPF at the beginning of Passive Oxidation during each test 
The passive oxidation PSD data shows similar trends as Stage 2 PSD data. B10 tests signified by a '+' symbol show a marginally higher particle concentration at the $11 \mathrm{~nm}$ particle diameter than B20 tests. B20 tests have a particle number peak at a larger particle diameter when compared to B10 tests. These shifts in peak particle diameter may indicate changes in PM structure and $\mathrm{HC}$ species due to biodiesel content.

ISL 425 Test 1 signified by ' $x$ ' symbols shows a significantly lower particle concentration and a larger peak particle diameter at each point data. This is consistent with decreasing PM concentrations and changing emissions composition.

\subsubsection{Passive Oxidation Reaction Rates}

The reaction rates for the passive oxidation portions of each test were calculated with equation 2. The reaction rates are plotted with a log scale on the y-axis against 1000/CPF temperature $(\mathrm{K})$ on the $\mathrm{X}$-axis in Figure 4.18.

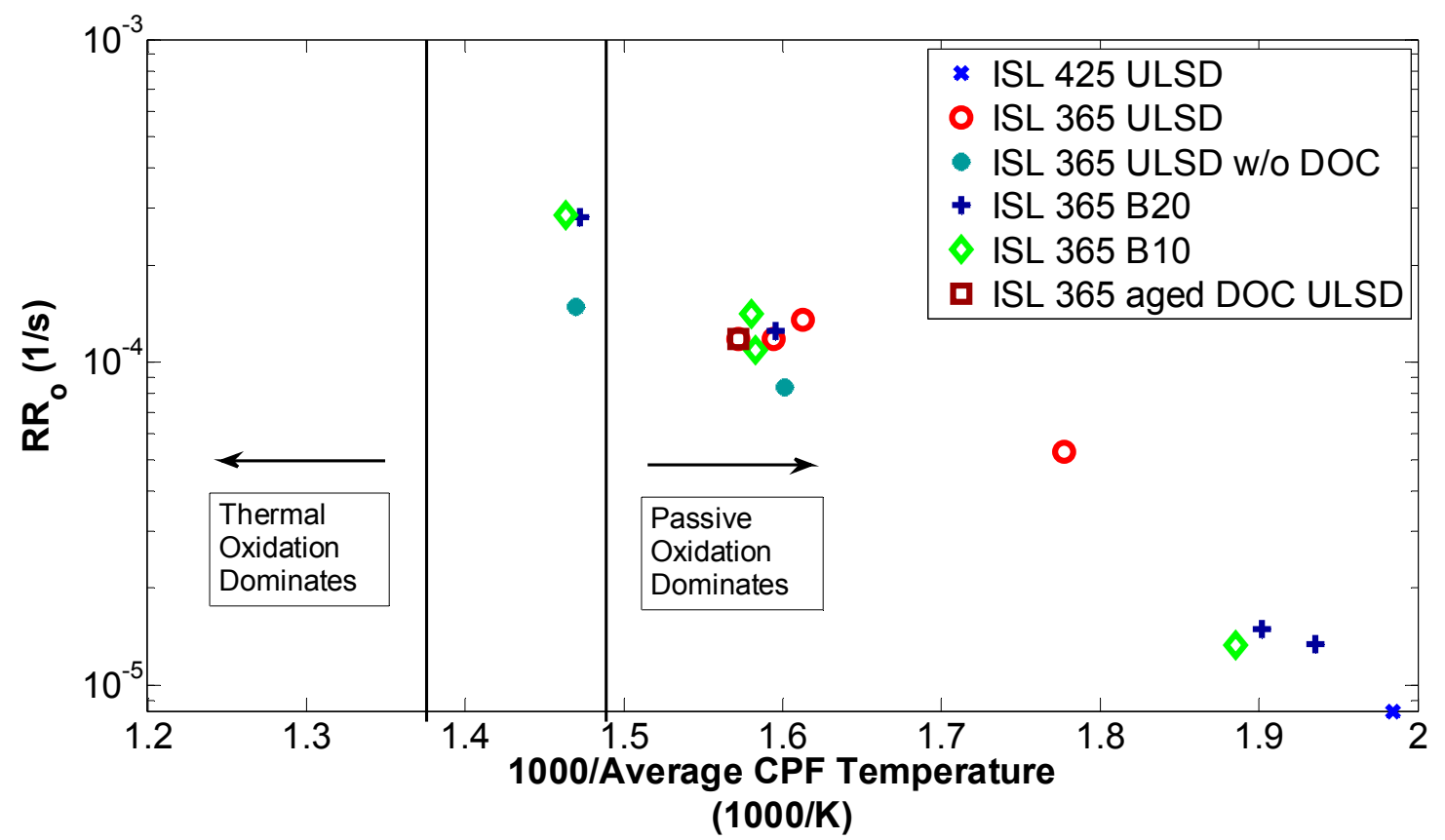

Figure 4.18: Log scale reaction rates for Passive Oxidation vs. 1000 / average CPF temperature in Kelvin

From Figure 4.18 it can be seen that the temperature of the CPF plays an important role in the reaction rate. As the CPF temperature increases so does the reaction rate. Under passive oxidation conditions the reaction rate depends upon the $\mathrm{NO}_{2}$ concentrations into the $\mathrm{CPF}$ and on the $\mathrm{NO}$ available at the $\mathrm{CPF}$ inlet. $\mathrm{The}^{\mathrm{NO}} \mathrm{x}_{\mathrm{x}}$ concentration then reflects the potential for PM oxidation since the $\mathrm{NO}$ contribution of this value can be oxidized to $\mathrm{NO}_{2}$ and then diffuse back into the PM cake layer increasing the reaction rate. Biodiesel PM has been shown to have higher structure disorder and increased oxygen content [8]. 
PM samples were collected onto quartz filters with ULSD, B10, and B20 fuels showing that the ISL 365 SOF fraction was similar with each fuel. Results of quartz filter testing can be seen in Appendix R. It can be seen that the B10 and B20 reaction rates were typically lower than ULSD reaction rates. This may be due to DOC aging causing lower DOC conversion of $\mathrm{NO}$ to $\mathrm{NO}_{2}$ and in turn lowered $\mathrm{NO}_{2}$ concentration at the CPF inlet. Decreasing $\mathrm{NO}$ to $\mathrm{NO} 2$ conversion efficiency as the DOC became aged is shown in Appendix S.

The effect of lowered $\mathrm{NO}_{2}$ concentration is shown in ISL 365 tests 6 and 7 which were performed without the DOC during passive oxidation. The decreased reaction rates of these tests confirm that an aged DOC is responsible for the decreased B10 and B20 reaction rates. The reaction rate equation used does not account for gaseous concentrations into the $\mathrm{CPF}$. The reaction rate and kinetic constants and the details of the PM oxidation process must be determined by a high fidelity CPF model.

\subsubsection{Passive Oxidation Differential Pressure Drop Profile}

As shown in section 4.1, the pressure drop profile for the modified test procedure was more consistent than the un-modified test procedure. During passive oxidation, the gradient of the pressure drop profile across the CPF is an indicator of the rate of PM oxidation in the CPF. A steep gradient indicates that the CPF is oxidizing PM at a rate faster than PM is coming in from the engine. Figure 4.19-4.21 show the pressure drop across the $\mathrm{CPF}$ during passive oxidation for the tests by engine operating conditions. Complete pressure drop data can be seen in Appendix P.

Figure 4.19 shows that the pressure drops of ISL 365 Test 14 and ISL 425 Test 1 with passive oxidation point A fall nearly on top of one another. The nearly flat pressure drop profile during this point indicates that the engine out $\mathrm{PM}$ is close to the rate the CPF is oxidizing PM. ISL 365 tests 11 and 18 show a lower pressure drop value during passive oxidation due to the stuck baseline valve discussed earlier in this chapter.

Figure 4.20 shows the pressure drop profile across the CPF for passive oxidation point $F$ tests. The slope of the pressure drop across the CPF during this point is steeper when compared to point A tests. This indicates that the CPF is oxidizing PM at a higher rate than the engine out PM rate.

Figure 4.21 shows the pressure drop profile across the CPF for passive oxidation point $\mathrm{H}$ tests. The slope of the pressure drop across the CPF during this point is steeper when compared to point $\mathrm{F}$ tests $(-0.016 \mathrm{kPa} / \mathrm{min},-0.05 \mathrm{kPa} / \mathrm{min})$. This point is performed at an average $\mathrm{CPF}$ temperature of $405 \pm 5^{\circ} \mathrm{C}$. A portion of the increased oxidation rate is due to this temperature. A high fidelity model will be used to determine the portion of thermal oxidation present at this point. 


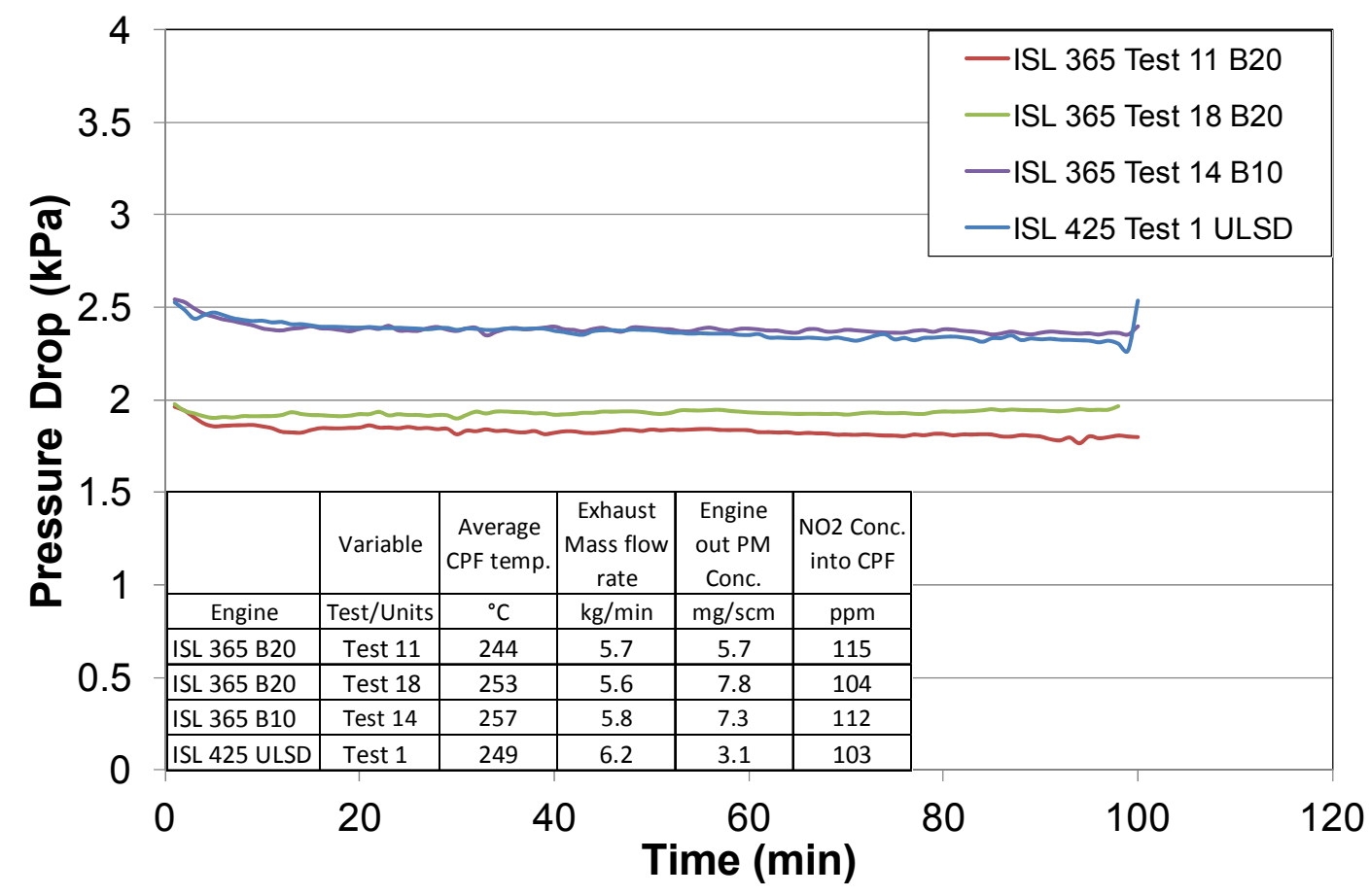

Figure 4.19: Differential pressure drop across the CPF during point A passive oxidation engine conditions

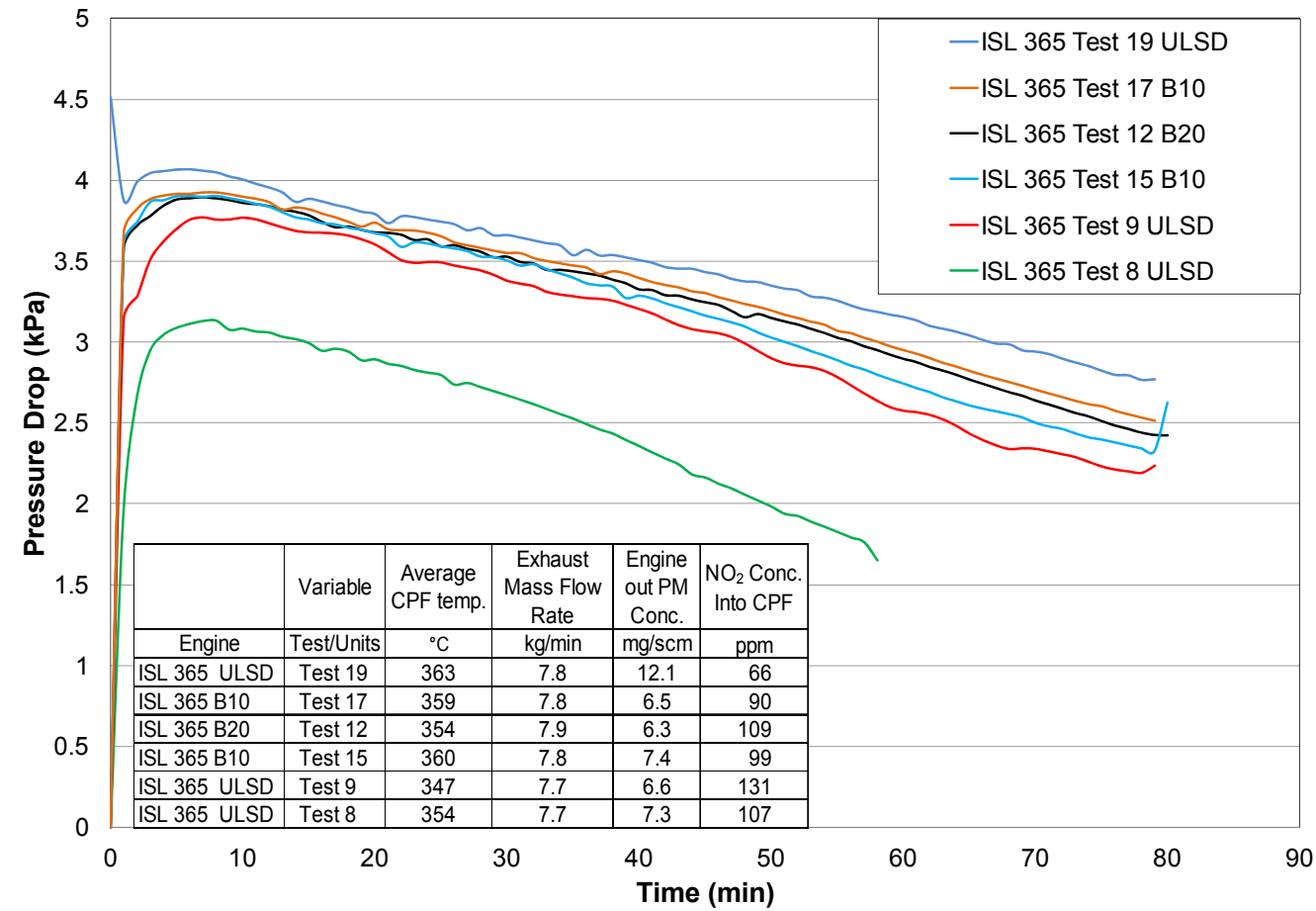

Figure 4.20: Differential pressure drop across the CPF during point $F$ passive oxidation engine operating conditions 


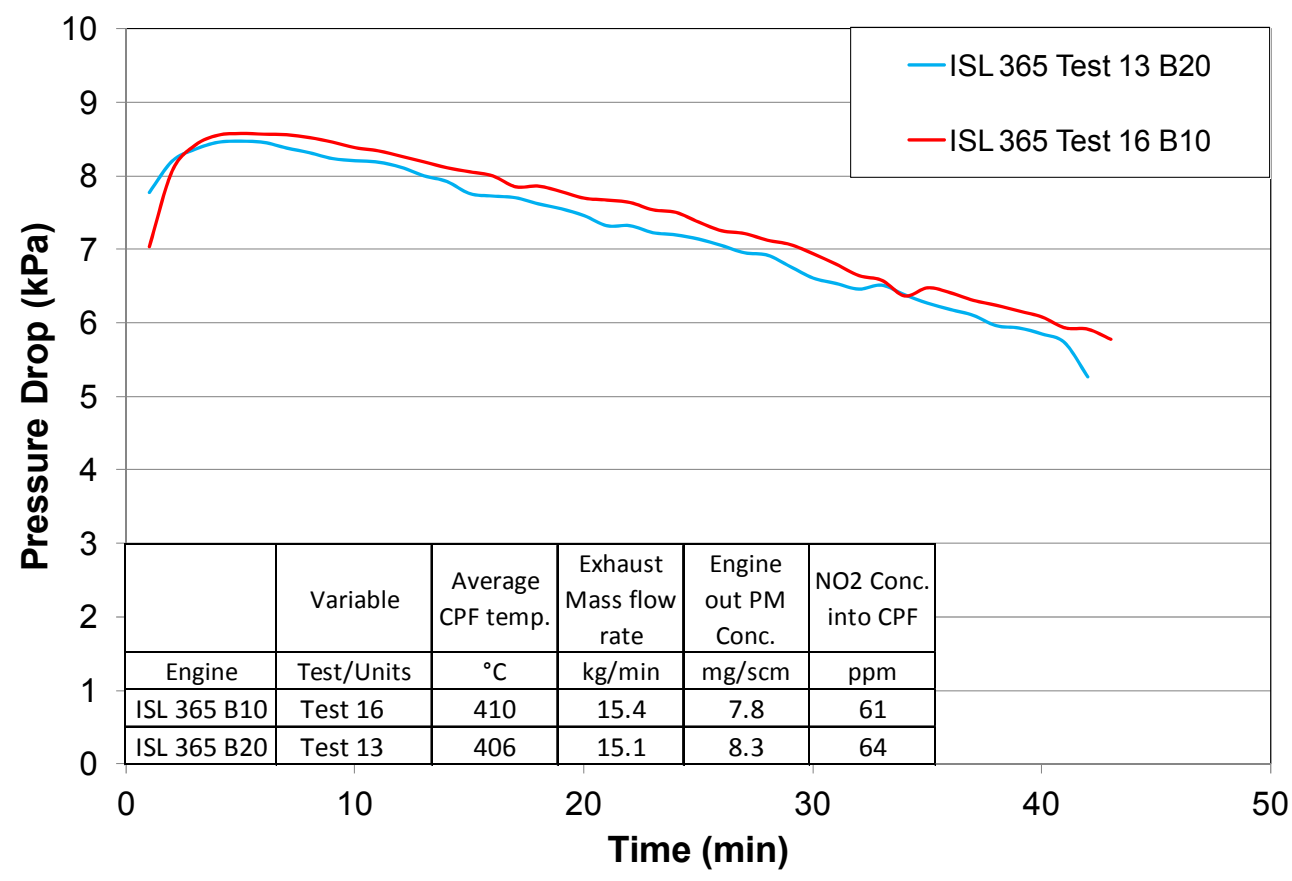

Figure 4.21: Differential pressure drop across the CPF during point $H$ passive oxidation engine operating conditions

\subsection{Stage 4 Loading}

The system is reassembled and the engine was operated at loading conditions for an additional hour after Stage 3 representing Stage 4 loading. The purpose of Stage 4 is to observe changes in the CPF pressure drop due to wall and cake layer PM oxidation. Stage 4 loading presents a better opportunity to calculate a reaction rate since there was a direct mass measurement before and after this stage of the test. An important input for the reaction rate equation are the beginning and ending PM mass values within the CPF and the direct mass measurement gives the most accurate values for this parameter. The reaction rates shown in Table 4.3 were calculated using equation 9 . The reaction rates found for Stage 4 were lower than the reaction rates found for Stage 2 during Tests 1118. The important difference between the Stage 2 and Stage 4 is the PM mass retained in the CPF and the distribution of the PM mass between the cake and wall layers. When the PM mass in the CPF during Stage 4 was similar to the Stage 2 (Point A conditions), the reaction rates were more similar, where as when the mass in the CPF was significantly lower during Stage 4 the reaction rates for Stage 4 were significantly lower. This is also true between the Stage 4's for different tests. Tests with higher mass in the CPF show higher reaction rates. This is shown visually in Figure 4.22 - 4.24. 


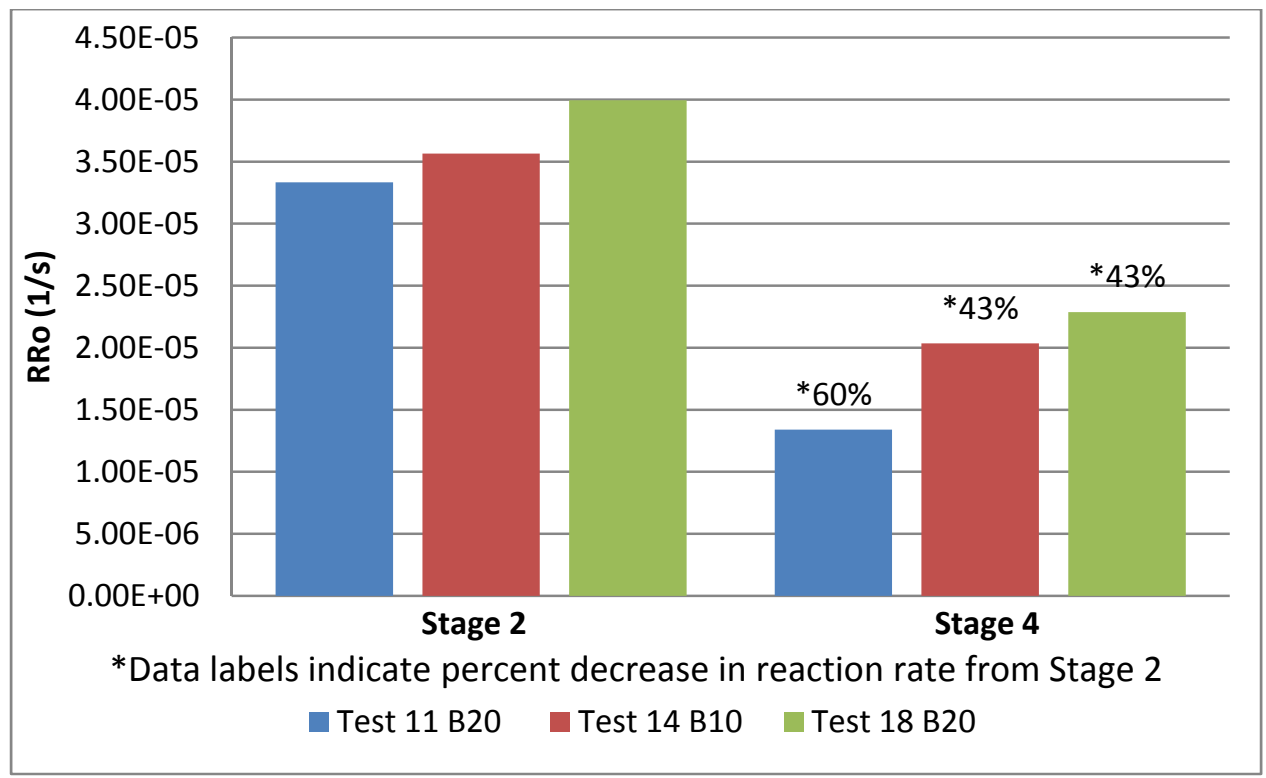

Figure 4.22: ISL loading reaction rate comparison for Point $A$ tests

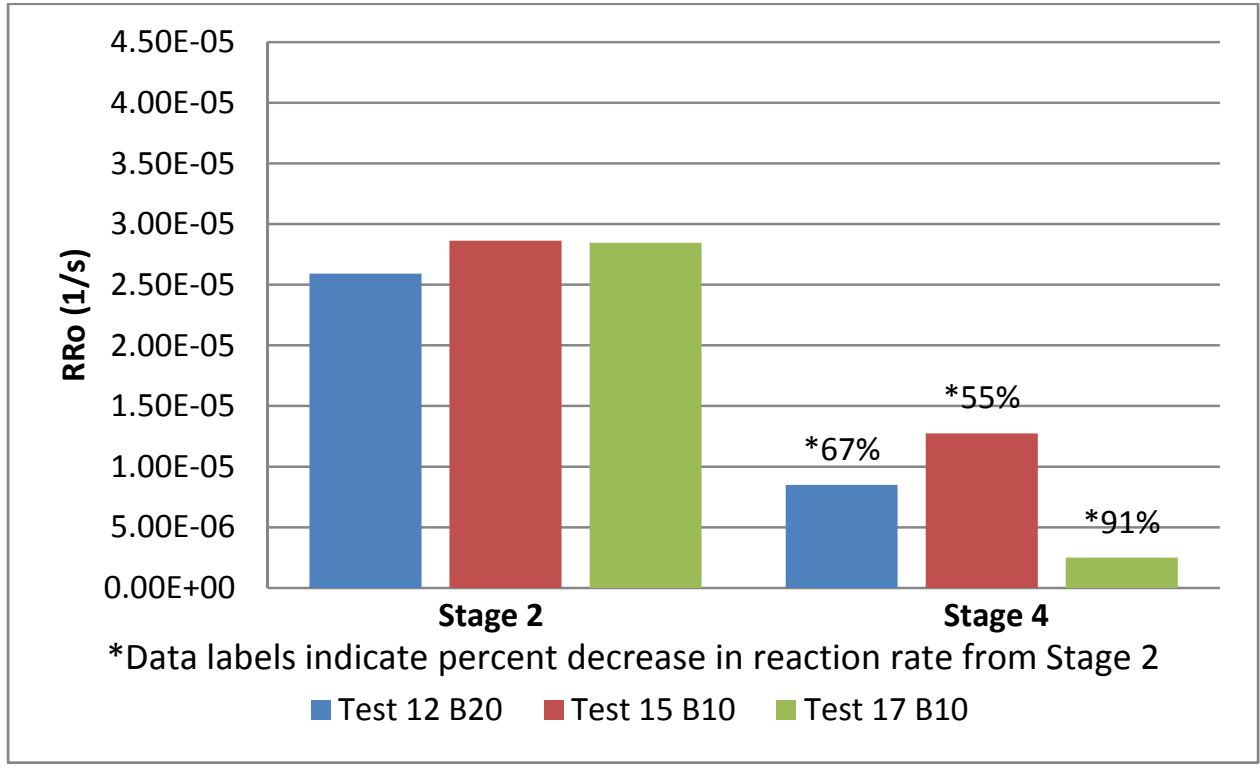

Figure 4.23: ISL loading reaction rate comparison for Point $F$ tests 


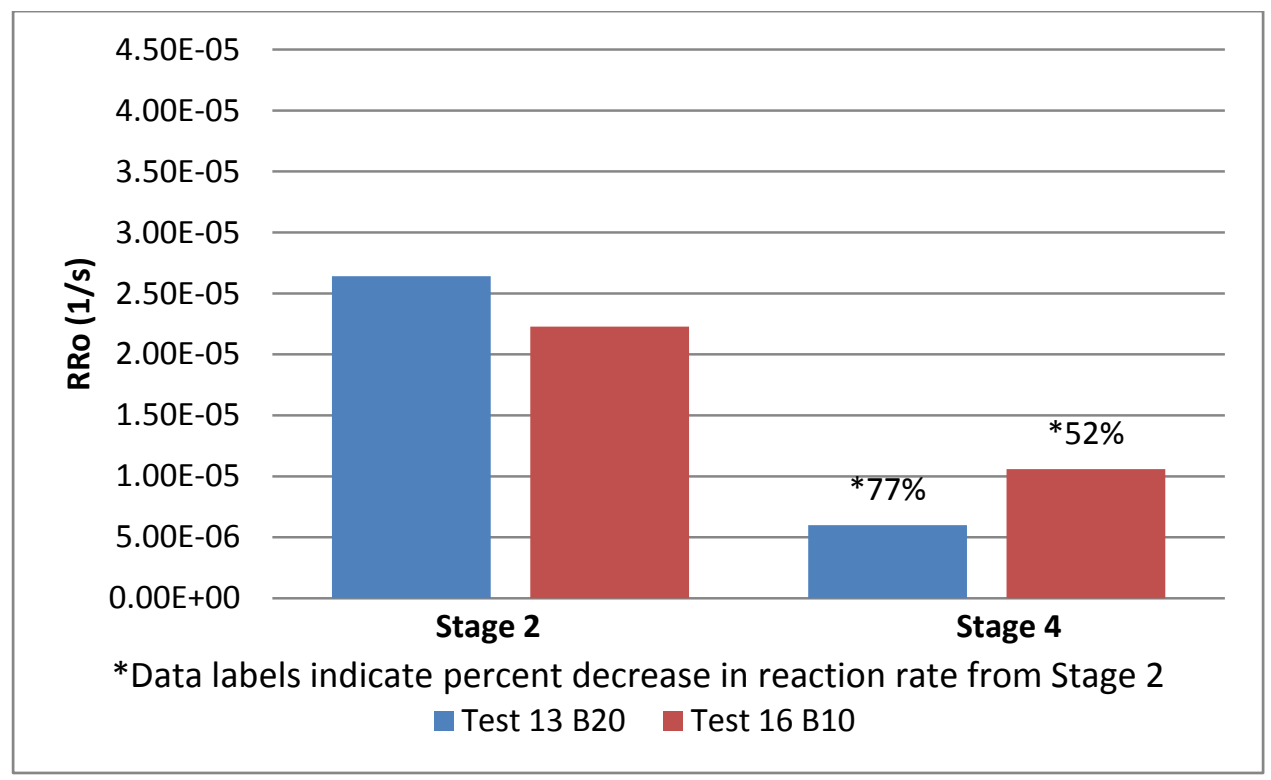

Figure 4.24: ISL loading reaction rate comparison for Point $F$ tests

The reaction rates shown in Table 4.3 are higher after passive oxidation during Point A tests. The amount of PM is oxidized during this passive oxidation point is less than point F or $\mathrm{H}$ tests. During Tests 11, 17, and 18 an exhaust leak to the bypass line was noticed and would inflate the PM oxidized and reaction rates for these tests. The exhaust diverted to the bypass line during these tests was accounted for by multiplying the actual volumetric flow rates by $87 \%, 87 \%$, and $80 \%$ respectively. For details on how these values were determined see section 4.7 . 


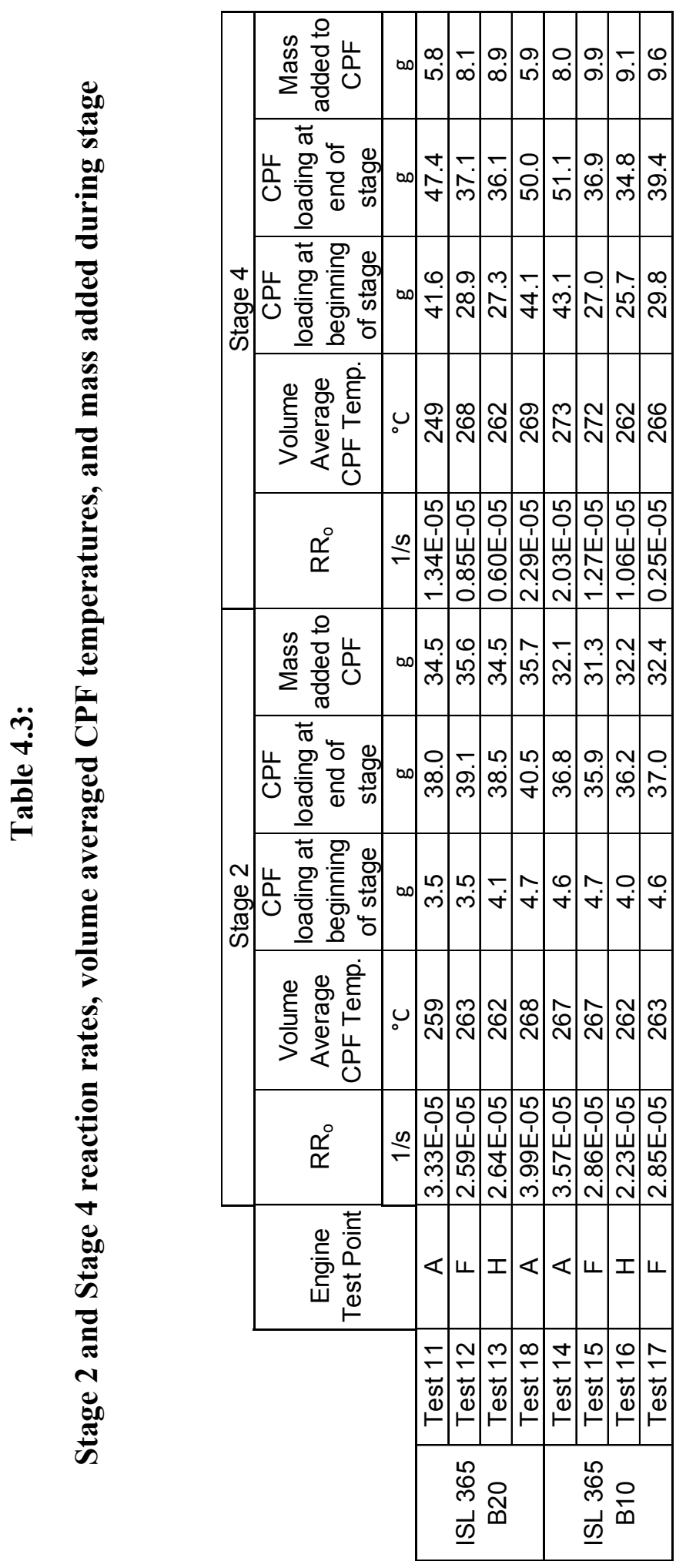




\subsection{Experimental Sensor Results}

Experimental sensor inputs may be beneficial to aftertreatment system model development. Models are used to simulate detailed chemical processes and reactions taking place in the aftertreatment system as the engine is operated. Emissions, PM mass retained in the $\mathrm{CPF}$, and temperature data collected during testing is used to calibrate a 1$\mathrm{D}$ CPF model so that it accurately reflects experimental results. Additional efforts are being made to create a sensor model which may be able to accurately predict the state of the aftertreatment system with a minimum amount of sensor inputs.

Knowing the engine out PM concentration as it varies over time with changing speed and load would be a beneficial input, along with temperature and gaseous concentrations of $\mathrm{NO}_{2}$, to accurately predict the PM mass retained in the CPF. These inputs will help to accurately calibrate a model, and may be used to improve state estimation strategies of the $\mathrm{CPF}$.

A sensor that could directly measure the PM mass retained within the CPF could be even more accurate and require less state estimation by a model. Improved state estimation will lead to improved control strategies of the engine and CPF regeneration to decrease fuel usage. Work continues with a range of new technology to accurately determine the PM mass retained in the CPF to improve control strategies on OEM equipment in the future.

\subsubsection{FST RF-DPF PM Mass Retained Sensors}

Multiple generations of RF-DPF PM mass retained sensors were tested on the ISL rated at $365 \mathrm{hp}$. The first generation of testing resulted in an initial calibration which appeared promising. Figure 4.26 shows results for two RF measurements over CPF loading engine operating conditions of $2100 \mathrm{RPM}$ and $200 \mathrm{Nm}$. Gravimetric measurements of the CPF were used to construct the curve shown red in Figure 4.26 by assuming a linear increase of PM loading from the beginning to the end of the testing. RF signal varies based on the temperature of the CPF, the amount of ash retained in the CPF, and the amount of PM retained in the CPF. The amount of ash retained in the CPF is assumed constant. Calibration RF data is collected over a range of operation temperatures $\left(260-410{ }^{\circ} \mathrm{C}\right)$ with a range of PM loadings $(0-2.6 \mathrm{~g} / \mathrm{L})$. Details on the RF-DPF sensor calibration data collection may be seen in Appendix G. This RF calibration data is then used to create a set of RF loading versus temperature curves. The dependency of the RF signal on temperature and PM loading between the curves is interpolated. An example of how the RF signal varies depending on CPF loading and temperature is shown in Figure 4.25. 


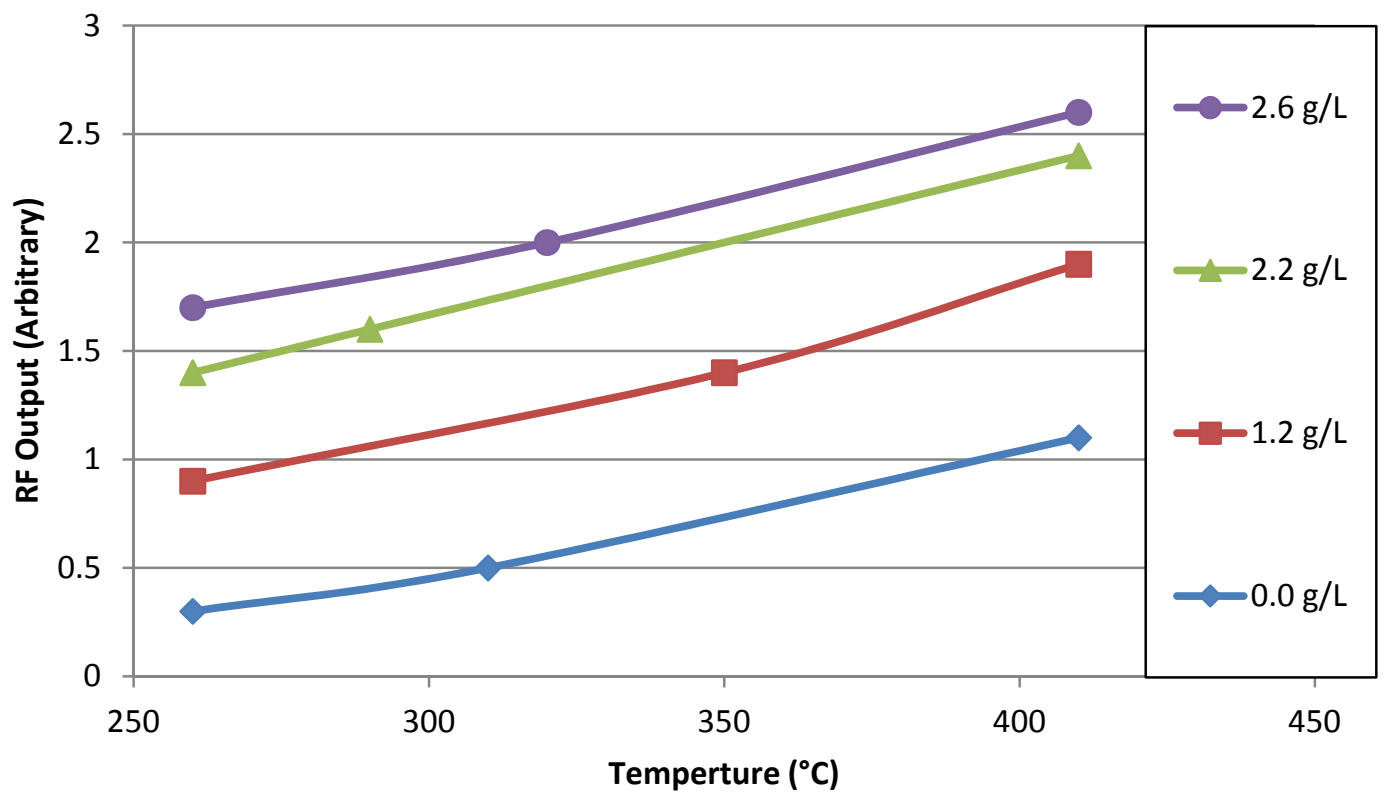

Figure 4.25: Example RF sensor calibration used to correlate RF output to CPF PM mass retained depending on the mass retained and temperature

The calibration was completed by Alex Sappok of FST. Additional tests showed that while the RF signal displayed the proper increasing value while loading the filter, it did not have a repeatable value from test to test. A changing offset shifted the signal as shown in Figure 4.27. Figure 4.27 shows the raw unprocessed RF signal. The RF data from these tests was not processed with a calibration due to the observed shift in the signal. Each of these tests resulted in similar CPF temperatures and ended at approximately the same loading.

This system used relatively high frequencies and, coupled with interactions of the RF signal with the large number of conducting elements in the CPF and DOC (thermocouples, sampling probes), caused in-accuracies of the calibration over the full measurement range. 
— Gravimetric PM -6hr PMLoad —2hr PMLoad

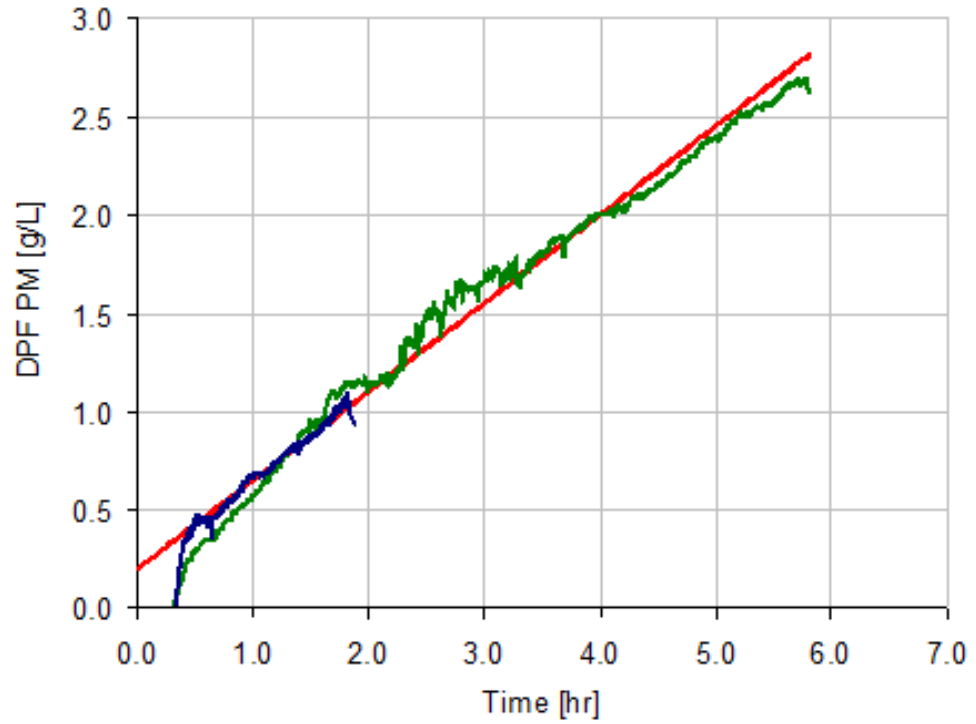

Figure 4.26: Comparison of RF output with gravimetric measurements of CPF PM load [30]

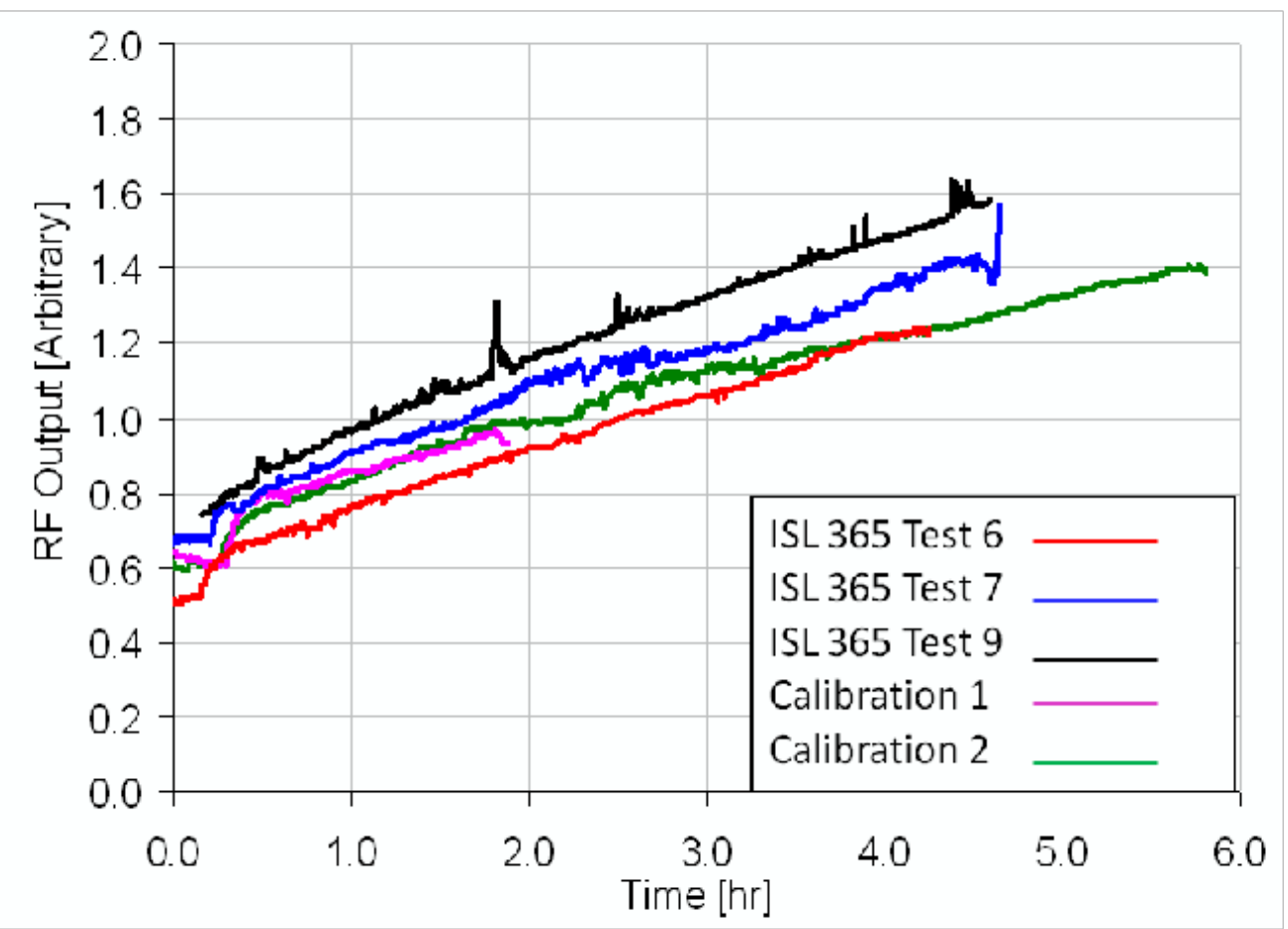

Figure 4.27: Raw RF output during passive oxidation testing. Each test ended at nearly the same CPF loading [30] 
The second RF system utilized lower frequencies to ensure the first resonant mode is captured in the resonance curve. Results from the use of this lower frequency sensor showed improvement, but still appeared to have an offset from test to test. This variation in signal for a given loading and temperature has been determined to be due to the conducting elements used during passive oxidation testing.

FST RF-DPF testing is being conducted on the ISL rated at $425 \mathrm{hp}$ without thermocouples, emissions probe, or differential pressure probe in place. These tests will then be repeated with the test equipment in place to gather additional data.

\subsubsection{Pegasor Sensor Results}

The test conducted to evaluate this sensor may be broken into four parts depending on engine operating variables being set to change the engine out PM concentration during each part.

The first part of the test consisted of operating the engine at $2090 \mathrm{rpm}$ and $245 \mathrm{Nm}$ and allowing the ECM to control all other variables for 30 minutes. PSD data was collected upstream of the DOC (UDOC). Three PM samples were collected UDOC to determine PM concentration by mass.

Fluctuation was noticed in the Pegasor sensor output during the first part of testing. During the second part, in order to verify that this fluctuation was due to an actual change in engine out PM concentration, the EGR was set to a constant value resulting in a steady PM sensor output for 5 minutes. This result suggests that the fluctuation in the Pegasor sensor was due to actual fluctuations in the PM concentration due to rapid changes in the EGR valve position and VGT boost pressure. These rapid changes in EGR and VGT are expected from prior testing. An attempt was made to cycle the EGR from computer controlled to a set value, but resulted in the VGT compensating for the fixed EGR value. It was decided to proceed with the test.

During the third and fourth parts of the test, the PM concentration out of the engine was increased by decreasing the fuel rail pressure from 1330 bar to 1100 bar and then to 900 bar for approximately 30 minutes at each pressure. PSD data and three PM samples were collected UDOC for each of these parts of the test.

Table 4.4 shows selected engine operating conditions and the average Pegasor sensor output for each part of the test. Figure 4.28 shows the UDOC PSD data by number and volume after being corrected for dilution ratio and thermodenuder losses. Figure 4.29 shows the pressure drop profile across the $\mathrm{CPF}$ and the Pegasor sensor output. Labels indicate the average Pegasor reading and PM concentration by mass during the three loading parts (Part 1, 3, and 4). Figure 4.30 shows the averaged PM concentration by mass versus the averaged PM concentration by the Pegasor sensor output during each loading part. The linear slope indicates that the difference between readings may be corrected by a multiplication factor, and a linear trend line is shown with the corresponding equation. 
Table 4.4:

Processed values of temperature, flow rate, and PM concentration for each test part

\begin{tabular}{|l|c|c|c|c|c|c|c|c|}
\hline \multicolumn{1}{|c|}{ Variable } & Speed & Load & $\begin{array}{c}\text { Rail } \\
\text { Pressure }\end{array}$ & $\begin{array}{c}\text { DOC inlet } \\
\text { temp. }\end{array}$ & $\begin{array}{c}\text { Exhaust } \\
\text { Volumetric } \\
\text { flow rate }\end{array}$ & $\begin{array}{c}\text { Exhaust } \\
\text { Mass flow } \\
\text { rate }\end{array}$ & $\begin{array}{c}\text { Engine out } \\
\text { PM Conc. } \\
\text { By Sample } \\
\text { Mass }\end{array}$ & $\begin{array}{c}\text { Engine out } \\
\text { PM Conc. By } \\
\text { Pegasor } \\
\text { Average }\end{array}$ \\
\hline Test/Units & $\mathrm{rpm}$ & $\mathrm{Nm}$ & $\mathrm{bar}$ & ${ }^{\circ} \mathrm{C}$ & $\mathrm{scm} / \mathrm{sec}$ & $\mathrm{kg} / \mathrm{min}$ & $\mathrm{mg} / \mathrm{scm}$ & $\mathrm{mg} / \mathrm{m}^{3}$ \\
\hline 425 ULSD & 2090 & 245 & 1330 & 257 & 0.182 & 13.2 & 10.9 & 8.9 \\
\hline
\end{tabular}

\begin{tabular}{|c|c|c|c|c|c|c|c|c|}
\hline \multicolumn{1}{|c|}{ Variable } & Speed & Load & $\begin{array}{c}\text { Rail } \\
\text { Pressure }\end{array}$ & $\begin{array}{c}\text { DOC inlet } \\
\text { temp. }\end{array}$ & $\begin{array}{c}\text { Exhaust } \\
\text { Volumetric } \\
\text { flow rate }\end{array}$ & $\begin{array}{c}\text { Exhaust } \\
\text { Mass flow } \\
\text { rate }\end{array}$ & $\begin{array}{c}\text { Engine out } \\
\text { PM Conc. } \\
\text { By Sample } \\
\text { Mass }\end{array}$ & $\begin{array}{c}\text { Engine out } \\
\text { PM Conc. By } \\
\text { Pegasor } \\
\text { Average }\end{array}$ \\
\hline Test/Units & $\mathrm{rpm}$ & $\mathrm{Nm}$ & bar & ${ }^{\circ} \mathrm{C}$ & $\mathrm{scm} / \mathrm{sec}$ & $\mathrm{kg} / \mathrm{min}$ & $\mathrm{mg} / \mathrm{scm}$ & $\mathrm{mg} / \mathrm{m}^{3}$ \\
\hline 425 ULSD & 2090 & 245 & 1330 & 255 & 0.195 & 14.1 & $\mathrm{~N} / \mathrm{A}$ & 5.3 \\
\hline
\end{tabular}

\begin{tabular}{|c|c|c|c|c|c|c|c|c|}
\hline \multicolumn{9}{|c|}{ Part 3 Loading with Fixed and Lowered Rail Pressure } \\
\hline Variable & Speed & Load & $\begin{array}{c}\text { Rail } \\
\text { Pressure }\end{array}$ & $\begin{array}{l}\text { DOC inlet } \\
\text { temp. }\end{array}$ & $\begin{array}{c}\text { Exhaust } \\
\text { Volumetric } \\
\text { flow rate }\end{array}$ & $\begin{array}{c}\text { Exhaust } \\
\text { Mass flow } \\
\text { rate }\end{array}$ & $\begin{array}{l}\text { Engine out } \\
\text { PM Conc. } \\
\text { By Sample } \\
\text { Mass }\end{array}$ & $\begin{array}{c}\text { Engine out } \\
\text { PM Conc. By } \\
\text { Pegasor } \\
\text { Average }\end{array}$ \\
\hline Test/Units & $\mathrm{rpm}$ & $\mathrm{Nm}$ & bar & ${ }^{\circ} \mathrm{C}$ & $\mathrm{scm} / \mathrm{sec}$ & $\mathrm{kg} / \mathrm{min}$ & $\mathrm{mg} / \mathrm{scm}$ & $\mathrm{mg} / \mathrm{m}^{3}$ \\
\hline 425 ULSD & 2090 & 245 & 1100 & 271 & 0.178 & 12.9 & 20.7 & 14.2 \\
\hline
\end{tabular}

\begin{tabular}{|c|c|c|c|c|c|c|c|c|}
\hline \multicolumn{2}{|c|}{ Part 4 Loading with Fixed and Lowered Rail Pressure } \\
\hline Variable & Speed & Load & $\begin{array}{c}\text { Rail } \\
\text { Pressure }\end{array}$ & $\begin{array}{c}\text { DoC inlet } \\
\text { temp. }\end{array}$ & $\begin{array}{c}\text { Exhaust } \\
\text { Volumetric } \\
\text { flow rate }\end{array}$ & $\begin{array}{c}\text { Exhaust } \\
\text { Mass flow } \\
\text { rate }\end{array}$ & $\begin{array}{c}\text { Engine out } \\
\text { PM Conc. } \\
\text { By Sample } \\
\text { Mass }\end{array}$ & $\begin{array}{c}\text { Engine out } \\
\text { PM Conc. By } \\
\text { Pegasor } \\
\text { Average }\end{array}$ \\
\hline Test/Units & $\mathrm{rpm}$ & $\mathrm{Nm}$ & $\mathrm{bar}$ & ${ }^{\circ} \mathrm{C}$ & $\mathrm{scm} / \mathrm{sec}$ & $\mathrm{kg} / \mathrm{min}$ & $\mathrm{mg} / \mathrm{scm}$ & $\mathrm{mg} / \mathrm{m}^{3}$ \\
\hline 425 ULSD & 2090 & 245 & 900 & 279 & 0.178 & 12.9 & 31.2 & 18.2 \\
\hline
\end{tabular}



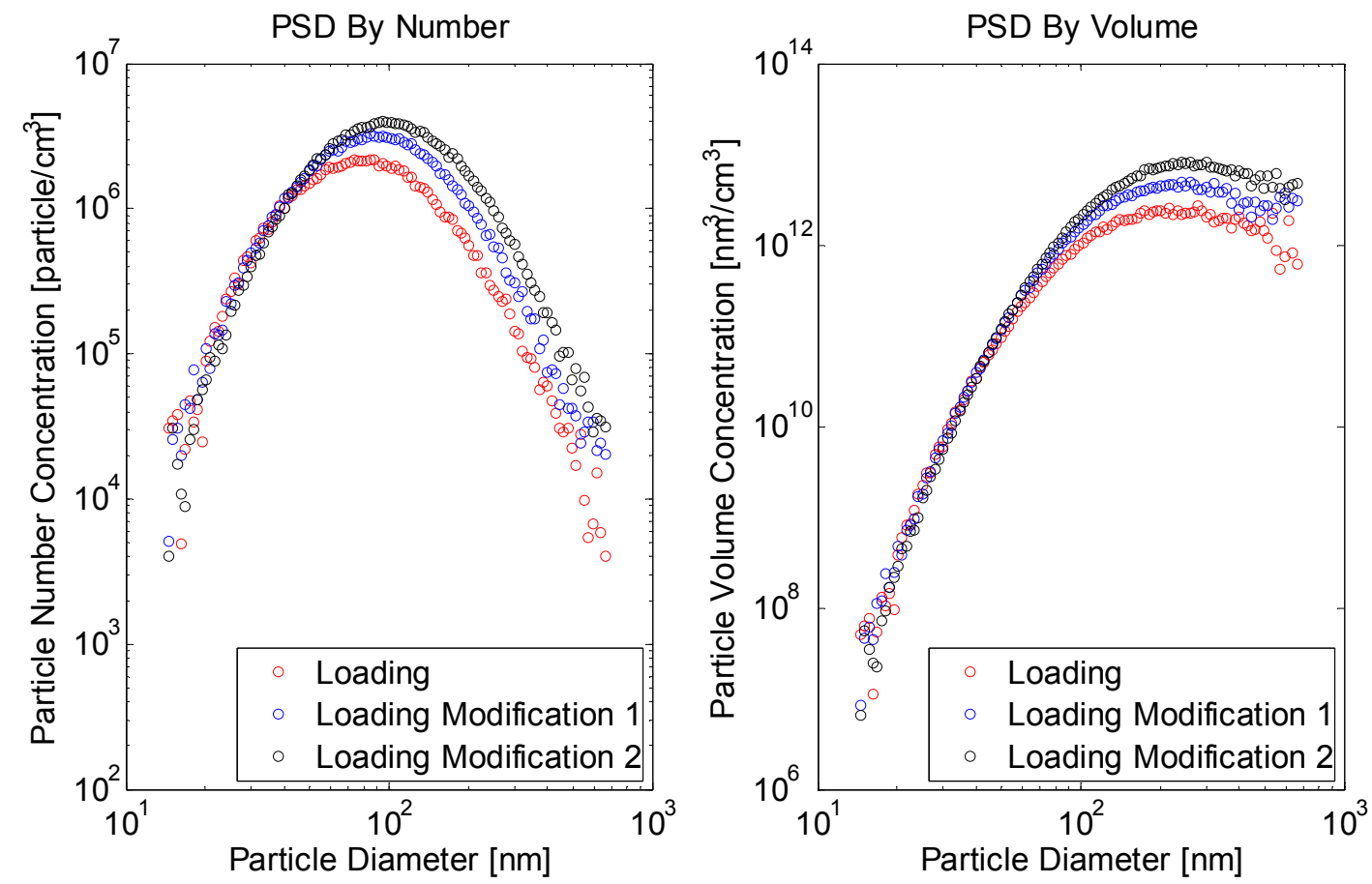

Figure 4.28: PSD data by number and by volume for the three loading parts of the test

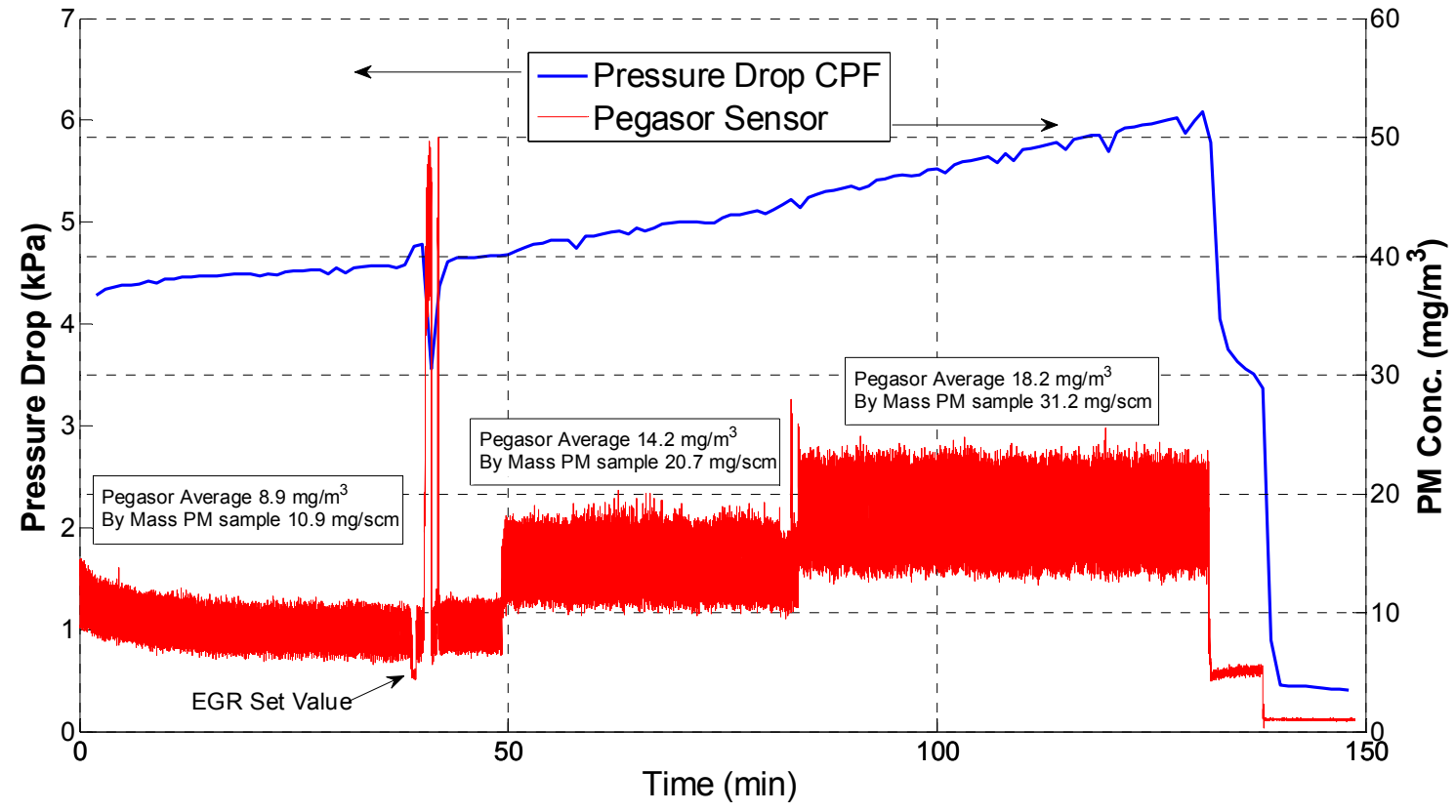

Figure 4.29: Pressure drop across the CPF and Pegasor sensor output during testing, averaged PM concentrations during each part of the test shown 


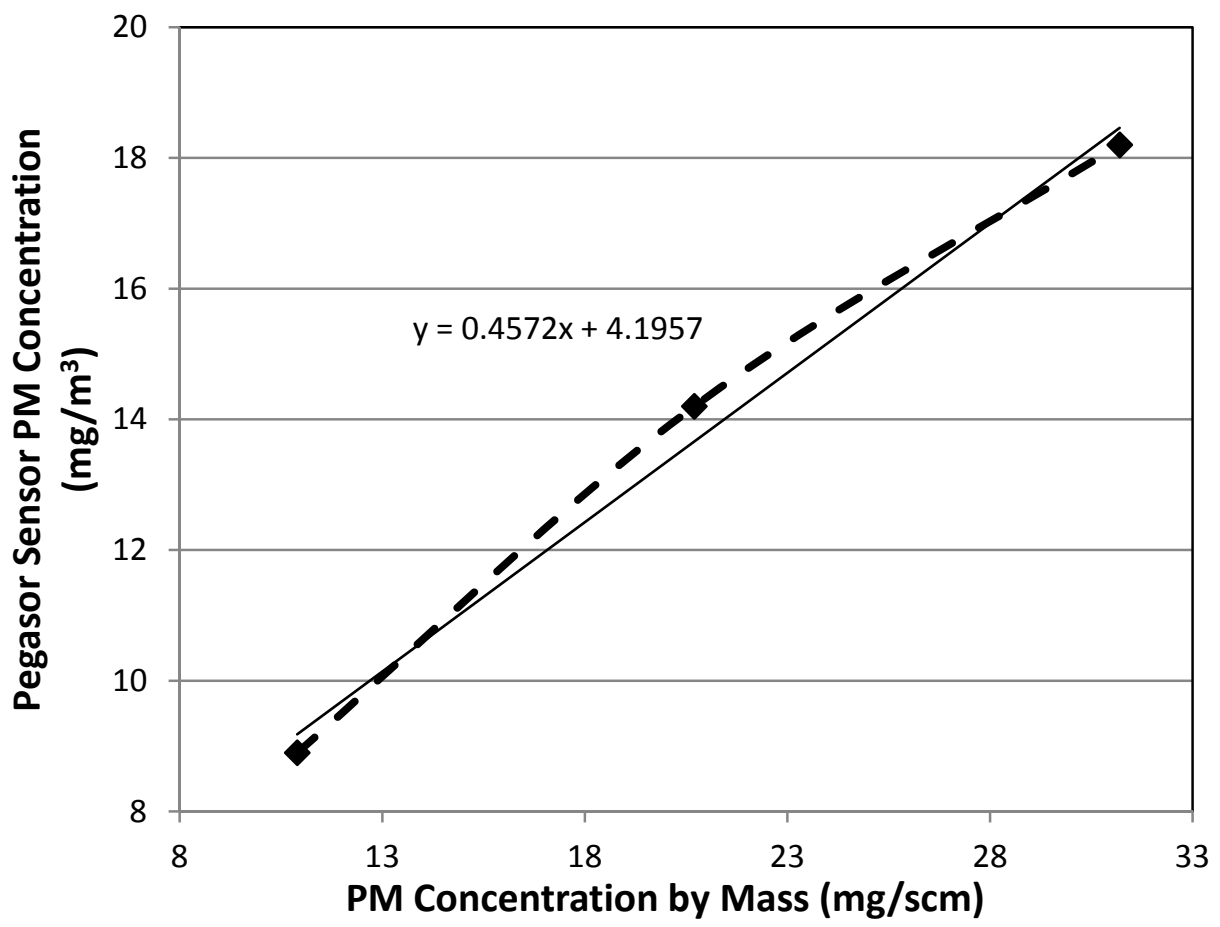

Figure 4.30: PM concentration by mass vs. PM concentration by Pegasor sensor output

The offset shown in Figure 4.30 between PM concentration determined by PM sample mass and PM concentration determined by the Pegasor sensor may be due to semi volatiles absorbing onto the glass PM filter samples.

Additional testing with the above described sensors and with additional PM sensors is planned to take place to increase accuracy of calibrations used for each sensor and further development. These sensors may be used along with modeling to optimize control strategies of future diesel engines.

\subsection{CPF Resistance Analysis}

In order to assist the modeling effort in correctly capturing the flow and pressure drop characteristics during passive oxidation testing, the changing resistance of exhaust gasses as they travel through the CPF has been plotted over time. This plot is expected to increase during loading and decrease during oxidation, and then increase during post loading. The temperature changes which occur during CPF weighing, and during the transition to a stable CPF temperature after weighing, do not reflect the changing resistance of the CPF. Many thermocouple combinations have been tried determine the actual volumetric flow rates to eliminate sudden changes in the resistance calculation. The use of thermocouple $\mathrm{C} 3$ at the $190 \mathrm{~mm}$ diameter radial location $12 \mathrm{~mm}$ into the inlet face of the CPF has been used for loading stages of each of the biodiesel tests conducted (Figure 3.3). Using the same thermocouple for the passive oxidation portion of the tests as was used during loading resulted in a rapid change in the calculated CPF resistance 
when transitioning from loading to passive oxidation and then back to loading. Thermocouple C8 at the $244 \mathrm{~mm}$ radial location $50 \mathrm{~mm}$ into the face of the CPF has been used for the passive oxidation stage of Point A tests consisting of an average CPF temperature of $250.5 \pm 6.5{ }^{\circ} \mathrm{C}$ and an exhaust mass flow rate of $5.9 \pm 0.3 \mathrm{~kg} / \mathrm{min}$. This thermocouple represented approximately $10{ }^{\circ} \mathrm{C}$ cooler temperature than $\mathrm{C} 3$ during passive oxidation portion and increased the calculated resistance. This resulted in a continuous resistance over the entire test. Thermocouple $\mathrm{C} 4$ at the $244 \mathrm{~mm}$ radial location $12 \mathrm{~mm}$ into the inlet face of the CPF has been used for the passive oxidation stage of Point $\mathrm{F}$ tests consisting of an average CPF temperature of $355 \pm 8{ }^{\circ} \mathrm{C}$ and an exhaust mass flow rate of $7.8 \pm 0.1 \mathrm{~kg} / \mathrm{min}$. Thermocouple $\mathrm{C} 1$ in the center radial location $12 \mathrm{~mm}$ into the inlet face of the CPF has been used for the passive oxidation stage of Point $\mathrm{H}$ tests consisting of an average CPF temperature of $408 \pm 2{ }^{\circ} \mathrm{C}$ and an exhaust mass flow rate of $15.25 \pm 0.15 \mathrm{~kg} / \mathrm{min}$. The use of these thermocouple temperatures to adjust the actual volumetric flow rate resulted in the expected CPF resistance changes over time. Additional work of this type needs to be continued in order to understand the CPF resistance characteristics. Figure $4.31-4.34$ show the CPF resistance plotted versus time for the ISL 365 tests 11-18 with biodiesel. ISL 365 Tests 11 and 18 experienced a stuck baseline valve after Stage 2 loading. In order to correct for the actual volumetric flow rate passing through the CPF a correction factor of $87 \%$ of the measured volumetric flow was used for Test 11 and a correction factor of $83 \%$ of the volumetric flow was used for Test 18 after Stage 2 loading. ISL 365 Test 17 experienced a stuck baseline valve during Stage 4 and a correction factor of $87 \%$ of the measured volumetric flow was used for Stage 4 of this test.

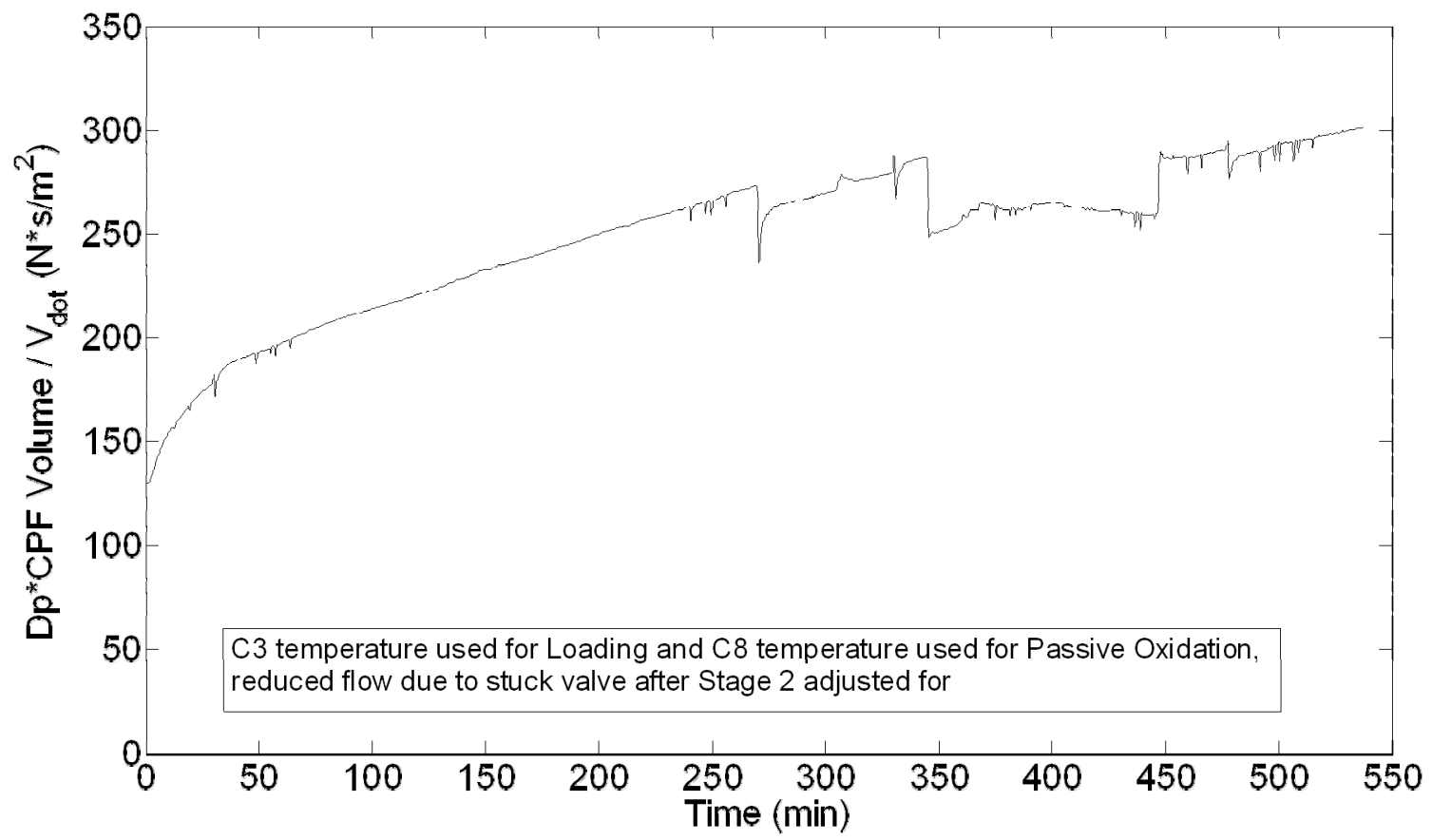

Figure 4.31: CPF resistance during Test 11 Point A with B20 


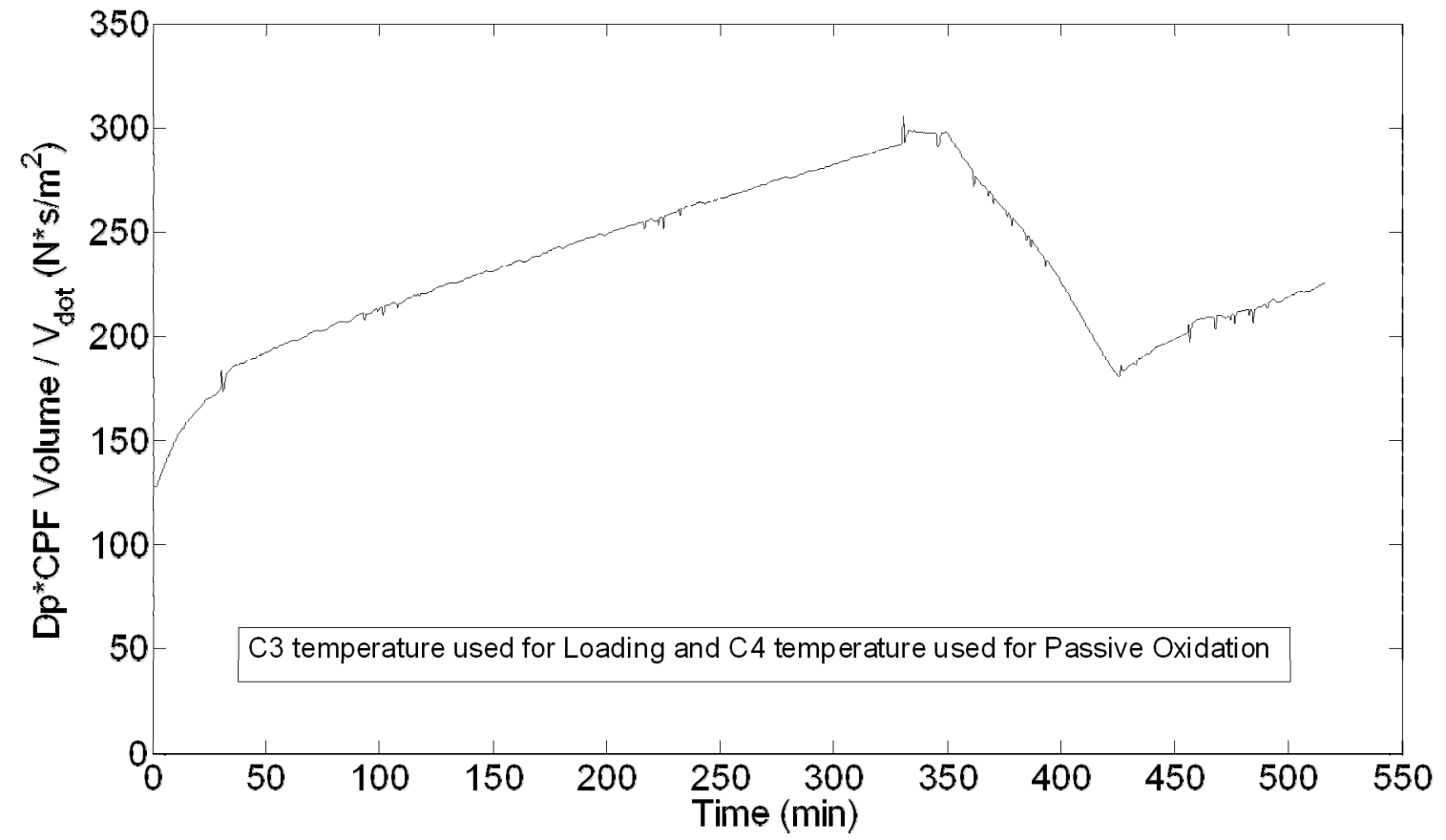

Figure 4.32: CPF resistance during Test 12 Point $\mathrm{F}$ with B20

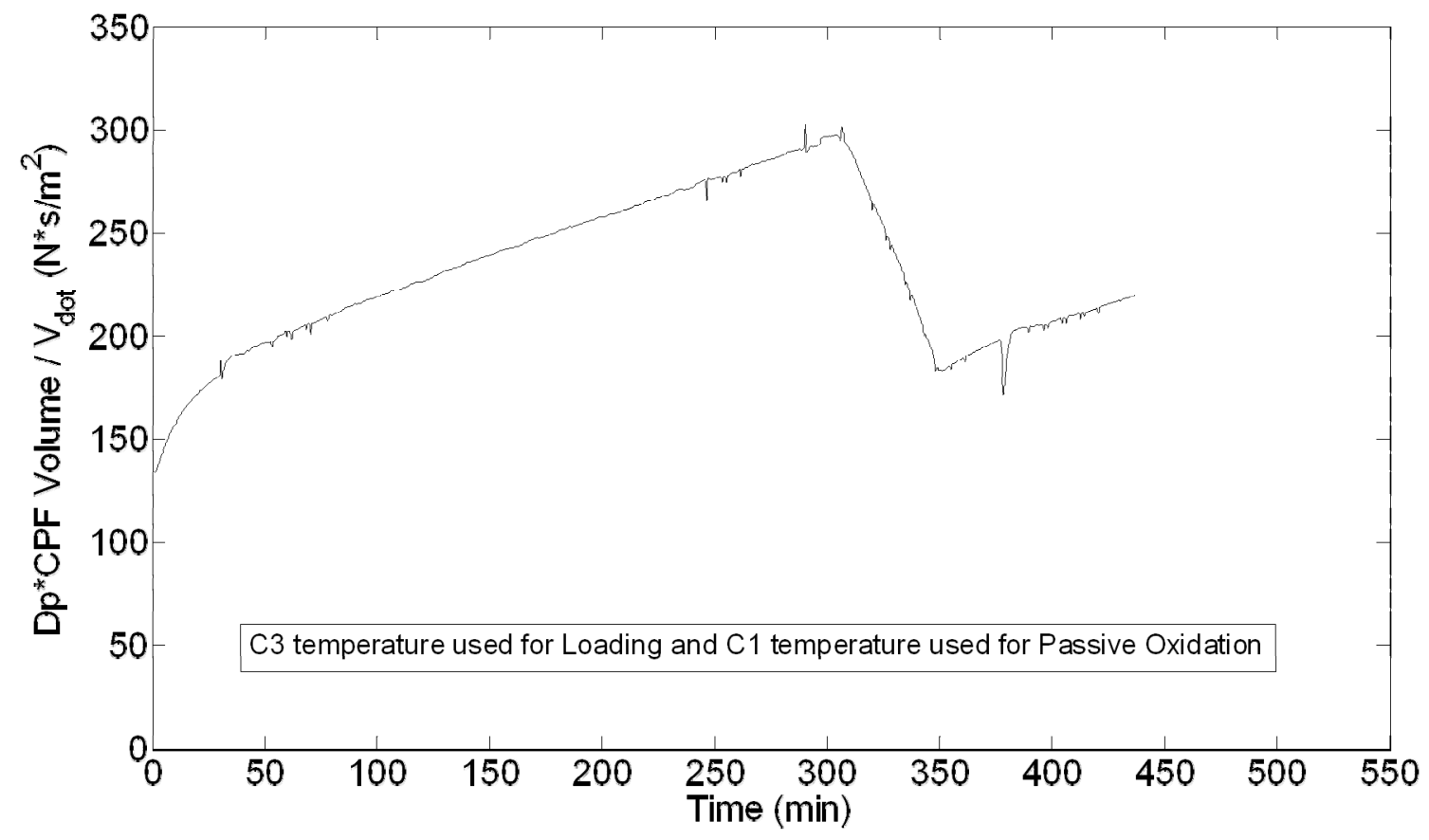

Figure 4.33: CPF resistance during Test 13 Point $\mathrm{H}$ with B20 


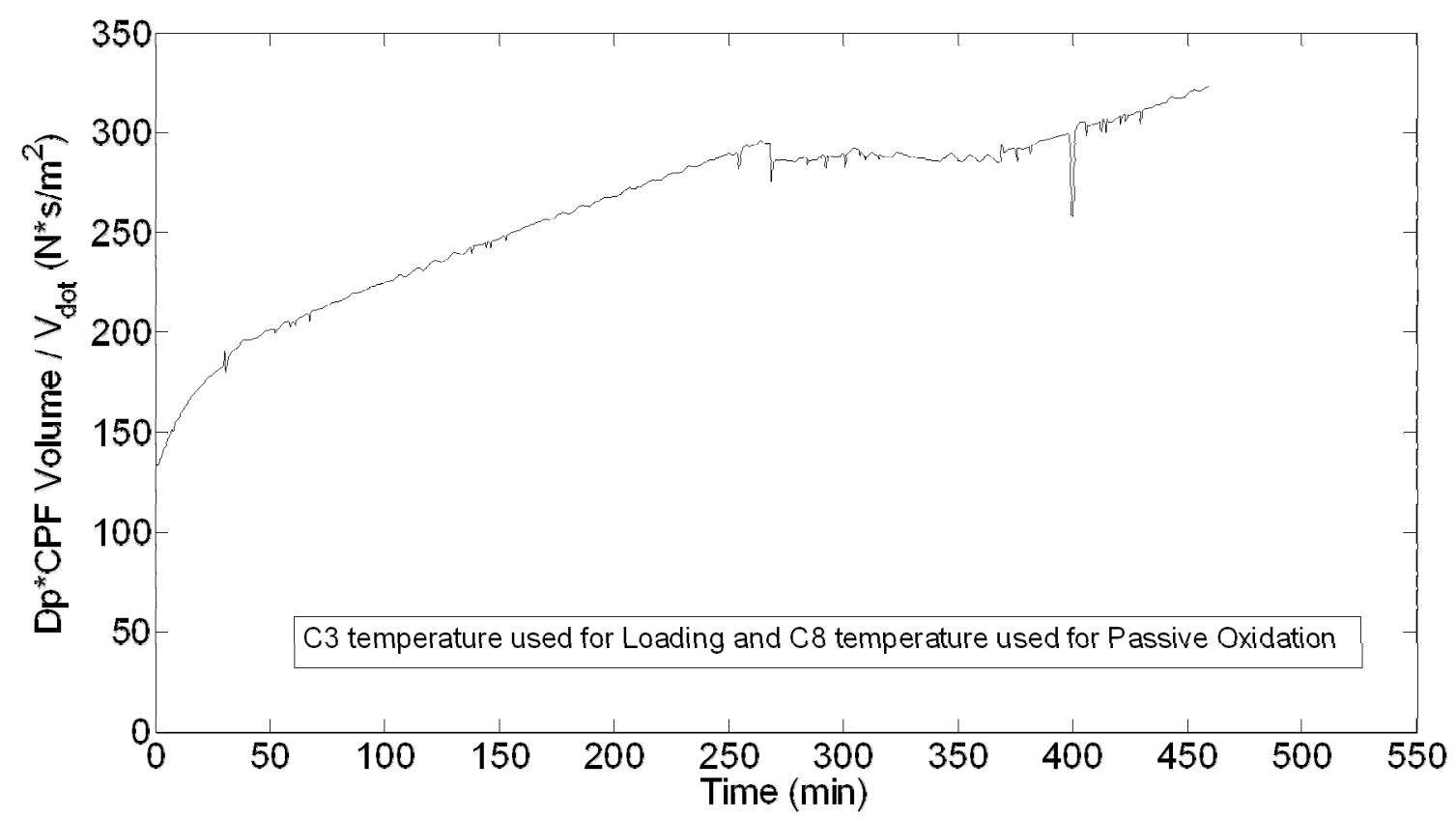

Figure 4.34: CPF resistance during Test 14 Point A with B10

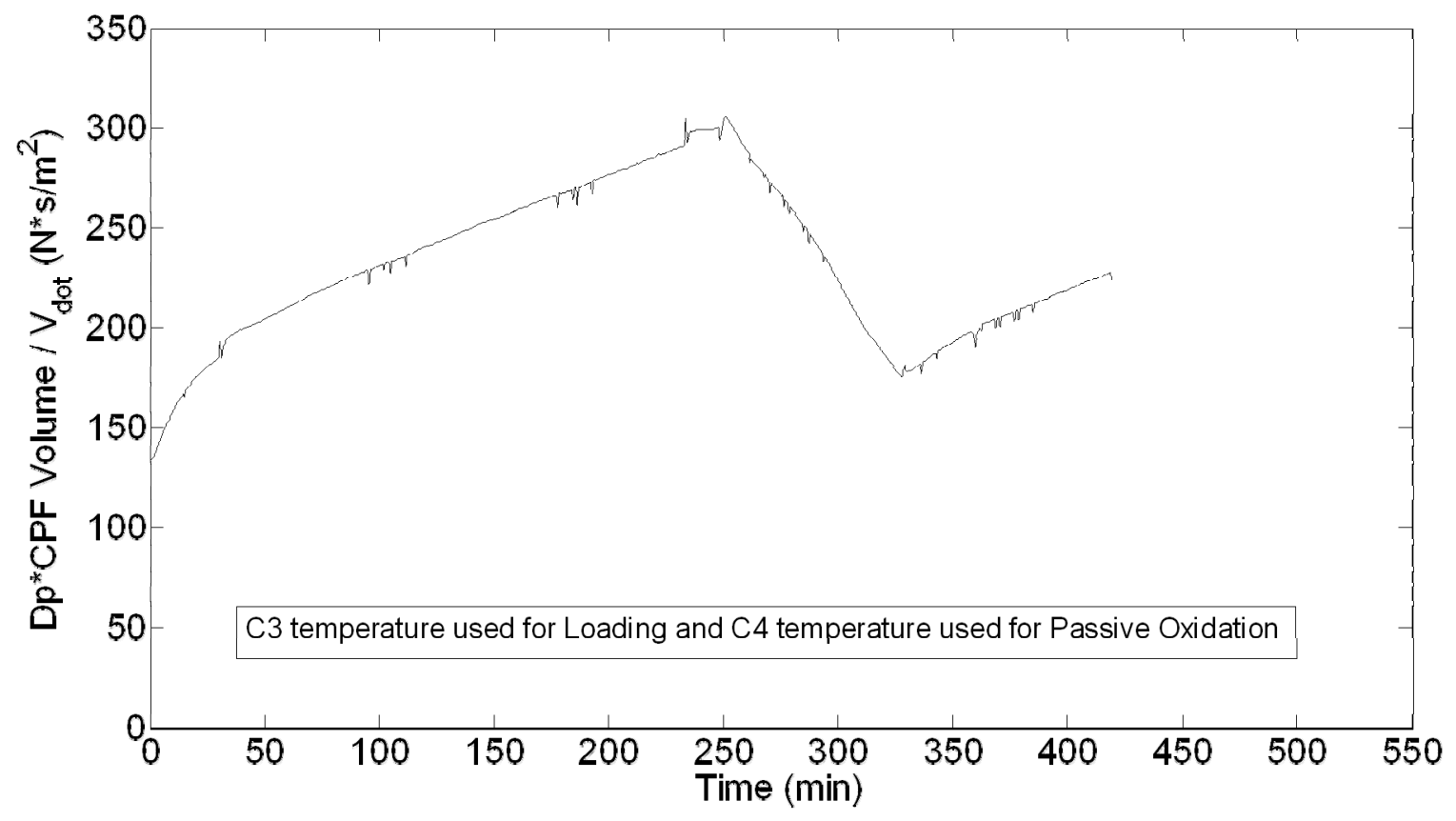

Figure 4.35: CPF resistance during Test 15 Point F with B10 


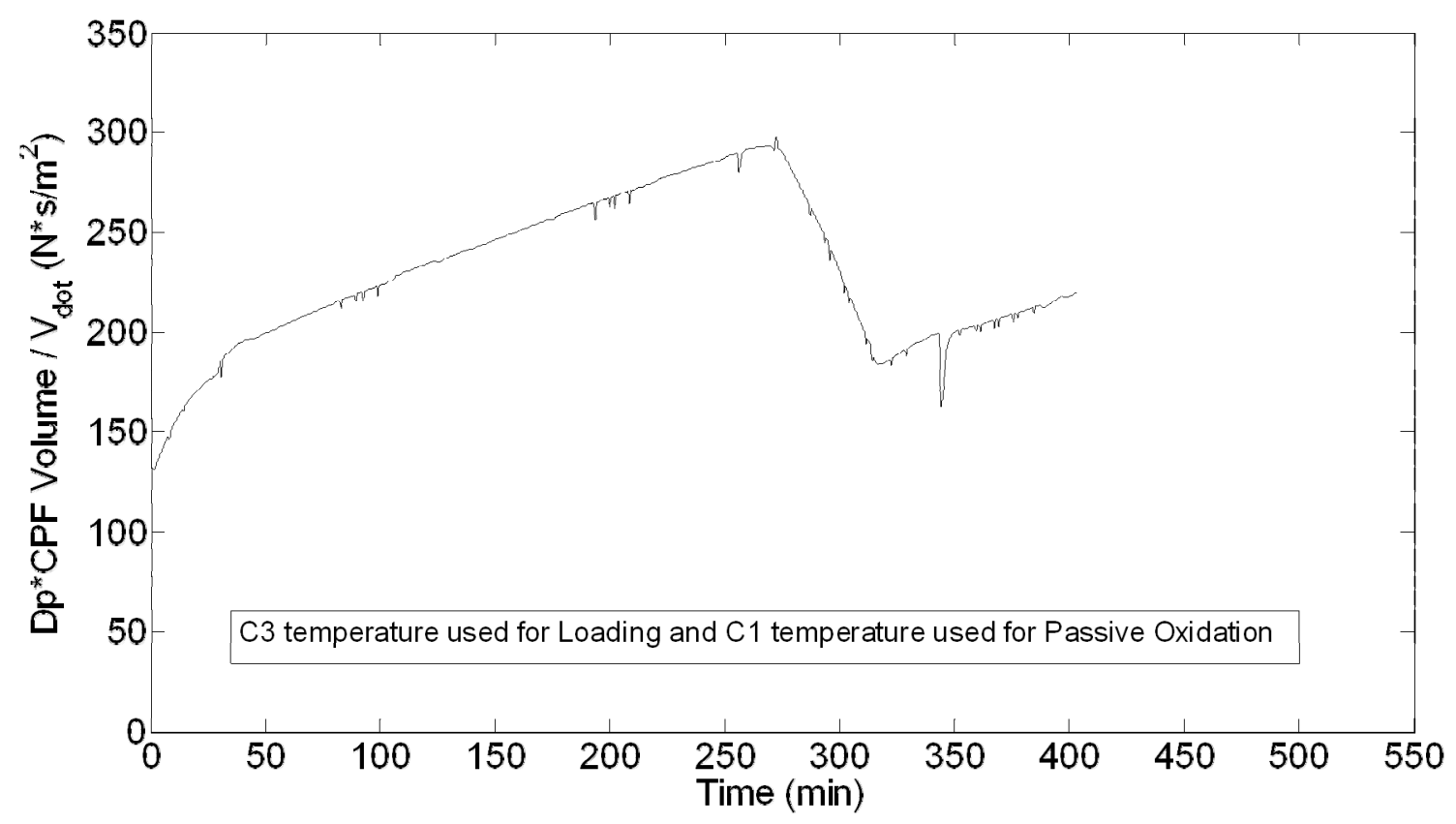

Figure 4.36: CPF resistance during Test 16 Point $H$ with $B 10$

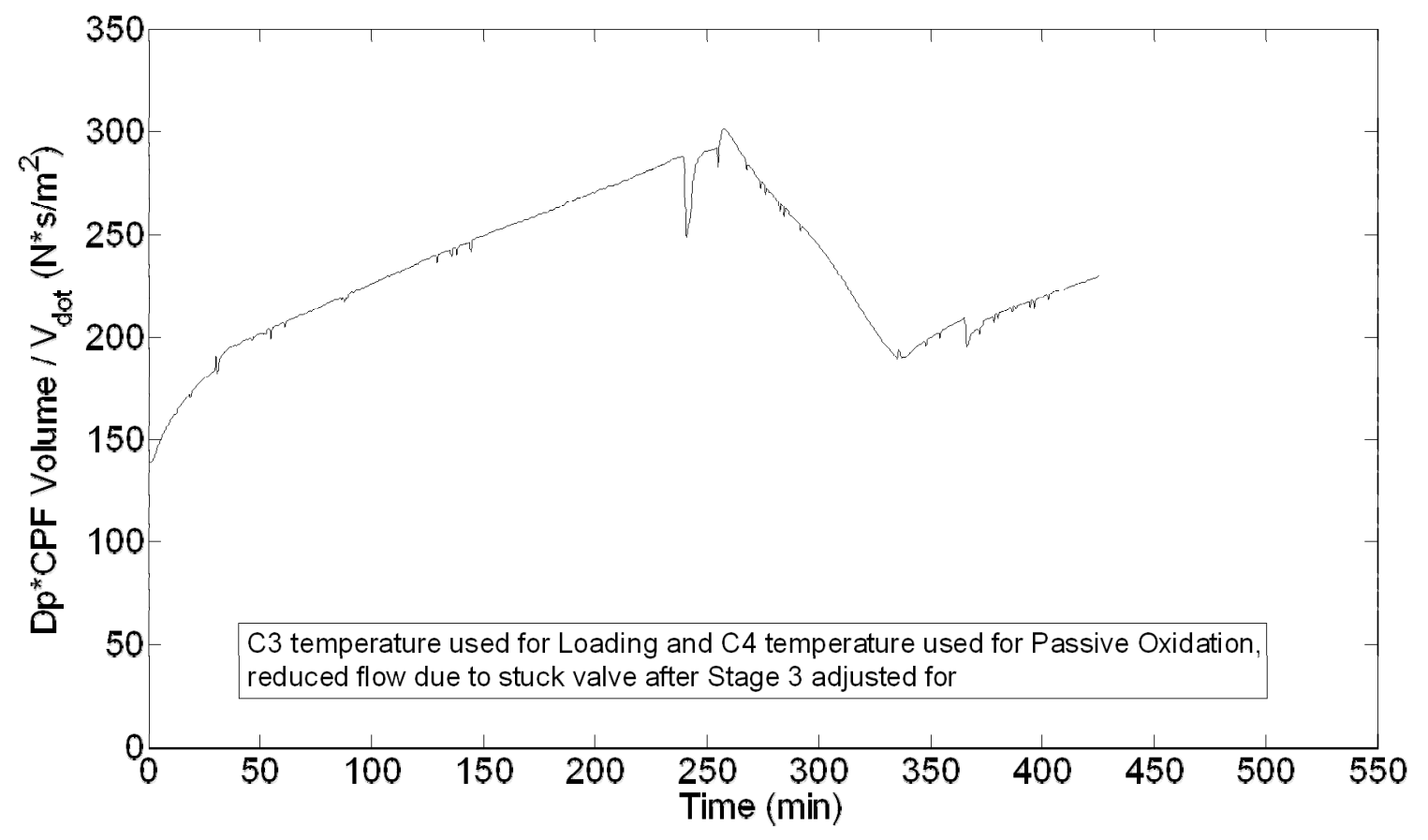

Figure 4.37: CPF resistance during Test 17 Point F with B10 


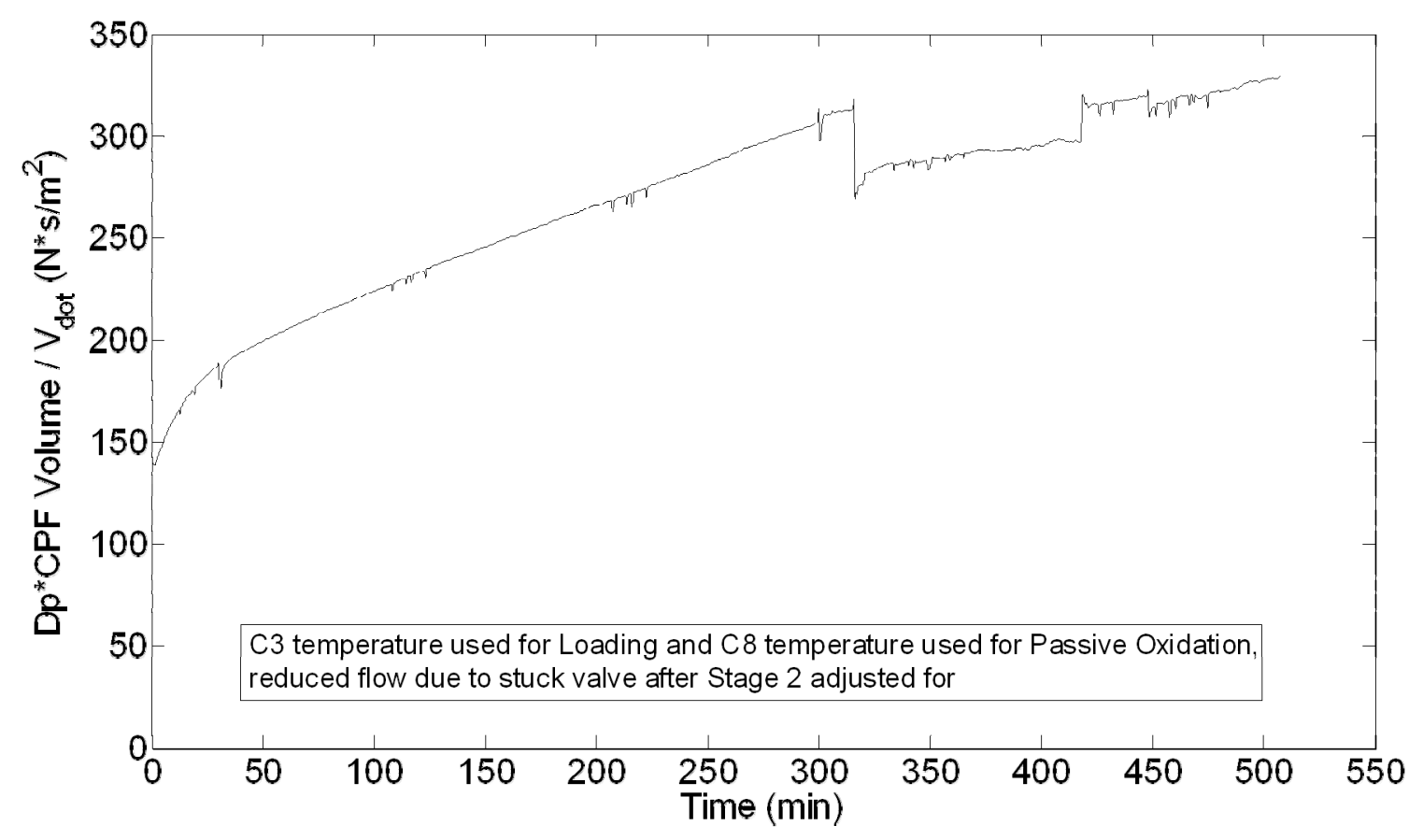

Figure 4.38: CPF resistance during Test 18 Point A with B20

ISL 365 Test 11 and 18 shown in Figure 4.31 and Figure 4.38 respectively each have a drop in resistance value when transitioning from loading to passive oxidation. During each of these tests the by-pass valve stuck open decreasing the actual volumetric flow rate through the aftertreatment system. Additional correction was made for the actual volumetric flow rate resulting in a more continuous resistance plot. Results of this can be seen in Figure 4.39 and Figure 4.40.

Volumetric flow rate correction factors of $87 \%, 80 \%, 87 \%$, and $87 \%$ were used for Test 11 (Figure 4.39) during Ramp-up, Passive Oxidation, Stage 3, and Stage 4 respectively. These correction factors were used to result in continuous resistance over the course of the test.

Volumetric flow rate correction factors of $83 \%, 74 \%, 79 \%$, and $79 \%$ were used for Test 18 (Figure 4.40) during Ramp-up, Passive Oxidation, Stage 3, and Stage 4 respectively. These correction factors were used to result in continuous resistance over the course of the test. The corrected volumetric flows have been used in the calculation of reaction rates for passive oxidation and stage 4 portions of the tests. 


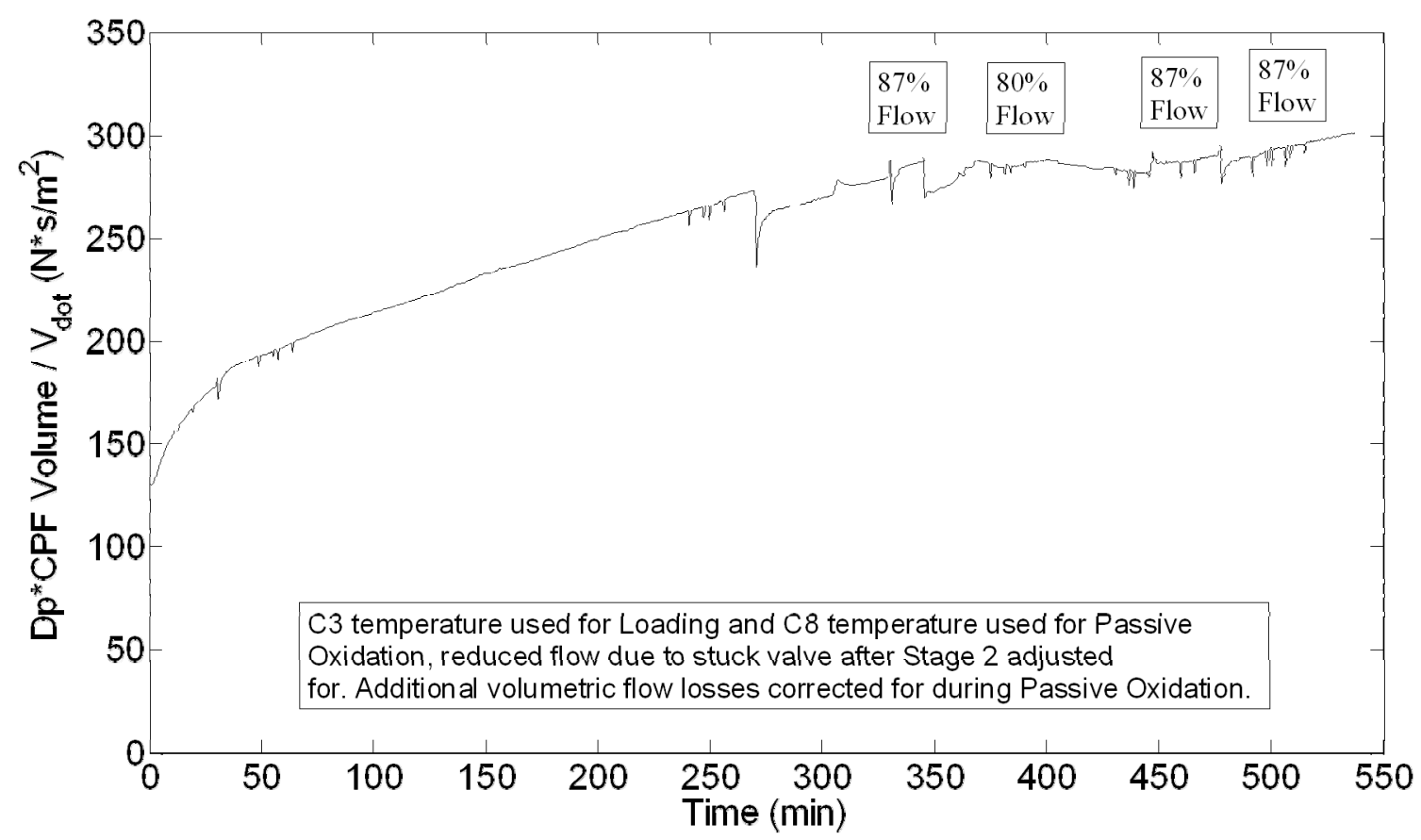

Figure 4.39: CPF corrected resistance during Test 11 Point $A$ with B20

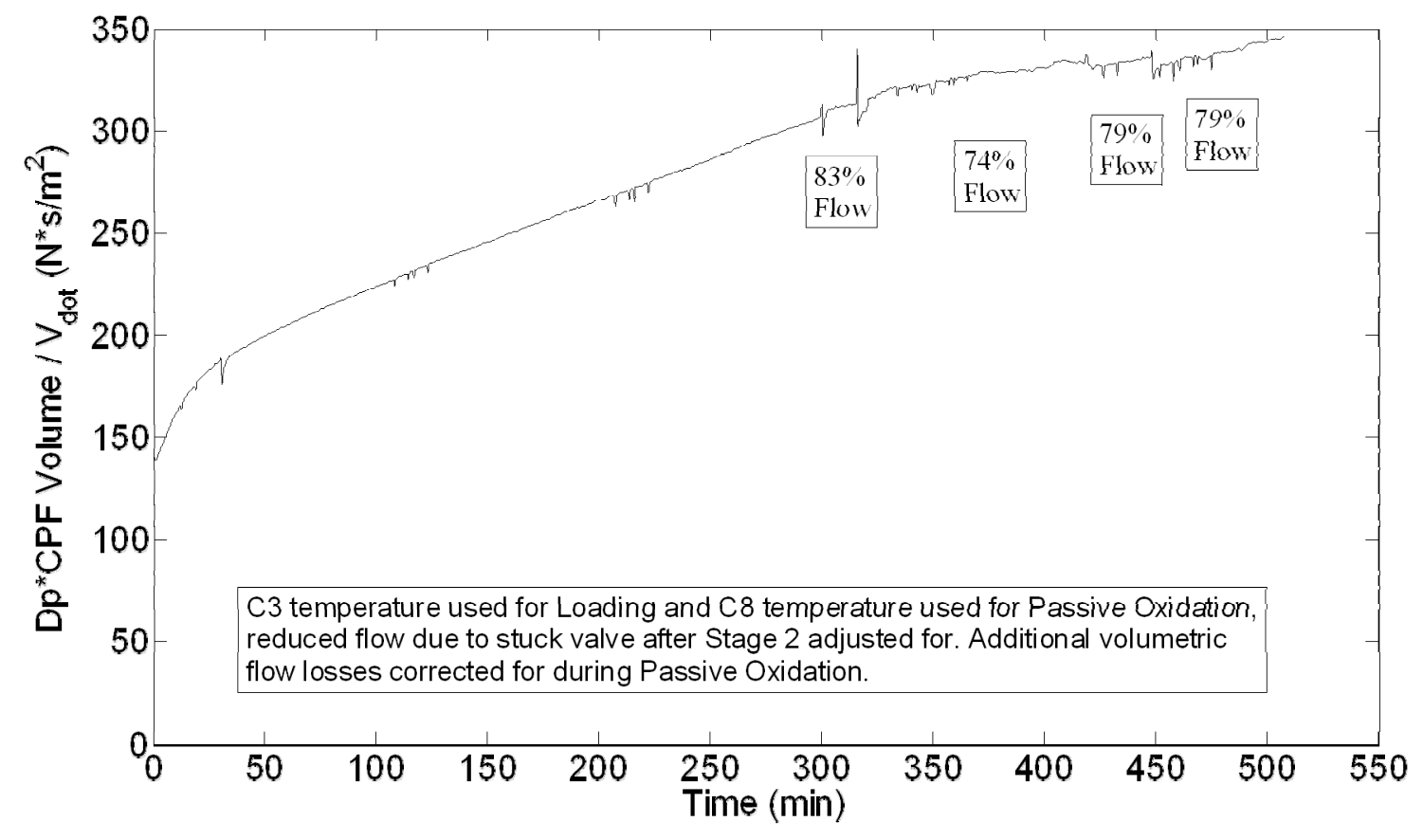

Figure 4.40: CPF corrected resistance during Test 18 Point A with B20 


\section{Chapter 5. Summary and Conclusions}

The main goals of this research were to further develop the procedure used by Hutton et al. [1] and use this procedure to collect and analyze the PM oxidation data when operating a 2007 Cummins ISL engine rated at $365 \mathrm{hp}$ and aftertreatment system with methyl-ester biodiesel blended fuel. This procedure was then used to determine how the same engine rated at $425 \mathrm{hp}$ impacted the passive oxidation of particulate matter. A modeling effort is proceeding in parallel with the experimental work to develop and calibrate a 1-D CPF simulation. A summary of the findings from analysis of the data are as follows.

1. Modifications were made to the test procedure providing more consistent data and more repeatable pressure drops across the CPF during the passive oxidation portion of tests.

2. Data over a range of CPF inlet temperatures with varying $\mathrm{NO}_{\mathrm{X}} / \mathrm{PM}$ and $\mathrm{NO}_{2} / \mathrm{PM}$ ratios using $\mathrm{B} 10$ and $\mathrm{B} 20$ biodiesel has been presented.

3. The PM reaction rates for Stage 2 and Passive Oxidation conditions have been determined. $\mathrm{B} 10$ and $\mathrm{B} 20$ reaction rates were typically lower than ULSD reaction rates during passive oxidation. This may be due to lower $\mathrm{NO}_{2}$ concentrations from the DOC aging prior to performing these tests.

4. The data has been collected so that the MTU 1-D CPF model can be used to determine the PM oxidation kinetics with B10 and B20 fuels as well as with additional data, to determine the effect of changing the engine rating.

Aging of the DOC was noticed during biodiesel testing. The aging of the DOC may have been accelerated by ash created during biodiesel fuel use. This aging caused less $\mathrm{NO}_{2}$ to be oxidized across the DOC during loading stages. This will be an additional effect to be determined from the modeling effort.

It was determined that the particle size related filtration efficiency of the CPF reaches its maximum peak within the first minute of loading. This knowledge was used in determining the proper method to calculate the mass retained during Stage 1, Ramp-up, and Stage 3. Use of this knowledge will result in increased accuracy of the modeling effort.

\subsection{Conclusions}

The modified test procedure resulted in the CPF achieving stable temperature sooner during the passive oxidation portion of each test. This stable temperature in turn stabilized the differential pressure drop profile across the CPF. This will provide better data for the modeling effort to determine the oxidation kinetics of PM in the CPF. 
The engine out exhaust gas emissions were found to be similar on the ISL rated at $365 \mathrm{hp}$ with ULSD, B10, and B20. The loading times with B20 fuel were significantly longer than with ULSD under similar test cell conditions on the ISL rated at $365 \mathrm{hp}$. This may be due to increased PM structure disorder and oxygen content [8, $21-23]$. In contrast to this, Stage 2 loading reaction rates were found to be statistically similar with the ISL rated at $365 \mathrm{hp}$ with all fuels used during this testing. The details resulting from DOC aging, higher PM reactivity, and changes in the $\mathrm{HC}$ species present during biodiesel testing will be examined during the modeling effort.

The experimental passive oxidation reaction rates varied based upon the average $\mathrm{CPF}$ temperature, $\mathrm{NO}_{2}$ concentrations, $\mathrm{NO}_{2}$ flow rates into the $\mathrm{CPF}$ and the $\mathrm{NO}_{2} / \mathrm{PM}$ ratios for each engine rating and with all fuels. As temperature of the CPF is increased so is the reaction rate. The $\mathrm{NO}_{2}$ production follows an exponential trend as CPF temperature increases with all fuels. The B10 and B20 reaction rates were typically lower than ULSD reaction rates. This may be due to DOC aging and lower DOC activity. The reaction rate and kinetic constants and the details of the PM oxidation process can only be determined by a high fidelity CPF model. Analysis of the data with the MTU 1-D CPF model is underway with data from ISL 365 tests 1-19. Analysis will then begin on ISL 425 tests 16 upon their completion.

\subsection{Recommendations}

1. An effort should be made to control the humidity of the intake air into the engine. As shown in Figure 3.8 the humidity plays an important role in the loading rate. This may cause significant changes in the PM structure affecting results.

2. Perform DOC/CPF comparison testing to verify that the DOC/CPF used for ISL 425 testing is comparable to the DOC/CPF used for ISL 365 testing, and to determine aged DOC effect. The reaction rates from B10 and B20 testing are not directly comparable due to the DOC aging observed. The DOC and CPF that will be used during ISL 425 testing may not oxidize PM in a similar manor. Before comparison is made between passive oxidation with the ISL at $365 \mathrm{hp}$ and at 425 $\mathrm{hp}$, the effect of the aftertreatment system should be determined.

3. Repeat ISL tests 11 and 18 performed at passive oxidation point $\mathrm{A}$ with $\mathrm{B} 20$ during which the data may have been affected by DOC face plugging and the bypass valve sticking open. These tests represent a test point that may be important in the modeling effort.

4. The passive oxidation portion of reference point $A$ tests conducted on the ISL rated at $425 \mathrm{hp}$ should be performed for a longer period of time than tests conducted on the ISL rated at $365 \mathrm{hp}$ at similar conditions to ensure enough PM mass is oxidized for accurate reaction rates. During ISL 425 Test 1 the amount of PM oxidized was near measurement accuracy of the scale used for testing (Table 4.1). 


\section{References}

1. Hutton C., Johnson J., Naber J., "Procedure Development and Experimental Study of Passive Particulate Matter Oxidation in a Diesel Catalyzed Particulate Filter," SAE Technical Paper No. 2012-01-0851, 2012

2. Hutton C., "An Experimental Investigation Into The Passive Oxidation Of Particulate Matter In A Catalyzed Particulate Filter," Master's Thesis, Mechanical Engineering - Engineering Mechanics Department, Michigan Technological University, Houghton, 2010

3. Morcos M., Ayyappan P., Harris T., "Characterization of DPF Ash for Development of DPF Regeneration Control and Ash Cleaning Requirements," SAE Technical Paper No. 2011-01-1248, 2011

4. Shiel K., Naber J., Johnson J., Hutton C., "Catalyzed Particulate Filter Passive Oxidation Study with Ultra Low Sulfur and Biodiesel Blended Fuel," SAE Technical Paper No. 2012-01-0837, 2012

5. Liu Z., Berg D., Schauer J., "Detailed Effects of a Diesel Particulate Filter on the Reduction of Chemical Species Emissions," SAE Technical Paper No. 2008-010333, 2008

6. Jeguirim M., Tschamber V., Brilhac J., "Kinetics of Catalyzed and Non-Catalyzed Soot Oxidation with Nitrogen Dioxide Under Regeneration Particle Trap Conditions," Journal of Chemical Technology \& Biotechnology; 84: 770-776, 2009, doi:10.1002/jctb.2110

7. Yang S., Lee K., Chong H., "Characterization of Oxidation Behaviors and Chemical-Kinetics Parameters of Diesel Particulates Relevant to DPF Regeneration," SAE Technical Paper No. 2010-01-2166, 2010

8. Strzelec A., Foster D., Rutland C., "Effect of Biodiesel Blending on Speciation of Soluble Organic Fraction from a Light Duty Diesel Engine," SAE Technical Paper No. 2010-01-1273, 2010

9. Triana A., Johnson J., Yang S., Baumgard K., " An Experimental and Computational Study of the Pressure Drop and Regeneration Characteristics of a Diesel Oxidation Catalyst and a Particulate Filter," SAE Technical Paper No. 2006-01-0266, 2006

10. Maly M., Claussen M., Carlowitz O., Kroner P., Renalli M., Schmidt S., "Influence of Nitrogen Dioxide Based Regeneration on Soot Distribution," SAE Technical Paper No. 2004-01-0823, 2004

11. York A., Ahmadinejad M., Watling T., Walker A., Cox J., Gast J., Blakeman P., Allansson R., "Modeling of the Catalyzed Continuously Regenerating Diesel Particulate Filter (CCR-DPF) System: Model Development and Passive Regeneration Studies," SAE Technical Paper No. 2007-01-0043, 2007 
12. Vlachos N., Patrianakos G., Kostoglou M., Konstandopoulos A., " MicroSimulation of NO-NO${ }_{2}$ Transport and Reaction in the Wall of a Catalyzed Diesel Particulate Filter," SAE Technical Paper No. 2008-01-0442, 2008

13. Schejbal M., Stepanek J., Marek M., Koci P., Kubicek M., "Modelling of Soot Oxidation by $\mathrm{NO}_{2}$ in Various Types of diesel Particulate Filters," Fuel 89: 23652375, 2010, doi:10.1016/j.fuel.2010.04.018

14. Konstandopoulos A., Kostoglou M., Lorentsou S., Pagkoura C., Papaioannou E., Ohno K., Ogyu K., Oya T., " soot Oxidation Kinetics in Diesel Particulate Filters," SAE Technical Paper No. 2007-01-1129, 2007

15. Pauli E., Lepperhoff G., Pischinger F., "The Description Behavior of Diesel Particulate Traps with the Aid of a Mathematical Model," SAE Technical Paper No. 830180, 1983

16. Tinsdale M., Price P., Chen R., "The Impact of Biodiesel on Particle Number, Size and Mass Emissions from a Euro4 Diesel Vehicle," SAE Technical Paper No. 2010-01-0796, 2010

17. Okamoto K., Kohakura M., Kaneko T., Fukuda K., Furui K., Okada M., Tsuchihashi K., Hirata K., Baba H., Hasegawa T., Hozumi A., Shibuya M., Koseki K., Kawatani T., Kameoka A., Hosono K., "Impact Study of High Biodiesel Blends on Exhaust Emissions to Advanced Aftertreatment Systems," SAE Technical Paper No. 2010-01-1292, 2010

18. Barloli Y., Lyford-Pike E., Lucke J., Khalek I., Feist M., McCormick R., “1000Hour Durability Evaluation of a Prototype 2007 Diesel Engine with Aftertreatment Using B20 Biodiesel Fuel," SAE Technical Paper No. 2009-012803, 2009

19. Eckerle W., Lyford-Pike E., Stanton D., LaPointe L., Whitacre S., Wall J., "Effects of Methyl Ester Biodiesel Blends on NOx Emissions," SAE Technical Paper No. 2008-01-0078, 2008

20. Maricq M., Giuliano J., Szente J., Tennison P., "Effects of B20 versus ULSD Fuel on Diesel Engine PM Emissions and Aftertreatment Performance," SAE Technical Paper No. 2010-01-0790, 2010

21. Williams A., McCormick R. L., Hayes R.R., Ireland J., Fang H. L., "Effect of Biodiesel Blends on Diesel Particulate Filter Performance," SAE Technical Paper No. 2006-01-3280, 2006

22. Austin G., Naber J., Johnson J., Hutton C., "Effects of Biodiesel Blends on Particulate Matter Oxidation in a Catalyzed Particulate Filter during Active Regeneration," SAE Technical Paper No. 2010-01-0557, 2010

23. Vertin K., He S., Heibel A., "Impacts of B20 Biodiesel on Cordierite Diesel Particulate Filter Performance," SAE Technical Paper No. 2009-01-2736, 2009

24. Northrop W., Assanis D., Bohac S., "Evaluation of Diesel Oxidation Catalyst Conversion of Hydrocarbons and Particulate Matter from Premixed Low 
Temperature Combustion of Biodiesel," SAE Technical Paper No. 2011-01-1186, 2011

25. Katare S., Patterson J., Laing P., "Aged DOC is a Net Consumer of NO2: Analysis of Vehicle, Engine-dynamometer and Reactor Data," SAE Technical Paper No. 2007-01-3984, 2007

26. Wenzel S., Wahiduzzaman S., "Analytical Study of Effectiveness of Degreened and Aged DOC as an Oxidation Device for NO under Variable Operating and Inlet Conditions," SAE Technical Paper No. 2009-01-0908, 2009

27. Henry C., Currier N., Ottinger N., Yezerets A., Castagnola M., Chen H., Hess H., "Decoupling the Interactions on Hydrocarbons and Oxides of Nitrogen Over Diesel Oxidation Catalysts," SAE Technical Paper No. 2011-01-1137, 2011

28. Williams A., McCormick R., Lueske J., Brezny R., Geisselmann A., Voss K., Hallstrom K., Leustek M., Parsons J., Abi-Akar H., "Impact of Biodiesel Impurities on the Performance and Durability of DOC, DPF and SCR Technologies," SAE Technical Paper No. 2011-01-1136, 2011

29. Kladopoulou E., Yang S., Johnson J., Parker G., "A Study describing the Perfromance of Diesel Particulate Filters During Loading and Regeneration - A Lumped Parameter Model for Control Applications," SAE Technical Paper No. 2003-01-0842, 2003

30. Johnson J., Keith J., Naber J., Parker G., Yang S., "Michigan Tech Quarterly Progress Report," Report Number DOE-2011-MTU-02-006, 2011

31. Sappok A., Bromberg L., Parks J., Prikhodko V., "Loading and Regeneration Analysis of a Diesel Particulate Filter with a Radio Frequency-Based Sensor," SAE Technical Paper No. 2010-01-2126, 2010

32. Ntziachristos L., Fragkiadoulakis P., Samaras Z., Janka K., Tikkanen J., "Exhaust Particle Sensor for OBD Application," SAE Technical Paper No. 2011-01-0626, 2011

33. Tanin K., Wickman D., Montgomery D., Das S., Reitz R., "The Influence of Boost Pressure on Emissions and Fuel Consumption of a Heavy-Duty SingleCylinder D.I. Diesel Engine,” SAE Technical Paper No. 1999-01-0840, 1999

34. Benajas J., Molina S., Garcia J., Novella R., "Influence of Boost Pressure an Injection Pressure on Combustion Process and Exhaust Emissions in a HD Diesel Engine,” SAE Technical Paper No. 2004-01-1842, 2004

35. Chilumukuru K. P. , "An Experimental Study of Particulate Thermal Oxidation in a Catalyzed Filter during Active Regeneration," Master's Thesis, Mechanical Engineering - Engineering Mechanics Department, Michigan Technological University, Houghton, 2008

36. Austin G., "Effects of Biodiesel Blends on Particulate Matter Oxidation in a Catalyzed Particulate Filter during Active Regeneration," Master's Thesis, 
Mechanical Engineering - Engineering Mechanics Department, Michigan Technological University, Houghton, 2010

37. Lakkireddy V. R. "The Effect of an Advanced Oxidation Catalytic Converter and a Catalyzed Particulate Filter on the Emissions from a Heavy Duty Diesel Engine," Master's Thesis, Mechanical Engineering - Engineering Mechanics Department, Michigan Technological University, Houghton, 2005

38. Burtscher, H., Baltensperger, U., Bukowiecki, N., Cohn, P., Huglin, C., Mohr, M., Matter, U., Nyeki, S., Schmatloch, V., Steit, N., Weingartner, E., "Separation of volatile and non-volatile aerosol fractions by thermodesorption: instrumental development and applications," Journal of Aerosol Science, Volume 32, Issue 4, Pages 427-442, 2001, doi:10.1016/S0021-8502(00)00089-6

39. Koltsakis G., Samaras Z., Karvountzis-Kontakiotis A., Zacharopoulou T., "Implications of Engine Start-Stop on Aftertreatment Operation," SAE Technical Paper No. 2011-01-1243, 2011 


\section{Appendices}

\section{Appendix A CPF Thermocouple Layout prior to ISL 365 Test 10}

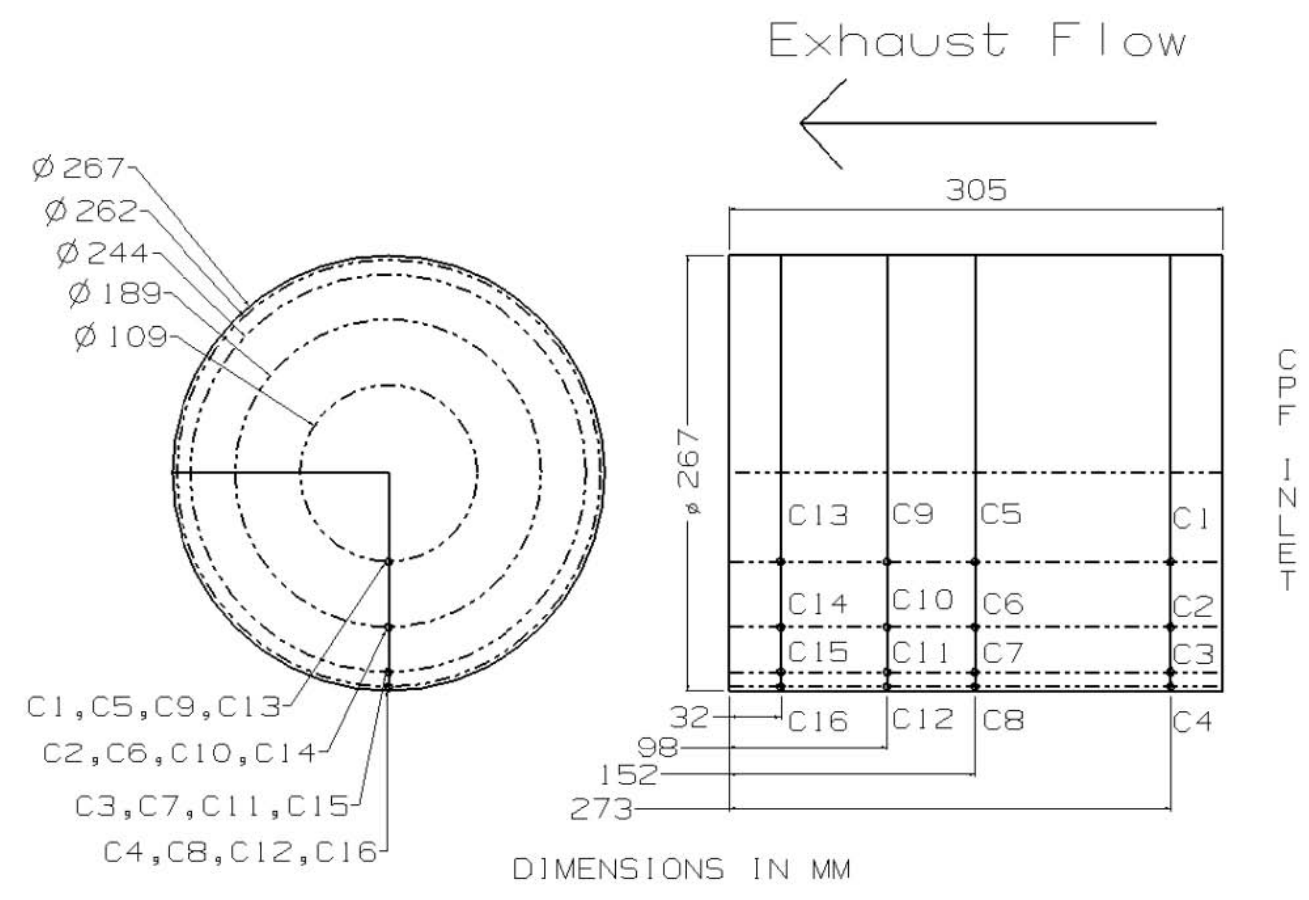

Figure A. 1: CPF Thermocouple Layout used prior to ISL 365 Test 10 


\section{Appendix B PM Sample Filter Preparation}

1. Label twelve plastic filter holders (Millipore Catalog Number PDMA04700) with the appropriate test number and filter number. (i.e.: B20-1-1, B20-1-2, etc)

2. Place one filter (Pall Corporation Part Number 61631) in each filter holder

3. The oven used for baking filters is located in the MEEM building, room B006, which is also the welding shop. The temperature setting on the oven is set at 575 ${ }^{\circ} \mathrm{F}$. The oven needs to be turned on and allowed to warm up for an hour prior to filter baking.

4. After the oven has warmed up for an hour, place each filter, without the plastic holder, onto the metal baking tray and place the tray in the oven. Leave the filters to bake for 15 minutes.

5. After the filters have baked, remove them from the oven and place each one in its filter holder.

6. Place each filter/filter holder combo, with the lid removed, in the humidity chamber located in the MEEM building, room SB013. The filters must stay in the chamber for 24 hours before weighing. The humidity chamber is maintained at $75 \% \pm 5 \%$ relative humidity.

7. Weigh each filter three times and record their weights, along with two control filters. The control filters are weighed at the time of filter weighing to track the weight change due to humidity changes in the chamber.

8. After each filter is weighed 3 times and recorded, the filters are ready to be removed from the chamber and are prepared for the upcoming test. The filters can stay in the chamber until testing day. 


\section{Appendix C PSD Sample Collection and Dilution Ratio Data Collection}

The engine is operated at the condition during which PSD data will be collected. The copper dilution line shown in Figure C.1 is connected from the heated filter to the dilution box outlet as shown. The PSD sample line is then connected to the gaseous emissions port corresponding to the location to be sampled as shown in Figure C.2.

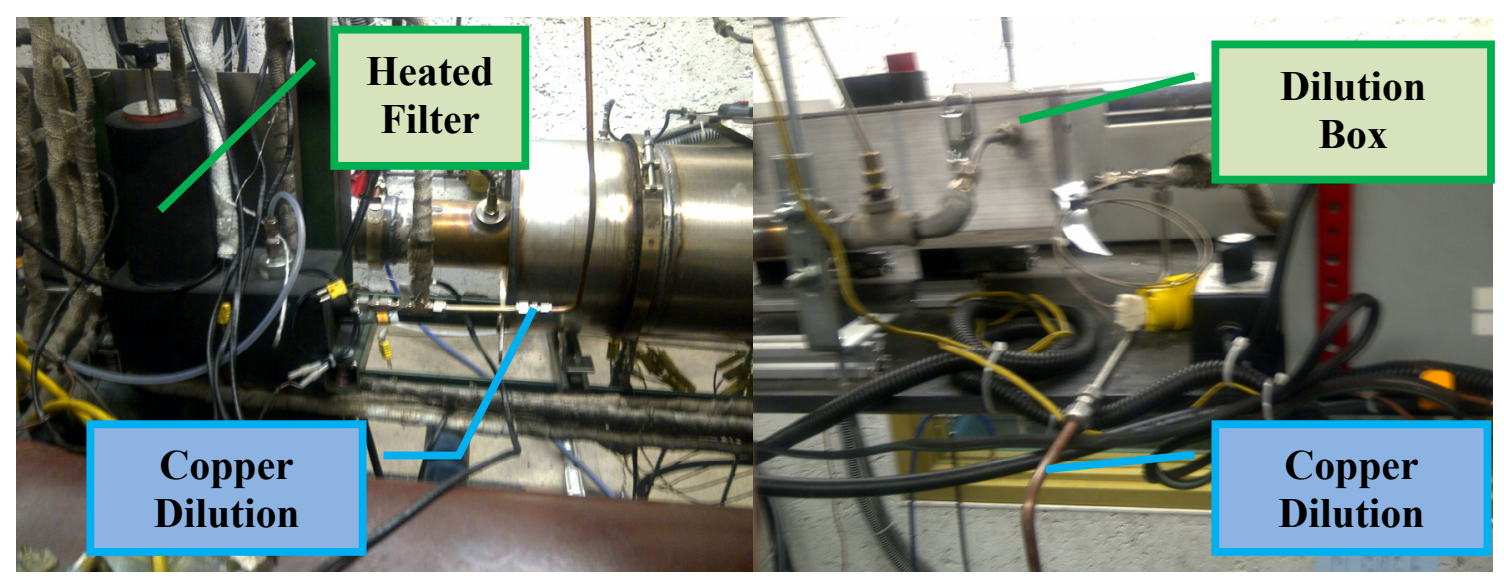

Figure C.1: Copper dilution line connected from the heated filter to the dilution box outlet

With the dilution line and PSD sample line in place, emissions data is collected with the Pierburg emissions analyzer. This data collection is performed with the exhaust sample valves for UDOC, DDOC, and DCPF, controlled by Labview, closed for five minutes. The value of $\mathrm{CO} 2$ given by the Pierburg emissions analyzer (dco2) is used with equation C. 1 to find the dilution ratio at that point for the engine operating condition being run. The value of engine out $\mathrm{CO} 2$ measured at each point while collecting emissions data during stage 2 and passive oxidation portions is used as $\mathrm{a}_{\mathrm{co} 2}$ in equation C. 1 for each point.

$$
\text { Dilution Ratio }=\frac{d_{c o 2}}{a_{c o 2}}
$$




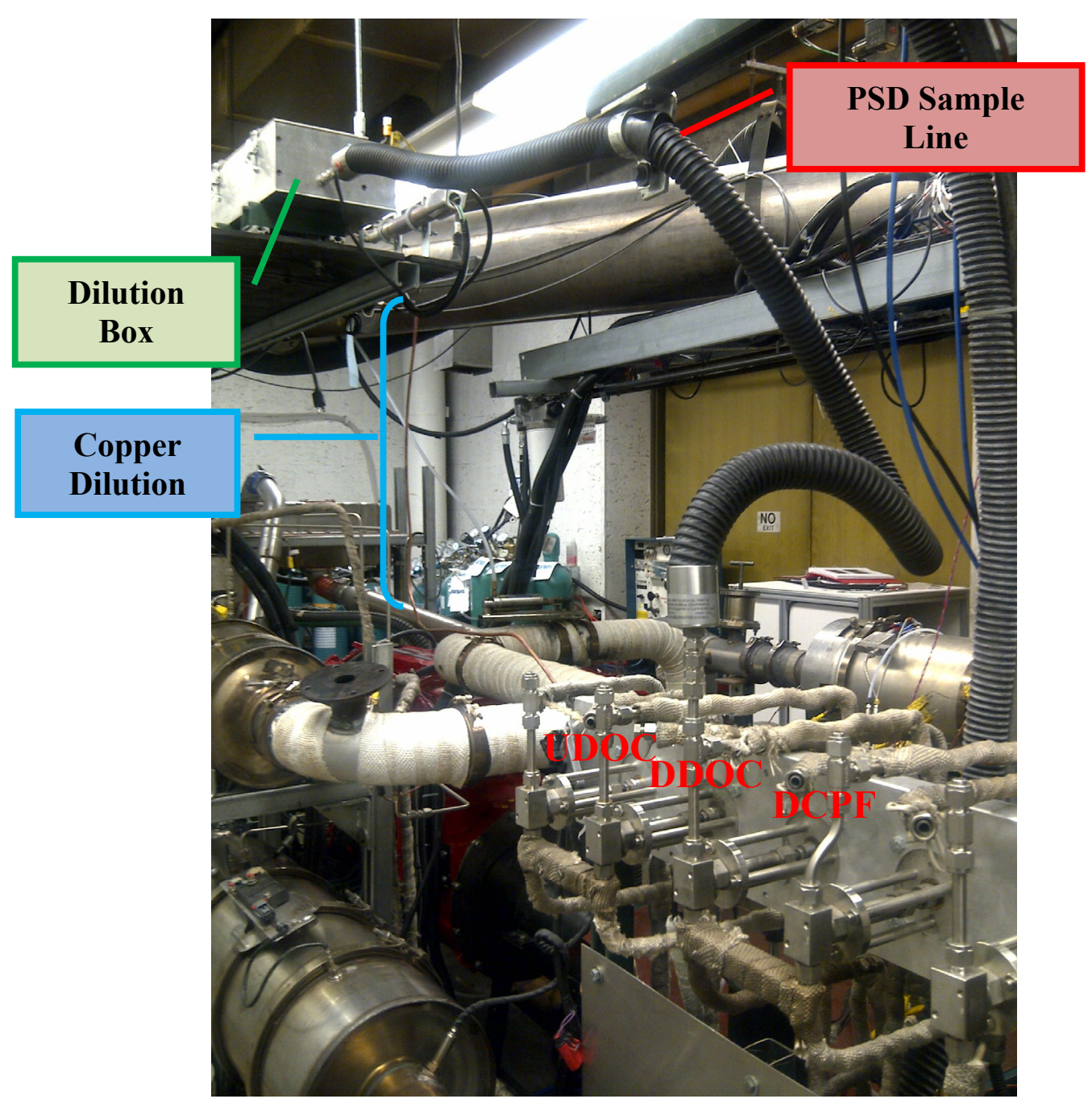

Figure C.2: PSD sample line connected to the DDOC gaseous emissions port

The PSD sample line is then moved to the next sample location to be tested and emissions data is collected for five minutes. All three sample locations (UDOC, DDOC, and DCPF) are measured in this manner. Every engine operating condition during which PSD data is to be collected must have the dilution ratio collected in this way. 


\section{Appendix D CPF Weighing Procedure}

During different portions of the test the CPF is removed from the aftertreatment system for weighing. The complete aftertreatment assembly is shown in Figure D. 1. In order to allow for clear communication, the individual parts are listed below and are correlated by number listed on the picture.

1. Inlet Cone

2. Diesel Oxidation Catalyst (DOC)

3. Catalyzed Particulate Filter (CPF)

4. Exit Cone

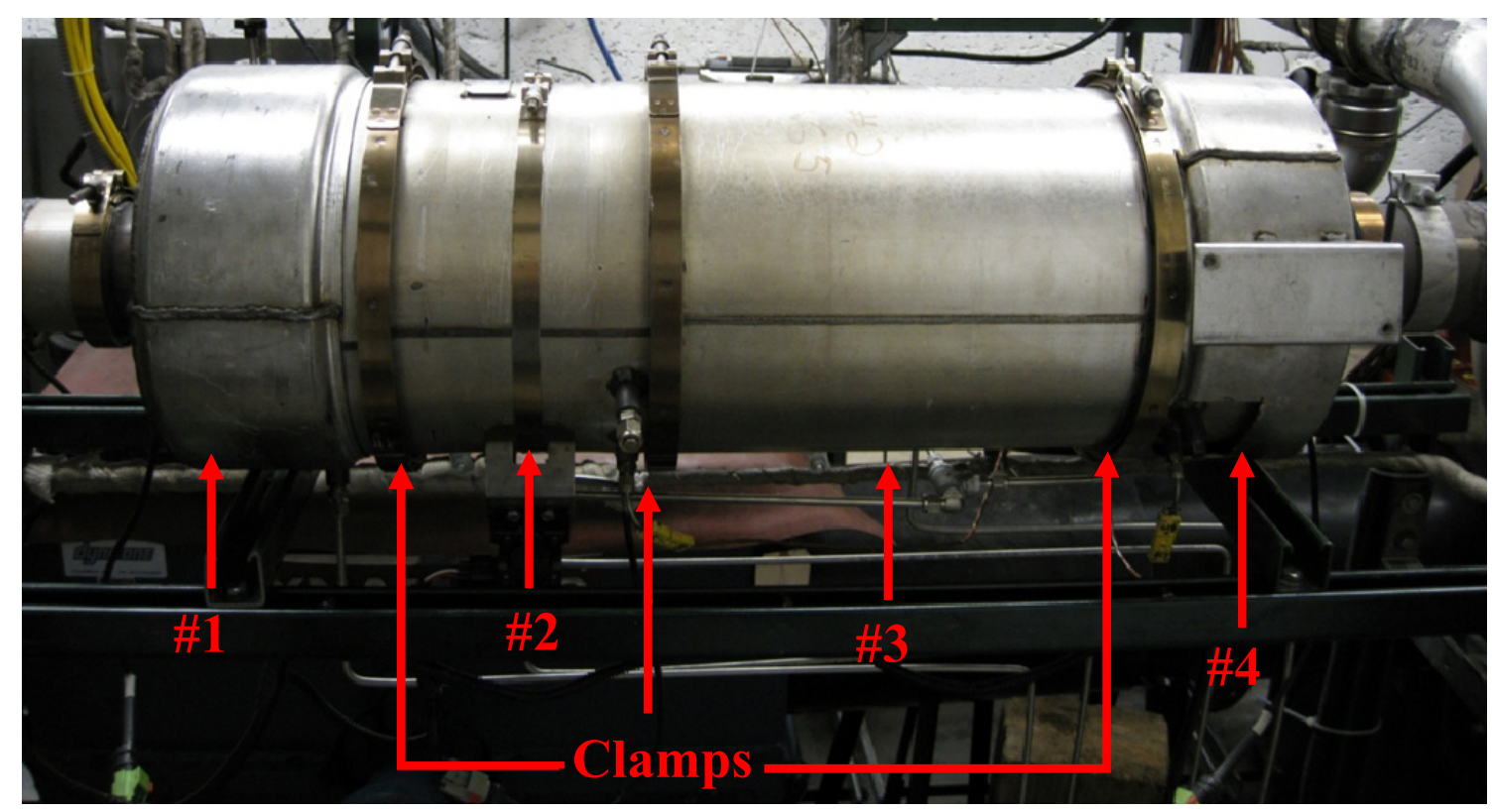

Figure D. 1:Cummins 2007 ISL aftertreatment system

Disassembly and weighing of the CPF takes place a minimum of four times for each of the passive regeneration tests. The filter and associated hardware are removed from the system hot, with surface temperatures up to and exceeding $300^{\circ} \mathrm{C}$. The weighing is done at elevated temperatures for two main reasons. First, as the CPF cools there is the possibility that the CPF will gain mass due to moisture absorption from the ambient air. Second, it has been shown that the weighing procedure is a dynamic process with the CPF appearing to gain mass as it cools due to the reduction of the buoyancy effect provided by the heat of the filter. Therefore, filter weighing takes place at similar temperatures during the different portions of the test. A detailed analysis investigating the variability of the mass measurement due to temperature variations is discussed in Greg Austin's thesis titled "Effects of Biodiesel Blends on Particulate Matter Oxidation in a Catalyzed Particulate Filter during Active Regeneration". 
The weighing procedure is detailed below.

1. Parts 1 - 4 in Figure D. 1 are removed from the exhaust system fully assembled.

2. The system is lowered to the ground and rests on Part \#4 which then puts the system in a vertical orientation.

3. The clamp between Part \#2 and \#3 is removed, the DOC and Inlet Cone is then removed as an assembly.

4. A steel cover is placed over the inlet of the CPF and fastened to the filter by the previously removed clamp.

5. The filter is then rotated to rest on the steel cover and the clamp between Part \#3 and \#4 is removed.

6. The exit cone is then removed and a separate steel cap is place over the exit of the $\mathrm{CPF}$. This cap is fastened to the filter by the previously removed clamp.

7. The filter is then brought to the scale and temperatures are recorded throughout the filter and caps.

8. The scale is zeroed prior to each mass measurement.

9. A calibration weight is measured to ensure scale accuracy.

10. The CPF is weighed three times, with the temperatures recorded throughout the $\mathrm{CPF}$ prior to weighing. An average of the mass measurements is then calculated to verify that the temperature of the $\mathrm{CPF}$ is $\pm 10^{\circ} \mathrm{C}$ between each weighing.

The reassembly process is the reverse of the disassembly process. 


\section{Appendix E $\quad$ PM Mass Balance Calculations for Stage 1 [Method created by Kiran Premchand]}

We want to get a good estimate of $\mathrm{CPF}$ clean weight $\left(M_{\text {clean }}\right)$ assuming the following:

1. The fraction of PM oxidized during stage-1 loading is equal to the fraction of PM oxidized during stage-2 loading.

2. Average filtration efficiency of the CPF during stage-1 loading and stage-2 loading are known $\left(\left(\bar{\eta}_{S 1}\right)\right.$ and $\left(\bar{\eta}_{S 2}\right)$ respectively).

We know the following relations:

$$
\begin{aligned}
& m_{\text {ret }, S 1}=M_{S 1}-M_{\text {clean }} \\
& m_{\text {ret }, S 2}=M_{S 2}-M_{\text {clean }} \\
& m_{\text {ret }, S 3}=M_{S 3}-M_{\text {clean }} \\
& m_{\text {ret }, S 4}=M_{S 4}-M_{\text {clean }}
\end{aligned}
$$

Also, from cumulative PM mass balance for stage- 1 and stage- 2 can be mathematically expressed as:

$$
\begin{aligned}
& m_{\text {in }, S 1}-m_{\text {ret }, S 1}-m_{o x, S 1}-m_{\text {out }, S 1}=0 \\
& m_{r e t, S 1}+m_{\text {in,S2 }}-m_{\text {ret }, S 2}-m_{o x, S 2}-m_{\text {out }, S 2}=0 \text {------------- [stage-2] }
\end{aligned}
$$

Also, from definition of average filtration efficiencies during stage-1 and stage-2,

$$
\begin{aligned}
& \bar{\eta}_{S 1}=\frac{m_{\text {in,S1 }}-m_{\text {out }, S 1}}{m_{\text {in,S1 }}} \\
& \bar{\eta}_{S 2}=\frac{m_{\text {in,S2 }}-m_{\text {out }, S 2}}{m_{\text {in,S2 }}}
\end{aligned}
$$

From (5) and (1),

$$
m_{r e t, S 1}=m_{i n, S 1}-m_{o x, S 1}-m_{o u t, S 1}=M_{S 1}-M_{\text {clean }}
$$


$\left(m_{\text {in }, S 1}-m_{\text {out }, S 1}\right)-m_{\text {ox }, S 1}=M_{S 1}-M_{\text {clean }}$

Substitute (7) in (9),

$\bar{\eta}_{S 1} m_{i n, S 1}-m_{o x, S 1}=M_{S 1}-M_{\text {clean }}$

Re-writing (10),

$M_{\text {clean }}=M_{S 1}-\left(\bar{\eta}_{S 1} m_{i n, S 1}-m_{o x, S 1}\right)$

or

$M_{\text {clean }}=M_{S 1}-\bar{\eta}_{S 1} m_{i n, S 1}+m_{o x, S 1}$

or

$m_{o x, S 1}=\bar{\eta}_{S 1} m_{i n, S 1}-\left(M_{S 1}-M_{\text {clean }}\right)$

From (6), (2) and (1),

$$
\begin{aligned}
& m_{\text {ox }, S 2}=m_{r e t, S 1}+m_{\text {in }, S 2}-m_{r e t, S 2}-m_{\text {out }, S 2} \\
& =m_{r e t, S 1}+\left(m_{i n, S 2}-m_{\text {out }, S 2}\right)-m_{\text {ret }, S 2} \\
& =m_{r e t, S 1}+\bar{\eta}_{S 2} m_{i n, S 2}-m_{r e t, S 2} \\
& =\bar{\eta}_{S 2} m_{i n, S 2}+m_{r e t, S 1}-m_{r e t, S 2} \\
& =\bar{\eta}_{S 2} m_{\text {in }, S 2}+\left(M_{S 1}-M_{\text {clean }}\right)-\left(M_{S 2}-M_{\text {clean }}\right) \\
& =\bar{\eta}_{S 2} m_{i n, S 2}-\left(M_{S 2}-M_{S 1}\right)
\end{aligned}
$$


From (11c),

$\frac{m_{o x, S 1}}{m_{i n, S 1}}=\bar{\eta}_{S 1}-\frac{M_{S 1}-M_{c l e a n}}{m_{i n, S 1}}$

And from (12),

$\frac{m_{o x, S 2}}{m_{i n, S 2}}=\bar{\eta}_{S 2}-\frac{M_{S 2}-M_{S 1}}{m_{i n, S 2}}$

So then if we equate the LHS of (13) and (14) [Assumption 1],

$$
\begin{aligned}
& \bar{\eta}_{S 1}-\frac{M_{S 1}-M_{\text {clean }}}{m_{\text {in, }, 1}}=\bar{\eta}_{S 2}-\frac{M_{S 2}-M_{S 1}}{m_{\text {in,S2 }}} \\
& \frac{M_{S 1}-M_{\text {clean }}}{m_{\text {in, }, S 1}}=\bar{\eta}_{S 1}-\left(\bar{\eta}_{S 2}-\frac{M_{S 2}-M_{S 1}}{m_{\text {in,S2 }}}\right)
\end{aligned}
$$

or

$$
m_{r e t, S 1}=M_{S 1}-M_{\text {clean }}=\bar{\eta}_{S 1} m_{i n, S 1}-\left(\bar{\eta}_{S 2}-\frac{M_{S 2}-M_{S 1}}{m_{i n, S 2}}\right) m_{i n, S 1}
$$

or

$$
m_{r e t, S 1}=\left(m_{i n, S 1}\left(\bar{\eta}_{S 1}-\bar{\eta}_{S 2}\right)+\left(M_{S 2}-M_{S 1}\right) \frac{m_{i n, S 1}}{m_{i n, S 2}}\right)
$$

or 
$M_{\text {clean }}=M_{S 1}-\left(\bar{\eta}_{S 1} m_{i n, S 1}-\left(\bar{\eta}_{S 2}-\frac{M_{S 2}-M_{S 1}}{m_{i n, S 2}}\right) m_{i n, S 1}\right)$

where: $\quad m_{i n, S 1}=C_{i n, S 1}\left(\frac{1}{1 \times 10^{3}} \frac{g}{m g}\right) \dot{V}_{S 1} t_{S 1}$ and $m_{i n, S 2}=C_{i n, S 2}\left(\frac{1}{1 \times 10^{3}} \frac{g}{m g}\right) \dot{V}_{S 2} t_{S 2}$.

\begin{tabular}{|c|c|c|}
\hline Variable & Description & Units \\
\hline$M_{S 1}$ & Substrate weight measurement at the end of stage-1 & {$[\mathrm{g}]$} \\
\hline$M_{S 2}$ & Substrate weight measurement at the end of stage- 2 & [g] \\
\hline$M_{S 3}$ & Substrate weight measurement at the end of stage- 3 & [g] \\
\hline$M_{S 4}$ & Substrate weight measurement at the end of stage- 4 & [g] \\
\hline$m_{i n, S 1}$ & PM mass into the CPF during stage- 1 & [g] \\
\hline$m_{\text {in,S2 }}$ & PM mass into the CPF during stage- 2 & {$[\mathrm{~g}]$} \\
\hline$m_{\text {in,S3 }}$ & PM mass into the CPF during stage- 3 & {$[\mathrm{~g}]$} \\
\hline$m_{i n, S 4}$ & PM mass into the CPF during stage-4 & [g] \\
\hline$m_{\text {out }, S 1}$ & PM mass out of the CPF during stage-1 & {$[\mathrm{g}]$} \\
\hline$m_{\text {out }, S 2}$ & PM mass out of the CPF during stage- 2 & {$[\mathrm{~g}]$} \\
\hline$m_{\text {out }, S 3}$ & PM mass out of the CPF during stage- 3 & {$[\mathrm{~g}]$} \\
\hline$m_{\text {out }, S 4}$ & PM mass out of the CPF during stage- 4 & [g] \\
\hline$m_{r e t, S 1}$ & PM mass retained in the CPF at the end of stage- 1 & [g] \\
\hline$m_{r e t, S 2}$ & PM mass retained in the CPF at the end of stage- 2 & {$[\mathrm{~g}]$} \\
\hline$m_{r e t, S 3}$ & PM mass retained in the CPF at the end of stage- 3 & {$[\mathrm{~g}]$} \\
\hline$m_{r e t, S 4}$ & PM mass retained in the CPF at the end of stage- 4 & [g] \\
\hline$m_{o x, S 1}$ & PM mass oxidized in the CPF during stage- 1 & {$[\mathrm{~g}]$} \\
\hline$m_{o x, S 2}$ & PM mass oxidized in the CPF during stage- 2 & [g] \\
\hline$m_{o x, S 3}$ & PM mass oxidized in the CPF during stage -3 & {$[\mathrm{~g}]$} \\
\hline$m_{o x, S 4}$ & PM mass oxidized in the CPF during stage- 4 & {$[\mathrm{~g}]$} \\
\hline $\bar{\eta}_{S 1}$ & Average filtration efficiency of the CPF during stage- 1 & {$[]$.} \\
\hline $\bar{\eta}_{S 2}$ & Average filtration efficiency of the CPF during stage- 2 & {$[]$.} \\
\hline$C_{i n, S 1}$ & CPF inlet PM concentration during stage- 1 & {$\left[\mathrm{mg} / \mathrm{std} \cdot \mathrm{m}^{3}\right]$} \\
\hline$C_{i n, S 2}$ & CPF inlet PM concentration during stage- 2 & {$\left[\mathrm{mg} / \mathrm{std}_{\mathrm{m}} \mathrm{m}^{3}\right]$} \\
\hline$\dot{V}_{S 1}$ & Volumetric flow rate of exhaust during stage- 1 & {$\left[\mathrm{std} . \mathrm{m}^{3} / \mathrm{s}\right]$} \\
\hline$\dot{V}_{S 2}$ & Volumetric flow rate of exhaust during stage- 2 & {$\left[\mathrm{std} . \mathrm{m}^{3} / \mathrm{s}\right]$} \\
\hline$t_{S 1}$ & Duration of stage-1 loading & {$[\mathrm{s}]$} \\
\hline$t_{S 2}$ & Duration of stage- 2 loading & {$[\mathrm{s}]$} \\
\hline
\end{tabular}




\section{Appendix F Filtration Efficiency during First Twenty Minutes of Loading}

In order to determine the true time required to achieve steady filtration efficiency a test was performed using the PSD set to collect data at 1 minute intervals in the DCPF location for twenty minutes. A CPF clean out was performed and the PSD data collection was began while simultaneously changing to loading engine operating conditions. After collecting twenty 1 minute samples, one single DDOC sample was collected to be used with equation F.1 to determine the changing filtration efficiency of the CPF during the first twenty minutes of Stage 1 loading. Figure F. 1 shows the PSD calculated filtration efficiency during the first twenty minutes of loading after a CPF clean out. This plot confirms that it requires less than a minute to achieve 99\% filtration efficiency (based on PSD data) in the CPF. This being known the filtration efficiency can be assumed constant during all loading stages and a constant rate of PM mass deposition appears valid during loading stages. The PSD filtration efficiency is typically higher than filtration efficiency found by PM filter mass, so the filtration efficiency found by PM sample mass for each test is used. 
Eqn. F.1

DDOC total $=$ total particles from 14.6 to $685.4 \mathrm{~nm}$ in diameter measured at the DDOC location

DCPF total $=$ total particles from 14.6 to $685.4 \mathrm{~nm}$ in diameter measured at the DCPF location

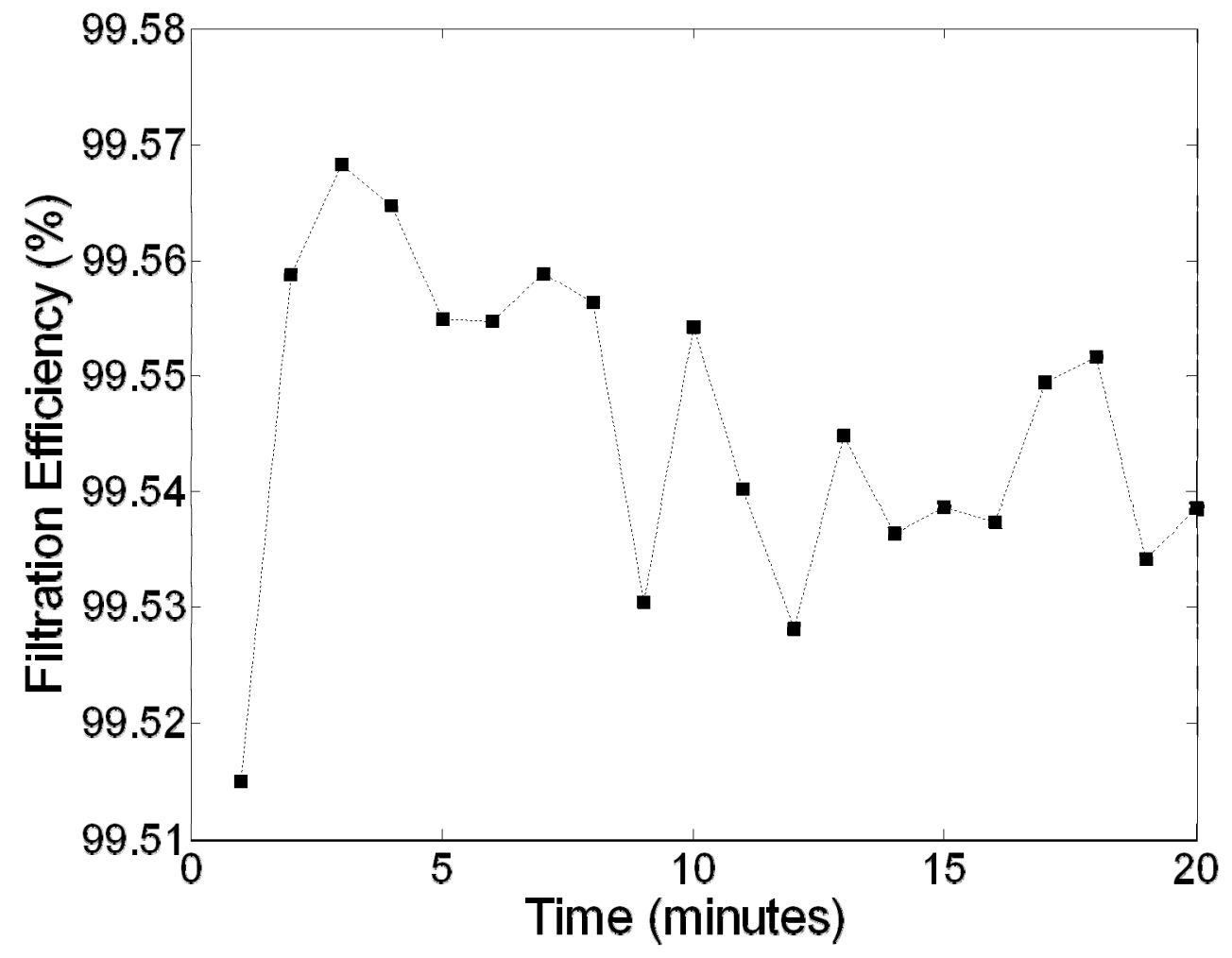

Figure F. 1: Filtration efficiency calculated from PSD data during first twenty minutes of loading after clean out of CPF

By assuming that the rate of PM mass deposited ( $\mathrm{g} / \mathrm{min}$ ) remains constant during Stage 2 and Stage 4 and is similar for all loading stages equation 5-7 may be used to determine the amount of mass retained during Stage 1, ramp-up, and Stage 3. The mass deposited during Stage 1, ramp-up, and Stage 3 has been calculated using this method for this thesis.

The MTU 1-D model will be calibrated and used to simulate each of the passive oxidation tests. This model accounts for the gaseous concentrations present, temperature of the CPF, and mass retained during each stage of the test. This model may lead to increased accuracy of the mass deposited during Stage 1, Ramp-up, and Stage 3. 


\section{Appendix G FST Calibration data collection}

Three iterations of FST's RF-DPF mass retained sensor have been tested. Prior to testing with each version of the sensor a set of calibration data was collected with it in order to determine RF signal dependence on CPF temperatures and loadings. The data collection for calibration of FST's DPF loading sensors required loading the DPF to typical loadings and observing the changes in the RF signal as temperature varied between high and low temperatures. In order to accomplish this, the DPF was loaded to a target value then the engine was operated at a speed and load to raise the temperature of the DPF to an upper value typically observed during testing. After reaching the higher temperature, the DPF was allowed to cool and the RF signal was observed. In order to verify DPF loading, the engine was shut down at pre-determined times during testing so the DPF could be removed and physically weighed. A typical pressure drop profile for this calibration data collection is shown in Figure G. 1.

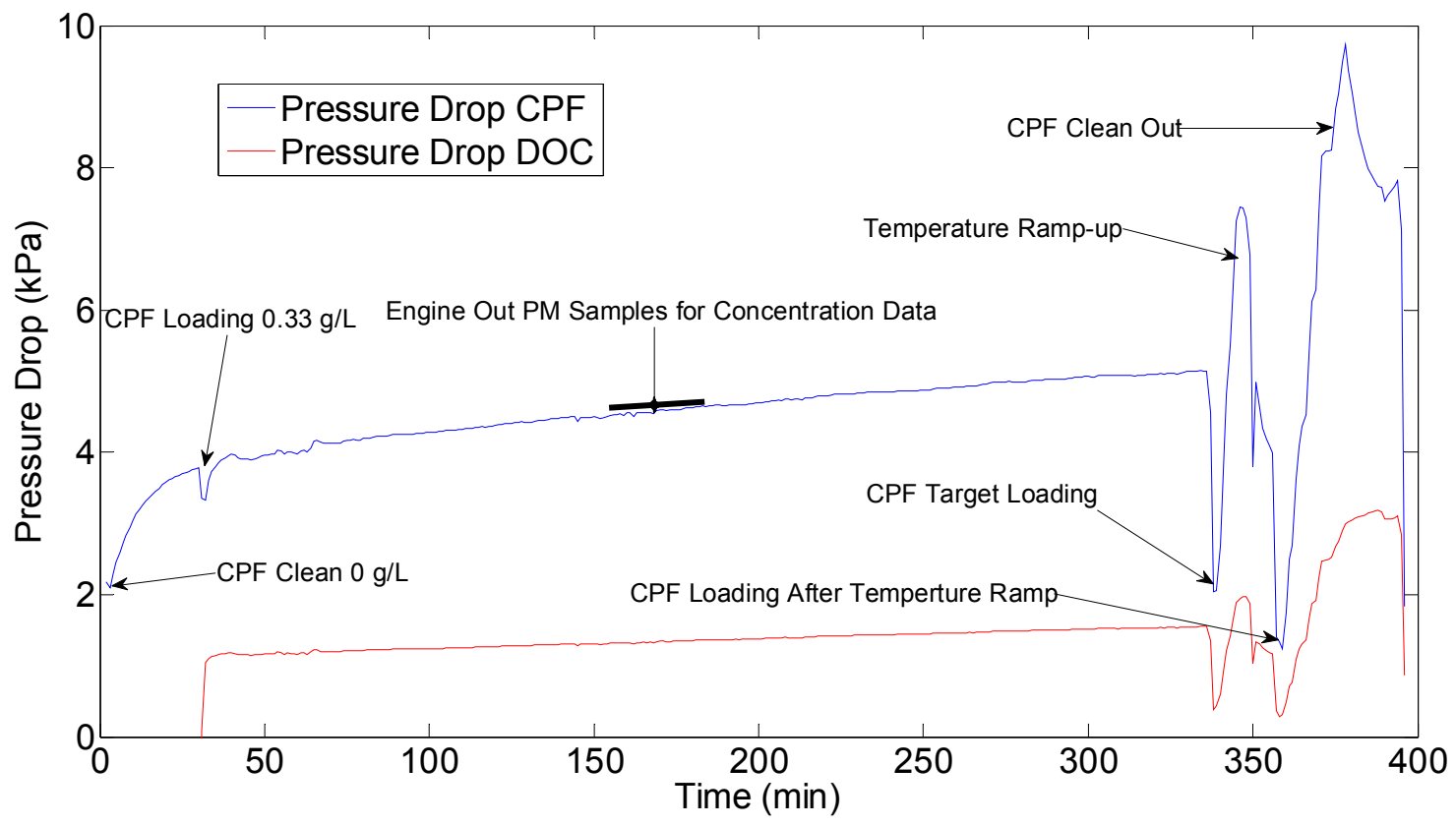

\section{Figure G. 1: Typical pressure drop profile during FST calibration data collection}

For each set of calibration data the CPF clean out procedure was used to determine the RF signal response with zero PM mass retained in the CPF. The CPF was then loaded in a similar manor as for the passive oxidation testing to a target load of $2.5 \mathrm{~g} / 1$. The CPF is weighed to verify loading followed by increasing the temperature of the CPF by operating the engine under reference Point $\mathrm{H}$ conditions. The $\mathrm{CPF}$ temperature is monitored during the temperature ramp-up. When it is determined that the CPF temperatures have begun to reach steady state, the engine load is decreased to allow the CPF to cool to measurement temperatures. The CPF is weighed to determine the amount of PM oxidized during the temperature ramp-up. Multiple temperature ramp-up stages may then be performed at varying lengths of time in order to gather RF data over a full range of PM loadings and temperatures. 


\section{Appendix H Space Velocity Calculations}

Space velocity (SV) is the actual volumetric flow rate divided by the open volume. The DOC is a flow through device while the CPF is a wall flow device. This means that the exhaust is forced to flow in one channel through a wall and out a different channel through the CPF. The mass flow rate used in equation H.2 is determined by air flow rate through the LFE plus the fuel flow rate. The density of the exhaust used in equation H.2 is adjusted for by the average temperature of the DOC or CPF during the period space velocity is being calculated for.

$$
S V=\frac{\left.\begin{array}{c}
\text { Actual Volumetric } \\
\text { Exhaust Flow Rate }
\end{array} \mathrm{m}^{3} / \mathrm{s}\right)}{\text { Open Catalyst Volume }\left(\mathrm{m}^{3}\right)}
$$

$$
\underset{\text { Exhaust Flow Rate }}{\text { Actual Volumetric }}\left(\mathrm{m}^{3} / \mathrm{s}\right)=\frac{\left.\begin{array}{c}
\text { Exhaust } \\
\text { Mass Flow }
\end{array} \mathrm{m}^{3} / \mathrm{s}\right)}{\left.\begin{array}{c}
\text { Actual } \\
\text { Density }
\end{array} \mathrm{m}^{3} / \mathrm{s}\right)}
$$

$$
\text { Open Catalyst Volume }=\text { Open Area } \times \text { Length } \quad \text { Eqn. (H.3) }
$$

$$
\begin{gathered}
\text { Open Area } a_{D O C}=\# \text { of Cells } \times \text { Cell Width }{ }^{2} \\
\text { Open Area } a_{C P F}=\frac{\# \text { of Cells } \times \text { Cell Width }}{2}
\end{gathered}
$$

The DOC and CPF catalyst length used in equation H.3 is $102 \mathrm{~mm}$ and $305 \mathrm{~mm}$ respectively. The open catalyst volume comes to $.005927 \mathrm{~m}^{3}$ for the CPF and $.004804 \mathrm{~m}^{3}$ for the DOC. Cell widths used in equation G.4 of the DOC and CPF are $1.09 \mathrm{~mm}$ and $1.49 \mathrm{~mm}$ respectively. The number of channels (\# of Cells) in the DOC and CPF are 34636 and 17318 respectively. Half of the inlet channels are blocked within the CPF and the opposite half of the channels are blocked on the outlet side. This is the reason for dividing by 2 in equation H.5. The blocking of channels is what forces the exhaust gasses to flow through the wall of the CPF. The DOC and CPF typically have similar space velocities with the system used for this study. 


\section{Appendix I Temperature Comparison between Original and Modified Test Procedure}

Figure I. 1 shows the temperature differences between Test 9 performed with the test procedure used by Hutton et al. [1,2] and Test 19 with the modified test procedure at each thermocouple (see Figure 3.3 for thermocouple locations) for the first twenty minutes of the passive oxidation stage. From this plot it can be seen that there is as much as $200{ }^{\circ} \mathrm{C}$ temperature difference between the modified and un-modified test procedures at the beginning of Passive Oxidation.

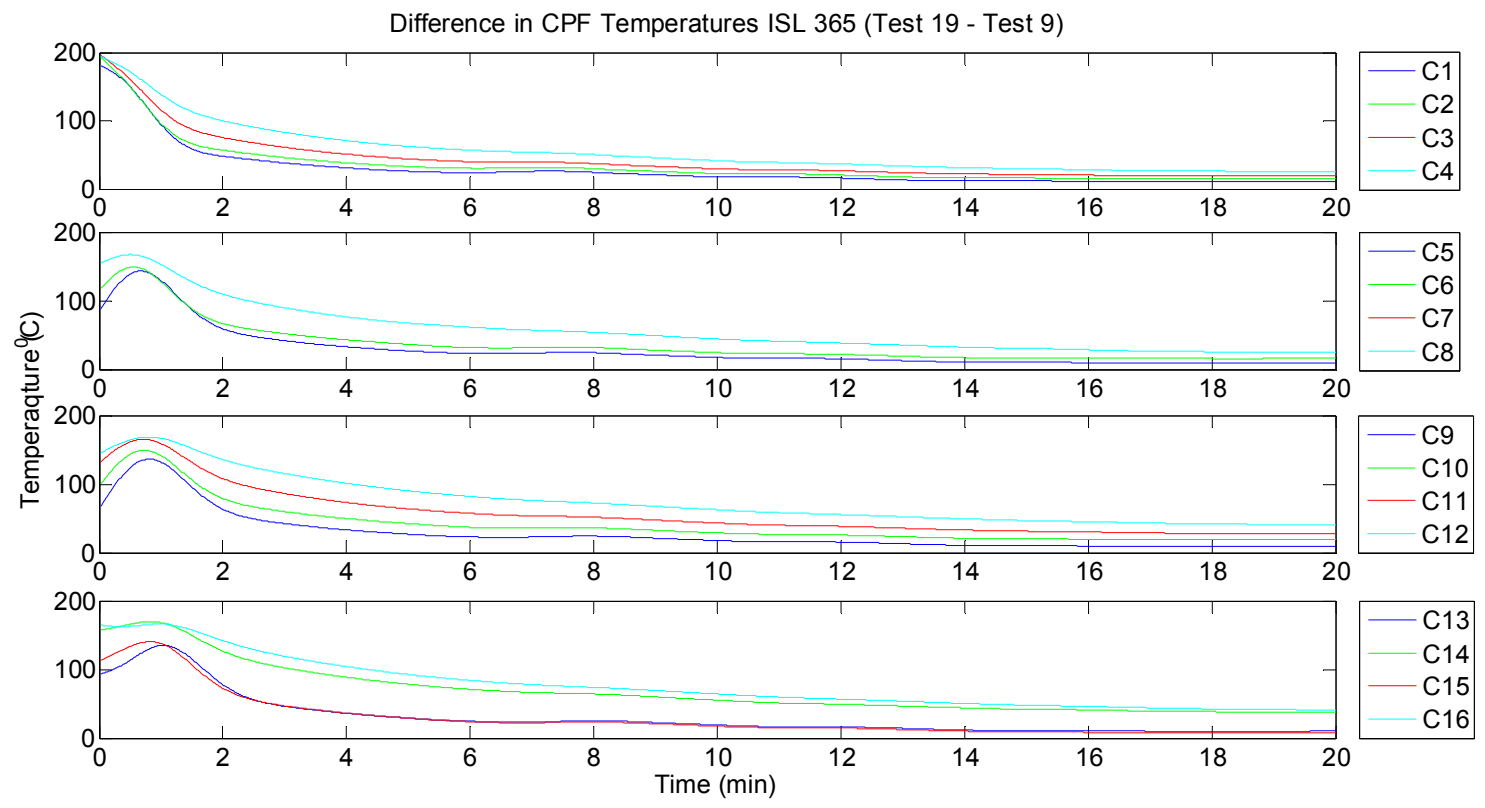

Figure I. 1: Difference in CPF temperatures during first twenty minutes of Passive Oxidation due to test procedure used

In Figure I. 2 it can be seen that the modified test procedure decreases the radial temperature gradient present in the un-modified test procedure. This plot shows the difference between the inner and outer thermocouple locations at four axial locations. 


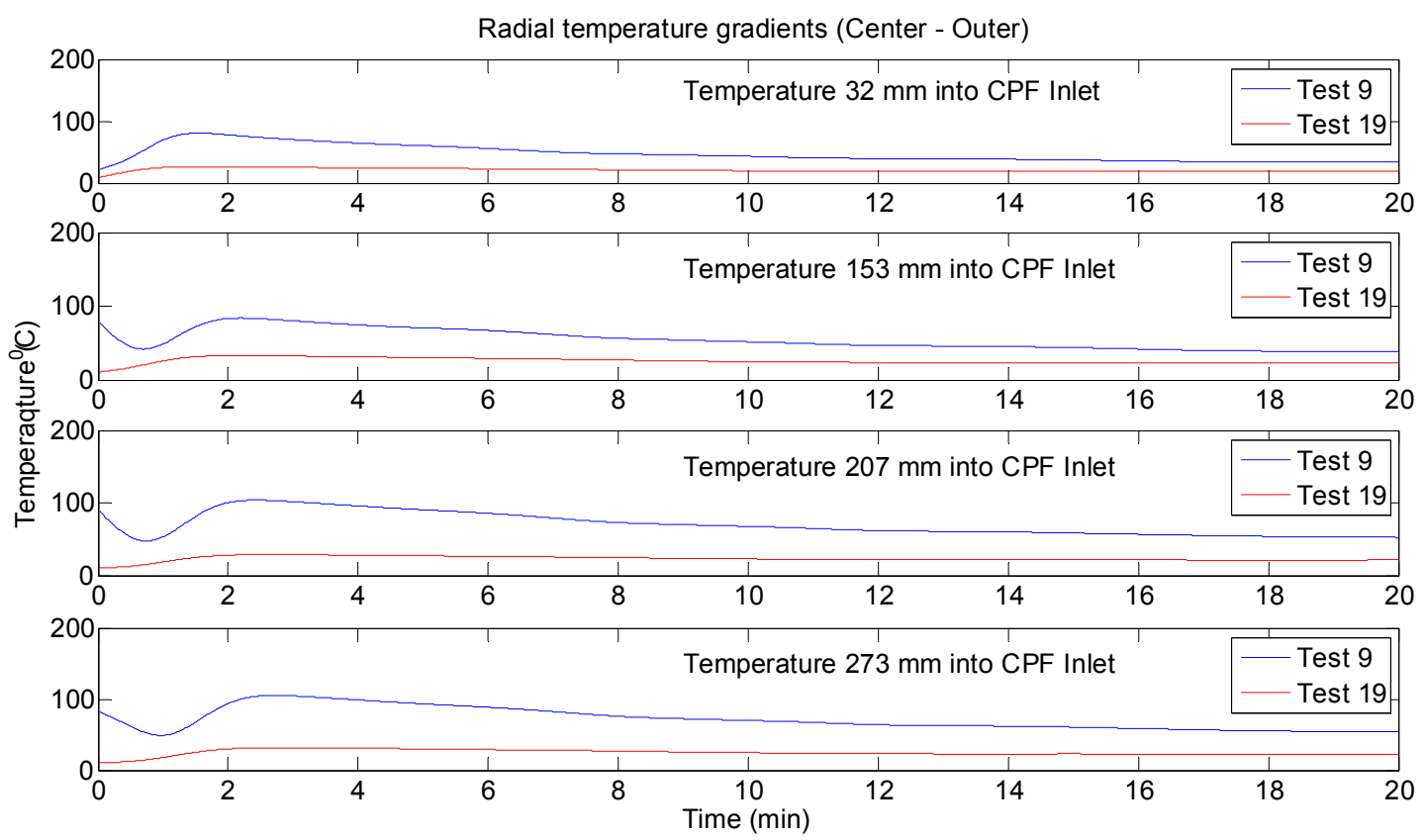

Figure I. 2: Radial temperature gradients Test $9=$ original, Test $19=\operatorname{modified}$ 


\section{Appendix J DOC and CPF Aging Data}

After concluding B10 and B20 testing a $\mathrm{NO}_{\mathrm{x}}$ sweep was performed with all three fuels used for this testing (ULSD, B10, and B20). This sweep was performed in an attempt to determine the affect fuel had on the $\mathrm{NO}_{2}$ overall consumption observed during biodiesel testing. Four engine operating points were chosen near loading conditions as shown in Table J.1. Each of these points was run with each fuel and emissions were collected UDOC, DDOC, and DCPF.

Table J.1:

Engine operating conditions used For $\mathrm{NO}_{\mathrm{x}}$ sweep with ULSD, B10, and B20 fuel

\begin{tabular}{|c|r|r|r|}
\hline RPM & 2000 & 2100 & 2200 \\
\hline \multirow{2}{*}{$\begin{array}{c}\text { Load } \\
(\mathrm{Nm})\end{array}$} & & 150 & \\
\cline { 2 - 4 } & 200 & 200 & 200 \\
\hline
\end{tabular}

Figure J.1 shows the calculated $\mathrm{NO}$ to $\mathrm{NO}_{2}$ conversion efficiencies for the $\mathrm{NO}_{\mathrm{x}}$ sweep. The scatter in this data and the primarily negative efficiency suggested that there was not a fuel dependency. Test 19 was then conducted with ULSD fuel and engine point $\mathrm{F}$ and showed negative conversion efficiency during loading stages as well. It has been concluded that the negative conversion efficiency of $\mathrm{NO}$ to $\mathrm{NO}_{2}$ during loading is due to DOC aging. Figure J.2 shows the CPF NO to $\mathrm{NO}_{2}$ conversion efficiency for Stage 2 of each test plotted in the order the test was performed. This plot shows no evidence of CPF aging. 


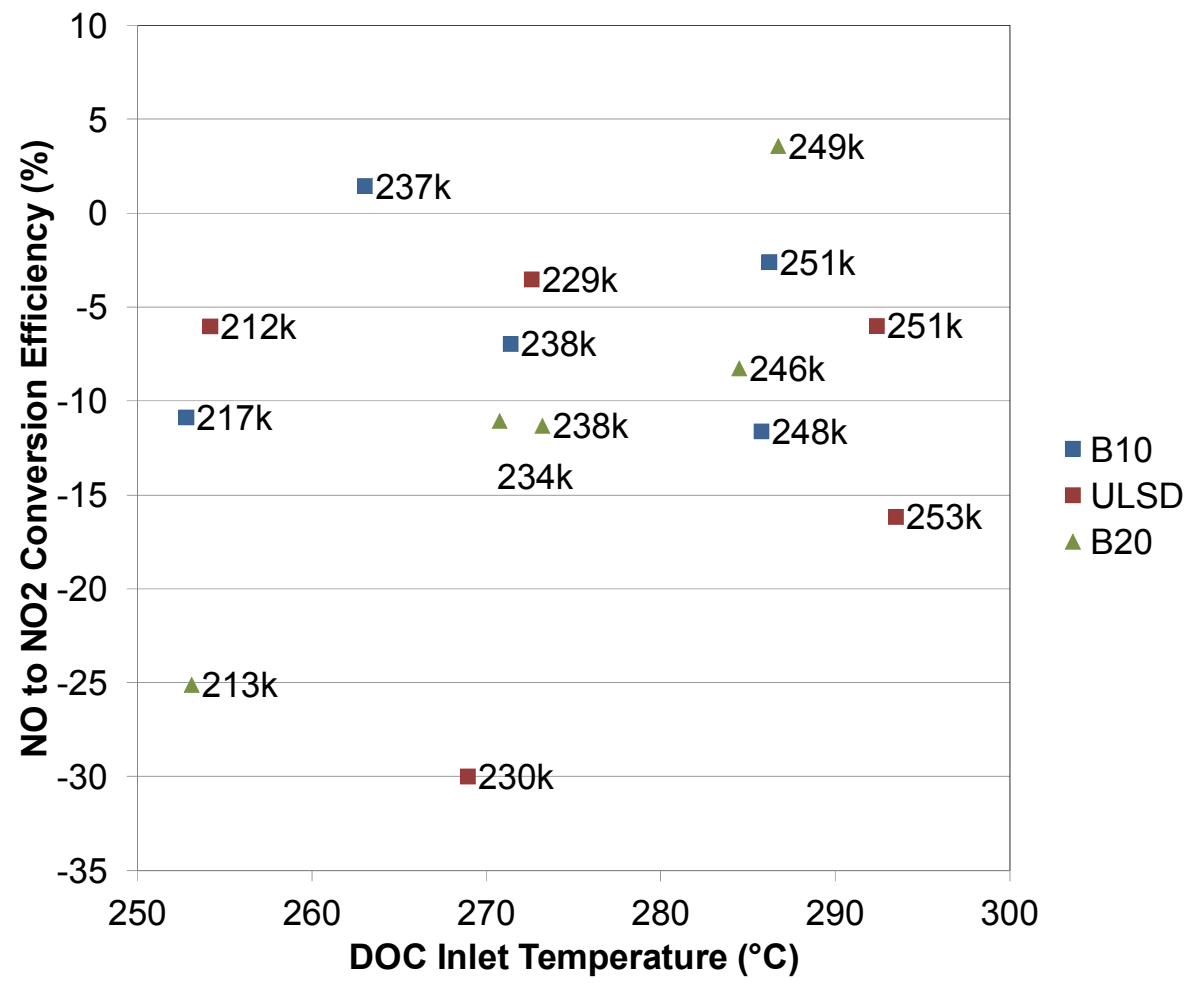

Figure J.1: $\mathrm{NO}$ to $\mathrm{NO}_{2}$ conversion efficiencies during $\mathrm{NO}_{\mathrm{x}}$ sweep

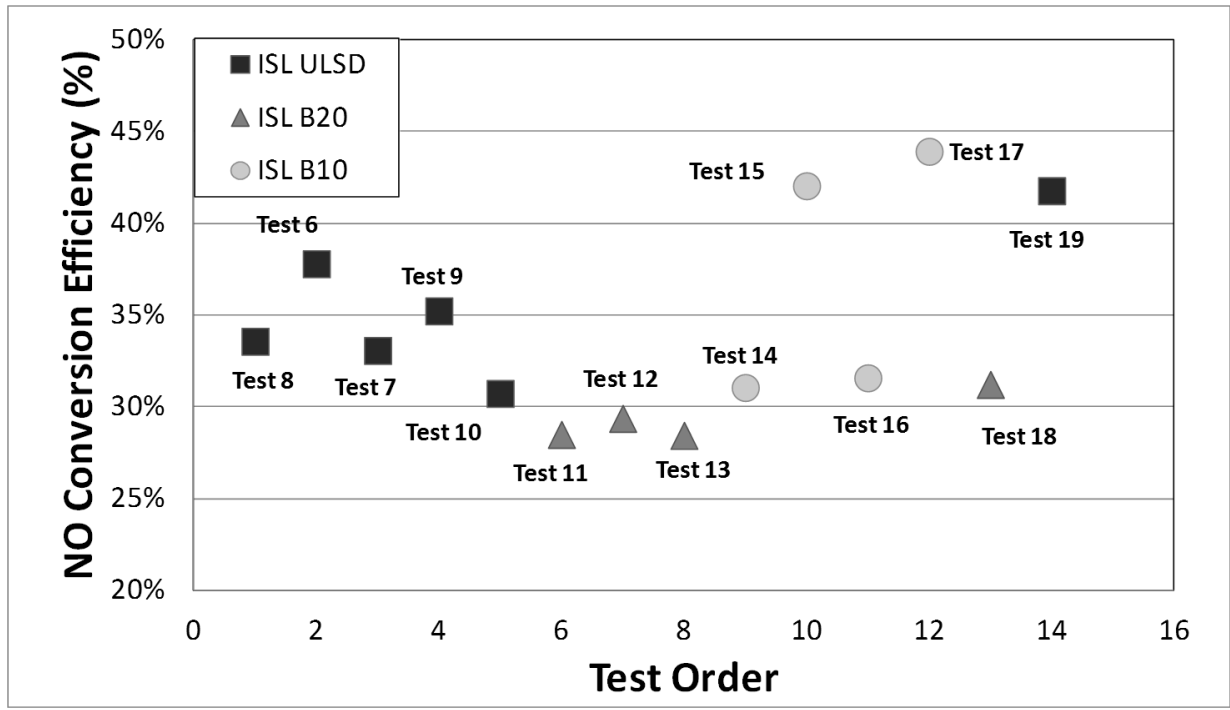

Figure J.2: Stage 2 CPF NO to $\mathrm{NO}_{2}$ conversion efficiency for each test plotted in the order the tests was performed. 


\section{Appendix K Complete Emissions Summaries}

Table K. 1:

ISL 365 Test 6 with ULSD emission summary

\begin{tabular}{|c|c|c|c|c|c|c|c|}
\hline \multicolumn{8}{|c|}{ Stage 1} \\
\hline & $\mathrm{HC}$ (ppm) & NOx (ppm) & NO (ppm) & NO2 (ppm) & CO (ppm) & CO2 (\%) & $\mathrm{O} 2(\%)$ \\
\hline UDOC & 101 & 93 & 76 & 18 & 130 & 5.19 & 13.80 \\
\hline DDOC & 12 & 92 & 64 & 27 & 0 & 5.24 & 13.75 \\
\hline DCPF & 0 & 86 & 36 & 50 & 0 & 5.17 & 13.85 \\
\hline \multicolumn{8}{|c|}{ Stage 2} \\
\hline & $\mathrm{HC}$ (ppm) & NOx (ppm) & NO (ppm) & $\mathrm{NO} 2$ (ppm) & $\mathrm{CO}$ (ppm) & CO2 (\%) & $\mathrm{O} 2(\%)$ \\
\hline UDOC & 81 & 91 & 70 & 21 & 131 & 5.13 & 13.89 \\
\hline DDOC & 14 & 88 & 65 & 22 & 1 & 5.10 & 13.96 \\
\hline DCPF & 0 & 85 & 41 & 45 & 0 & 5.11 & 13.91 \\
\hline \multicolumn{8}{|c|}{ Passive Oxidation } \\
\hline & $\mathrm{HC}$ (ppm) & NOx (ppm) & NO (ppm) & NO2 (ppm) & $\mathrm{CO}(\mathrm{ppm})$ & CO2 (\%) & $\mathrm{O} 2(\%)$ \\
\hline UDOC & 52 & 235 & 219 & 16 & 58 & 8.64 & 9.07 \\
\hline DDOC & $\mathrm{N} / \mathrm{A}$ & N/A & $\mathrm{N} / \mathrm{A}$ & $\mathrm{N} / \mathrm{A}$ & $\mathrm{N} / \mathrm{A}$ & $\mathrm{N} / \mathrm{A}$ & $\mathrm{N} / \mathrm{A}$ \\
\hline DCPF & 0 & 228 & 118 & 110 & 0 & 8.61 & 9.09 \\
\hline \multicolumn{8}{|c|}{ Stage 3} \\
\hline & $\mathrm{HC}$ (ppm) & NOx (ppm) & NO (ppm) & $\mathrm{NO} 2$ (ppm) & CO (ppm) & CO2 (\%) & $\mathrm{O} 2(\%)$ \\
\hline UDOC & 70 & 93 & 71 & 22 & 122 & 5.16 & 13.82 \\
\hline DDOC & $\mathrm{N} / \mathrm{A}$ & N/A & $\mathrm{N} / \mathrm{A}$ & $\mathrm{N} / \mathrm{A}$ & $\mathrm{N} / \mathrm{A}$ & $\mathrm{N} / \mathrm{A}$ & $\mathrm{N} / \mathrm{A}$ \\
\hline DCPF & 0 & 91 & 56 & 35 & 0 & 5.19 & 13.78 \\
\hline
\end{tabular}


Table K. 2:

ISL 365 Test 7 with ULSD emission summary

\begin{tabular}{|c|c|c|c|c|c|c|c|}
\hline \multicolumn{8}{|c|}{ Stage 1} \\
\hline & $\mathrm{HC}(\mathrm{ppm})$ & NOx $(p p m)$ & NO (ppm) & NO2 (ppm) & $\mathrm{CO}(\mathrm{ppm})$ & $\mathrm{CO} 2(\%)$ & $\mathrm{O} 2(\%)$ \\
\hline UDOC & \multirow{3}{*}{\multicolumn{7}{|c|}{ Bad Data Due To Heated Filter Not Being Plugged In }} \\
\hline DDOC & & & & & & & \\
\hline DCPF & & & & & & & \\
\hline \multicolumn{8}{|c|}{ Stage 2} \\
\hline & $\mathrm{HC}(\mathrm{ppm})$ & NOx $(p p m)$ & NO (ppm) & NO2 (ppm) & $\mathrm{CO}(\mathrm{ppm})$ & $\mathrm{CO} 2(\%)$ & $\mathrm{O} 2(\%)$ \\
\hline UDOC & 78 & 101 & 82 & 19 & 121 & 5.10 & 13.72 \\
\hline DDOC & 9 & 98 & 67 & 31 & 0 & 5.13 & 13.75 \\
\hline DCPF & 0 & 95 & 45 & 51 & 0 & 5.12 & 13.72 \\
\hline \multicolumn{8}{|c|}{ Passive Oxidation } \\
\hline & $\mathrm{HC}(p p m)$ & NOx (ppm) & NO (ppm) & NO2 (ppm) & $\mathrm{CO}$ (ppm) & $\mathrm{CO} 2(\%)$ & $\mathrm{O} 2(\%)$ \\
\hline UDOC & 20 & 224 & 213 & 12 & 60 & 9.75 & 7.18 \\
\hline DDOC & N/A & N/A & N/A & N/A & N/A & N/A & N/A \\
\hline DCPF & 0 & 217 & 140 & 77 & 0 & 9.77 & 7.18 \\
\hline \multicolumn{8}{|c|}{ Stage 3} \\
\hline & $\mathrm{HC}(p p m)$ & NOx (ppm) & NO (ppm) & NO2 (ppm) & $\mathrm{CO}(\mathrm{ppm})$ & CO2 (\%) & $\mathrm{O} 2(\%)$ \\
\hline UDOC & 71 & 93 & 77 & 16 & 126 & 5.03 & 13.66 \\
\hline DDOC & N/A & N/A & N/A & N/A & $\mathrm{N} / \mathrm{A}$ & N/A & $\mathrm{N} / \mathrm{A}$ \\
\hline DCPF & 0 & 92 & 65 & 28 & 0 & 5.12 & 13.54 \\
\hline
\end{tabular}


Table K. 3:

ISL 365 Test 8 with ULSD emission summary

\begin{tabular}{|c|c|c|c|c|c|c|c|}
\hline \multicolumn{8}{|c|}{ Stage 1} \\
\hline & $\mathrm{HC}(\mathrm{ppm})$ & NOx (ppm) & NO (ppm) & NO2 (ppm) & $\mathrm{CO}(\mathrm{ppm})$ & CO2 (\%) & $\mathrm{O} 2(\%)$ \\
\hline UDOC & $\mathrm{N} / \mathrm{A}$ & 93 & 69 & 24 & 133 & 5.13 & 13.79 \\
\hline DDOC & 25 & 92 & 58 & 34 & 0 & 5.18 & 13.73 \\
\hline DCPF & 0 & 87 & 38 & 49 & 0 & 5.13 & 13.78 \\
\hline \multicolumn{8}{|c|}{ Pierburg HC overdosed before UDOC sampling } \\
\hline \multicolumn{8}{|c|}{ Stage 2} \\
\hline & $\mathrm{HC}(\mathrm{ppm})$ & NOx (ppm) & NO (ppm) & NO2 (ppm) & $\mathrm{CO}(\mathrm{ppm})$ & $\mathrm{CO} 2(\%)$ & $\mathrm{O} 2(\%)$ \\
\hline UDOC & 124 & 92 & 66 & 26 & 133 & 5.09 & 13.87 \\
\hline DDOC & 19 & 89 & 60 & 29 & 0 & 5.08 & 13.93 \\
\hline DCPF & 0 & 86 & 40 & 46 & 0 & 5.13 & 13.82 \\
\hline \multicolumn{8}{|c|}{ Passive Oxidation } \\
\hline & $\mathrm{HC}$ (ppm) & NOx (ppm) & NO (ppm) & NO2 (ppm) & $\mathrm{CO}$ (ppm) & $\mathrm{CO} 2(\%)$ & O2 (\%) \\
\hline UDOC & 66 & 231 & 217 & 14 & 63 & 8.81 & 8.71 \\
\hline DDOC & 0 & 220 & 106 & 114 & 0 & 8.84 & 8.68 \\
\hline DCPF & 0 & 220 & 110 & 110 & 0 & 8.82 & 0.87 \\
\hline \multicolumn{8}{|c|}{ Stage 3} \\
\hline & $\mathrm{HC}(\mathrm{ppm})$ & NOx (ppm) & NO (ppm) & NO2 (ppm) & $\mathrm{CO}$ (ppm) & $\mathrm{CO} 2(\%)$ & $\mathrm{O} 2(\%)$ \\
\hline UDOC & 96 & 93 & 69 & 24 & 130 & 5.16 & 13.76 \\
\hline DDOC & 16 & 92 & 63 & 29 & 0 & 5.18 & 13.75 \\
\hline DCPF & 0 & 89 & 47 & 42 & 0 & 5.15 & 13.78 \\
\hline
\end{tabular}


Table K. 4:

ISL 365 Test 9 with ULSD emissions summary

\begin{tabular}{|c|c|c|c|c|c|c|c|}
\hline \multicolumn{8}{|c|}{ Stage 1} \\
\hline & $\mathrm{HC}(\mathrm{ppm})$ & NOx (ppm) & NO (ppm) & NO2 (ppm) & $\mathrm{CO}(\mathrm{ppm})$ & $\mathrm{CO} 2(\%)$ & $\mathrm{O} 2(\%)$ \\
\hline UDOC & 107 & 95 & 67 & 29 & 127 & 5.04 & 13.67 \\
\hline DDOC & 0 & 94 & 59 & 35 & 0 & 5.01 & 13.73 \\
\hline DCPF & 0 & 91 & 36 & 55 & 0 & 4.98 & 13.78 \\
\hline \multicolumn{8}{|c|}{ Pierburg HC overdosed before UDOC sampling } \\
\hline \multicolumn{8}{|c|}{ Stage 2} \\
\hline & $\mathrm{HC}(\mathrm{ppm})$ & NOx (ppm) & NO (ppm) & NO2 (ppm) & $\mathrm{CO}$ (ppm) & $\mathrm{CO} 2(\%)$ & $\mathrm{O} 2(\%)$ \\
\hline UDOC & 86 & 96 & 66 & 31 & 126 & 4.98 & 13.68 \\
\hline DDOC & 7 & 96 & 63 & 33 & 0 & 5.02 & 13.63 \\
\hline DCPF & 0 & 92 & 41 & 51 & 0 & 5.03 & 13.63 \\
\hline \multicolumn{8}{|c|}{ Passive Oxidation } \\
\hline & $\mathrm{HC}$ (ppm) & NOx (ppm) & NO (ppm) & NO2 (ppm) & $\mathrm{CO}$ (ppm) & $\mathrm{CO} 2(\%)$ & $\mathrm{O} 2(\%)$ \\
\hline UDOC & 56 & 247 & 226 & 21 & 57 & 8.56 & 8.88 \\
\hline DDOC & 0 & 235 & 104 & 131 & 0 & 8.52 & 8.96 \\
\hline DCPF & 0 & 236 & 118 & 118 & 0 & 8.49 & 8.97 \\
\hline \multicolumn{8}{|c|}{ Stage 3} \\
\hline & HC (ppm) & NOx (ppm) & NO (ppm) & $\mathrm{NO} 2$ (ppm) & $\mathrm{CO}$ (ppm) & $\mathrm{CO} 2(\%)$ & $\mathrm{O} 2(\%)$ \\
\hline UDOC & 76 & 100 & 70 & 30 & 118 & 5.09 & 13.53 \\
\hline DDOC & 1 & 97 & 63 & 34 & 0 & 5.09 & 13.54 \\
\hline DCPF & 0 & 96 & 42 & 53 & 0 & 5.11 & 13.51 \\
\hline
\end{tabular}


Table K. 5:

ISL 365 Test 10 with ULSD emission summary

\begin{tabular}{|c|c|c|c|c|c|c|c|}
\hline \multicolumn{8}{|c|}{ Stage 1} \\
\hline & $\mathrm{HC}(\mathrm{ppm})$ & NOx (ppm) & NO (ppm) & NO2 (ppm) & $\mathrm{CO}(\mathrm{ppm})$ & CO2 (\%) & $\mathrm{O} 2(\%)$ \\
\hline UDOC & 88 & 93 & 62 & 31 & 132 & 4.91 & 13.888 \\
\hline DDOC & 16 & 93 & 61 & 32 & 0 & 4.96 & 13.832 \\
\hline DCPF & 0 & 88 & 39 & 50 & 0 & 4.93 & 13.879 \\
\hline \multicolumn{8}{|c|}{ Stage 2} \\
\hline & $\mathrm{HC}(\mathrm{ppm})$ & NOx (ppm) & NO (ppm) & $\mathrm{NO} 2$ (ppm) & $\mathrm{CO}$ (ppm) & CO2 (\%) & $\mathrm{O} 2(\%)$ \\
\hline UDOC & 75 & 98 & 63 & 35 & 128 & 4.92 & 13.781 \\
\hline DDOC & 13 & 96 & 66 & 30 & 0 & 4.93 & 13.824 \\
\hline DCPF & 0 & 93 & 46 & 47 & 0 & 4.95 & 13.771 \\
\hline \multicolumn{8}{|c|}{ Passive Oxidation } \\
\hline & $\mathrm{HC}(p p m)$ & NOx (ppm) & NO (ppm) & $\mathrm{NO} 2$ (ppm) & $\mathrm{CO}(\mathrm{ppm})$ & CO2 (\%) & $\mathrm{O} 2(\%)$ \\
\hline UDOC & 50 & 561 & 515 & 45 & 42 & 6.51 & 11.559 \\
\hline DDOC & 0 & 536 & 306 & 230 & 0 & 6.49 & 11.618 \\
\hline DCPF & 0 & 513 & 193 & 320 & 0 & 6.49 & 11.590 \\
\hline \multicolumn{8}{|c|}{ Stage 3} \\
\hline & $\mathrm{HC}(\mathrm{ppm})$ & NOx (ppm) & NO (ppm) & NO2 (ppm) & $\mathrm{CO}$ (ppm) & CO2 (\%) & $\mathrm{O} 2(\%)$ \\
\hline UDOC & 70 & 96 & 62 & 34 & 128 & 4.93 & 13.682 \\
\hline DDOC & 12 & 94 & 65 & 29 & 0 & 4.98 & 13.628 \\
\hline DCPF & 0 & 92 & 40 & 52 & 0 & 4.96 & 13.642 \\
\hline
\end{tabular}


Table K. 6:

ISL 365 Test 19 with ULSD emissions summary

\begin{tabular}{|c|c|c|c|c|c|c|c|}
\hline \multicolumn{8}{|c|}{ Stage 1} \\
\hline & $\mathrm{HC}(\mathrm{ppmC})$ & NOx (ppm) & NO (ppm) & NO2 (ppm) & CO (ppm) & $\mathrm{CO} 2(\%)$ & $02(\%)$ \\
\hline UDOC & 113 & 83 & 59 & 24 & 132 & 5.34 & 13.70 \\
\hline DDOC & 62 & 83 & 68 & 14 & 0 & 5.38 & 13.64 \\
\hline DCPF & 19 & 75 & 47 & 28 & 0 & 5.37 & 13.63 \\
\hline \multicolumn{8}{|c|}{ Stage 2_2 } \\
\hline & $\mathrm{HC}(\mathrm{ppmC})$ & NOx (ppm) & NO (ppm) & NO2 (ppm) & CO (ppm) & $\mathrm{CO} 2(\%)$ & $\mathrm{O} 2(\%)$ \\
\hline UDOC & 122 & 85 & 63 & 23 & 135 & 5.35 & 13.72 \\
\hline DDOC & 59 & 82 & 65 & 17 & 2 & 5.38 & 13.72 \\
\hline DCPF & 21 & 78 & 38 & 40 & 0 & 5.39 & 13.68 \\
\hline \multicolumn{8}{|c|}{ Ramp-up assume same as Stage 2 due to short stage duration } \\
\hline \multicolumn{8}{|c|}{ Passive Oxidation } \\
\hline & $\mathrm{HC}(\mathrm{ppmC})$ & NOx (ppm) & NO (ppm) & NO2 (ppm) & $\mathrm{CO}(\mathrm{ppm})$ & $\mathrm{CO} 2(\%)$ & $\mathrm{O} 2(\%)$ \\
\hline UDOC & 95 & 191 & 182 & 9 & 72 & 8.84 & 8.88 \\
\hline DDOC & 45 & 187 & 121 & 66 & 0 & 8.96 & 8.79 \\
\hline DCPF & 21 & 169 & 84 & 85 & 0 & 8.88 & 8.86 \\
\hline \multicolumn{8}{|c|}{ Stage 3} \\
\hline & $\mathrm{HC}(\mathrm{ppmC})$ & NOx (ppm) & NO (ppm) & NO2 (ppm) & CO (ppm) & CO2 (\%) & O2 (\%) \\
\hline UDOC & 99 & 84 & 62 & 22 & 131 & 5.40 & 13.59 \\
\hline DDOC & 60 & 84 & 72 & 12 & 3 & 5.43 & 13.56 \\
\hline DCPF & 25 & 77 & 39 & 38 & 0 & 5.44 & 13.53 \\
\hline \multicolumn{8}{|c|}{ Stage 4} \\
\hline & $\mathrm{HC}$ (ppmC) & NOx (ppm) & NO (ppm) & NO2 (ppm) & CO (ppm) & CO2 (\%) & O2 (\%) \\
\hline UDOC & 96 & 85 & 64 & 21 & 130 & 5.40 & 13.54 \\
\hline DDOC & 52 & 83 & 69 & 14 & 5 & 5.40 & 13.56 \\
\hline DCPF & 18 & 77 & 39 & 38 & 0 & 5.41 & 13.51 \\
\hline
\end{tabular}


Table K. 7:

ISL 365 Test 11 with B20 emissions summary

\begin{tabular}{|c|c|c|c|c|c|c|c|}
\hline \multicolumn{8}{|c|}{ Stage 1} \\
\hline & $\mathrm{HC}$ (ppm) & NOx (ppm) & NO (ppm) & NO2 (ppm) & $\mathrm{CO}$ (ppm) & CO2 (\%) & $\mathrm{O} 2(\%)$ \\
\hline UDOC & 94 & 88 & 58 & 31 & 127 & 5.02 & 14.00 \\
\hline DDOC & 34 & 87 & 60 & 27 & 1 & 5.03 & 14.01 \\
\hline DCPF & 11 & 85 & 38 & 47 & 0 & 5.00 & 14.03 \\
\hline \multicolumn{8}{|c|}{ Stage 2} \\
\hline & $\mathrm{HC}$ (ppm) & NOx (ppm) & NO (ppm) & NO2 (ppm) & $\mathrm{CO}$ (ppm) & CO2 (\%) & $\mathrm{O} 2(\%)$ \\
\hline UDOC & 79 & 90 & 60 & 31 & 125 & \begin{tabular}{|l|}
5.05 \\
\end{tabular} & 14.00 \\
\hline DDOC & 33 & 89 & 64 & 24 & 4 & 5.06 & 14.00 \\
\hline DCPF & 8 & 86 & 46 & 40 & 0 & 5.06 & 13.99 \\
\hline \multicolumn{8}{|c|}{ Stage $2-2$} \\
\hline & $\mathrm{HC}$ (ppm) & NOx (ppm) & NO (ppm) & NO2 (ppm) & $\mathrm{CO}$ (ppm) & $\mathrm{CO} 2(\%)$ & $\mathrm{O} 2(\%)$ \\
\hline UDOC & 78 & 92 & 62 & 31 & 124 & \begin{tabular}{|l|}
5.08 \\
\end{tabular} & 14.02 \\
\hline DDOC & 37 & 90 & 66 & 24 & 6 & 5.07 & 14.03 \\
\hline DCPF & 8 & 87 & 43 & 44 & 0 & 5.09 & 13.99 \\
\hline \multicolumn{8}{|c|}{ Ramp-up assume same as Stage 2 due to short stage duration } \\
\hline \multicolumn{8}{|c|}{ Passive Oxidation } \\
\hline & $\mathrm{HC}(\mathrm{ppm})$ & NOx (ppm) & NO (ppm) & NO2 (ppm) & $\mathrm{CO}$ (ppm) & $\mathrm{CO} 2(\%)$ & $\mathrm{O} 2(\%)$ \\
\hline UDOC & 78 & 318 & 271 & 47 & 69 & 5.93 & 12.94 \\
\hline DDOC & 22 & 310 & 194 & 115 & 0 & 6.00 & 12.85 \\
\hline DCPF & 7 & 303 & 145 & 158 & 0 & 5.93 & 12.93 \\
\hline \multicolumn{8}{|c|}{ Stage 3} \\
\hline & $\mathrm{HC}$ (ppm) & NOx (ppm) & NO (ppm) & NO2 (ppm) & $\mathrm{CO}$ (ppm) & $\mathrm{CO} 2(\%)$ & $\mathrm{O} 2(\%)$ \\
\hline UDOC & 72 & 93 & 62 & 31 & 122 & 5.07 & 14.11 \\
\hline DDOC & 31 & 92 & 65 & 27 & 6 & 5.09 & 14.11 \\
\hline DCPF & 8 & 89 & 42 & 47 & 0 & 5.09 & 14.10 \\
\hline \multicolumn{8}{|c|}{ Stage 4} \\
\hline & $\mathrm{HC}$ (ppm) & NOx (ppm) & NO (ppm) & NO2 (ppm) & $\mathrm{CO}$ (ppm) & CO2 (\%) & $\mathrm{O} 2(\%)$ \\
\hline UDOC & 74 & 94 & 63 & 31 & 120 & 5.12 & 13.99 \\
\hline DDOC & 32 & 90 & 65 & 25 & 6 & 5.05 & 14.10 \\
\hline DCPF & 6 & 89 & 42 & 47 & 0 & 5.12 & 13.98 \\
\hline
\end{tabular}


Table K. 8:

ISL 365 Test 12 with B20 emissions summary

\begin{tabular}{|c|c|c|c|c|c|c|c|}
\hline \multicolumn{8}{|c|}{ Stage 1} \\
\hline & $\mathrm{HC}(\mathrm{ppm})$ & NOx (ppm) & NO (ppm) & NO2 (ppm) & $\mathrm{CO}$ (ppm) & $\mathrm{CO} 2(\%)$ & $\mathrm{O} 2(\%)$ \\
\hline UDOC & 85 & 86 & 59 & 27 & 125 & & 13.98 \\
\hline DDOC & 20 & 86 & 63 & 24 & 0 & & 13.92 \\
\hline DCPF & 7 & 79 & 37 & 41 & 0 & & 14.16 \\
\hline \multicolumn{8}{|c|}{ Stage 2} \\
\hline & $\mathrm{HC}$ (ppm) & NOx (ppm) & NO (ppm) & NO2 (ppm) & $\mathrm{CO}$ (ppm) & $\mathrm{CO} 2(\%)$ & $\mathrm{O} 2(\%)$ \\
\hline UDOC & 69 & 89 & 61 & 28 & 124 & 5.02 & 13.99 \\
\hline DDOC & 19 & 88 & 63 & 25 & 0 & 5.03 & 14.00 \\
\hline DCPF & 6 & 81 & 45 & 36 & 0 & 4.91 & 14.12 \\
\hline \multicolumn{8}{|c|}{ Ramp-up assume same as Stage 2 due to short stage duration } \\
\hline \multicolumn{8}{|c|}{ Passive Oxidation } \\
\hline & $\mathrm{HC}(\mathrm{ppm})$ & NOx (ppm) & NO (ppm) & NO2 (ppm) & $\mathrm{CO}$ (ppm) & $\mathrm{CO} 2(\%)$ & $\mathrm{O} 2(\%)$ \\
\hline UDOC & 41 & 214 & 196 & 18 & 59 & 8.55 & 9.05 \\
\hline DDOC & 5 & 206 & 97 & 109 & 0 & 8.33 & 9.40 \\
\hline DCPF & 0 & 195 & 94 & 101 & 0 & 8.33 & 9.38 \\
\hline \multicolumn{8}{|c|}{ Stage 3} \\
\hline & $\mathrm{HC}(\mathrm{ppm})$ & NOx (ppm) & NO (ppm) & NO2 (ppm) & $\mathrm{CO}(\mathrm{ppm})$ & CO2 (\%) & $\mathrm{O} 2(\%)$ \\
\hline UDOC & 59 & 89 & 60 & 29 & 122 & 5.08 & 13.85 \\
\hline DDOC & 15 & 89 & 64 & 25 & 0 & 5.11 & 13.81 \\
\hline DCPF & 5 & 82 & 41 & 41 & 0 & 4.99 & 13.97 \\
\hline \multicolumn{8}{|c|}{ Stage 4} \\
\hline & $\mathrm{HC}$ (ppm) & NOx (ppm) & NO (ppm) & NO2 (ppm) & $\mathrm{CO}$ (ppm) & $\mathrm{CO} 2(\%)$ & $\mathrm{O} 2(\%)$ \\
\hline UDOC & 68 & 91 & 63 & 28 & 122 & 5.14 & 13.92 \\
\hline DDOC & 22 & 90 & 63 & 28 & 0 & 5.09 & 14.00 \\
\hline DCPF & 9 & 85 & 45 & 40 & 0 & 5.02 & 14.07 \\
\hline
\end{tabular}


Table K. 9:

ISL 365 Test 13 with B20 emissions summary

\begin{tabular}{|c|c|c|c|c|c|c|c|}
\hline \multicolumn{8}{|c|}{ Stage 1} \\
\hline & $\mathrm{HC}$ (ppm) & NOx (ppm) & NO (ppm) & NO2 (ppm) & $\mathrm{CO}$ (ppm) & CO2 (\%) & $\mathrm{O} 2(\%)$ \\
\hline UDOC & 63 & 81 & 54 & 27 & 129 & \begin{tabular}{|l|}
5.04 \\
\end{tabular} & 13.82 \\
\hline DDOC & 25 & 82 & 75 & 6 & 0 & 5.07 & 13.79 \\
\hline DCPF & 19 & 71 & 56 & 15 & 0 & 4.59 & 14.43 \\
\hline \multicolumn{8}{|c|}{ Stage 2} \\
\hline & $\mathrm{HC}$ (ppm) & NOx (ppm) & $\mathrm{NO}(\mathrm{ppm})$ & NO2 (ppm) & $\mathrm{CO}$ (ppm) & CO2 (\%) & $\mathrm{O} 2(\%)$ \\
\hline UDOC & 48 & 85 & 58 & 26 & 125 & 5.12 & 13.80 \\
\hline DDOC & 13 & 85 & 68 & 17 & 0 & 5.08 & 13.84 \\
\hline DCPF & 2 & 81 & 49 & 32 & 0 & 5.10 & 13.80 \\
\hline \multicolumn{8}{|c|}{ Ramp-up assume same as Stage 2 due to short stage duration } \\
\hline \multicolumn{8}{|c|}{ Passive Oxidation } \\
\hline & $\mathrm{HC}(\mathrm{ppm})$ & NOx (ppm) & NO (ppm) & NO2 (ppm) & $\mathrm{CO}(\mathrm{ppm})$ & $\mathrm{CO} 2(\%)$ & $\mathrm{O} 2(\%)$ \\
\hline UDOC & 10 & 196 & 183 & 13 & 61 & 9.87 & 7.36 \\
\hline DDOC & 2 & 204 & 140 & 64 & 0 & 9.92 & 7.31 \\
\hline DCPF & 0 & 184 & 112 & 72 & 0 & 9.87 & 7.35 \\
\hline \multicolumn{8}{|c|}{ Stage 3} \\
\hline & $\mathrm{HC}(\mathrm{ppm})$ & NOx (ppm) & NO (ppm) & NO2 (ppm) & $\mathrm{CO}(\mathrm{ppm})$ & CO2 (\%) & $\mathrm{O} 2(\%)$ \\
\hline UDOC & 58 & 83 & 56 & 27 & 127 & 5.14 & 13.88 \\
\hline DDOC & 8 & 81 & 58 & 23 & 0 & 5.15 & 13.87 \\
\hline DCPF & 0 & 80 & 36 & 44 & 0 & 5.15 & 13.87 \\
\hline \multicolumn{8}{|c|}{ Stage 4} \\
\hline & $\mathrm{HC}$ (ppm) & NOx (ppm) & NO (ppm) & NO2 (ppm) & $\mathrm{CO}$ (ppm) & CO2 (\%) & $\mathrm{O} 2(\%)$ \\
\hline UDOC & 46 & 84 & 57 & 27 & 125 & 5.12 & 13.86 \\
\hline DDOC & 14 & 81 & 57 & 24 & 0 & 5.12 & 13.93 \\
\hline DCPF & 2 & 68 & 32 & 36 & 0 & 4.37 & 14.92 \\
\hline
\end{tabular}


Table K. 10:

ISL 365 Test 14 with B10 emissions summary

\begin{tabular}{|c|c|c|c|c|c|c|c|}
\hline \multicolumn{8}{|c|}{ Stage 1} \\
\hline & $\mathrm{HC}(\mathrm{ppmC})$ & NOx (ppm) & NO (ppm) & NO2 (ppm) & $\mathrm{CO}$ (ppm) & $\mathrm{CO} 2(\%)$ & O2 (\%) \\
\hline UDOC & & 82 & 57 & 25 & 130 & 5.14 & 13.77 \\
\hline DDOC & & 82 & 63 & 20 & 0 & 5.14 & 13.78 \\
\hline DCPF & & 77 & 45 & 32 & 0 & 5.05 & 13.87 \\
\hline \multicolumn{8}{|c|}{ Stage 2} \\
\hline & $\mathrm{HC}(\mathrm{ppmC})$ & NOx (ppm) & NO (ppm) & NO2 (ppm) & $\mathrm{CO}$ (ppm) & $\mathrm{CO} 2(\%)$ & $\mathrm{O} 2(\%)$ \\
\hline UDOC & & 84 & 54 & 30 & 127 & 5.16 & 13.83 \\
\hline DDOC & & 84 & 59 & 25 & 0 & 5.16 & 13.84 \\
\hline DCPF & & 79 & 40 & 38 & 0 & 5.16 & 13.83 \\
\hline \multicolumn{8}{|c|}{ Ramp-up assume same as Stage 2 due to short stage duration } \\
\hline \multicolumn{8}{|c|}{ Passive Oxidation } \\
\hline & $\mathrm{HC}(\mathrm{ppmC})$ & NOx (ppm) & NO (ppm) & NO2 (ppm) & $\mathrm{CO}(\mathrm{ppm})$ & $\mathrm{CO} 2(\%)$ & $\mathrm{O} 2(\%)$ \\
\hline UDOC & & 270 & 232 & 38 & 67 & 6.08 & 12.57 \\
\hline DDOC & & 256 & 145 & 112 & 0 & 6.11 & 12.55 \\
\hline DCPF & & 243 & 115 & 128 & 0 & 6.09 & 12.57 \\
\hline \multicolumn{8}{|c|}{ Stage 3} \\
\hline & $\mathrm{HC}(\mathrm{ppmC})$ & NOx (ppm) & NO (ppm) & NO2 (ppm) & $\mathrm{CO}$ (ppm) & $\mathrm{CO} 2(\%)$ & $\mathrm{O} 2(\%)$ \\
\hline UDOC & & 86 & 60 & 26 & 124 & 5.17 & 13.81 \\
\hline DDOC & & 86 & 58 & 29 & 0 & 5.18 & 13.81 \\
\hline DCPF & & 82 & 39 & 44 & 0 & 5.14 & 13.85 \\
\hline \multicolumn{8}{|c|}{ Stage 4} \\
\hline & $\mathrm{HC}(\mathrm{ppmC})$ & NOx (ppm) & NO (ppm) & NO2 (ppm) & CO (ppm) & $\mathrm{CO} 2(\%)$ & $\mathrm{O} 2(\%)$ \\
\hline UDOC & & 86 & 62 & 24 & 123 & 5.19 & 13.84 \\
\hline DDOC & & 86 & 58 & 28 & 0 & 5.22 & 13.79 \\
\hline DCPF & & 80 & 38 & 43 & 0 & 5.20 & 13.82 \\
\hline
\end{tabular}

* HC data unavailable due to FID being repaired 
Table K. 11:

ISL 365 Test 15 with B10 emissions summary

\begin{tabular}{|c|c|c|c|c|c|c|c|}
\hline \multicolumn{8}{|c|}{ Stage 1} \\
\hline & $\mathrm{HC}(\mathrm{ppmC})$ & NOx (ppm) & NO (ppm) & NO2 (ppm) & CO (ppm) & $\mathrm{CO} 2(\%)$ & $\mathrm{O} 2$ (\%) \\
\hline UDOC & & 76 & 50 & 25 & 132 & 5.24 & 13.62 \\
\hline DDOC & & 77 & 69 & 9 & 0 & 5.28 & 13.58 \\
\hline DCPF & & 72 & 57 & 15 & 0 & 5.10 & 13.81 \\
\hline \multicolumn{8}{|c|}{ Stage 2} \\
\hline & $\mathrm{HC}(p p m C)$ & NOx (ppm) & NO (ppm) & NO2 (ppm) & $\mathrm{CO}(\mathrm{ppm})$ & $\mathrm{CO} 2(\%)$ & $\mathrm{O} 2$ (\%) \\
\hline UDOC & & 79 & 53 & 25 & 129 & 5.30 & 13.60 \\
\hline DDOC & & 77 & 50 & 27 & 0 & 5.29 & 13.62 \\
\hline DCPF & & 73 & 29 & 44 & 0 & 5.21 & 13.73 \\
\hline \multicolumn{8}{|c|}{ Ramp-up assume same as Stage 2 due to short stage duration } \\
\hline \multicolumn{8}{|c|}{ Passive Oxidation } \\
\hline & $\mathrm{HC}(\mathrm{ppmC})$ & NOx (ppm) & NO (ppm) & NO2 (ppm) & $\mathrm{CO}(\mathrm{ppm})$ & $\mathrm{CO} 2(\%)$ & $\mathrm{O} 2(\%)$ \\
\hline UDOC & & 195 & 178 & 17 & 62 & 8.70 & 8.87 \\
\hline DDOC & & 193 & 93 & 99 & 0 & 8.74 & 8.91 \\
\hline DCPF & & 171 & 81 & 90 & 0 & 8.60 & 9.03 \\
\hline \multicolumn{8}{|c|}{ Stage 3} \\
\hline & $\mathrm{HC}(\mathrm{ppmC})$ & NOx (ppm) & NO (ppm) & NO2 (ppm) & $\mathrm{CO}$ (ppm) & $\mathrm{CO} 2(\%)$ & $\mathrm{O} 2(\%)$ \\
\hline UDOC & & 77 & 52 & 25 & 130 & 5.32 & 13.46 \\
\hline DDOC & & 77 & 56 & 22 & 0 & 5.34 & 13.42 \\
\hline DCPF & & 71 & 28 & 43 & 0 & 5.27 & 13.52 \\
\hline \multicolumn{8}{|c|}{ Stage 4} \\
\hline & $\mathrm{HC}(p p m C)$ & NOx (ppm) & NO (ppm) & NO2 (ppm) & $\mathrm{CO}(\mathrm{ppm})$ & $\mathrm{CO} 2(\%)$ & $\mathrm{O} 2(\%)$ \\
\hline UDOC & & 79 & 54 & 25 & 129 & 5.30 & 13.56 \\
\hline DDOC & & 76 & 55 & 21 & 0 & 5.30 & 13.57 \\
\hline DCPF & & 72 & 32 & 40 & 0 & 5.23 & 13.66 \\
\hline
\end{tabular}

* HC data unavailable due to FID being repaired 
Table K. 12:

ISL 365 Test 16 with B10 emissions summary

\begin{tabular}{|c|c|c|c|c|c|c|c|}
\hline \multicolumn{8}{|c|}{ Stage 1} \\
\hline & $\mathrm{HC}$ (ppm) & NOx (ppm) & NO (ppm) & NO2 (ppm) & $\mathrm{CO}$ (ppm) & CO2 (\%) & $\mathrm{O} 2(\%)$ \\
\hline UDOC & & 81 & 55 & 26 & 128 & \begin{tabular}{|l|}
5.04 \\
\end{tabular} & 13.85 \\
\hline DDOC & & 81 & 58 & 23 & 0 & 5.07 & 13.82 \\
\hline DCPF & & 77 & 36 & 41 & 0 & 4.82 & 14.16 \\
\hline \multicolumn{8}{|c|}{ Stage 2} \\
\hline & $\mathrm{HC}$ (ppm) & NOx (ppm) & $\mathrm{NO}(\mathrm{ppm})$ & NO2 (ppm) & $\mathrm{CO}$ (ppm) & CO2 (\%) & $\mathrm{O} 2(\%)$ \\
\hline UDOC & & 84 & 57 & 26 & 125 & 5.08 & 13.72 \\
\hline DDOC & & 84 & 61 & 23 & 0 & 5.09 & 13.76 \\
\hline DCPF & & 76 & 42 & 34 & 0 & 4.89 & 14.00 \\
\hline \multicolumn{8}{|c|}{ Ramp-up assume same as Stage 2 due to short stage duration } \\
\hline \multicolumn{8}{|c|}{ Passive Oxidation } \\
\hline & $\mathrm{HC}(\mathrm{ppm})$ & NOx (ppm) & NO (ppm) & NO2 (ppm) & $\mathrm{CO}(\mathrm{ppm})$ & $\mathrm{CO} 2(\%)$ & $\mathrm{O} 2(\%)$ \\
\hline UDOC & & 210 & 194 & 16 & 58 & 9.90 & 7.15 \\
\hline DDOC & & 210 & 148 & 61 & 0 & 9.95 & 7.13 \\
\hline DCPF & & 187 & 125 & 62 & 0 & 9.68 & 7.46 \\
\hline \multicolumn{8}{|c|}{ Stage 3} \\
\hline & $\mathrm{HC}(\mathrm{ppm})$ & NOx (ppm) & NO (ppm) & NO2 (ppm) & $\mathrm{CO}(\mathrm{ppm})$ & CO2 (\%) & $\mathrm{O} 2(\%)$ \\
\hline UDOC & & 82 & 57 & 25 & 126 & 5.08 & 13.71 \\
\hline DDOC & & 81 & 56 & 25 & 0 & 5.08 & 13.73 \\
\hline DCPF & & 75 & 36 & 39 & 0 & 4.99 & 13.83 \\
\hline \multicolumn{8}{|c|}{ Stage 4} \\
\hline & $\mathrm{HC}$ (ppm) & NOx (ppm) & NO (ppm) & NO2 (ppm) & $\mathrm{CO}$ (ppm) & CO2 (\%) & $\mathrm{O} 2(\%)$ \\
\hline UDOC & & 85 & 59 & 26 & 124 & 5.04 & 13.76 \\
\hline DDOC & & 83 & 59 & 23 & 0 & 5.07 & 13.75 \\
\hline DCPF & & 64 & 34 & 31 & 0 & 4.11 & 15.04 \\
\hline
\end{tabular}


Table K. 13:

ISL 365 Test 17 with B10 emissions summary

\begin{tabular}{|c|c|c|c|c|c|c|c|}
\hline \multicolumn{8}{|c|}{ Stage 1} \\
\hline & $\mathrm{HC}(\mathrm{ppmC})$ & NOx (ppm) & NO (ppm) & NO2 (ppm) & $\mathrm{CO}$ (ppm) & $\mathrm{CO} 2(\%)$ & $\mathrm{O} 2(\%)$ \\
\hline UDOC & & 79 & 53 & 26 & 130 & 5.18 & 13.86 \\
\hline DDOC & & 79 & 57 & 22 & 0 & 5.18 & 13.87 \\
\hline DCPF & & 70 & 33 & 37 & 0 & 4.77 & 14.41 \\
\hline \multicolumn{8}{|c|}{ Stage 2} \\
\hline & $\mathrm{HC}(\mathrm{ppmC})$ & NOx (ppm) & NO (ppm) & NO2 (ppm) & $\mathrm{CO}$ (ppm) & $\mathrm{CO} 2(\%)$ & $\mathrm{O} 2(\%)$ \\
\hline UDOC & & 77 & 51 & 26 & 130 & 5.22 & 13.69 \\
\hline DDOC & & 77 & 55 & 22 & 0 & 5.21 & 13.77 \\
\hline DCPF & & 65 & 31 & 35 & 0 & 4.73 & 14.29 \\
\hline \multicolumn{8}{|c|}{ Ramp-up assume same as Stage 2 due to short stage duration } \\
\hline \multicolumn{8}{|c|}{ Passive Oxidation } \\
\hline & $\mathrm{HC}(\mathrm{ppmC})$ & NOx (ppm) & NO (ppm) & NO2 (ppm) & $\mathrm{CO}$ (ppm) & $\mathrm{CO} 2(\%)$ & $\mathrm{O} 2(\%)$ \\
\hline UDOC & & 180 & 165 & 15 & 65 & 8.75 & 8.79 \\
\hline DDOC & & 178 & 88 & 90 & 0 & 8.80 & 8.74 \\
\hline DCPF & & 142 & 69 & 73 & 0 & 7.81 & 10.06 \\
\hline \multicolumn{8}{|c|}{ Stage 3} \\
\hline & $\mathrm{HC}(\mathrm{ppmC})$ & NOx (ppm) & NO (ppm) & NO2 (ppm) & $\mathrm{CO}$ (ppm) & $\mathrm{CO} 2(\%)$ & $\mathrm{O} 2(\%)$ \\
\hline UDOC & & 74 & 48 & 25 & 132 & 5.31 & 13.48 \\
\hline DDOC & & 76 & 53 & 24 & 0 & 5.30 & 13.50 \\
\hline DCPF & & 63 & 28 & 35 & 0 & 4.76 & 14.20 \\
\hline \multicolumn{8}{|c|}{ Stage 4} \\
\hline & $\mathrm{HC}(\mathrm{ppmC})$ & NOx (ppm) & NO (ppm) & NO2 (ppm) & $\mathrm{CO}$ (ppm) & $\mathrm{CO} 2(\%)$ & $\mathrm{O} 2(\%)$ \\
\hline UDOC & & 74 & 50 & 23 & 130 & 5.24 & 13.67 \\
\hline DDOC & & 74 & 65 & 9 & 0 & 5.23 & 13.69 \\
\hline DCPF & & 66 & 49 & 17 & 0 & 4.69 & 14.40 \\
\hline
\end{tabular}

* HC data unavailable due to FID being repaired 
Table K. 14:

ISL 365 Test 18 with B20 emissions summary

\begin{tabular}{|c|c|c|c|c|c|c|c|}
\hline \multicolumn{8}{|c|}{ Stage 1} \\
\hline & $\mathrm{HC}(\mathrm{ppmC})$ & NOx (ppm) & NO (ppm) & NO2 (ppm) & $\mathrm{CO}$ (ppm) & $\mathrm{CO} 2(\%)$ & $\mathrm{O} 2(\%)$ \\
\hline UDOC & & 75 & 51 & 24 & 131 & 5.22 & 13.76 \\
\hline DDOC & & 75 & 53 & 22 & 0 & 5.26 & 13.72 \\
\hline DCPF & & 68 & 32 & 36 & 0 & 5.05 & 14.01 \\
\hline \multicolumn{8}{|c|}{ Stage 2} \\
\hline & $\mathrm{HC}(\mathrm{ppmC})$ & NOx (ppm) & NO (ppm) & NO2 (ppm) & $\mathrm{CO}$ (ppm) & $\mathrm{CO} 2(\%)$ & $\mathrm{O} 2(\%)$ \\
\hline UDOC & & 77 & 55 & 22 & 128 & 5.28 & 13.67 \\
\hline DDOC & & 76 & 56 & 20 & 0 & 5.26 & 13.75 \\
\hline DCPF & & 69 & 38 & 31 & 0 & 5.10 & 13.92 \\
\hline \multicolumn{8}{|c|}{ Ramp-up assume same as Stage 2 due to short stage duration } \\
\hline \multicolumn{8}{|c|}{ Passive Oxidation } \\
\hline & $\mathrm{HC}(\mathrm{ppmC})$ & NOx (ppm) & NO (ppm) & NO2 (ppm) & $\mathrm{CO}$ (ppm) & $\mathrm{CO} 2(\%)$ & $\mathrm{O} 2(\%)$ \\
\hline UDOC & & 266 & 229 & 37 & 66 & 5.78 & 13.20 \\
\hline DDOC & & 234 & 131 & 104 & 0 & 5.74 & 13.29 \\
\hline DCPF & & 239 & 120 & 119 & 0 & 5.89 & 13.08 \\
\hline \multicolumn{8}{|c|}{ Stage 3} \\
\hline & $\mathrm{HC}(\mathrm{ppmC})$ & NOx (ppm) & NO (ppm) & NO2 (ppm) & $\mathrm{CO}$ (ppm) & $\mathrm{CO} 2(\%)$ & $\mathrm{O} 2(\%)$ \\
\hline UDOC & & 82 & 57 & 25 & 126 & 5.28 & 13.88 \\
\hline DDOC & & 78 & 56 & 22 & 0 & 5.25 & 13.93 \\
\hline DCPF & & 75 & 40 & 35 & 0 & 5.13 & 14.08 \\
\hline \multicolumn{8}{|c|}{ Stage 4} \\
\hline & $\mathrm{HC}(\mathrm{ppmC})$ & NOx (ppm) & NO (ppm) & NO2 (ppm) & $\mathrm{CO}$ (ppm) & $\mathrm{CO} 2(\%)$ & $\mathrm{O} 2(\%)$ \\
\hline UDOC & & 83 & 58 & 25 & 125 & 5.30 & 13.96 \\
\hline DDOC & & 83 & 56 & 27 & 0 & 5.28 & 13.99 \\
\hline DCPF & & 77 & 41 & 36 & 0 & 5.14 & 14.16 \\
\hline
\end{tabular}

* HC data unavailable due to FID being repaired 
Table K. 15:

ISL 425 Test 1 with ULSD emissions summary

\begin{tabular}{|c|c|c|c|c|c|c|c|}
\hline \multicolumn{8}{|c|}{ Stage 1} \\
\hline & $\mathrm{HC}(\mathrm{ppmC})$ & NOx (ppm) & NO (ppm) & NO2 (ppm) & $\mathrm{CO}$ (ppm) & $\mathrm{CO} 2(\%)$ & $\mathrm{O} 2(\%)$ \\
\hline UDOC & 81 & 206 & 178 & 29 & 80 & 5.06 & 14.00 \\
\hline DDOC & 25 & 183 & 124 & 59 & 0 & 5.04 & 14.03 \\
\hline DCPF & 2 & 154 & 82 & 73 & 0 & 5.06 & 14.01 \\
\hline \multicolumn{8}{|c|}{ Stage 2} \\
\hline & $\mathrm{HC}(\mathrm{ppmC})$ & NOx (ppm) & NO (ppm) & NO2 (ppm) & $\mathrm{CO}$ (ppm) & CO2 (\%) & $\mathrm{O} 2(\%)$ \\
\hline UDOC & 68 & 200 & 173 & 27 & 80 & 5.09 & 13.82 \\
\hline DDOC & 25 & 187 & 135 & 53 & 0 & 5.05 & 13.93 \\
\hline DCPF & 3 & 160 & 98 & 62 & 0 & 5.08 & 13.84 \\
\hline \multicolumn{8}{|c|}{ Ramp-Up assume same as Stage 2} \\
\hline \multicolumn{8}{|c|}{ Passive Oxidation } \\
\hline & $\mathrm{HC}(\mathrm{ppmC})$ & NOx (ppm) & NO (ppm) & NO2 (ppm) & $\mathrm{CO}$ (ppm) & $\mathrm{CO} 2(\%)$ & $\mathrm{O} 2(\%)$ \\
\hline UDOC & 66 & 548 & 506 & 42 & 47 & 5.57 & 13.13 \\
\hline DDOC & 14 & 428 & 325 & 103 & 0 & 5.62 & 13.08 \\
\hline DCPF & 3 & 398 & 264 & 134 & 0 & 5.59 & 13.11 \\
\hline \multicolumn{8}{|c|}{ Stage 3} \\
\hline & $\mathrm{HC}(\mathrm{ppmC})$ & NOx (ppm) & NO (ppm) & NO2 (ppm) & $\mathrm{CO}$ (ppm) & CO2 (\%) & $\mathrm{O} 2(\%)$ \\
\hline UDOC & 54 & 196 & 172 & 24 & 79 & 5.14 & 13.65 \\
\hline DDOC & 16 & 177 & 129 & 48 & 0 & 5.13 & 13.67 \\
\hline DCPF & 2 & 155 & 100 & 55 & 0 & 5.13 & 13.66 \\
\hline \multicolumn{8}{|c|}{ Stage 4} \\
\hline & $\mathrm{HC}(\mathrm{ppmC})$ & NOx (ppm) & $\mathrm{NO}(\mathrm{ppm})$ & NO2 (ppm) & $\mathrm{CO}$ (ppm) & CO2 (\%) & $\mathrm{O} 2(\%)$ \\
\hline UDOC & 56 & 195 & 171 & 24 & 79 & 5.18 & 13.62 \\
\hline DDOC & 14 & 179 & 124 & 55 & 0 & 5.13 & 13.68 \\
\hline DCPF & 1 & 160 & 102 & 59 & 0 & 5.13 & 13.67 \\
\hline
\end{tabular}




\section{Appendix L Stage 2 Loading PSD Data Separated by Test}
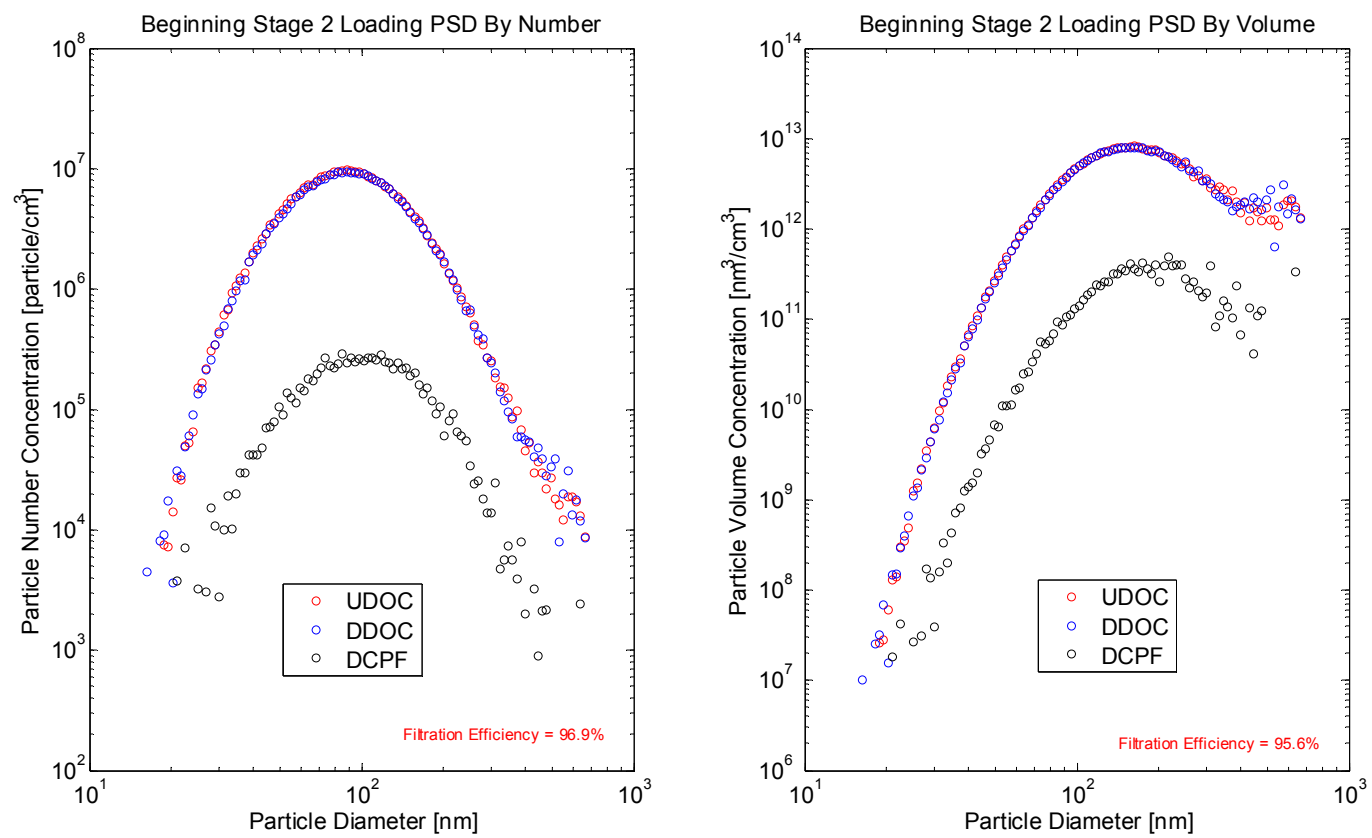

Figure L. 1: ISL 365 B20 Test 11 beginning Stage 2 loading PSD data
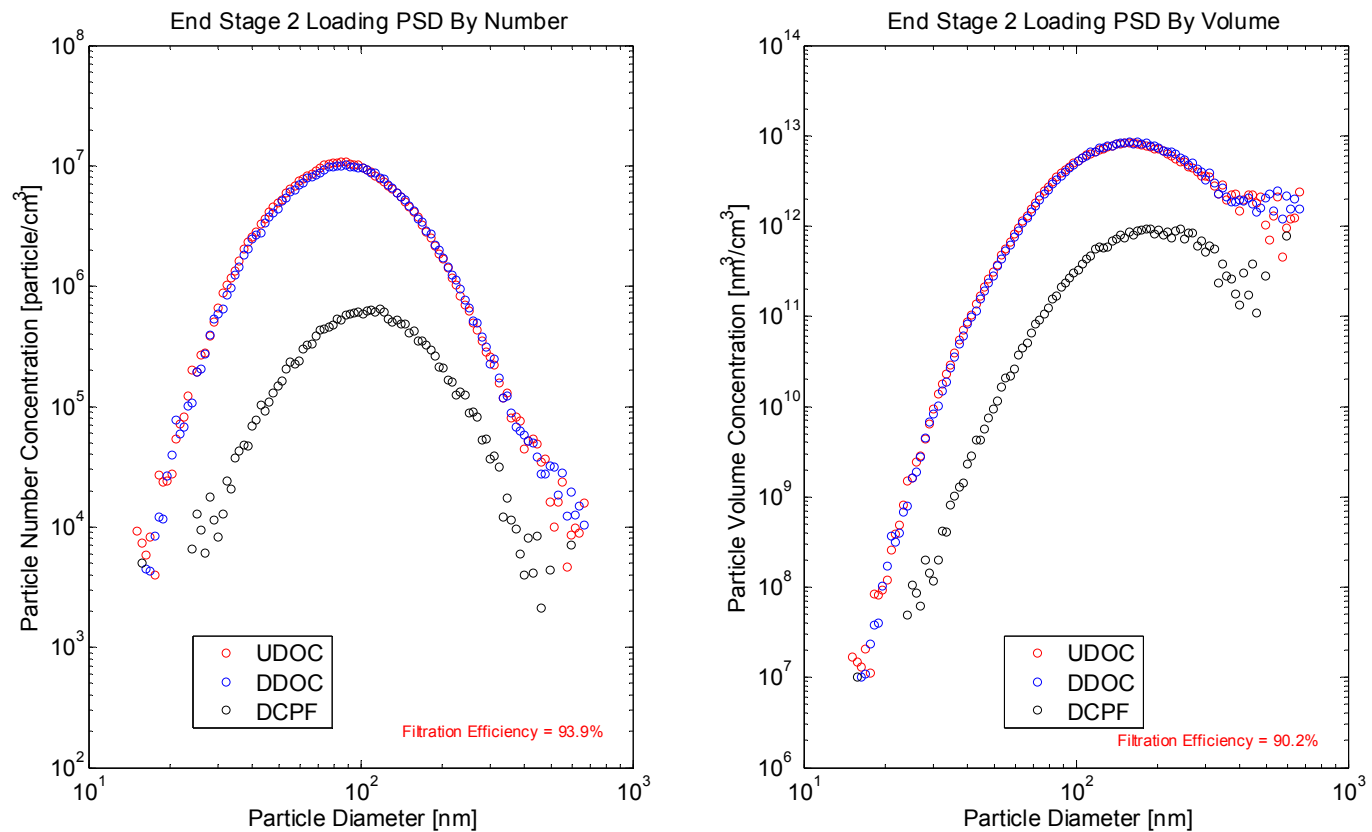

Figure L. 2: ISL 365 B20 Test 11 end Stage 2 loading PSD data 

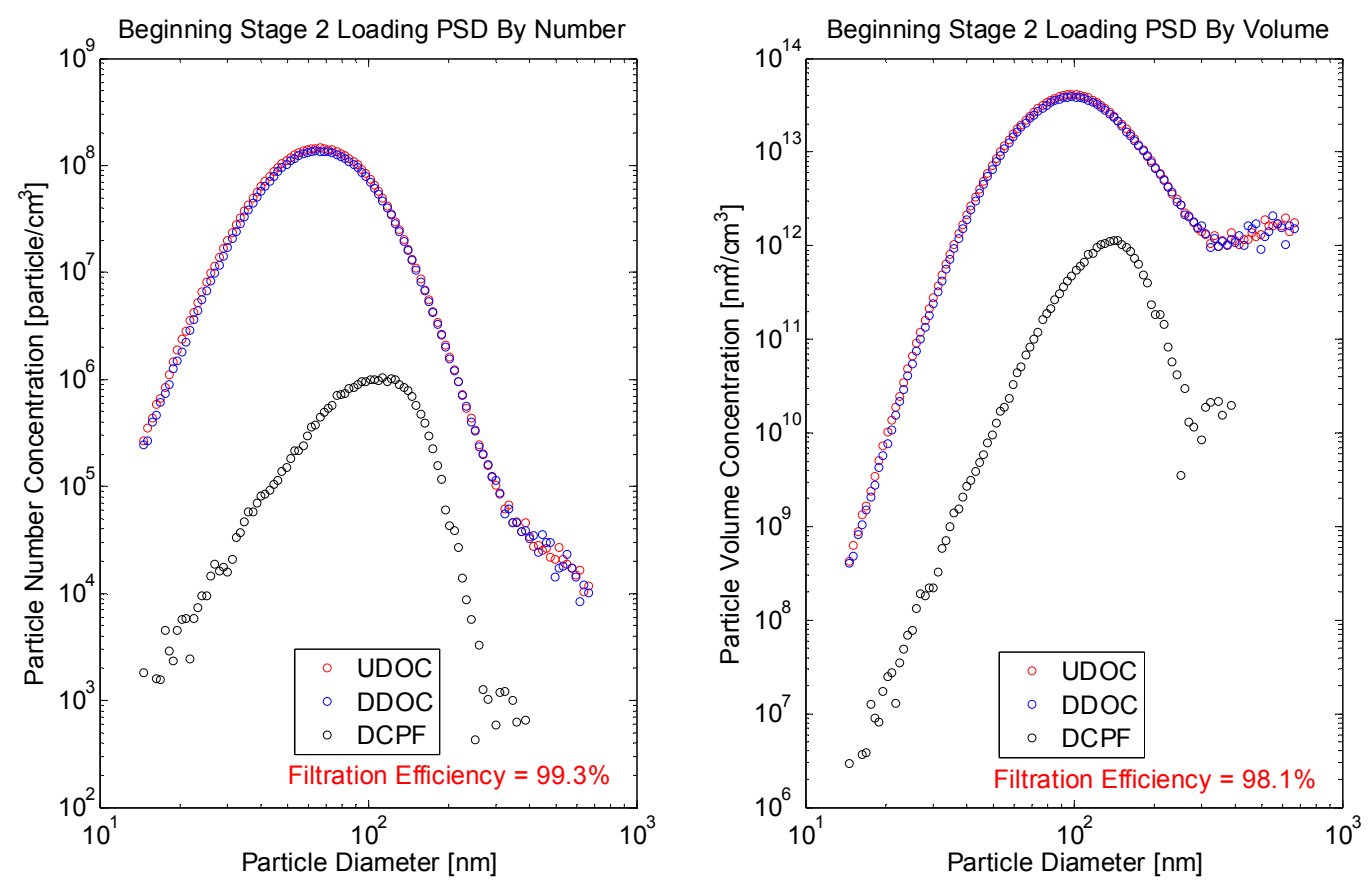

Figure L. 3: ISL 365 B20 Test 12 beginning Stage 2 loading PSD data
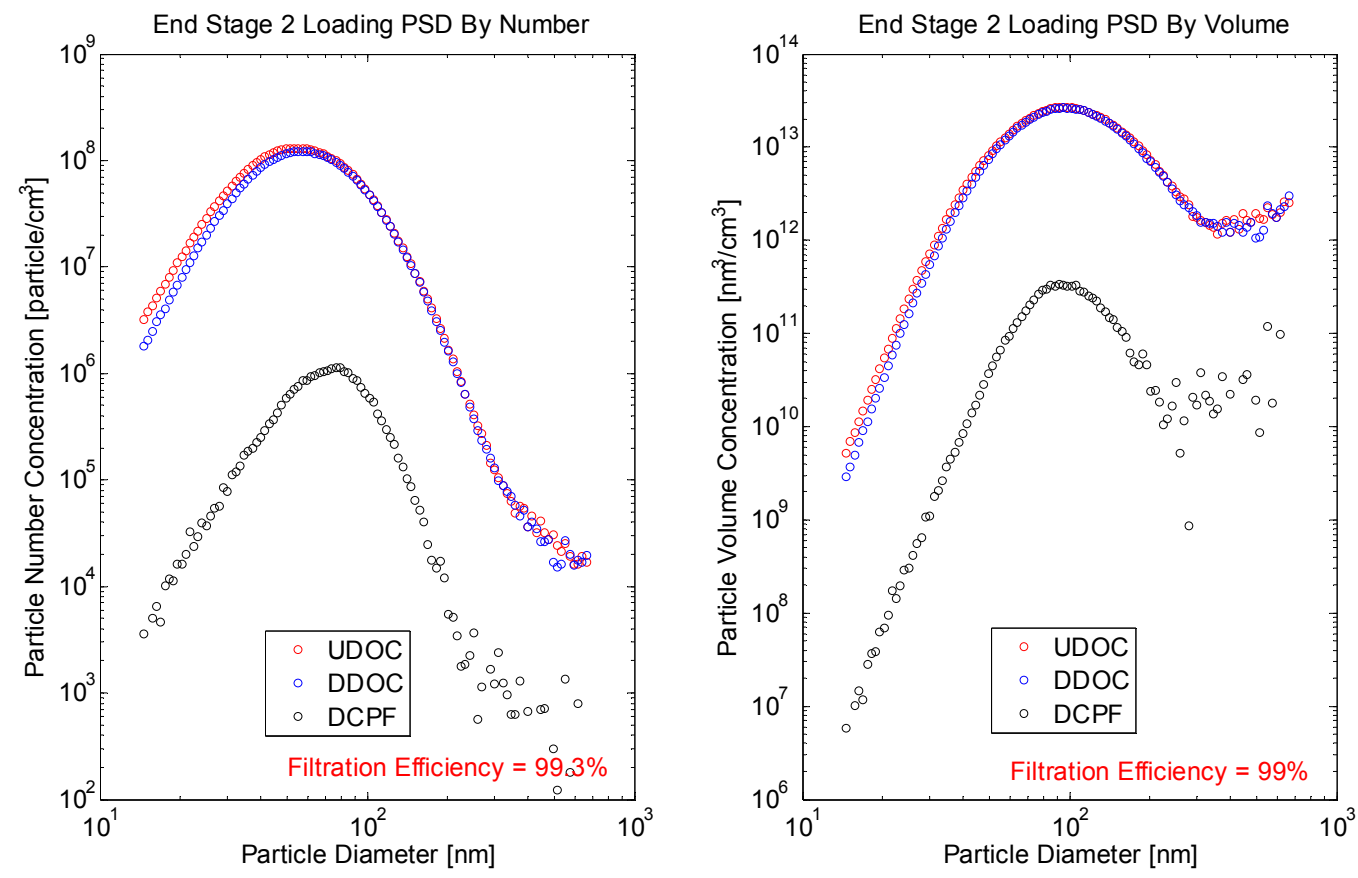

Figure L. 4: ISL 365 B20 Test 12 end Stage 2 loading PSD data 

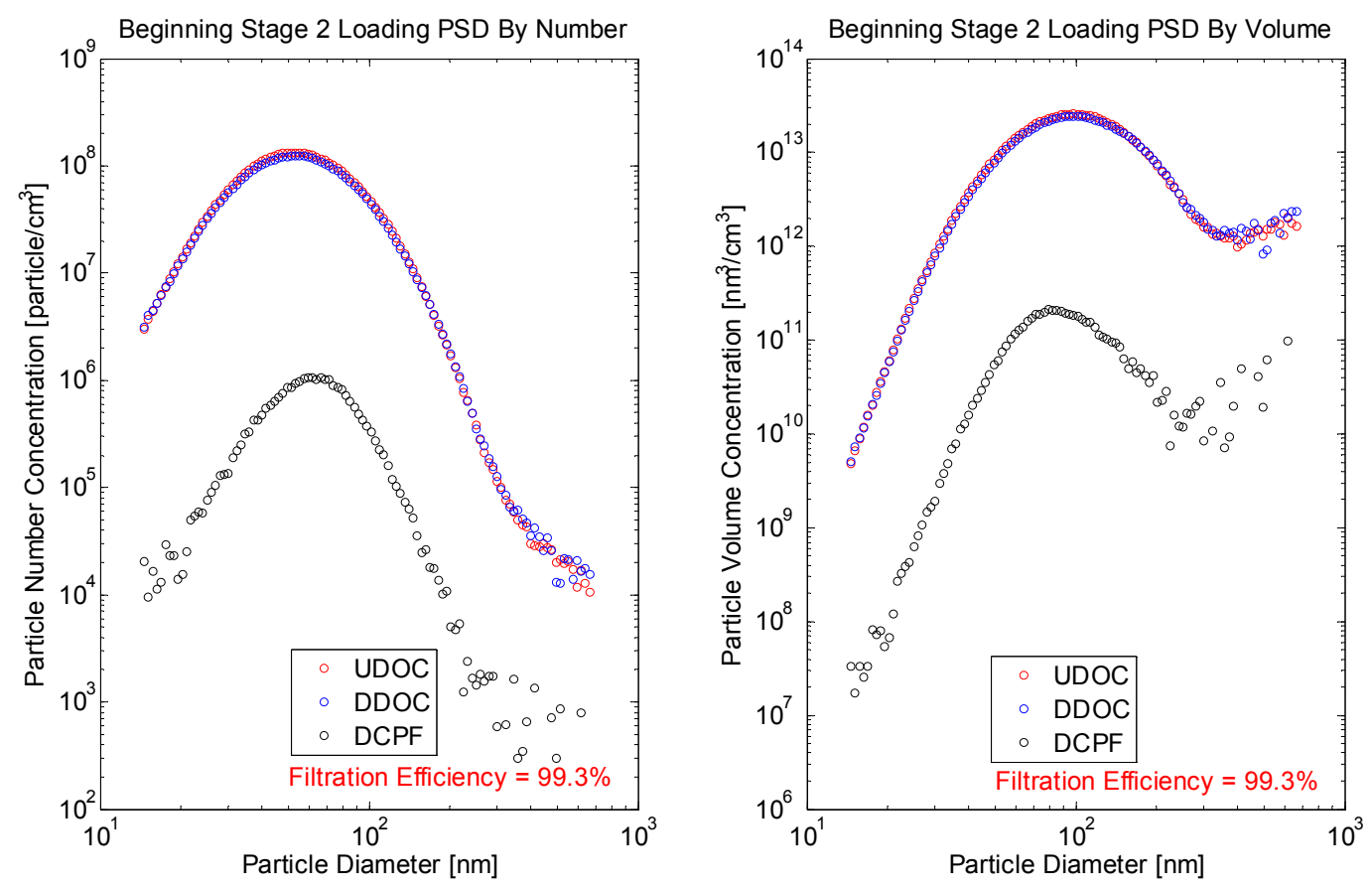

Figure L. 5: ISL 365 B20 Test 13 beginning Stage 2 loading PSD data
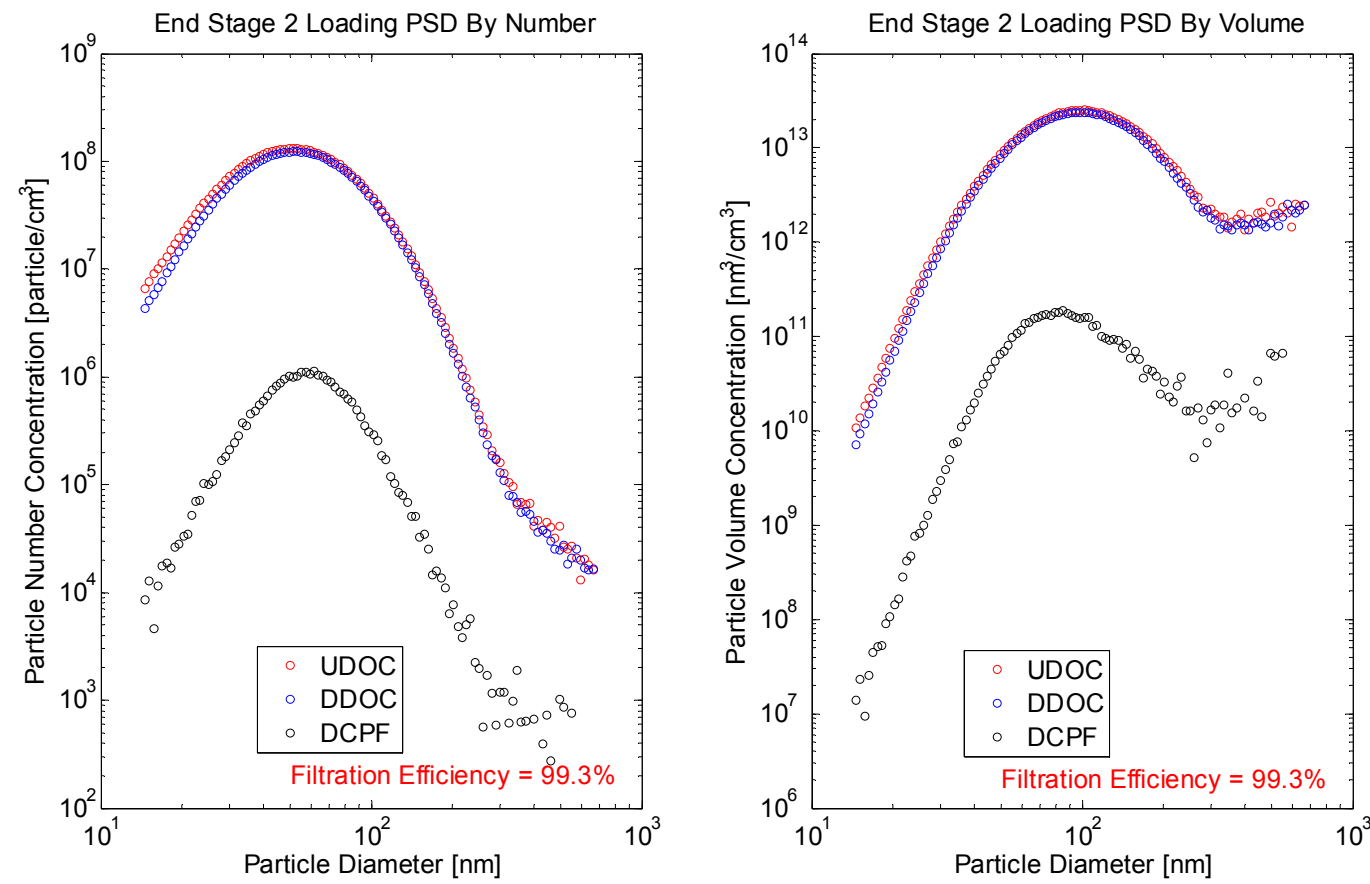

Figure L. 6: ISL 365 B20 Test 13 end Stage 2 loading PSD data 

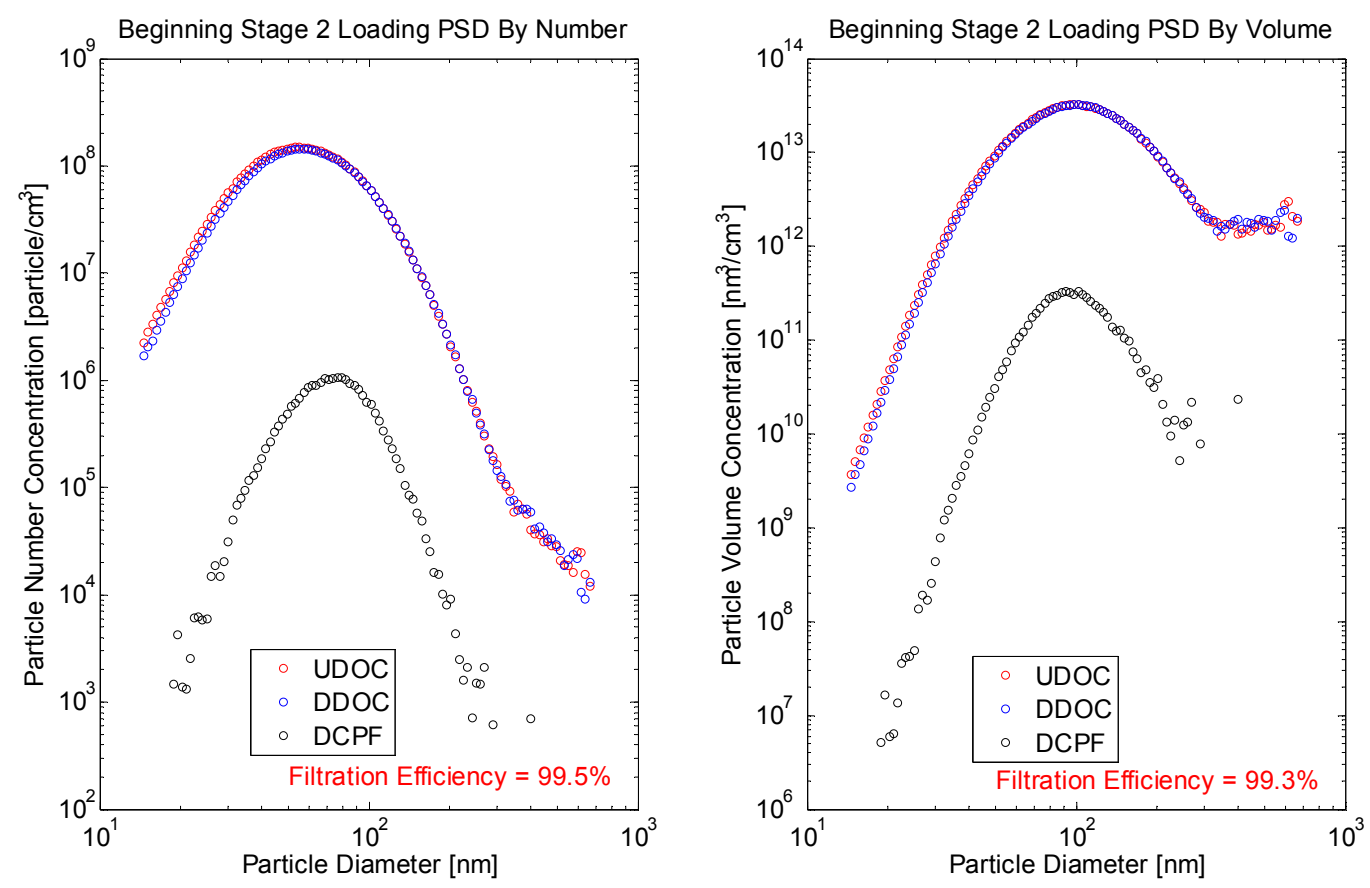

Figure L. 7: ISL 365 B10 Test 14 beginning Stage 2 loading PSD data
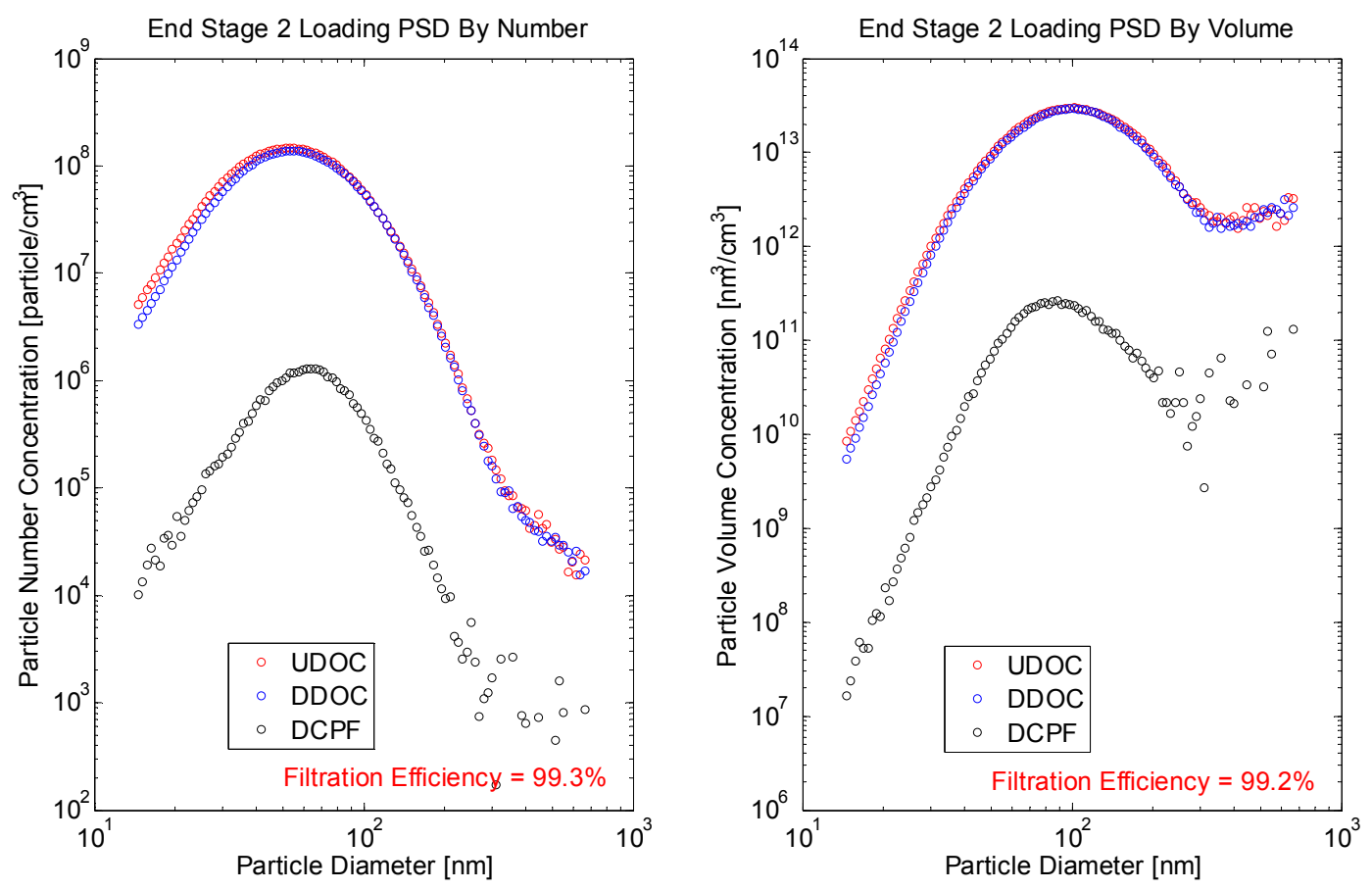

Figure L. 8: ISL 365 B10 Test 14 end Stage 2 loading PSD data 

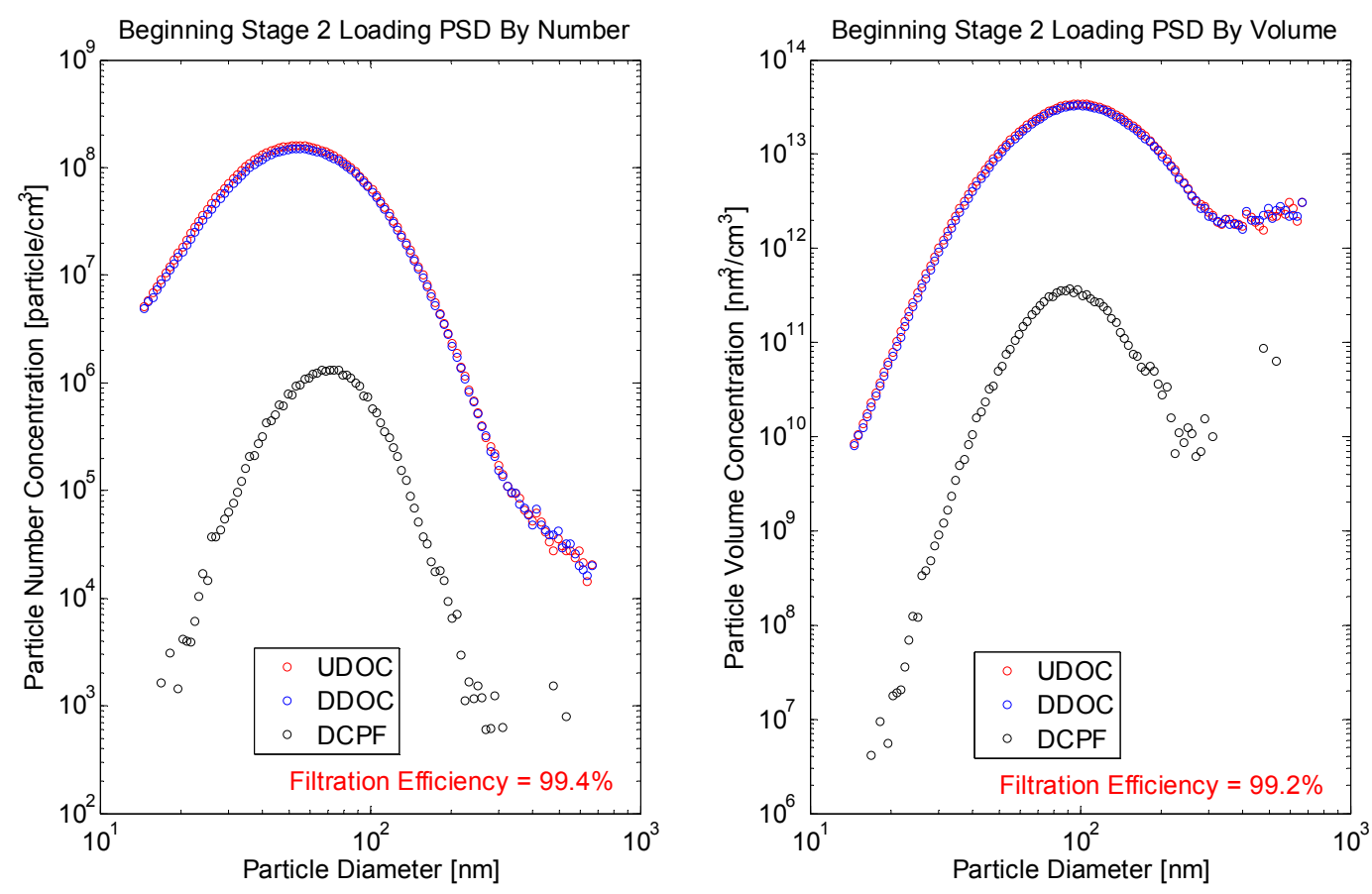

Figure L. 9: ISL 365 B10 Test 15 beginning Stage 2 loading PSD data
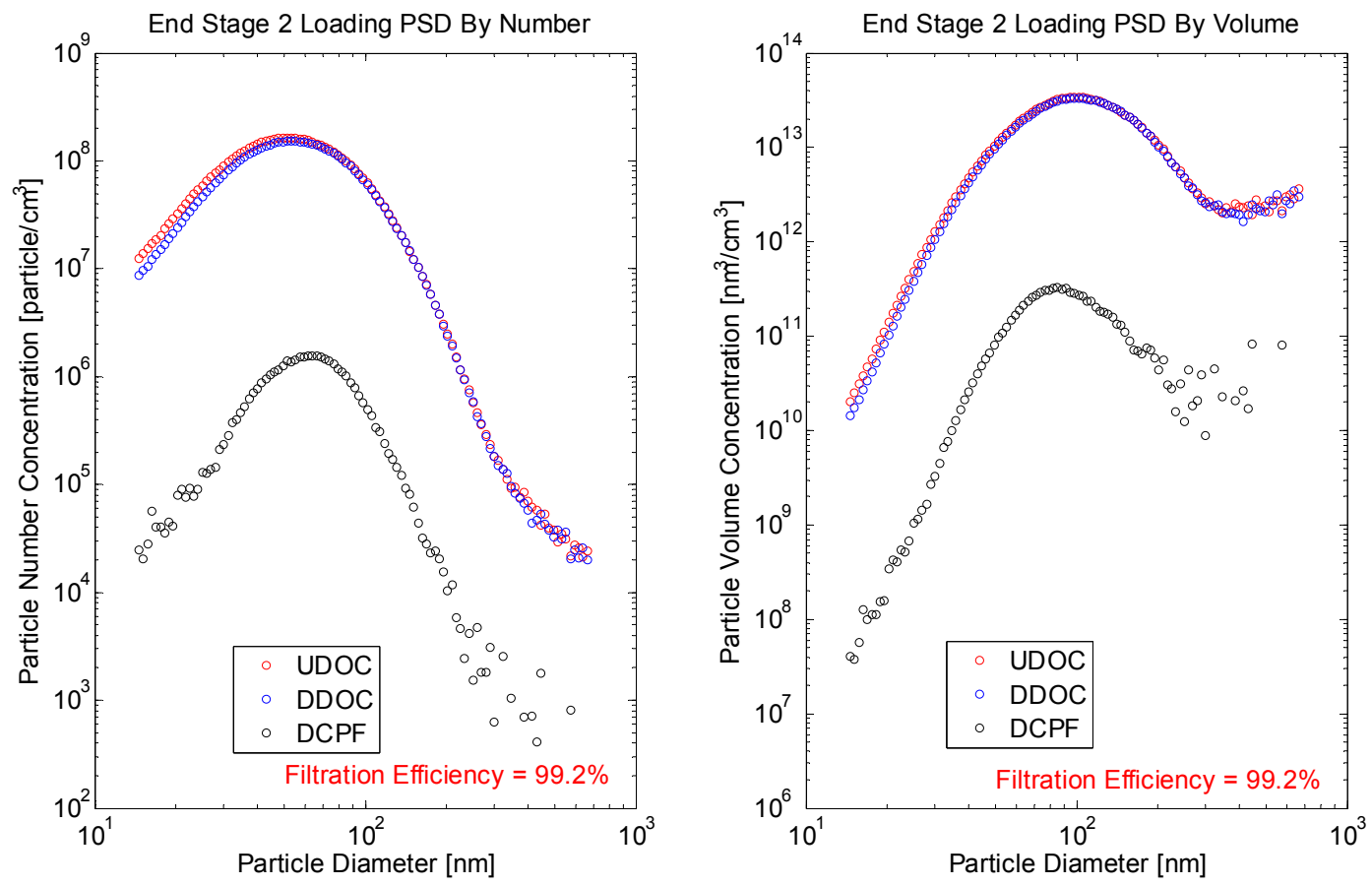

Figure L. 10: ISL 365 B10 Test 15 end Stage 2 loading PSD data 

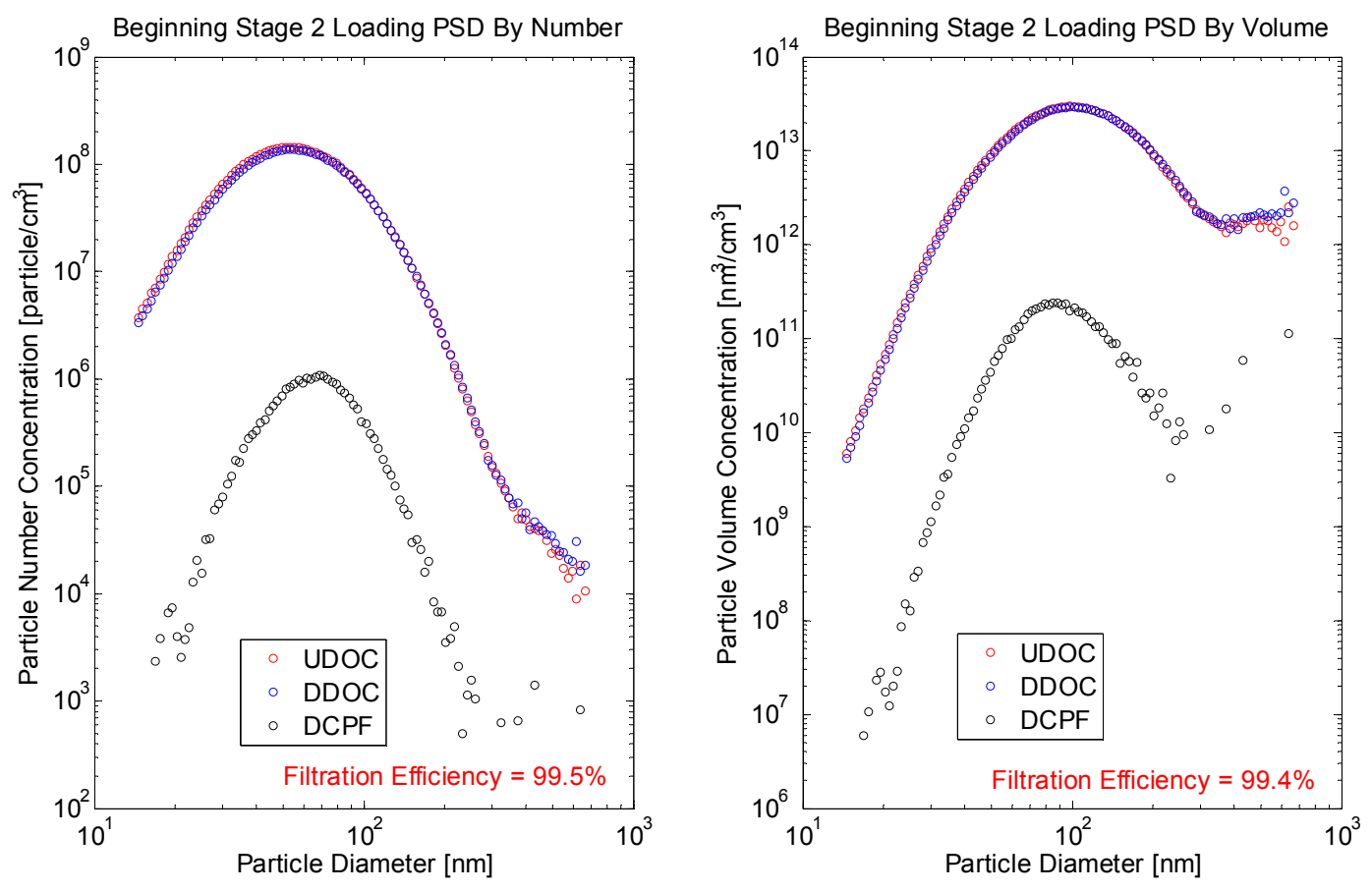

Figure L. 11: ISL 365 B10 Test 16 beginning Stage 2 loading PSD data
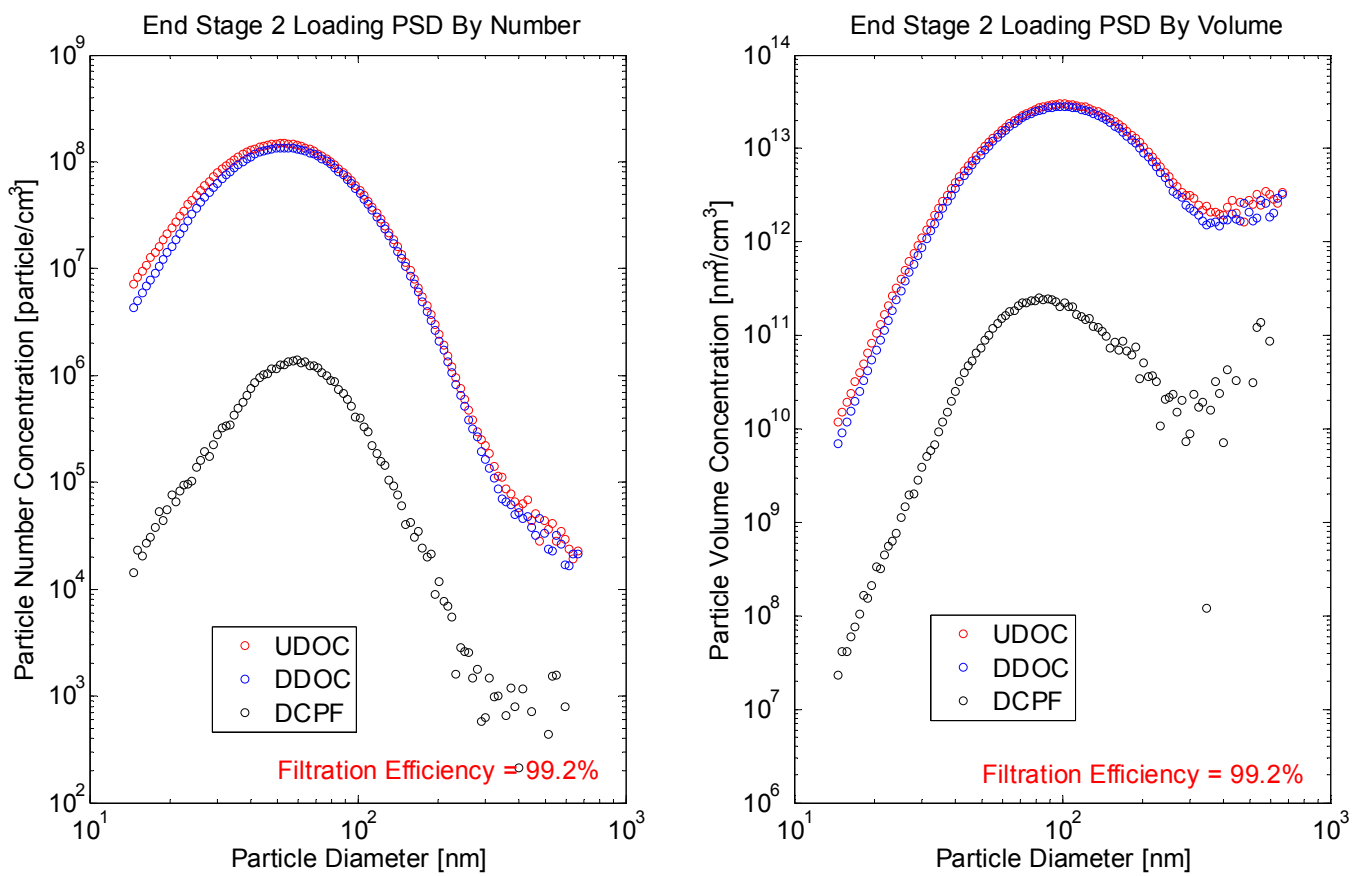

Figure L. 12: ISL 365 B10 Test 16 end Stage 2 loading PSD data 

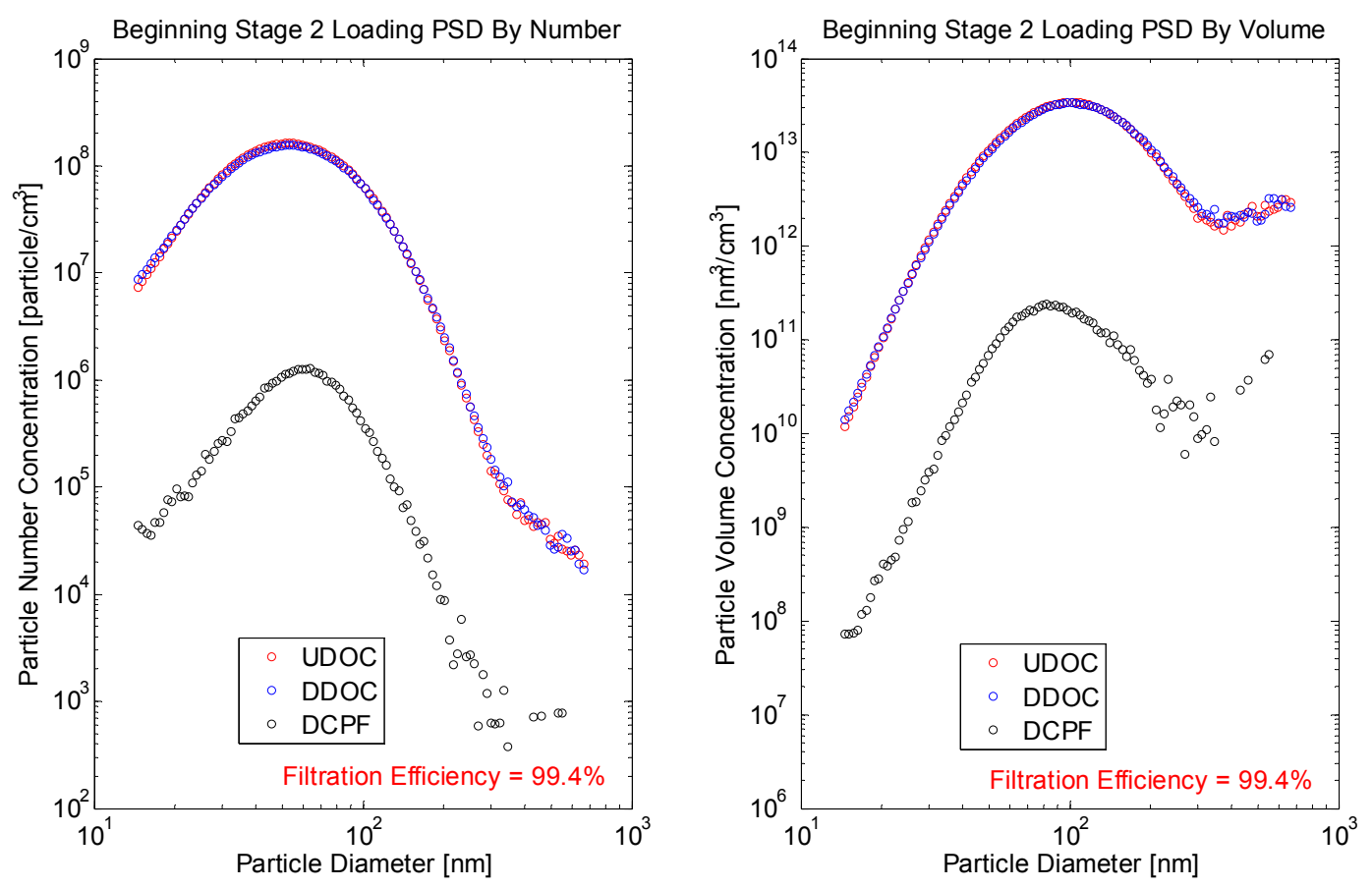

Figure L. 13: ISL 365 B10 Test 17 beginning Stage 2 loading PSD data
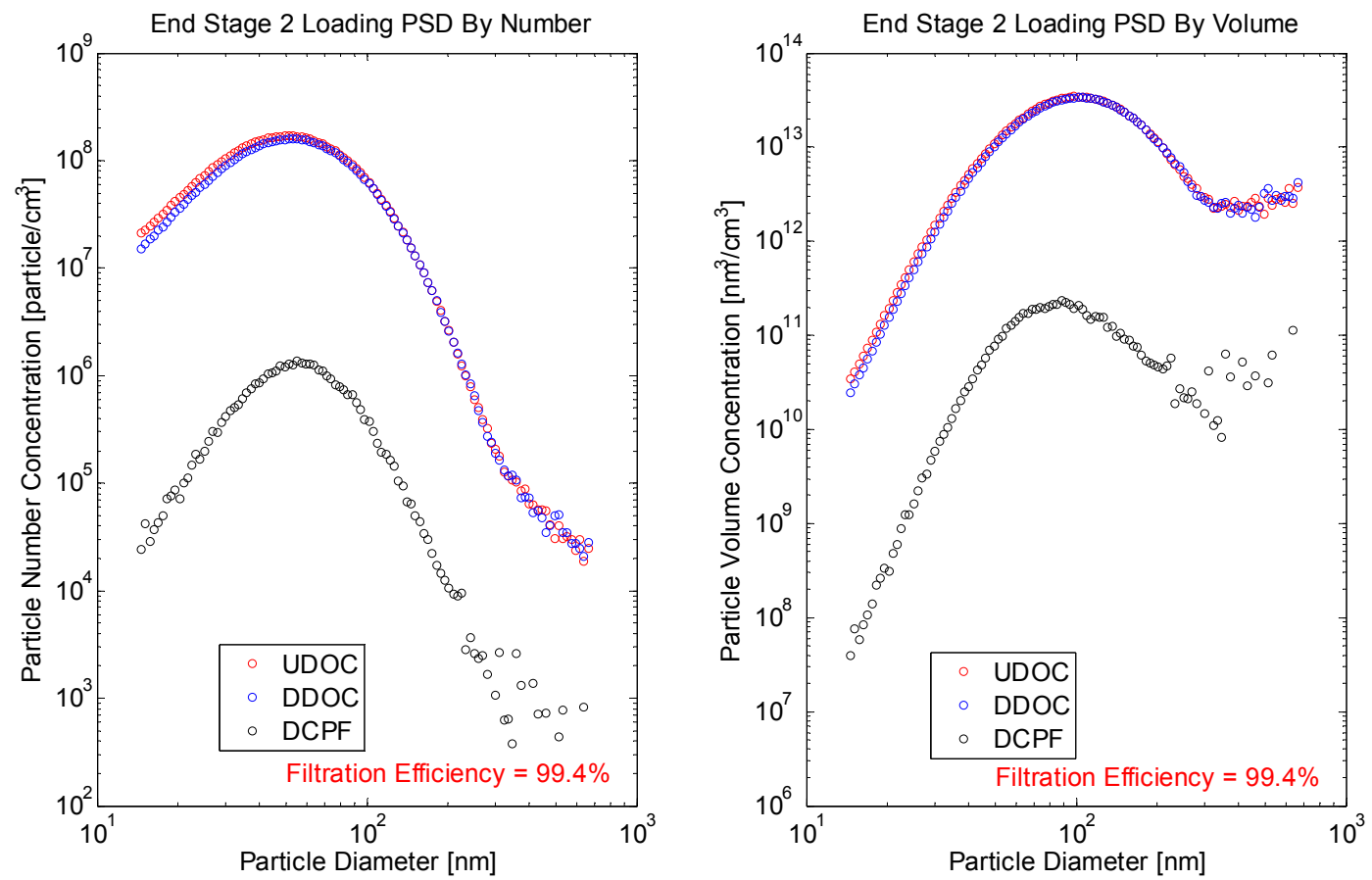

Figure L. 14: ISL 365 B10 Test 17 end Stage 2 loading PSD data 

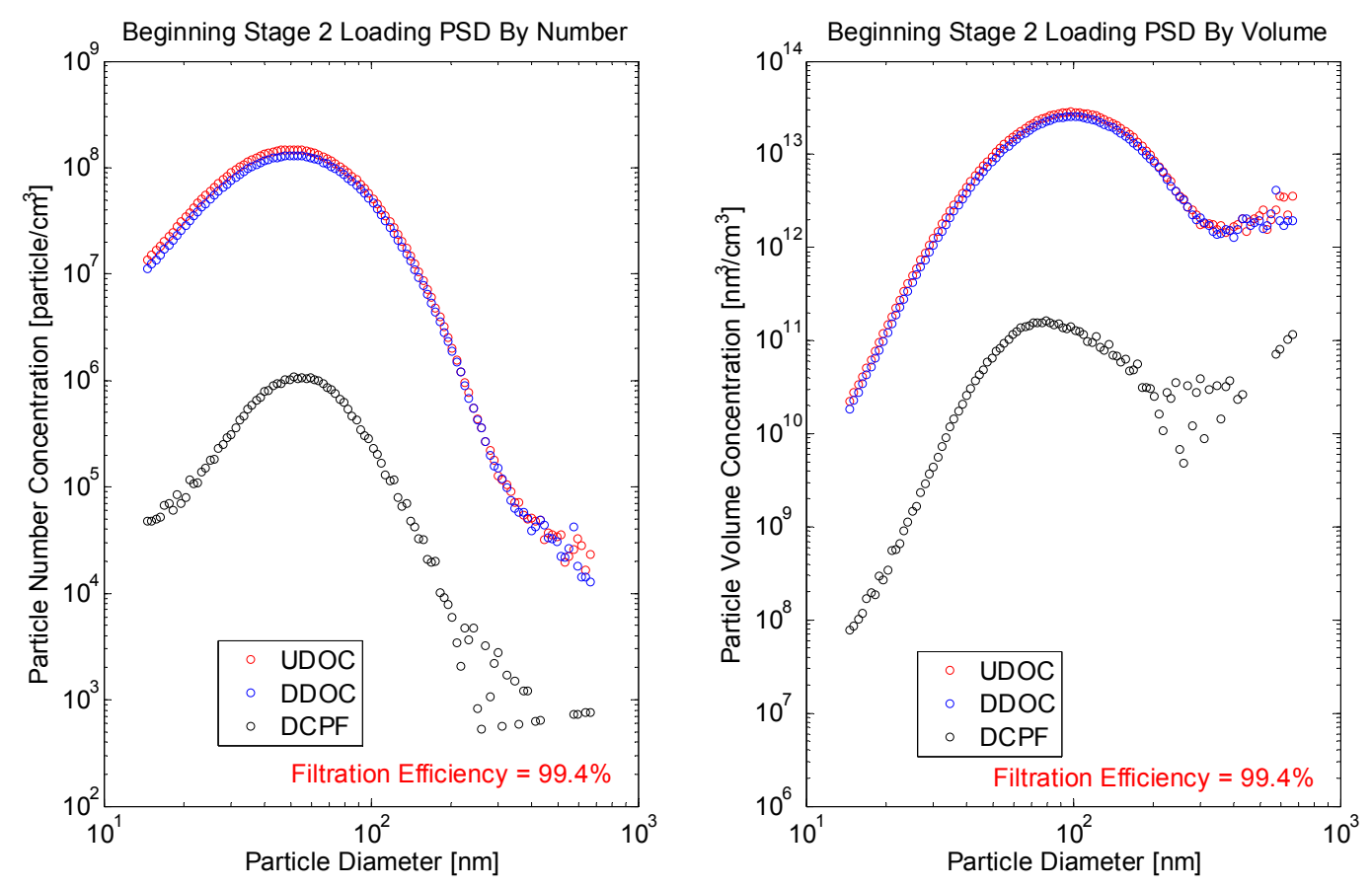

\section{Figure L. 15: ISL 365 B20 Test 18 beginning Stage 2 loading PSD data}
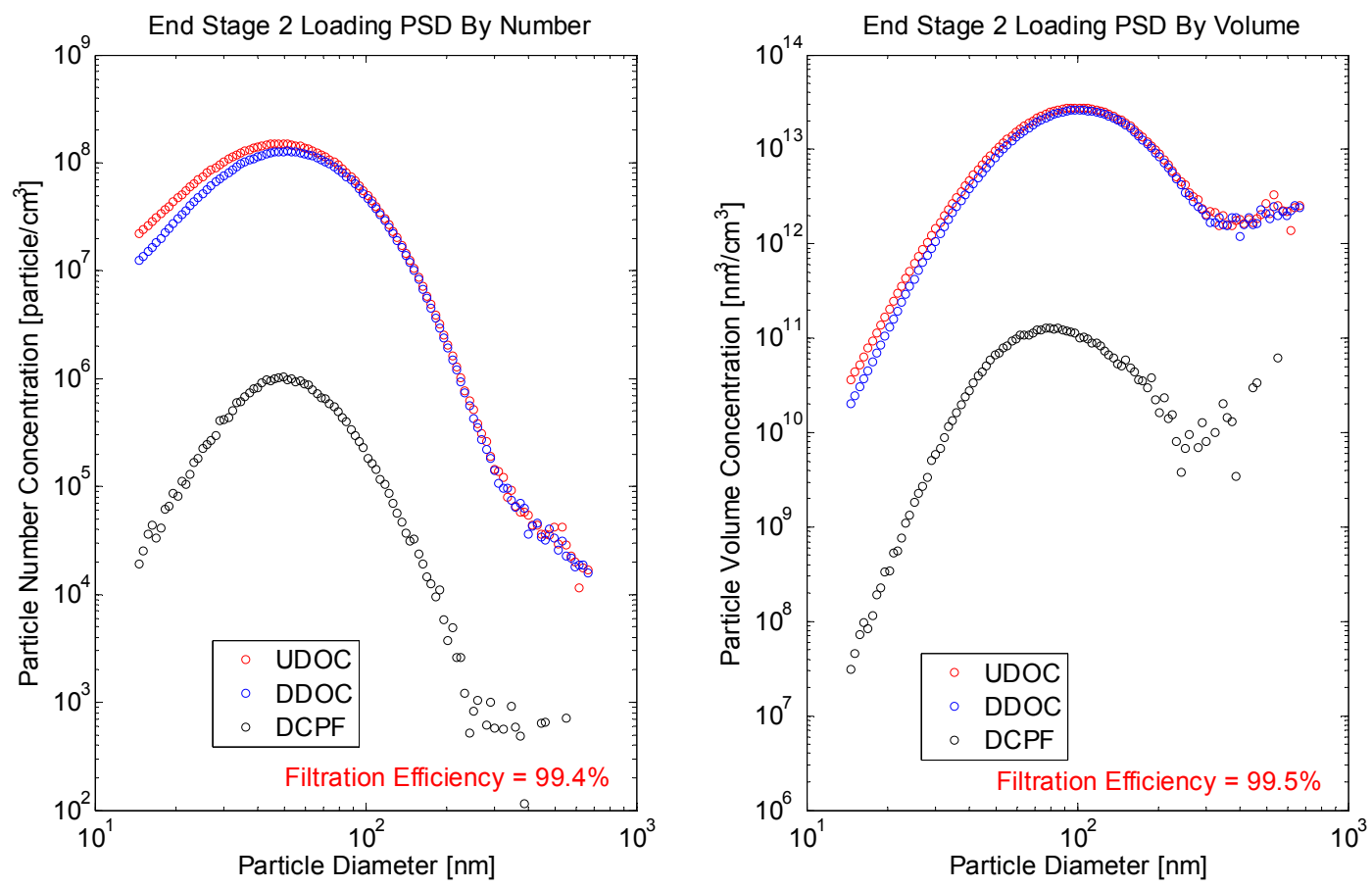

Figure L. 16: ISL 365 B20 Test 18 end Stage 2 loading PSD data 

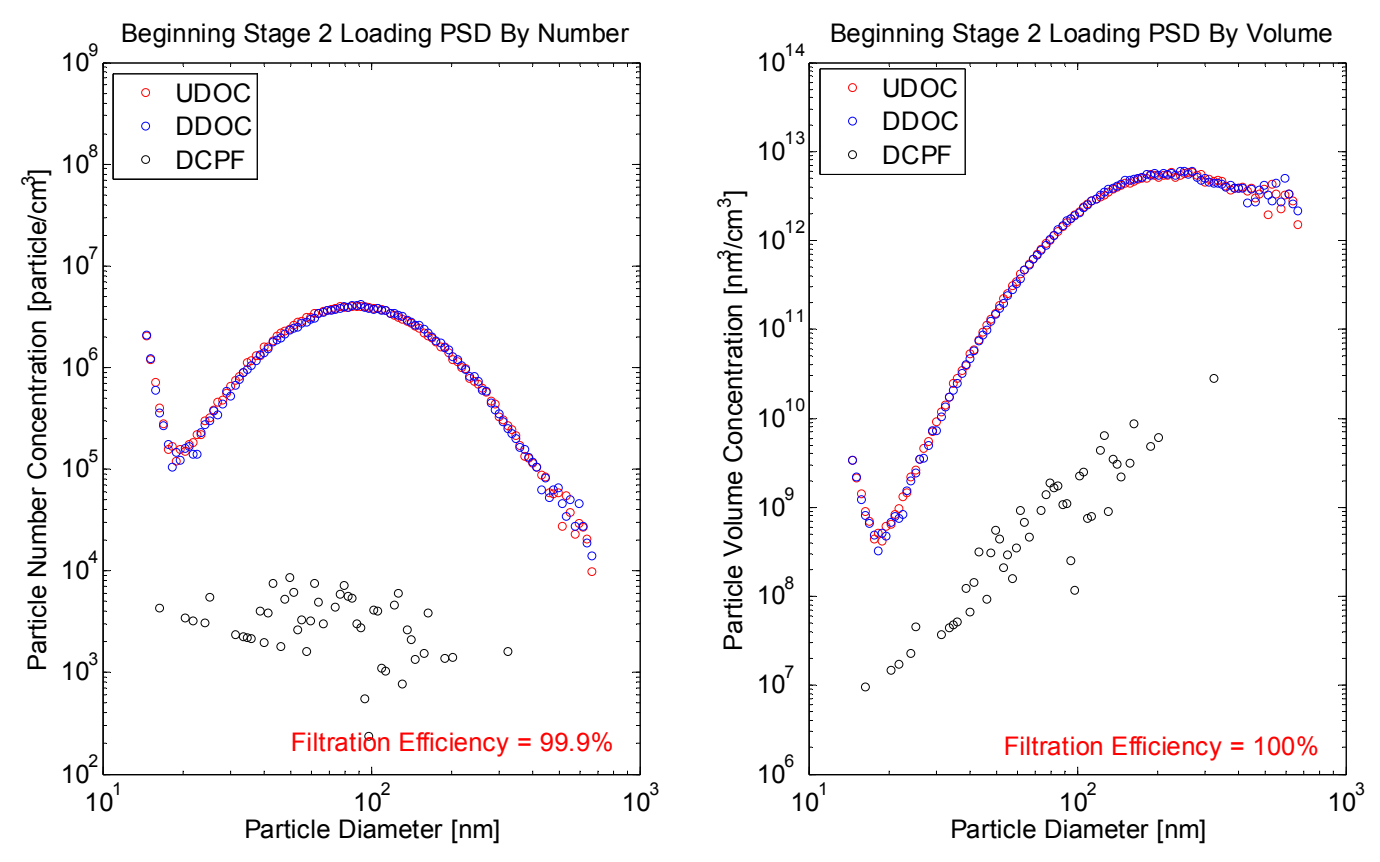

Figure L. 17: ISL 425 Test 1 beginning Stage 2 loading PSD data
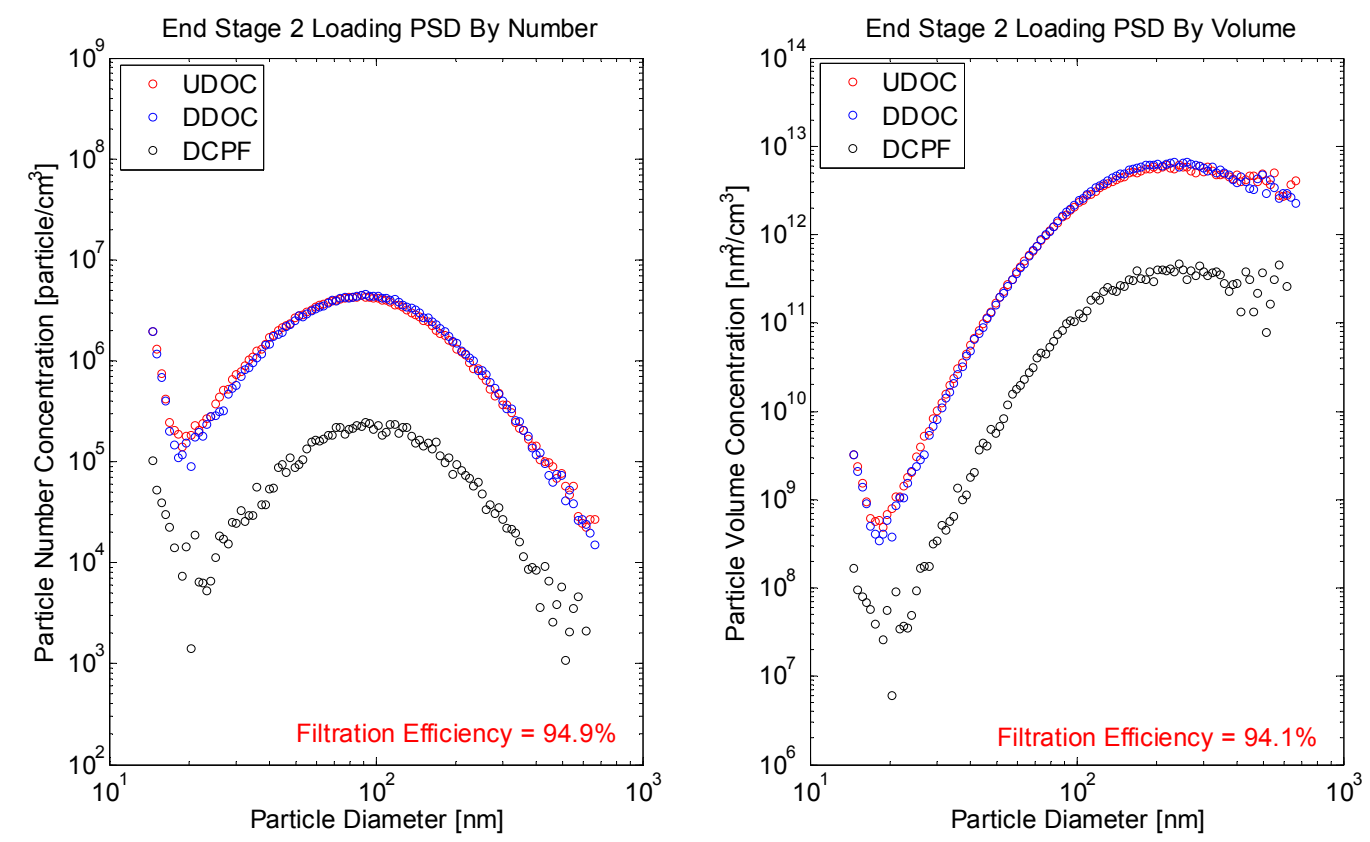

Figure L. 18: ISL 425 Test 1 end Stage 2 loading PSD data 


\section{Appendix M PSD Data Collected at the End of Stage 2 and Passive Oxidation Separated by Collection Point}

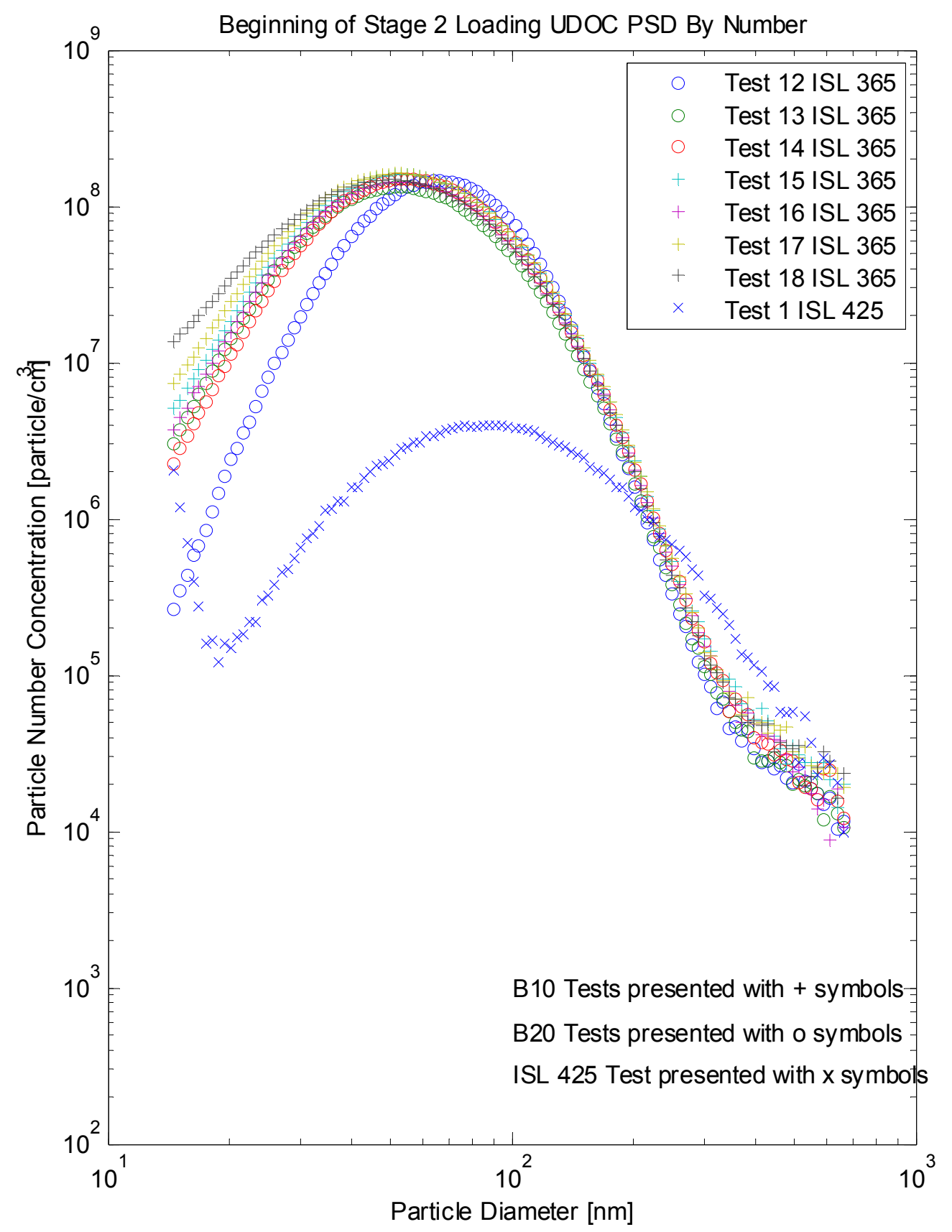

Figure M. 1: End of Stage 2 loading UDOC PSD by number 


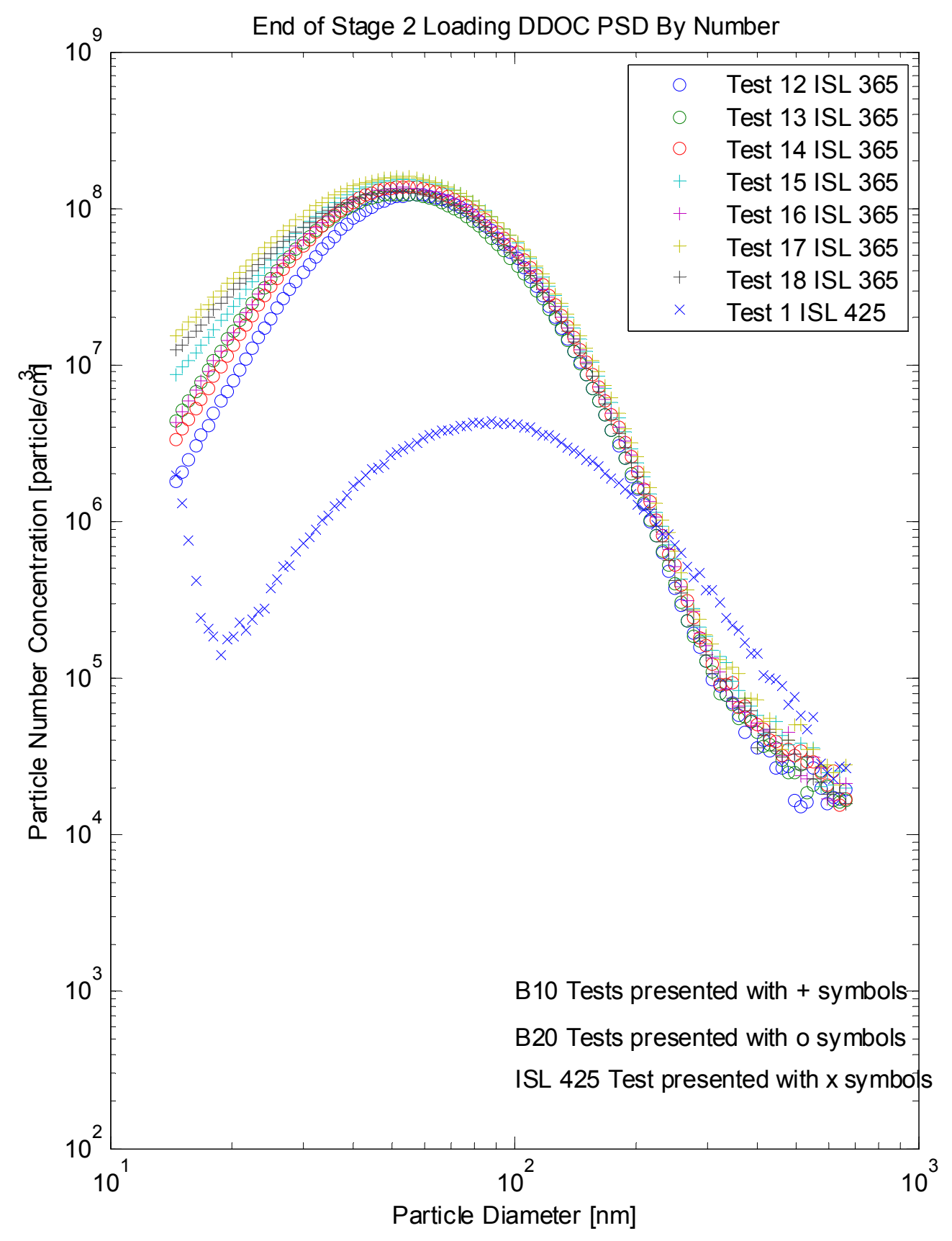

Figure M. 2: End of Stage 2 loading DDOC PSD by number 


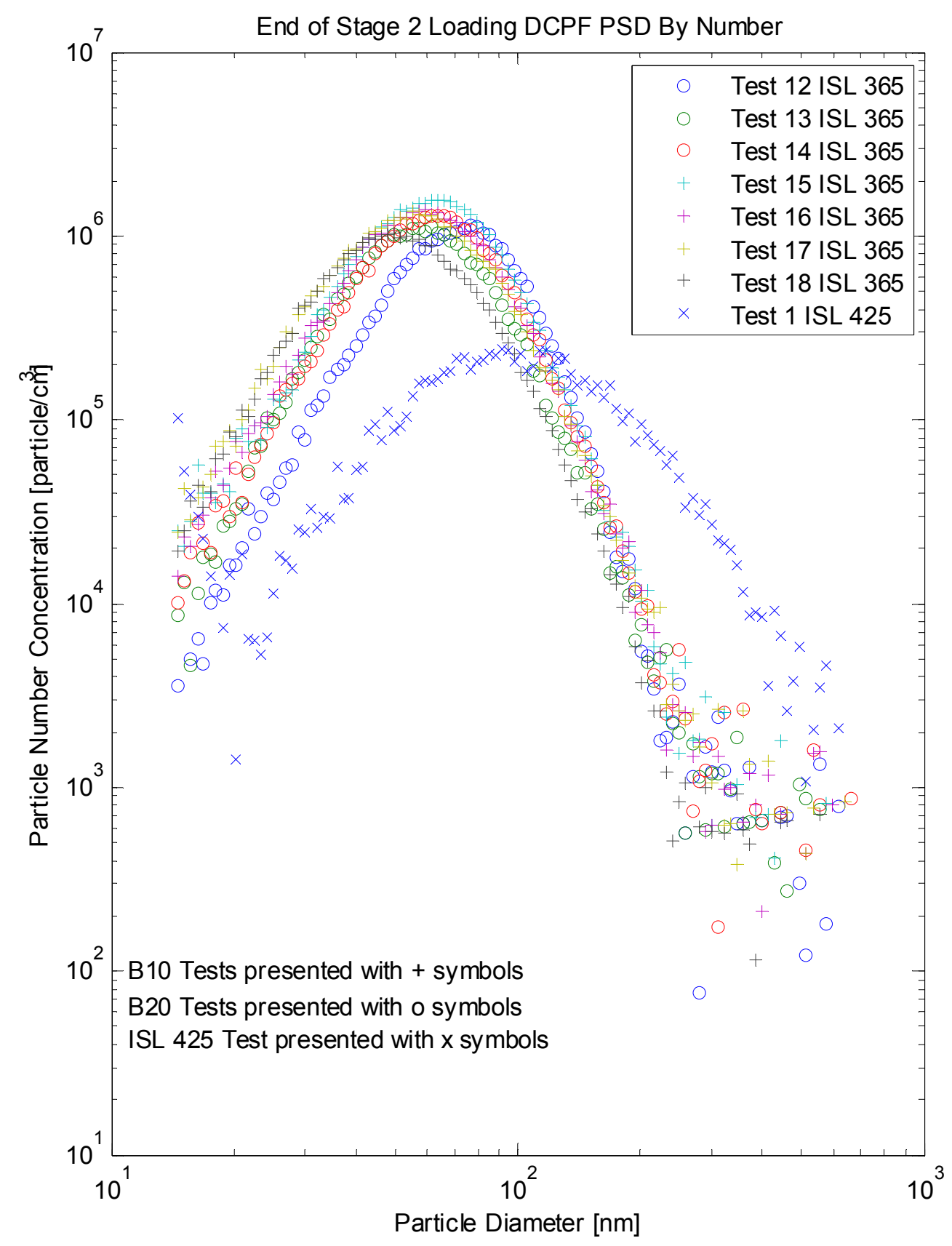

Figure M. 3: End of Stage 2 loading DCPF PSD by number 


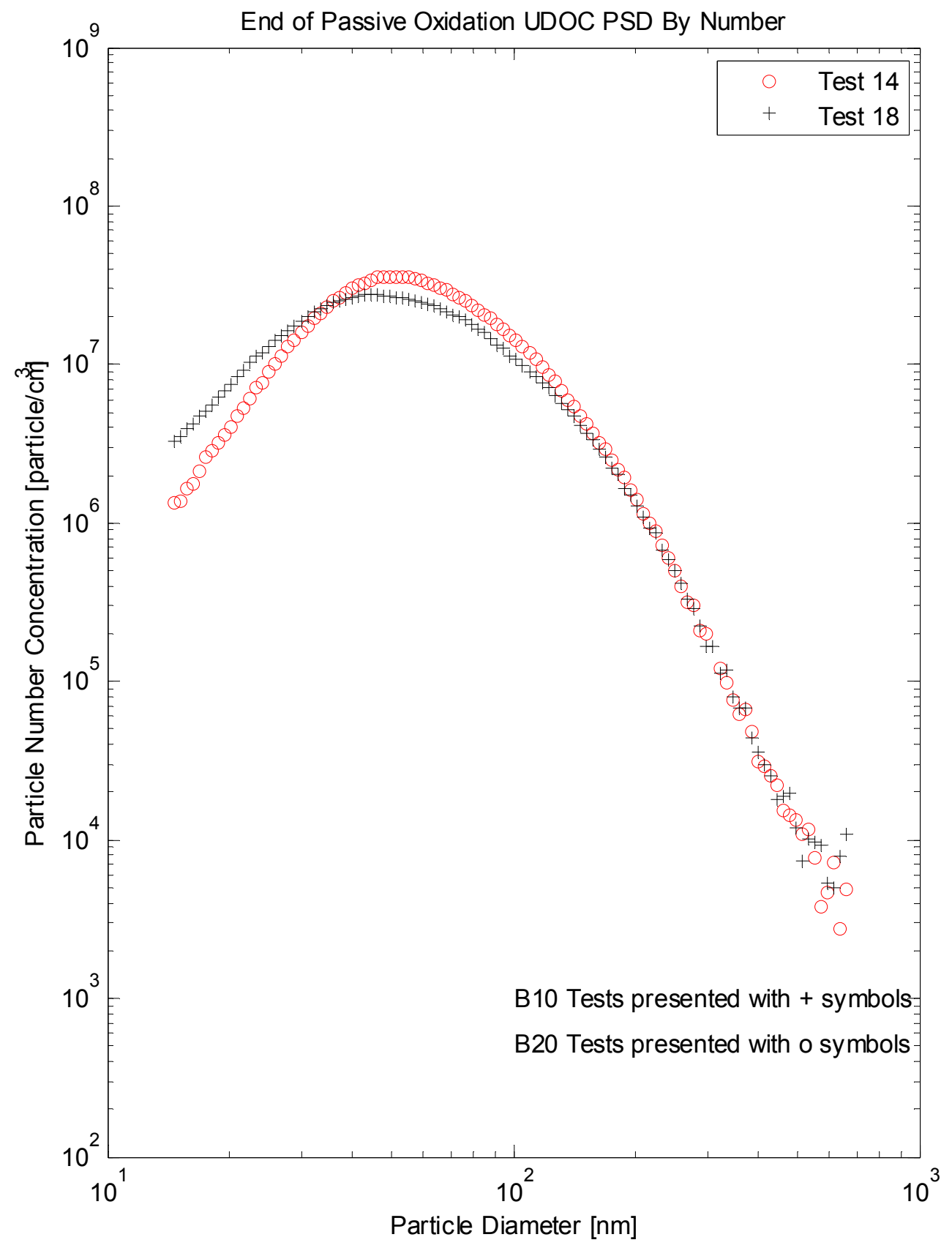

Figure M. 4: End of Passive Oxidation UDOC PSD by number 


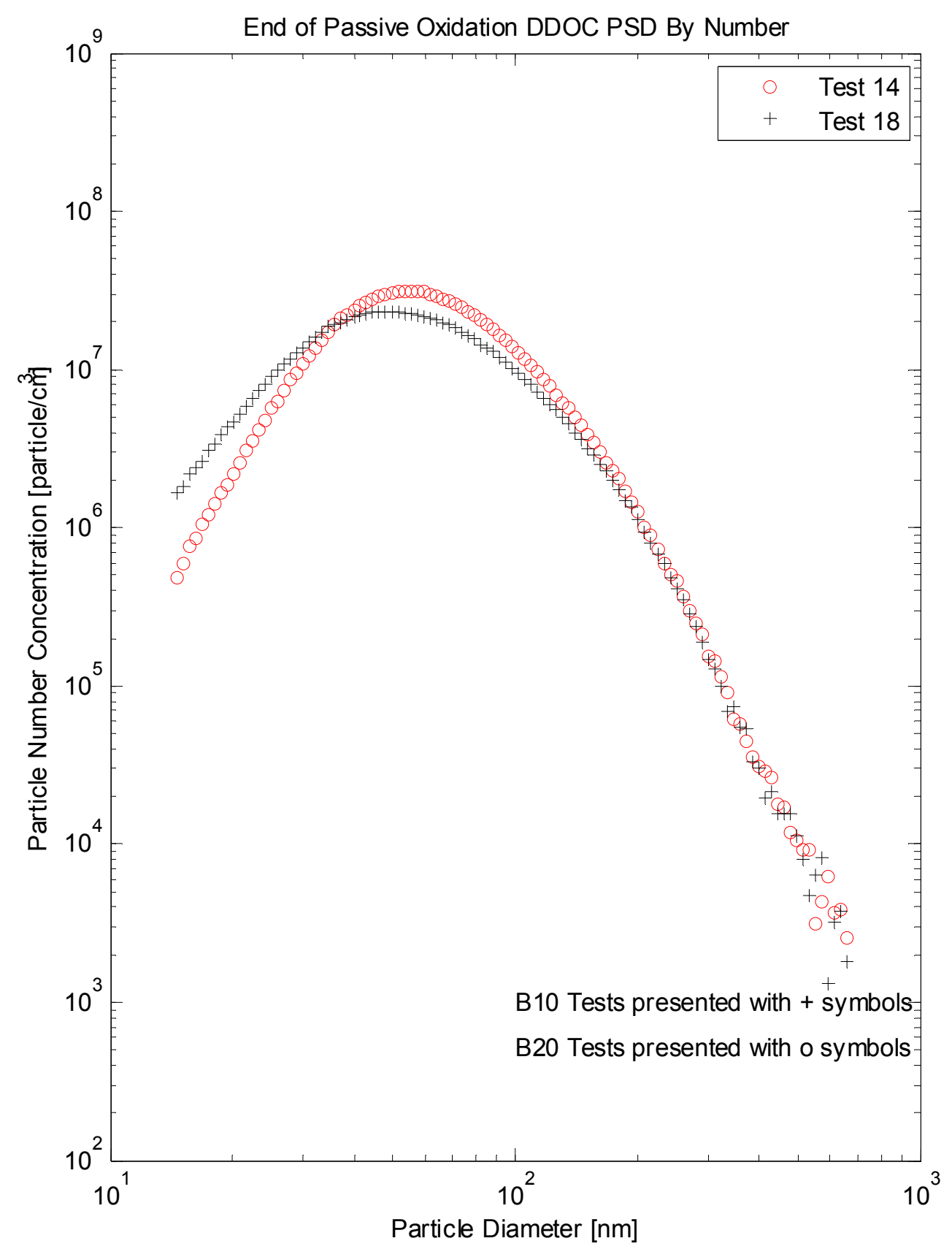

Figure M. 5: End of Passive Oxidation DDOC PSD by number 


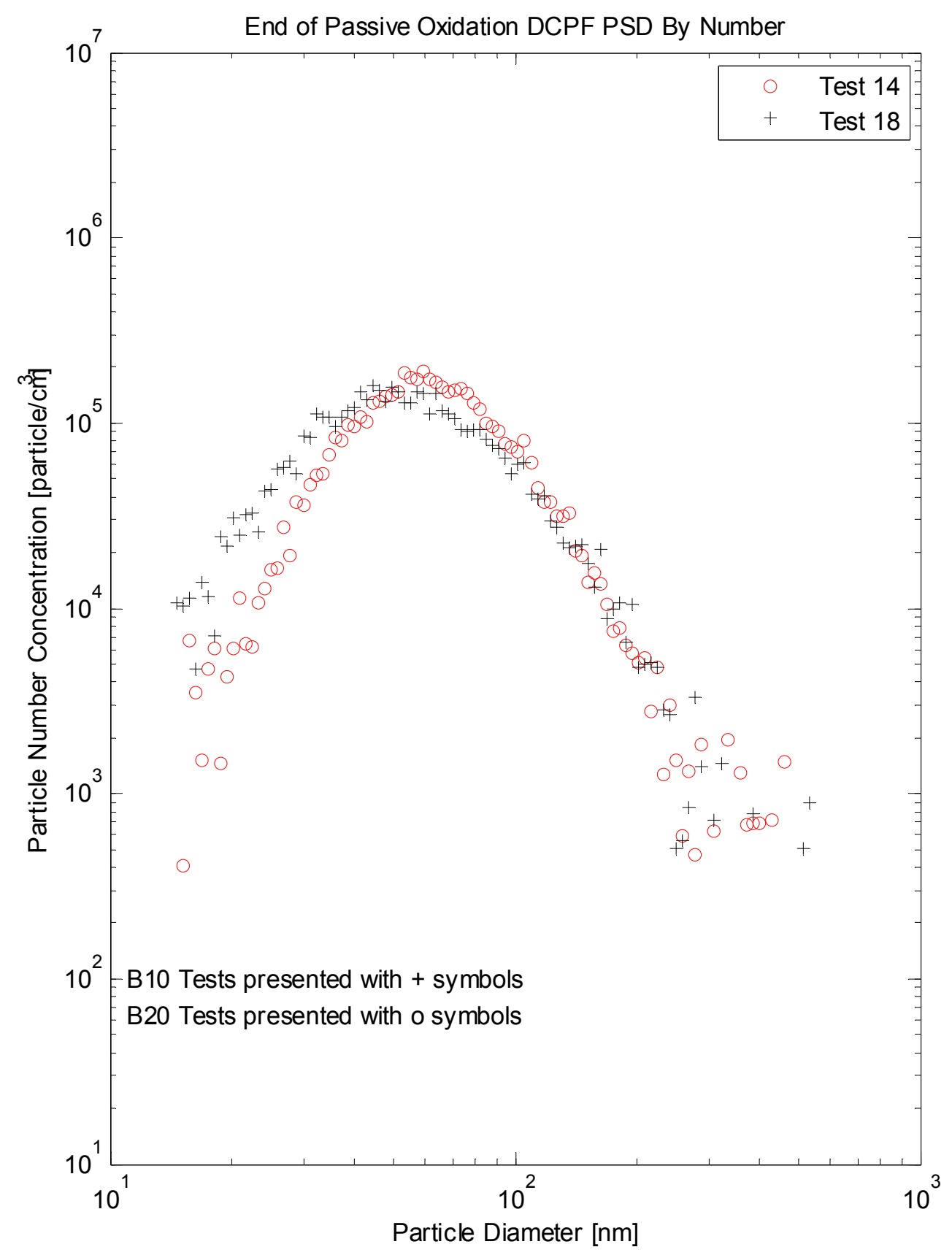

Figure M. 6: End of Passive Oxidation DCPF PSD by number 


\section{Appendix N Complete Mass Balances}

Key results for Stage 2 loading are shown in Table N. 1. The average value of each factor is given for ISL 365 with ULSD fuel, ISL 365 with B20 fuel, and ISL 365 with B10 fuel. The average percent PM oxidized for ISL 365 with ULSD tests was $19 \%$. Test 19 had a significantly higher percent $\mathrm{PM}$ oxidized (40\%). The $\mathrm{NO}_{2}$ concentration into the CPF for Test 19 was significantly lower than the average (17 versus $29 \mathrm{ppm}$ ), and the engine out PM concentration was significantly higher than the average (24.2 versus 17.3 $\mathrm{mg} / \mathrm{scm}$ ). The lower $\mathrm{NO}_{2}$ concentration into the CPF is likely due to the aged DOC, and the higher PM concentration is likely due to the absolute humidity during the test. Each of these factors should have lead to a decreased reaction rate and percent PM oxidized. The EGR was closed during the first half of Stage 2 loading for this test due to a fault code on the engine computer. This may have caused significantly different PM build up in the CPF. ISL 365 tests with B10 and B20 had higher percent PM oxidized, 20 and 24 percent respectively compared to 19 percent. B10 and B20 tests also had higher reaction rates, but according to the statistical analysis performed in Appendix $O$ there is no evidence to prove they are different.

Table N. 1:

Key results for passive oxidation during Stage 2

\begin{tabular}{|c|c|c|c|c|c|c|c|c|c|c|c|c|c|c|}
\hline & & Time & $\begin{array}{l}\text { Avg } \\
\text { CPF } \\
\text { temp. }\end{array}$ & $\begin{array}{l}\text { Avg } \\
\text { CPF } \\
\text { temp. }\end{array}$ & $\begin{array}{l}\text { CPF } \\
\text { temp. }\end{array}$ & RRo & $\begin{array}{c}\text { Percent } \\
\text { PM } \\
\text { Oxidized }\end{array}$ & $\begin{array}{l}\text { Engine } \\
\text { out PM } \\
\text { Conc. }\end{array}$ & $\begin{array}{c}\mathrm{NO}_{2} \\
\text { Conc. } \\
\text { into CPF }\end{array}$ & $\begin{array}{c}\mathrm{NO}_{2} \text { into } \\
\text { CPF }\end{array}$ & $\begin{array}{c}\mathrm{NO}_{x} \\
\text { Conc. } \\
\text { into CPF }\end{array}$ & $\begin{array}{c}\mathrm{NO}_{x} \text { into } \\
\text { CPF }\end{array}$ & $\begin{array}{c}\mathrm{NO}_{2} / \mathrm{PM} \\
\text { ratio into } \\
\mathrm{CPF}\end{array}$ & $\begin{array}{c}\mathrm{NO}_{\mathrm{x}} / \mathrm{PM} \\
\text { ratio into } \\
\mathrm{CPF}\end{array}$ \\
\hline & & $\min$ & ${ }^{\circ} \mathrm{C}$ & $\mathrm{K}$ & $1000 / \mathrm{K}$ & $(1 / \mathrm{s})$ & $\%$ & $\mathrm{mg} / \mathrm{scm}$ & $\mathrm{ppm}$ & $\mathrm{mg} / \mathrm{scm}$ & $\mathrm{ppm}$ & $\mathrm{mg} / \mathrm{scm}$ & - & - \\
\hline \multirow{7}{*}{$\begin{array}{c}\text { ISL } 365 \\
\text { ULSD }\end{array}$} & Test 6 & 271 & 261 & 534 & 1.87 & $2.35 \mathrm{E}-05$ & 18 & 16.7 & 25 & 47.0 & 85 & 160 & 2.8 & 9.6 \\
\hline & Test 7 & 291 & 264 & 537 & 1.86 & 2.22E-05 & 15 & 15.0 & 32 & 60.7 & 101 & 190 & 4.0 & 12.7 \\
\hline & Test 8 & 270 & 261 & 534 & 1.87 & 2.81E-05 & 16 & 16.5 & 30 & 56.4 & 92 & 173 & 3.4 & 10.5 \\
\hline & Test 9 & 310 & 256 & 529 & 1.89 & $2.02 \mathrm{E}-05$ & 15 & 15.8 & 33 & 62.0 & 96 & 180 & 3.9 & 11.4 \\
\hline & Test 10 & 253 & 259 & 532 & 1.88 & $1.82 \mathrm{E}-05$ & 11 & 14.7 & 30 & 56.4 & 96 & 180 & 3.8 & 12.3 \\
\hline & Test 19 & 276 & 266 & 539 & 1.86 & 4.34E-05 & 40 & 24.2 & 17 & 32.0 & 82 & 154 & 1.3 & 6.4 \\
\hline & Average & 276 & 262 & 535 & 1.87 & $2.51 \mathrm{E}-05$ & 19 & 17.3 & 29 & 57.6 & 88 & 167 & 3.5 & 10.2 \\
\hline \multirow{5}{*}{$\begin{array}{c}\text { ISL } 365 \\
\text { B20 }\end{array}$} & Test 11 & 270 & 259 & 532 & 1.88 & $3.33 \mathrm{E}-05$ & 21 & 14.3 & 24 & 46.0 & 89 & 167 & 3.2 & 12.0 \\
\hline & Test 12 & 330 & 263 & 536 & 1.87 & $2.59 \mathrm{E}-05$ & 21 & 14.3 & 25 & 46.6 & 88 & 165 & 3.3 & 11.5 \\
\hline & Test 13 & 290 & 262 & 535 & 1.87 & $2.64 \mathrm{E}-05$ & 22 & 16.4 & 17 & 32.0 & 85 & 160 & 1.9 & 9.7 \\
\hline & Test 18 & 300 & 268 & 541 & 1.85 & $3.99 \mathrm{E}-05$ & 30 & 18.6 & 20 & 38.4 & 76 & 143 & 2.1 & 7.7 \\
\hline & Average & 298 & 263 & 536 & 1.87 & $3.14 \mathrm{E}-05$ & 24 & 15.9 & 22 & 40.8 & 85 & 159 & 2.6 & 10.2 \\
\hline \multirow{5}{*}{$\begin{array}{c}\text { ISL } 365 \\
\text { B10 }\end{array}$} & Test 14 & 254 & 267 & 540 & 1.85 & $3.57 \mathrm{E}-05$ & 23 & 18.4 & 25 & 47.0 & 84 & 158 & 2.6 & 8.6 \\
\hline & Test 15 & 233 & 267 & 540 & 1.85 & $2.86 \mathrm{E}-05$ & 19 & 18.3 & 27 & 50.8 & 77 & 145 & 2.8 & 7.9 \\
\hline & Test 16 & 255 & 262 & 535 & 1.87 & $2.23 \mathrm{E}-05$ & 17 & 16.4 & 23 & 43.0 & 84 & 157 & 2.6 & 9.6 \\
\hline & Test 17 & 240 & 263 & 536 & 1.87 & $2.85 \mathrm{E}-05$ & 20 & 18.5 & 22 & 41.9 & 77 & 145 & 2.3 & 7.9 \\
\hline & Average & 246 & 265 & 538 & 1.86 & $2.88 \mathrm{E}-05$ & 20 & 17.9 & 24 & 45.7 & 81 & 151 & 2.6 & 8.5 \\
\hline ISL 425 & Test 1 & 256 & 261 & 534 & 1.87 & $3.23 \mathrm{E}-06$ & 2 & 12.1 & 103 & 194.0 & 428 & 805 & 8.2 & 29.1 \\
\hline
\end{tabular}




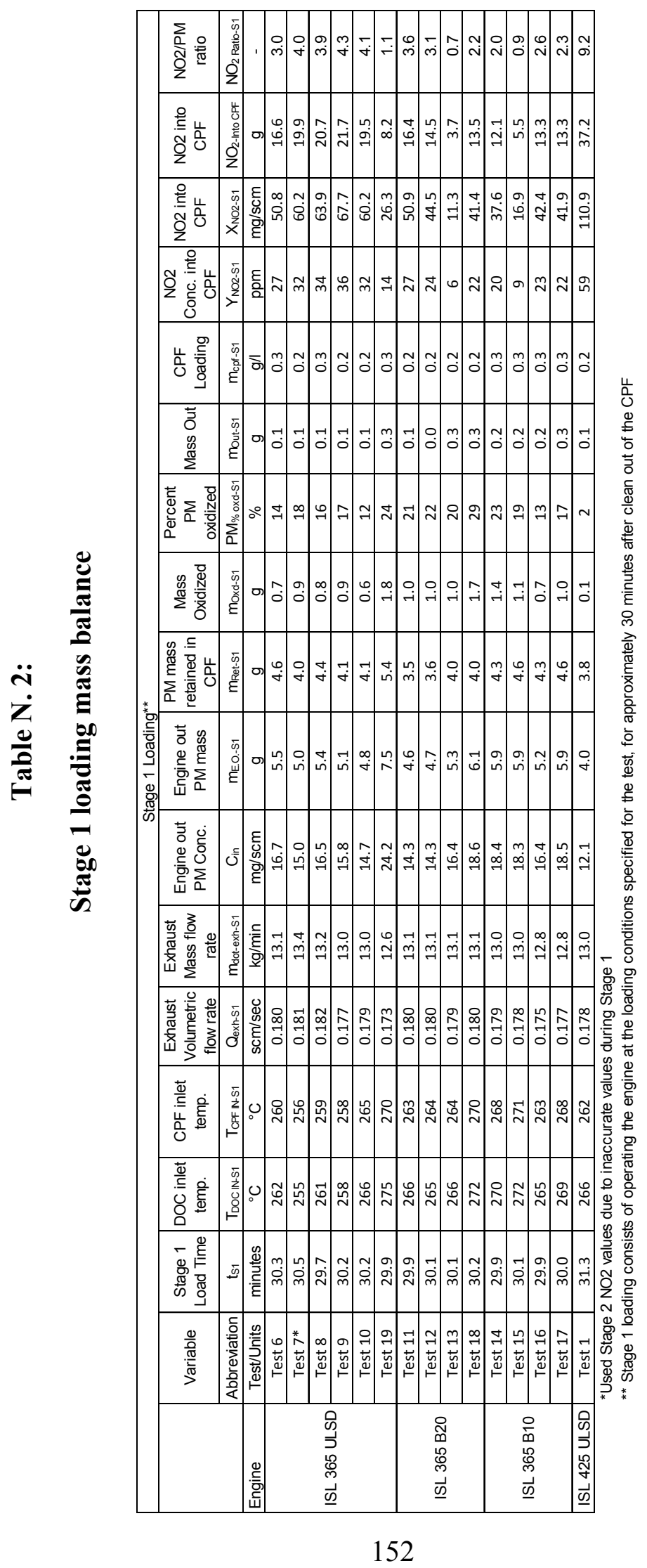




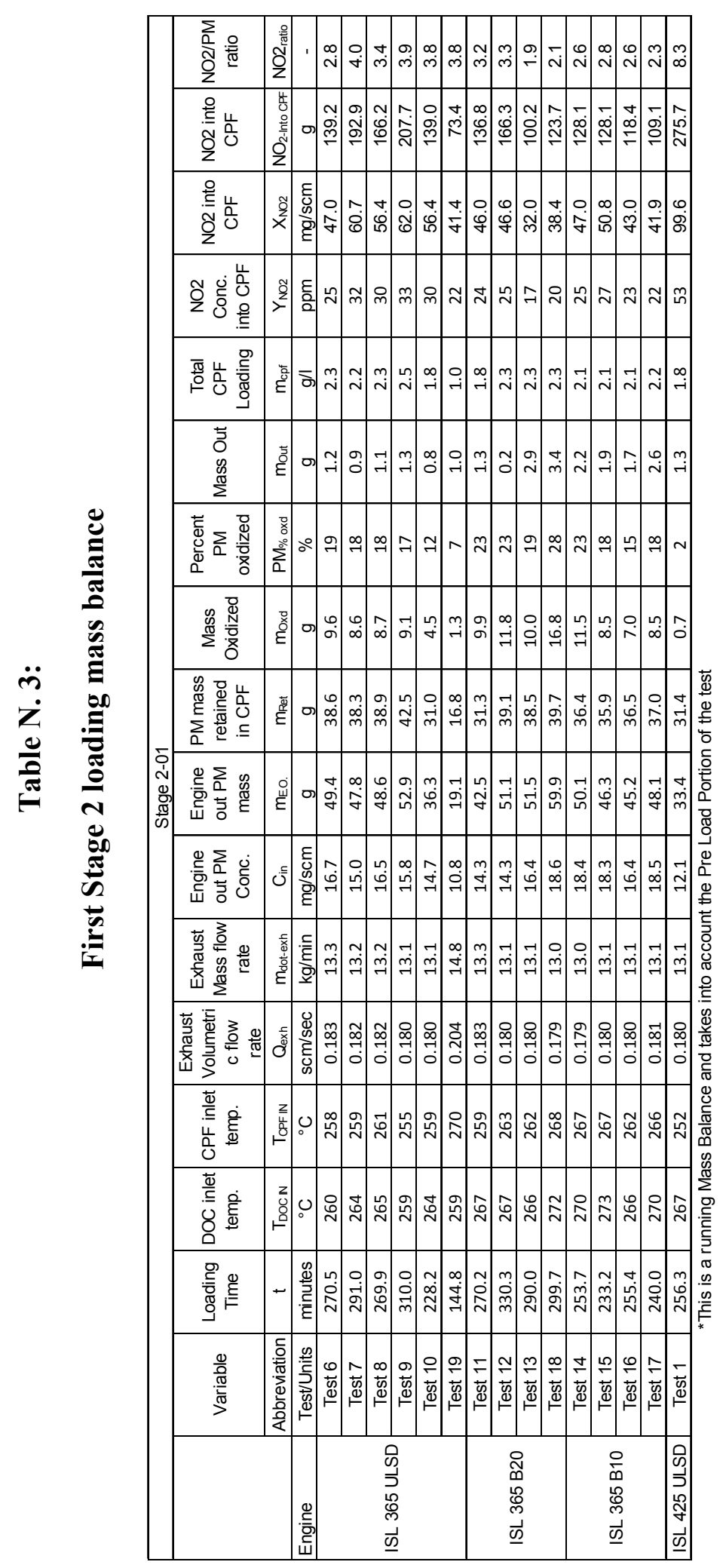




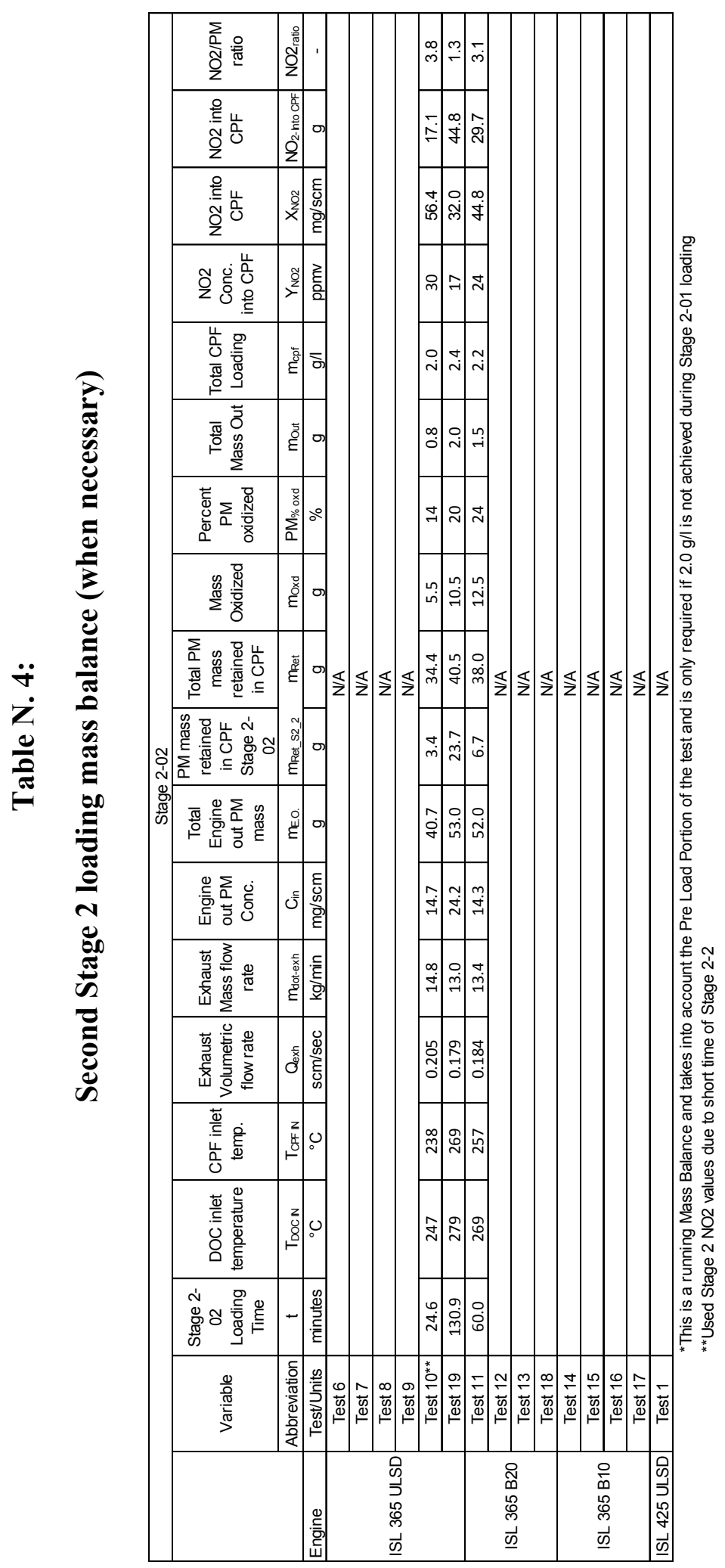




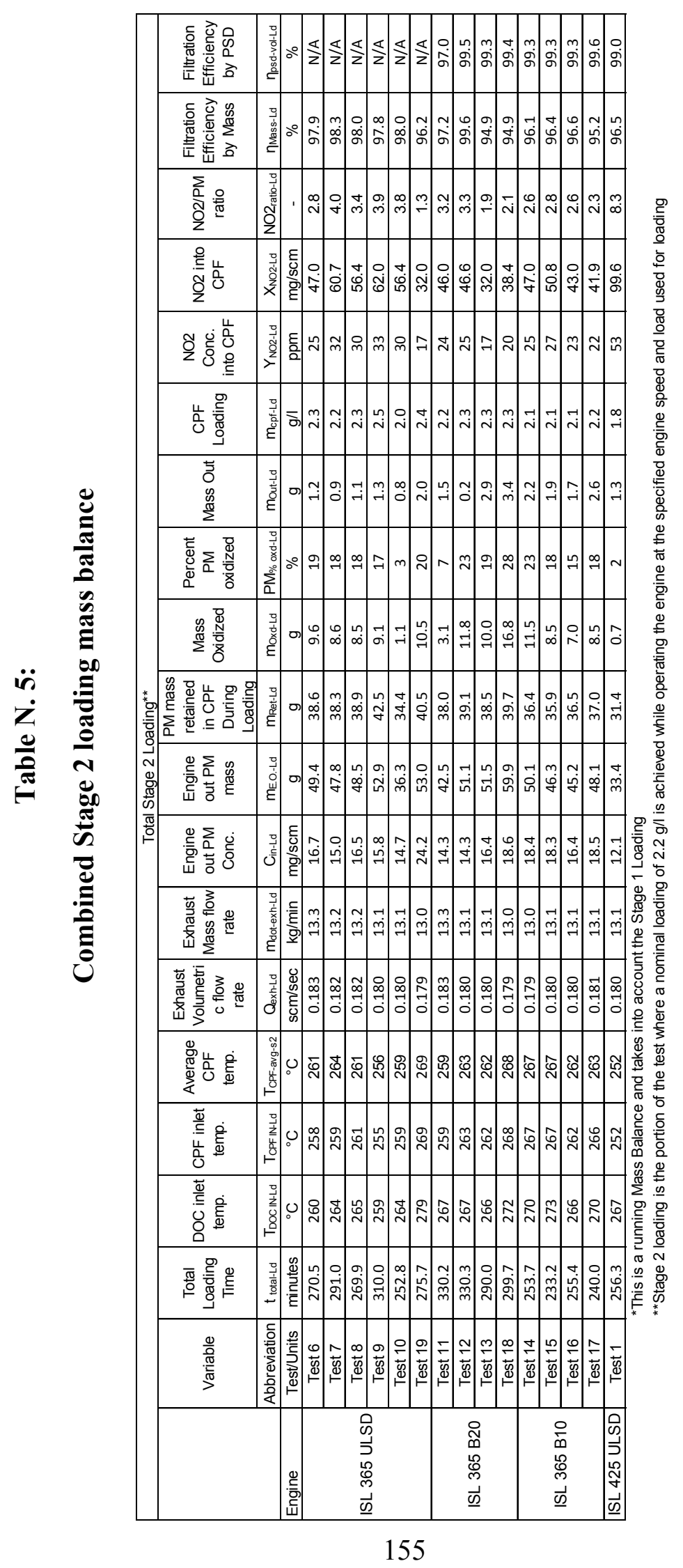




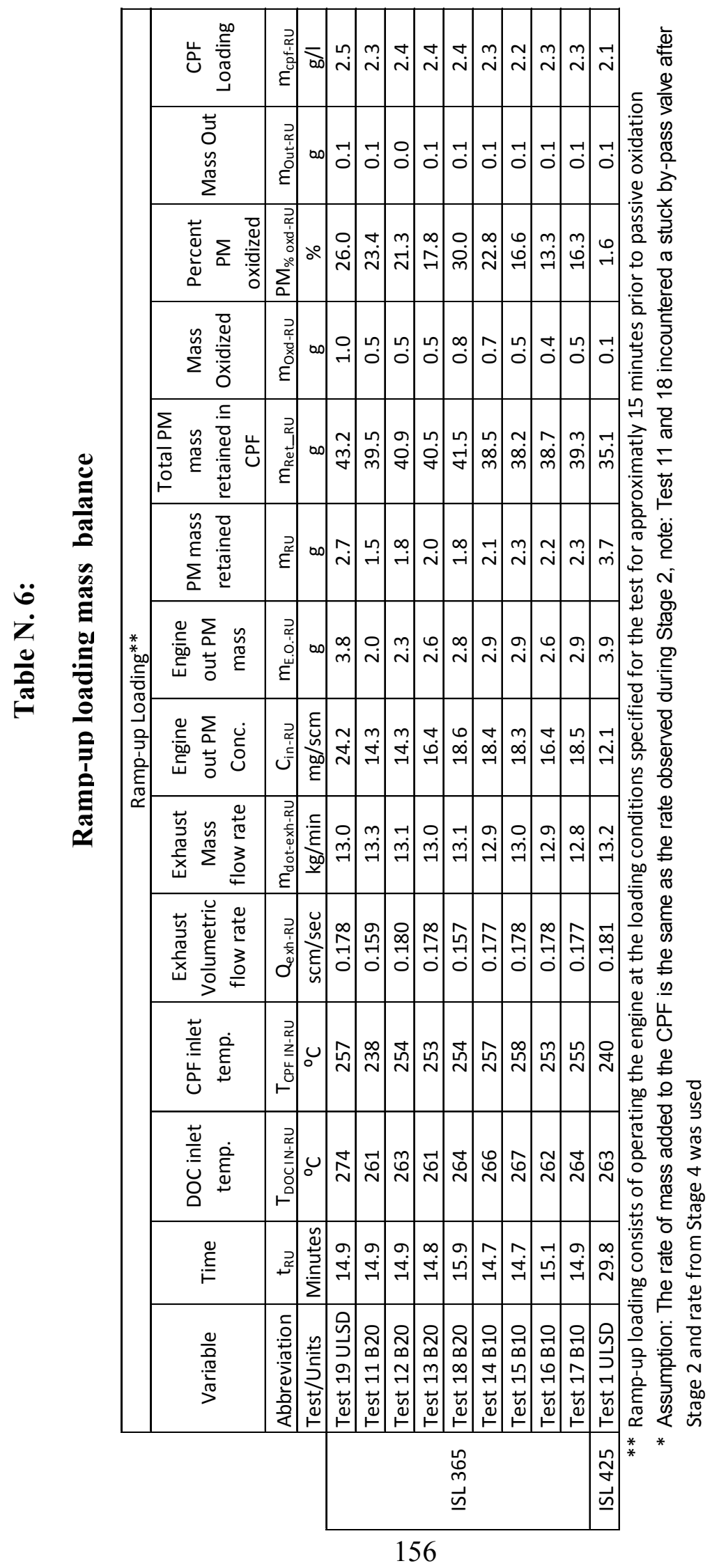




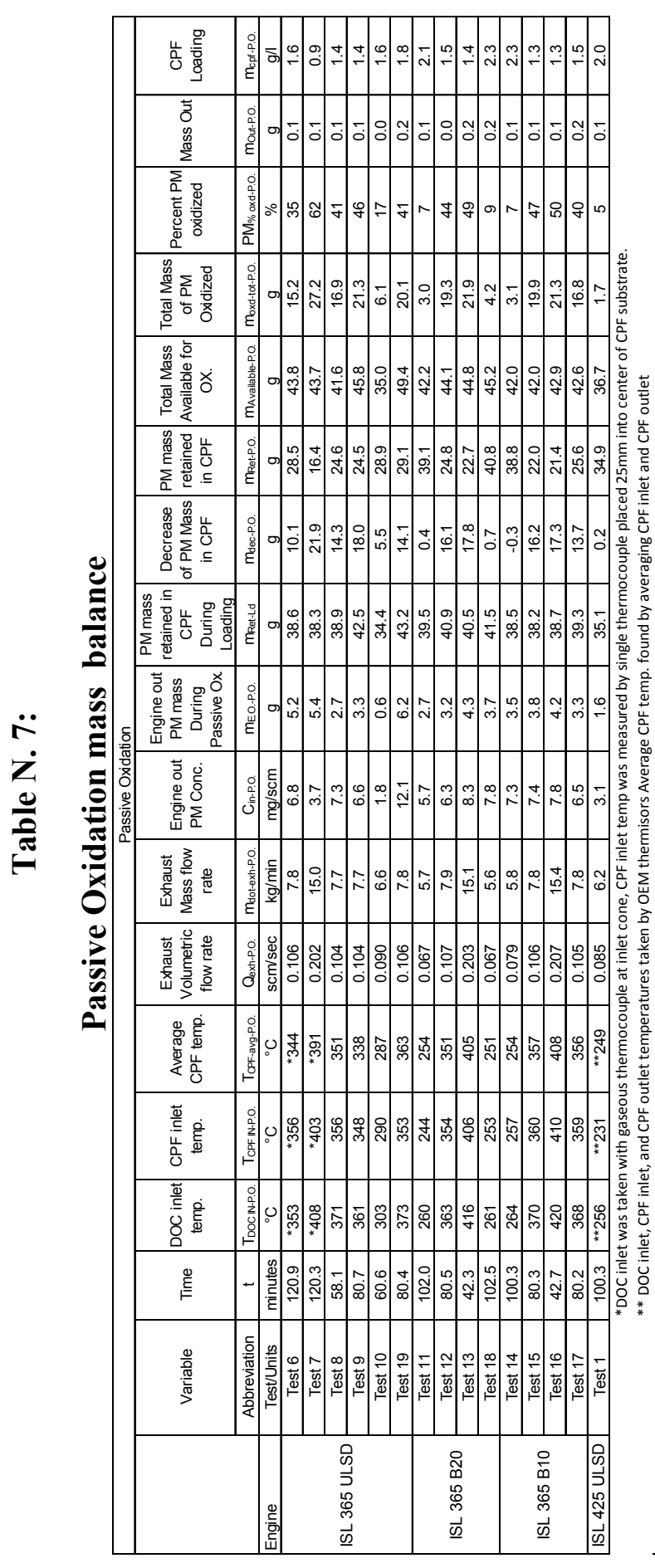

\begin{tabular}{|c|c|c|c|c|c|c|c|c|}
\hline 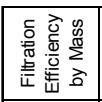 & 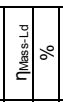 & $\mid \begin{array}{ll}\infty & m \\
\dot{\alpha} & \infty \\
\infty\end{array}$ & 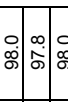 & 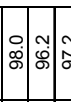 & 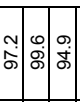 & $\dot{\dot{\rho}}$ & 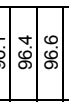 & 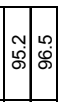 \\
\hline 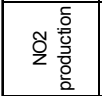 & 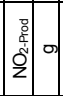 & ป ป & $\stackrel{\circ}{\circ} \stackrel{\bullet}{:}$ & $\stackrel{5}{\infty} \infty$ & 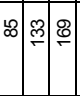 & sin & 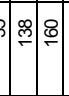 & 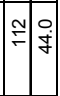 \\
\hline 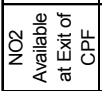 & 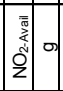 & $\rightarrow \stackrel{8}{\stackrel{2}{2}}$ & 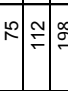 & 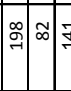 & 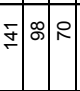 & 의 을 & 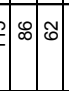 & 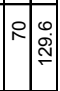 \\
\hline 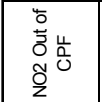 & 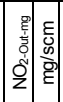 & 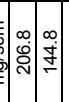 & 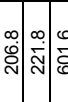 & 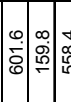 & 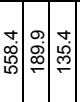 & 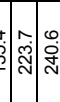 & 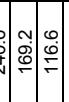 & 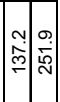 \\
\hline 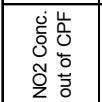 & 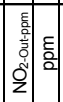 & & $\stackrel{\circ}{=} \stackrel{\infty}{=}$ & ল্লি & 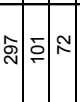 & 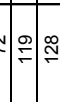 & ৩ ৪ & $\curvearrowright \underset{\sim}{\sim}$ \\
\hline 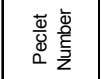 & 娄 & 豙 & 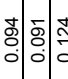 & 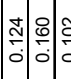 & 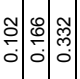 & مُ & 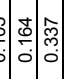 & $\begin{array}{lll}0 & 0 \\
0 & 0 \\
0 & 0 \\
0\end{array}$ \\
\hline 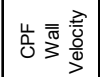 & $>^{3}$ है & 象 & 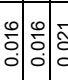 & 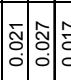 & 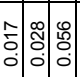 & 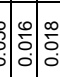 & 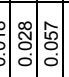 & $\mid \begin{array}{l}\infty \\
\substack{0 \\
0 \\
0} \\
0\end{array}$ \\
\hline 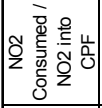 & 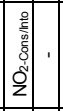 & 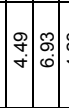 & 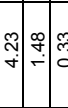 & 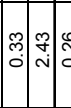 & 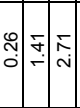 & 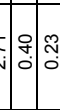 & 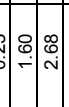 & 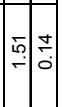 \\
\hline 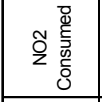 & 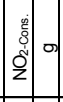 & 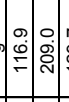 & 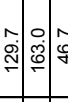 & 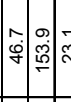 & 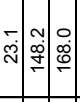 & 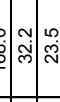 & 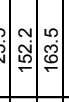 & 产 \\
\hline 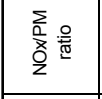 & 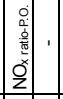 & 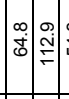 & 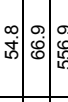 & 它 & 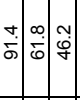 & 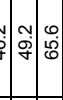 & 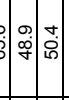 & 至 \\
\hline 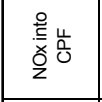 & 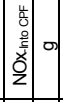 & 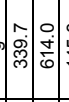 & 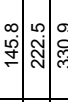 & 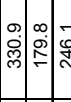 & 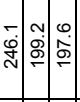 & : & 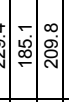 & 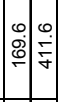 \\
\hline 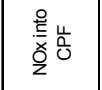 & 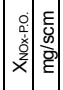 & $\dot{q}$ & 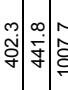 & 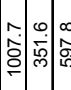 & 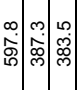 & $\dot{\vec{g}}$ & 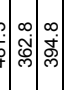 & 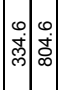 \\
\hline 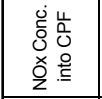 & \begin{tabular}{|l|l|} 
& \\
0 \\
$\vdots$ \\
\hdashline
\end{tabular} & $\stackrel{\sim}{\sim} \underset{\sim}{\mathbb{N}}$ & $\stackrel{\nabla}{\sim} \sim$ & {$\left[\begin{array}{l}0 \\
i \\
i\end{array} \mid \underset{m}{-\infty}\right.$} & $\stackrel{\infty}{m} \stackrel{\sim}{\sim} \stackrel{\sim}{\sim}$ & 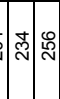 & 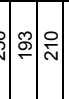 & $\mid$\begin{tabular}{cc|}
$\infty$ & $\infty$ \\
$\stackrel{2}{f}$ & \multirow{\gamma}{*}{}
\end{tabular} \\
\hline 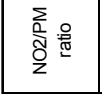 & 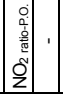 & ஸ่ & 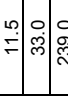 & 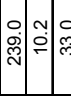 & 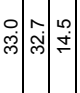 & $\stackrel{\sim}{\grave{n}}$ & 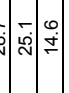 & 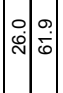 \\
\hline 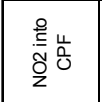 & 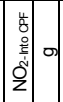 & 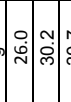 & 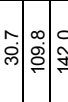 & 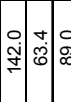 & 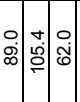 & ڤ & 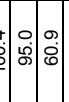 & 倌 \\
\hline 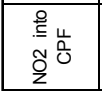 & 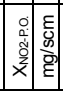 & 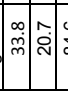 & 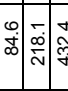 & 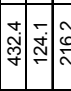 & 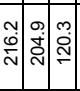 & 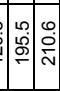 & 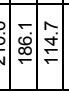 & 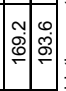 \\
\hline 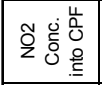 & 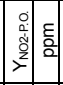 & $\stackrel{\infty}{\sim}=$ & \&) & ๙ి & $\stackrel{\circ}{=}: \stackrel{0}{0}$ & $\stackrel{N}{\rightleftharpoons}$ & $=8 . \bar{\circ}$ & ৪ \\
\hline $\begin{array}{l}\frac{0}{0} \\
\frac{0}{0.0} \\
\frac{10}{7}\end{array}$ & 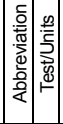 & 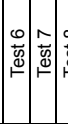 & 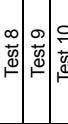 & 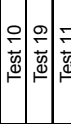 & 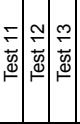 & 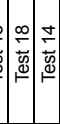 & 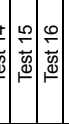 & 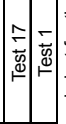 \\
\hline & 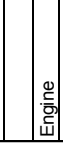 & & $\begin{array}{l}0 \\
\stackrel{0}{5} \\
\stackrel{0}{0} \\
\underline{e} \\
\underline{\omega} \\
\end{array}$ & & $\begin{array}{l}\stackrel{\widetilde{N}}{\infty} \\
\stackrel{0}{0} \\
\tilde{D} \\
\underline{\omega}\end{array}$ & & $\begin{array}{l}\stackrel{\circ}{0} \\
\stackrel{0}{0} \\
\stackrel{0}{\infty} \\
\underline{\omega}\end{array}$ & 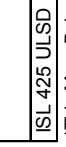 \\
\hline
\end{tabular}




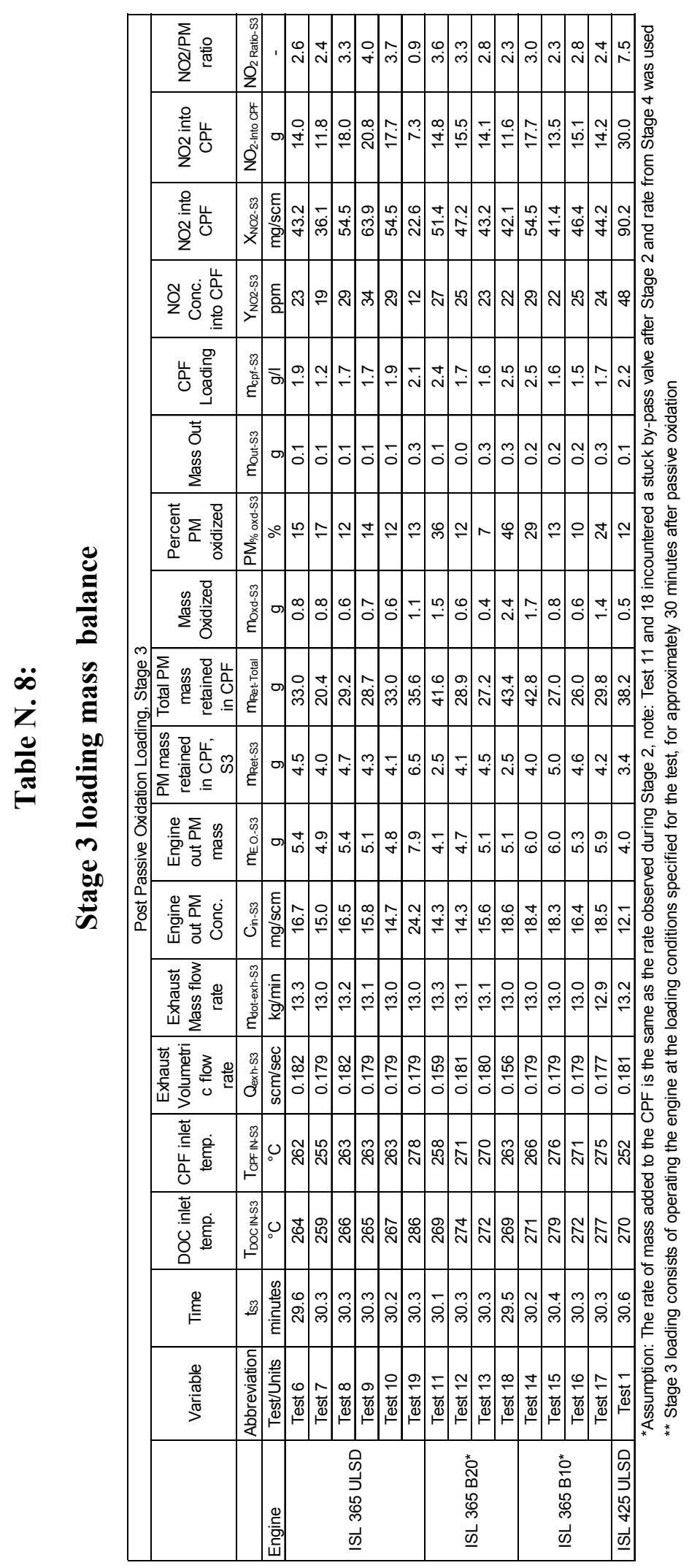

158 


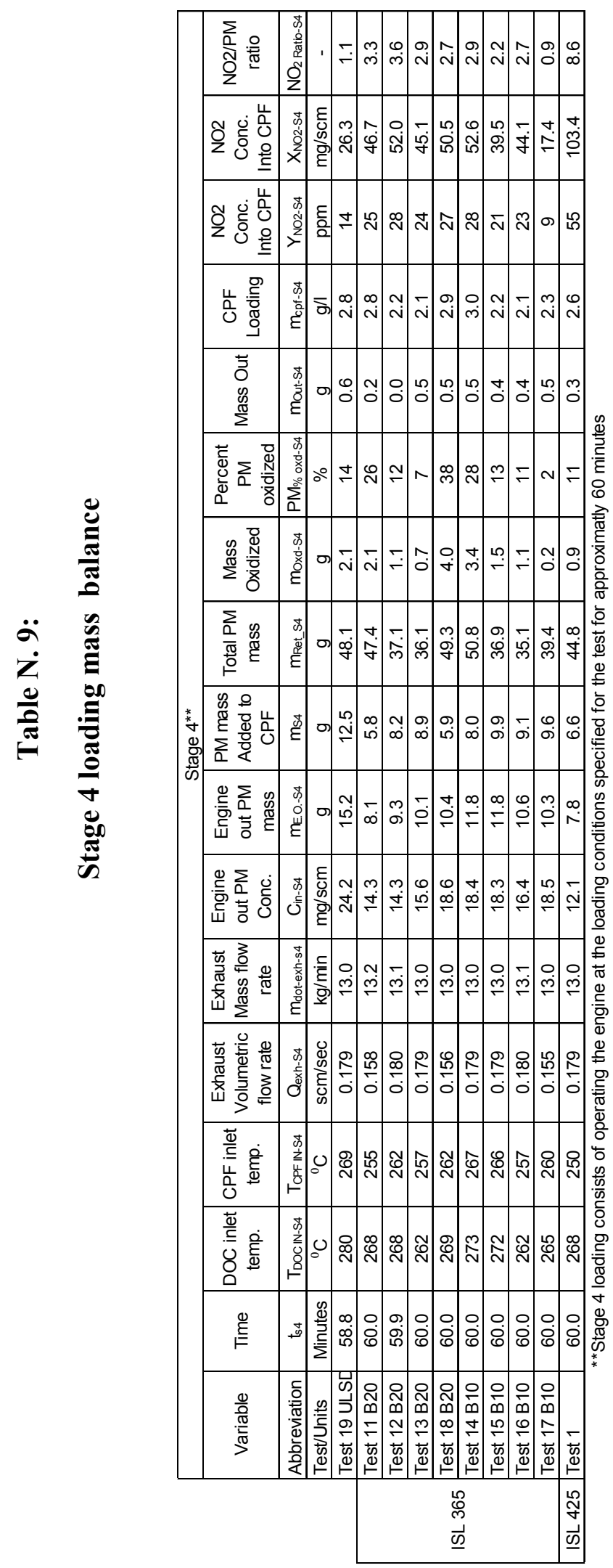




\section{Appendix O Statistical Analysis of Stage 2 Loading Reaction Rates}

A statistical analysis was performed to determine if the average of the calculated reaction rates were different for the ISL rated at $365 \mathrm{hp}$ with ULSD, B20, and B10. Reaction rates from work performed by Hutton et al. [1,2] with the ISL rated at $365 \mathrm{hp}$ with ULSD fuel are included to increase accuracy of the distribution. The null hypothesis was that the mean reaction rates during Stage 2 loading is the same for both engines and for all fuels, the alternative hypothesis is that the mean reaction rates are not the same. The results of these calculations are shown in Table O. 1 along with the 99\% confidence interval associated with this statistic. The calculated $t$-value $\left(T_{0}\right)$ is less than the critical $t$-value which results in a failure to reject the null hypothesis. Therefore, when using a significance level of 0.01 the mean reaction rates come from the same population. The calculated $99 \%$ confidence interval includes zero which reinforces the above conclusion. The confidence interval can be used as check for the calculated $\mathrm{T}_{0}$ value. Since the value zero is included in the confidence interval and we are testing the difference in the means of the reaction rates, the reaction rate means may be the same for both engines with ULSD and the ISL with B20 and B10. Table 3.8 - 11 show that each engine and fuel type had a different average $\mathrm{NO}_{2}$ and $\mathrm{NO}_{\mathrm{x}}$ to $\mathrm{PM}$ ratios during loading which should have resulted in different reaction rates. Biodiesel particulate matter has been found to be more reactive with $\mathrm{NO}_{2}$ possibly due to higher PM structure disorder and higher oxygen content under thermal oxidation [6]. Increased particulate matter (PM) reactivity is believed to have compensated for decreased $\mathrm{NO}_{2}$ concentrations during loading. ISL 365 Test 19 encountered an engine fault code during the first half of Stage 2 loading and it is believed this may have had an effect on the reaction rate. In order to verify that this test did not adversely affect the statistical analysis results Table O. 2 shows an analysis conducted without Test 19 data with similar results and the same conclusions.

Table O. 1: T-Statistic and 99\% confidence interval for Stage 2 loading reaction rate
comparison

\begin{tabular}{|c|c|c|c|c|}
\cline { 2 - 4 } \multicolumn{1}{c|}{} & $\begin{array}{c}\text { Significance } \\
\text { Level }\end{array}$ & $\mathrm{T}_{\text {Critical }}$ & $\left|\mathrm{T}_{0}\right|$ & $\begin{array}{c}\text { Confidence Interval } \\
(1 / \mathrm{s})\end{array}$ \\
\hline $\begin{array}{c}\text { ISL with ULSD, } \\
\text { ISL with B20 }\end{array}$ & 0.01 & 3.500 & 1.60 & $(-1.88 \mathrm{E}-5,6.97 \mathrm{E}-6)$ \\
\hline $\begin{array}{c}\text { ISL with ULSD, } \\
\text { ISL with B10 }\end{array}$ & 0.01 & 3.250 & 1.05 & $(-1.46 \mathrm{E}-5,7.45 \mathrm{E}-6)$ \\
\hline
\end{tabular}


Table O. 2:

T-Statistic and $99 \%$ confidence interval for Stage 2 loading reaction rate comparison without ISL 365 Test 19 data

\begin{tabular}{|c|c|c|c|c|}
\cline { 2 - 5 } \multicolumn{1}{c|}{} & $\begin{array}{c}\text { Significance } \\
\text { Level }\end{array}$ & $T_{\text {Critical }}$ & $\left|\mathrm{T}_{0}\right|$ & $\begin{array}{c}\text { Confidence Interval } \\
(1 / \mathrm{s})\end{array}$ \\
\hline $\begin{array}{c}\text { ISL with ULSD, } \\
\text { ISL with B20 }\end{array}$ & 0.01 & 3.500 & 2.41 & $(-1.89 \mathrm{E}-5,3.51 \mathrm{E}-6)$ \\
\hline $\begin{array}{c}\text { ISL with ULSD, } \\
\text { ISL with B10 }\end{array}$ & 0.01 & 3.250 & 1.87 & $(-1.47 \mathrm{E}-5,3.95 \mathrm{E}-6)$ \\
\hline
\end{tabular}




\section{Appendix P Complete Pressure Drops}

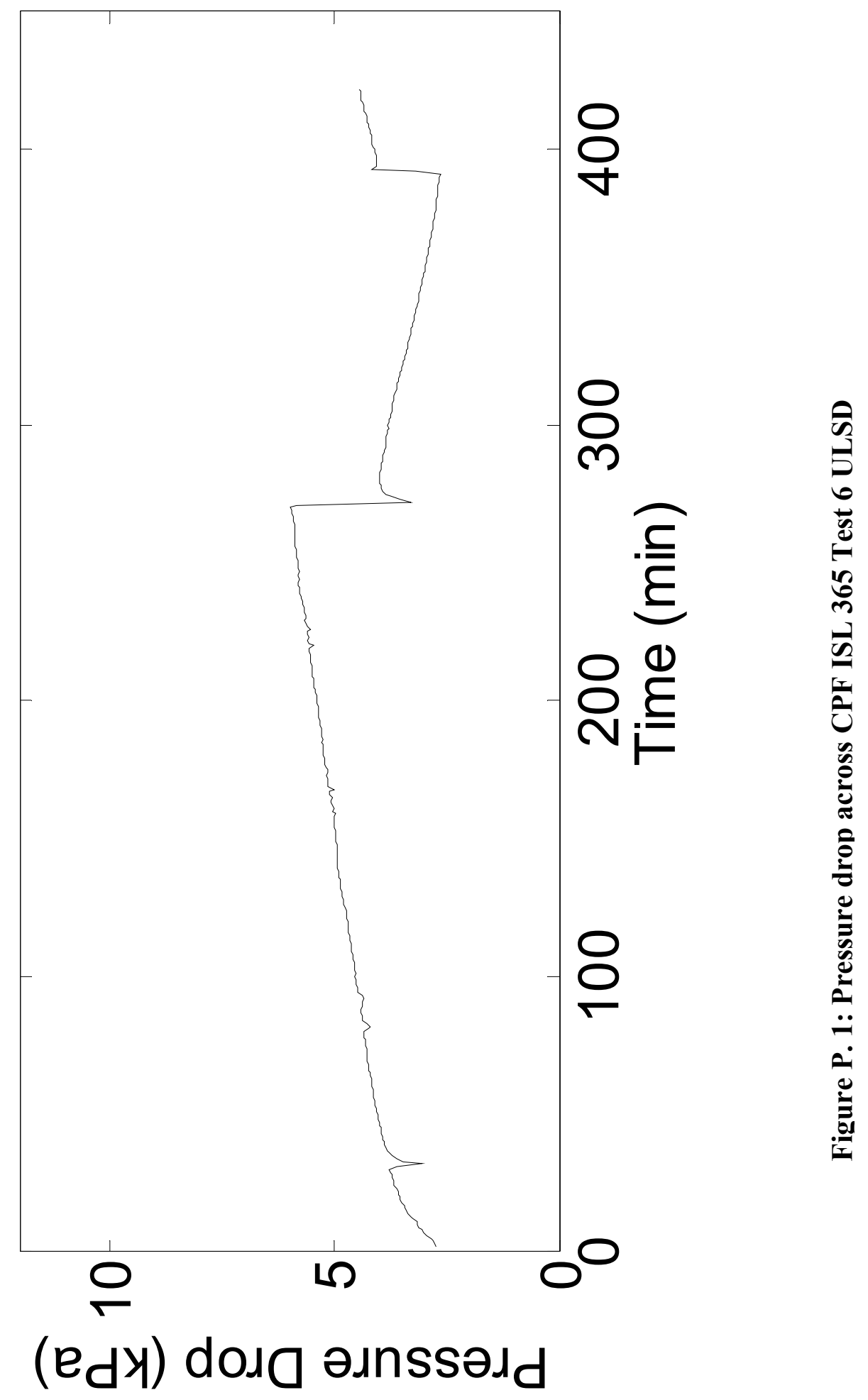




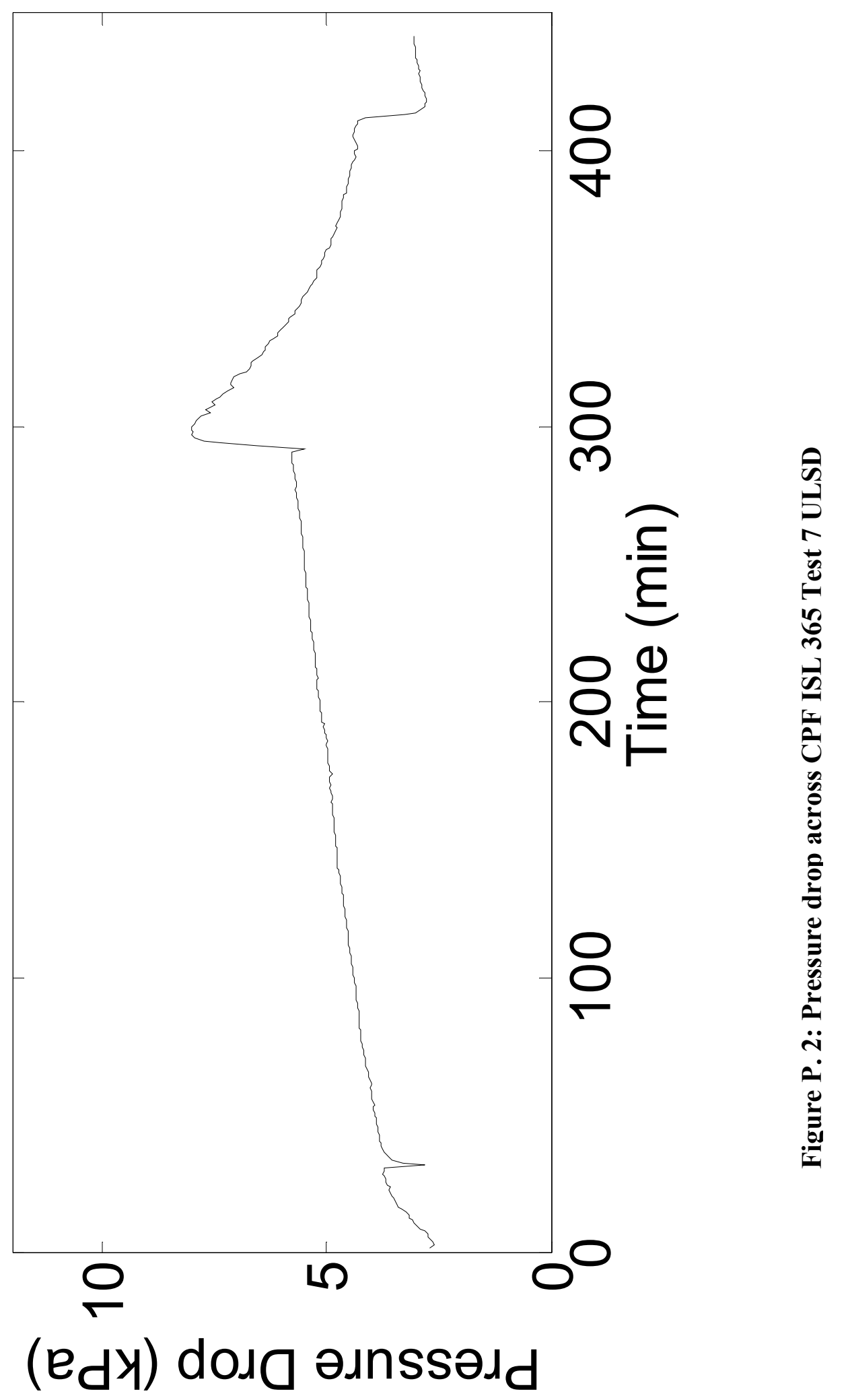




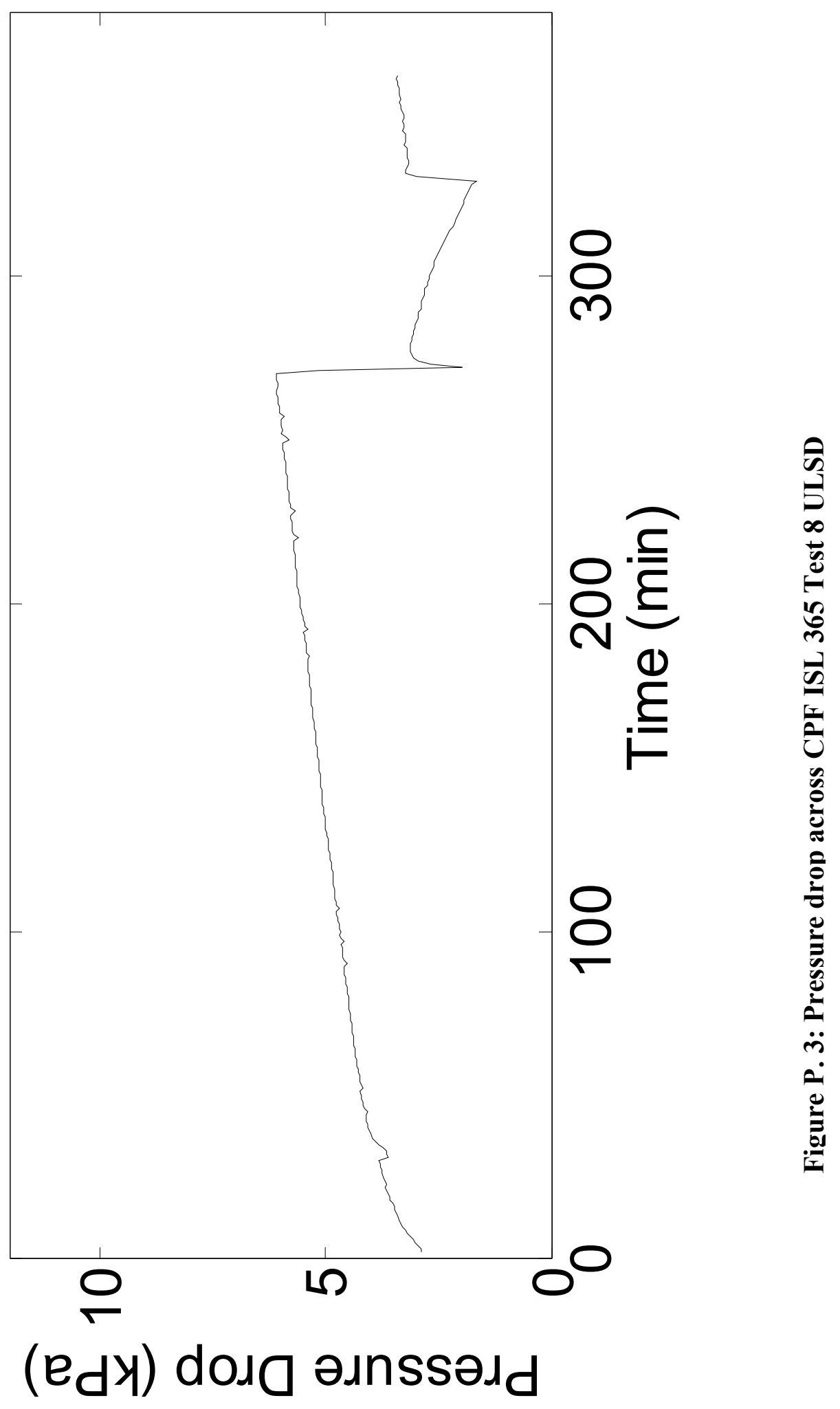




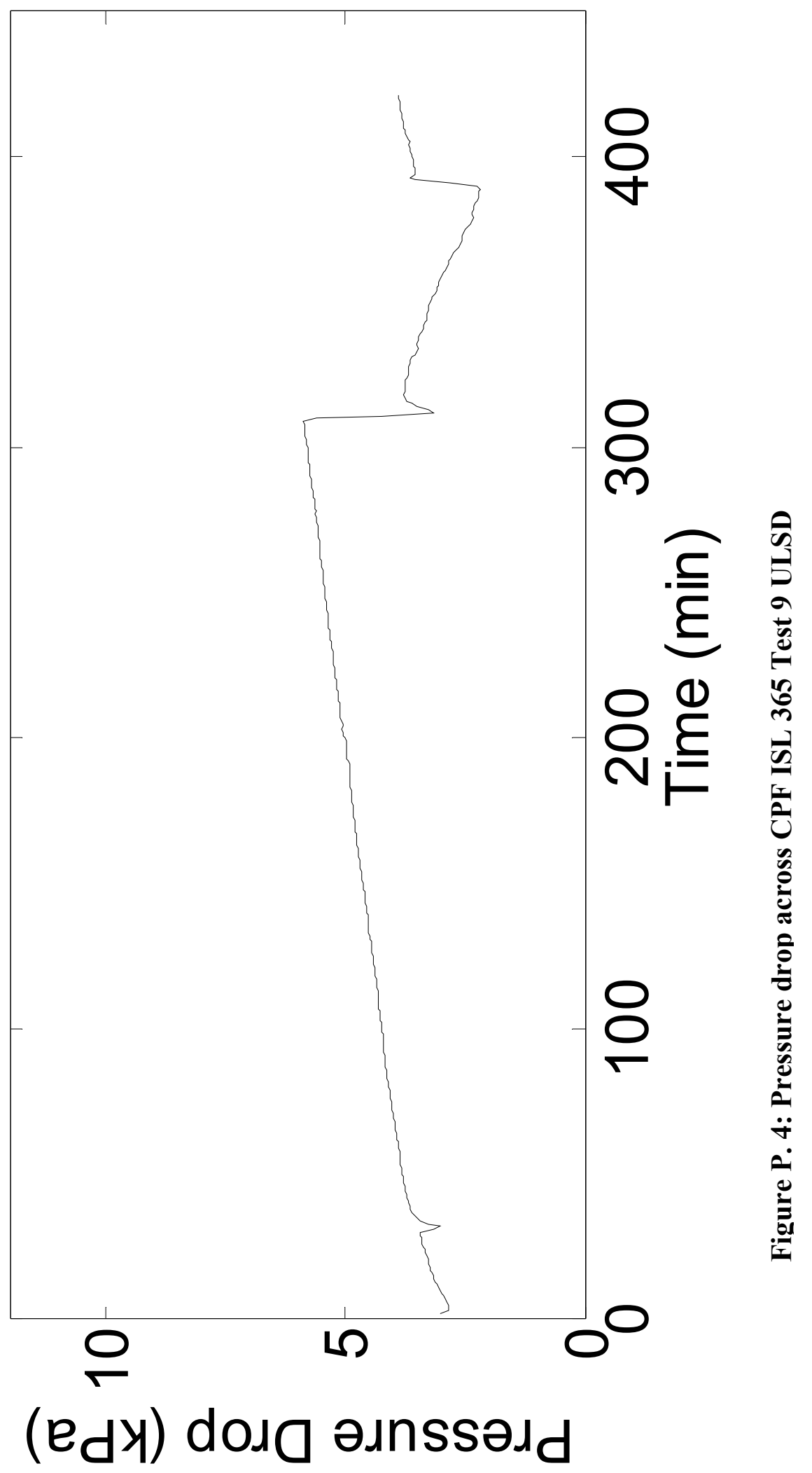




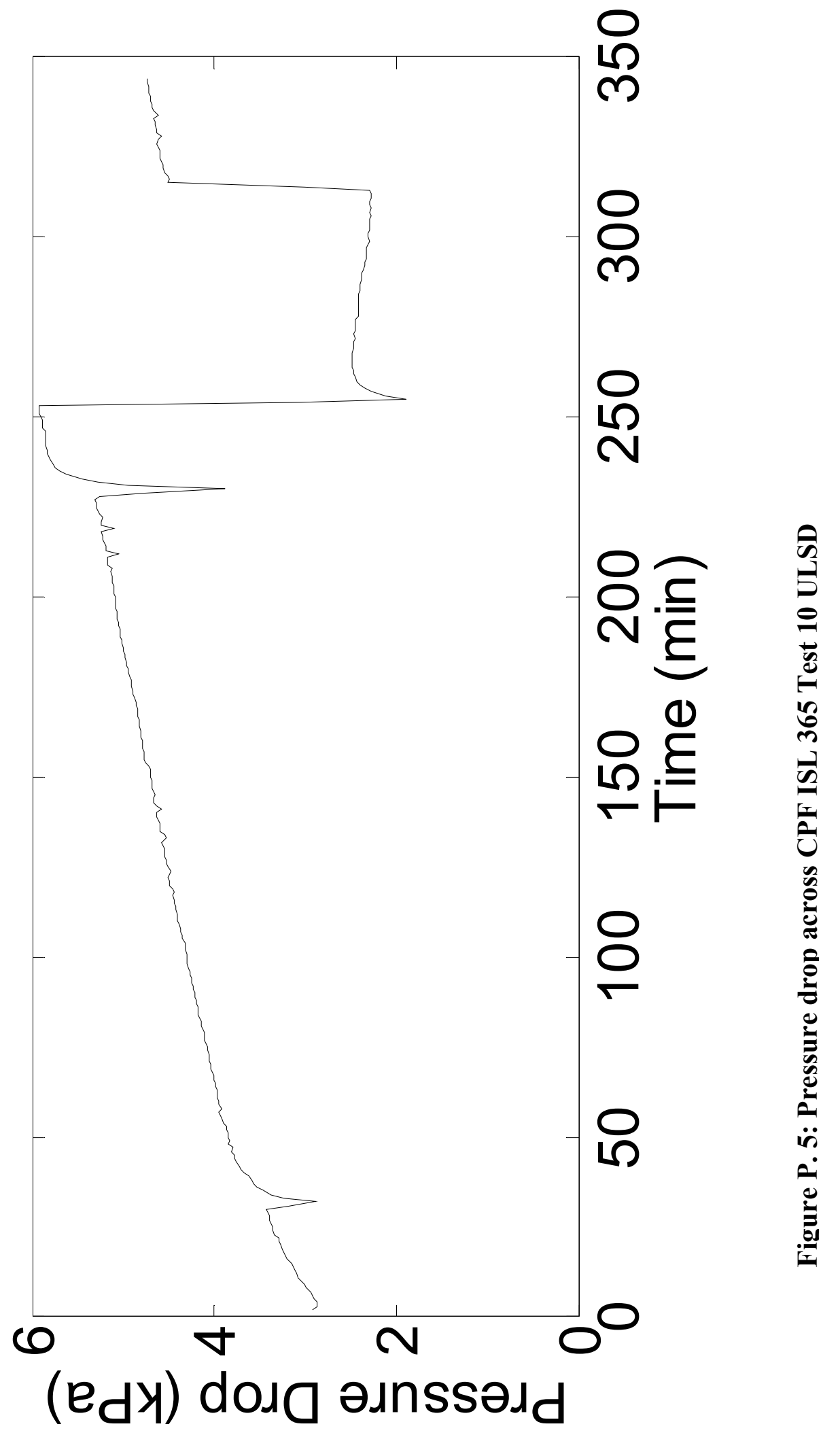

166 


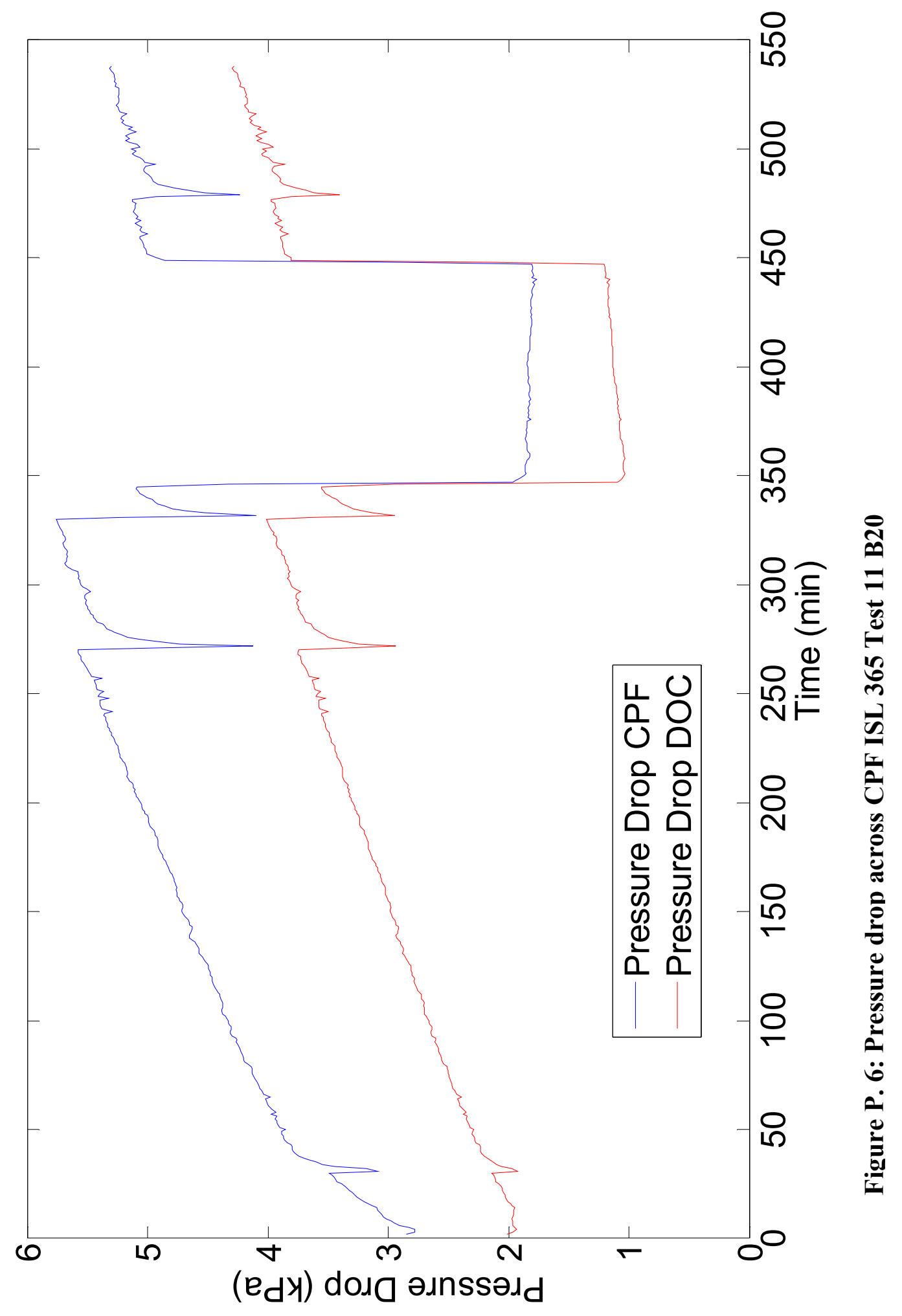




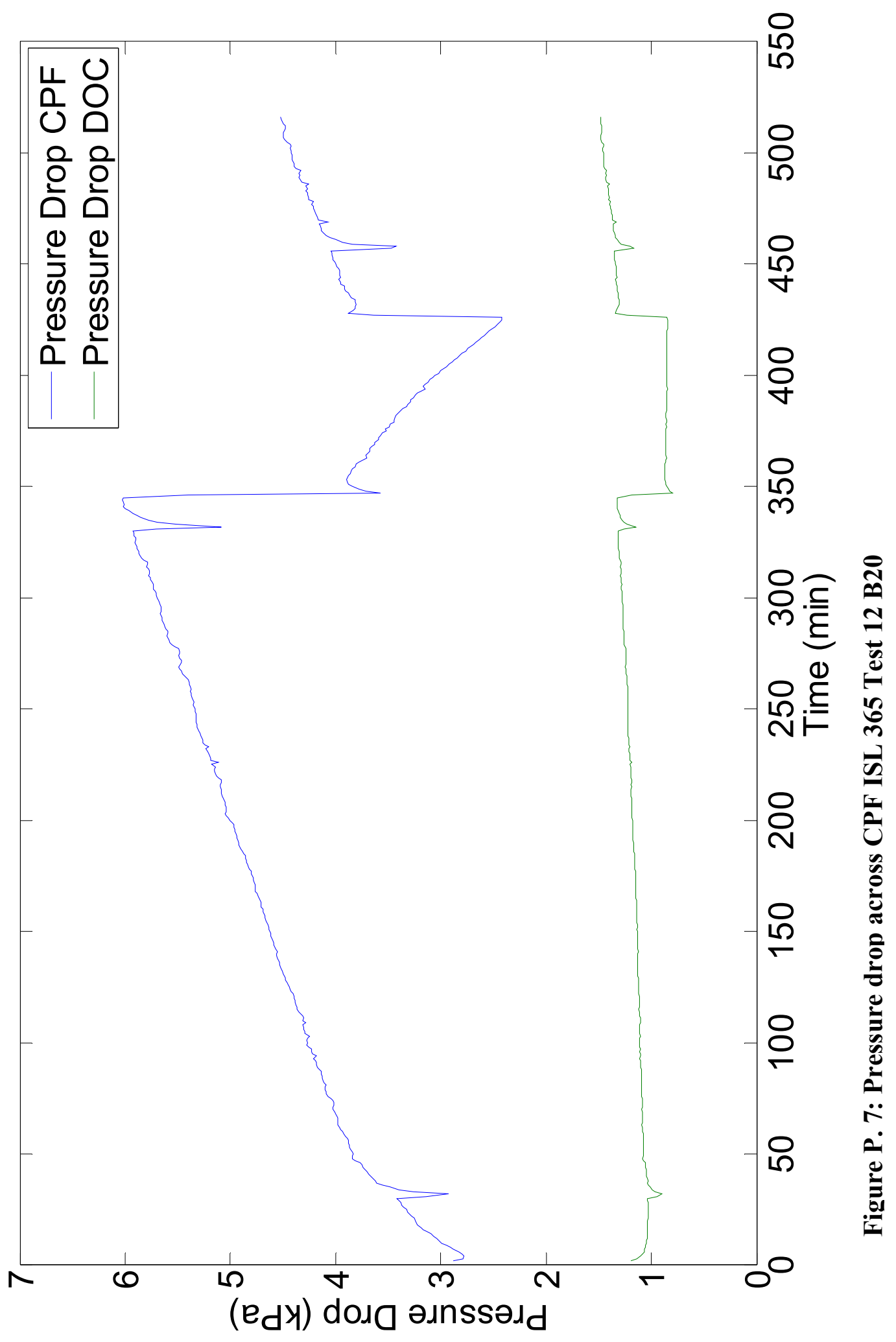




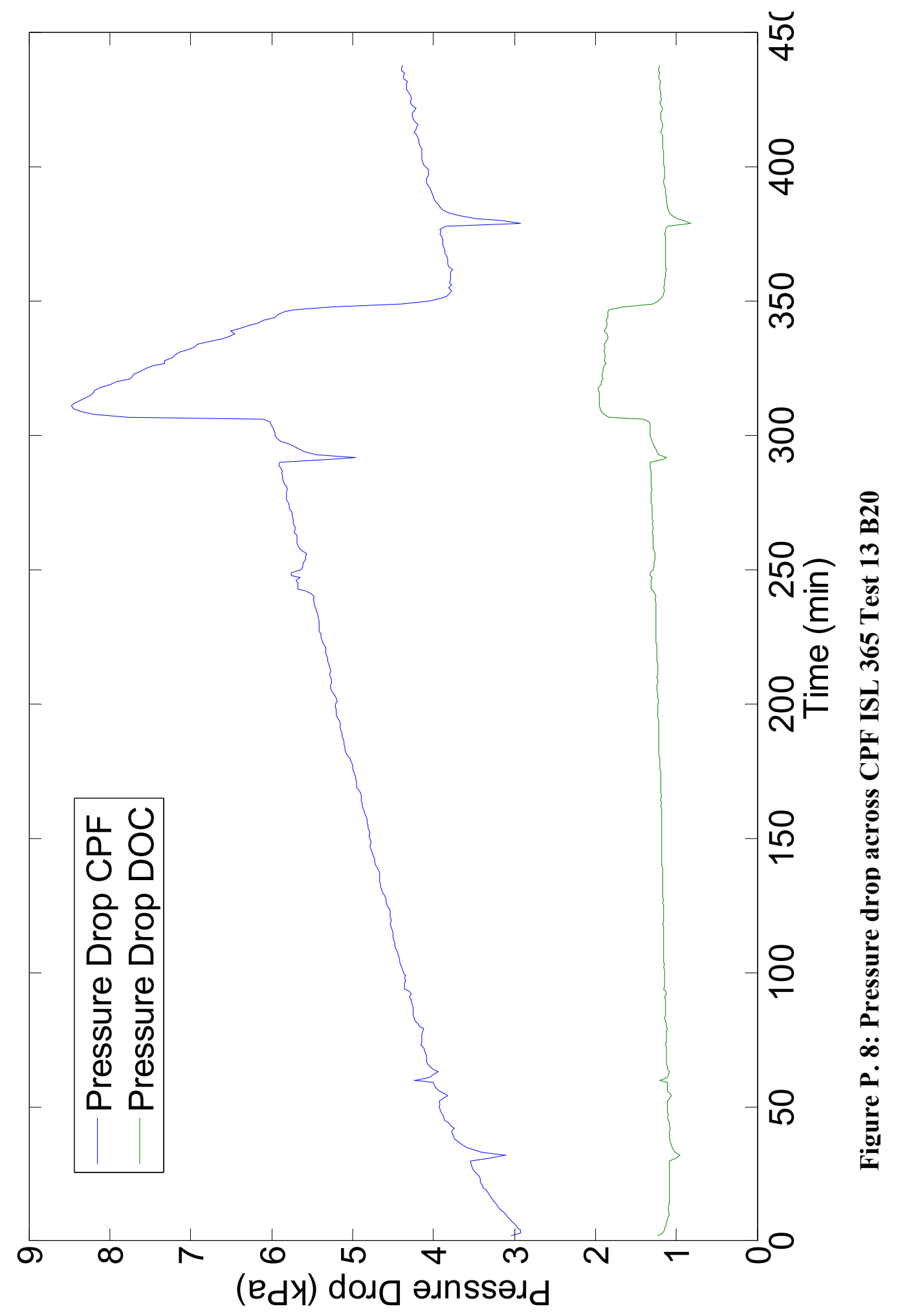




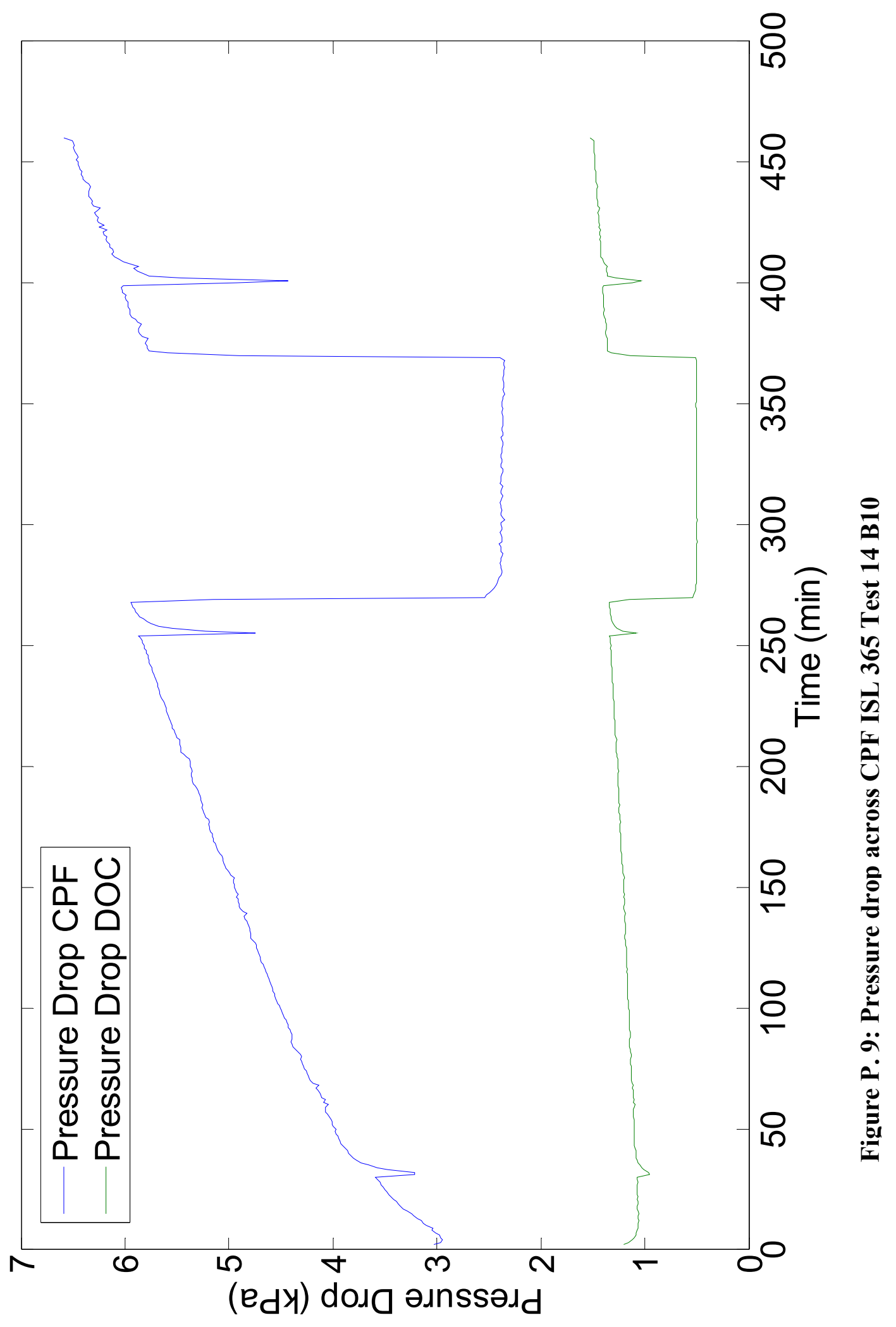




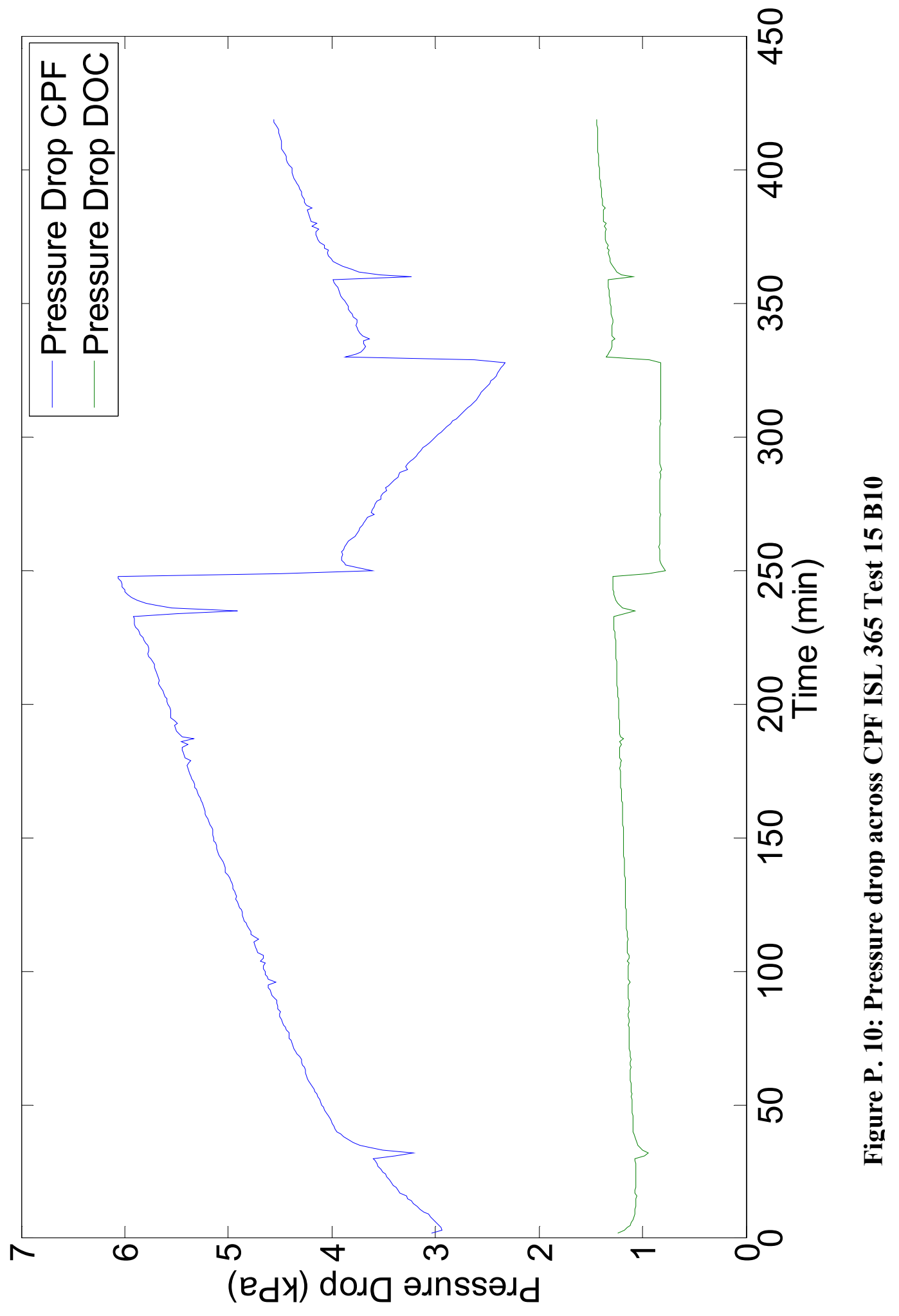




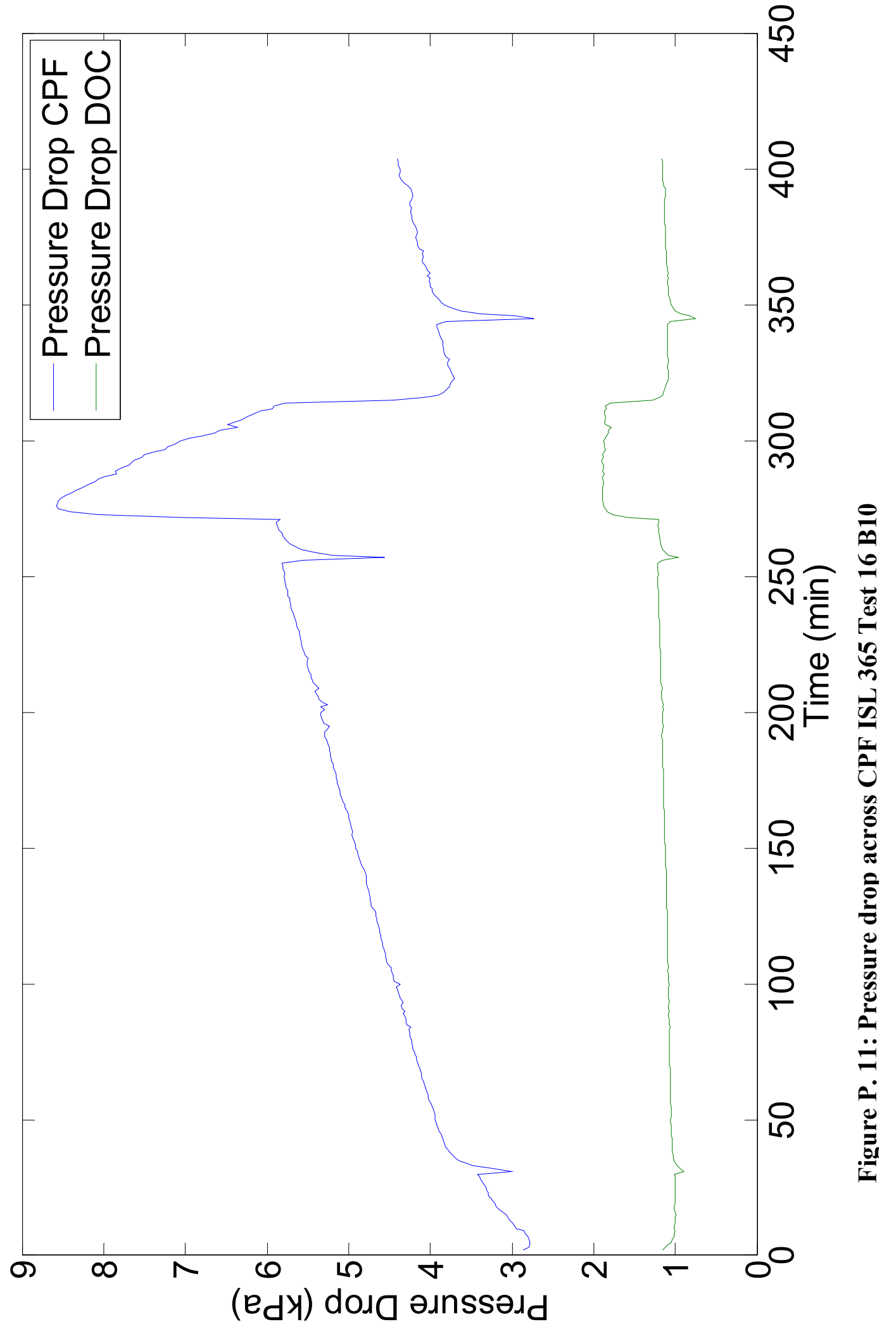




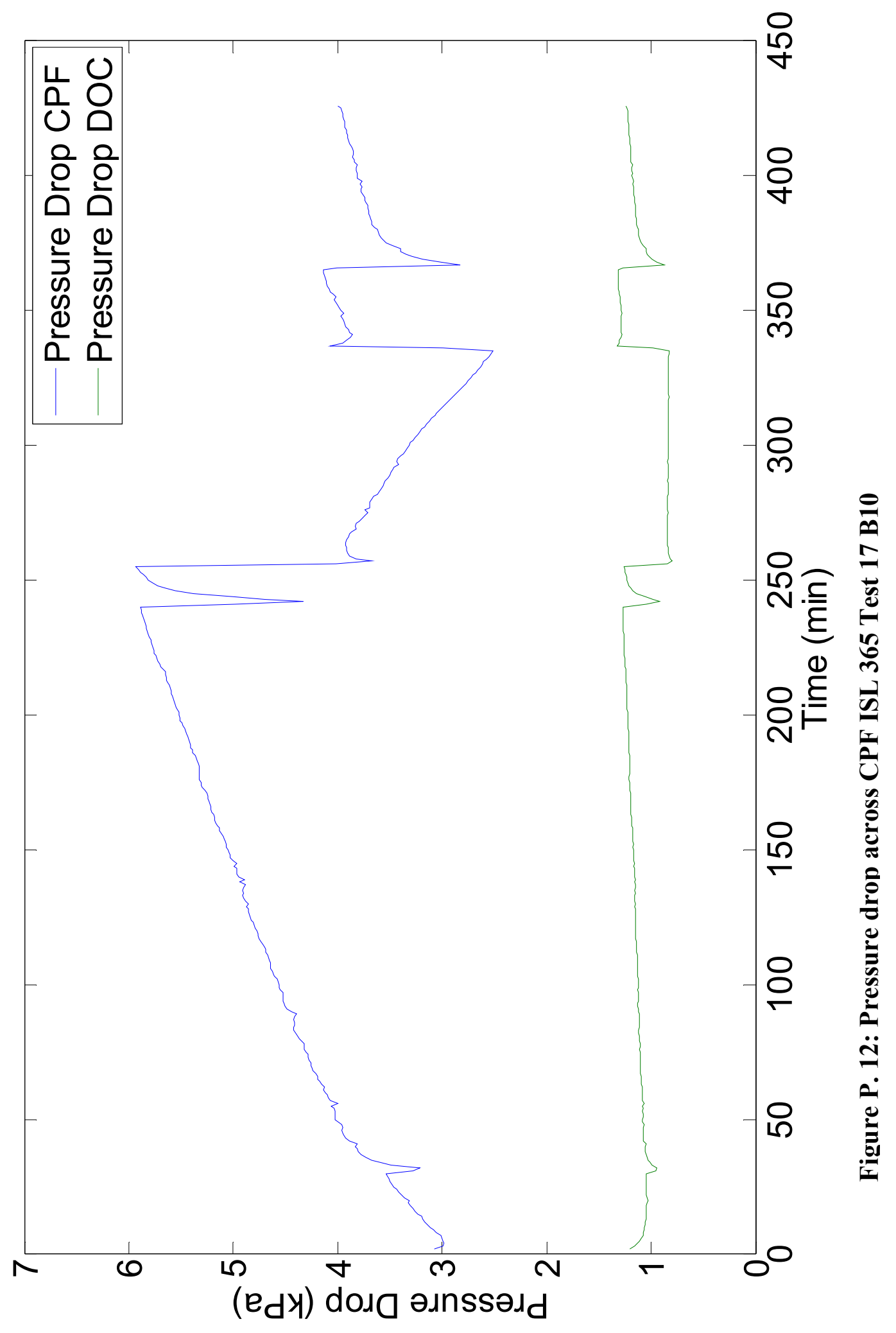




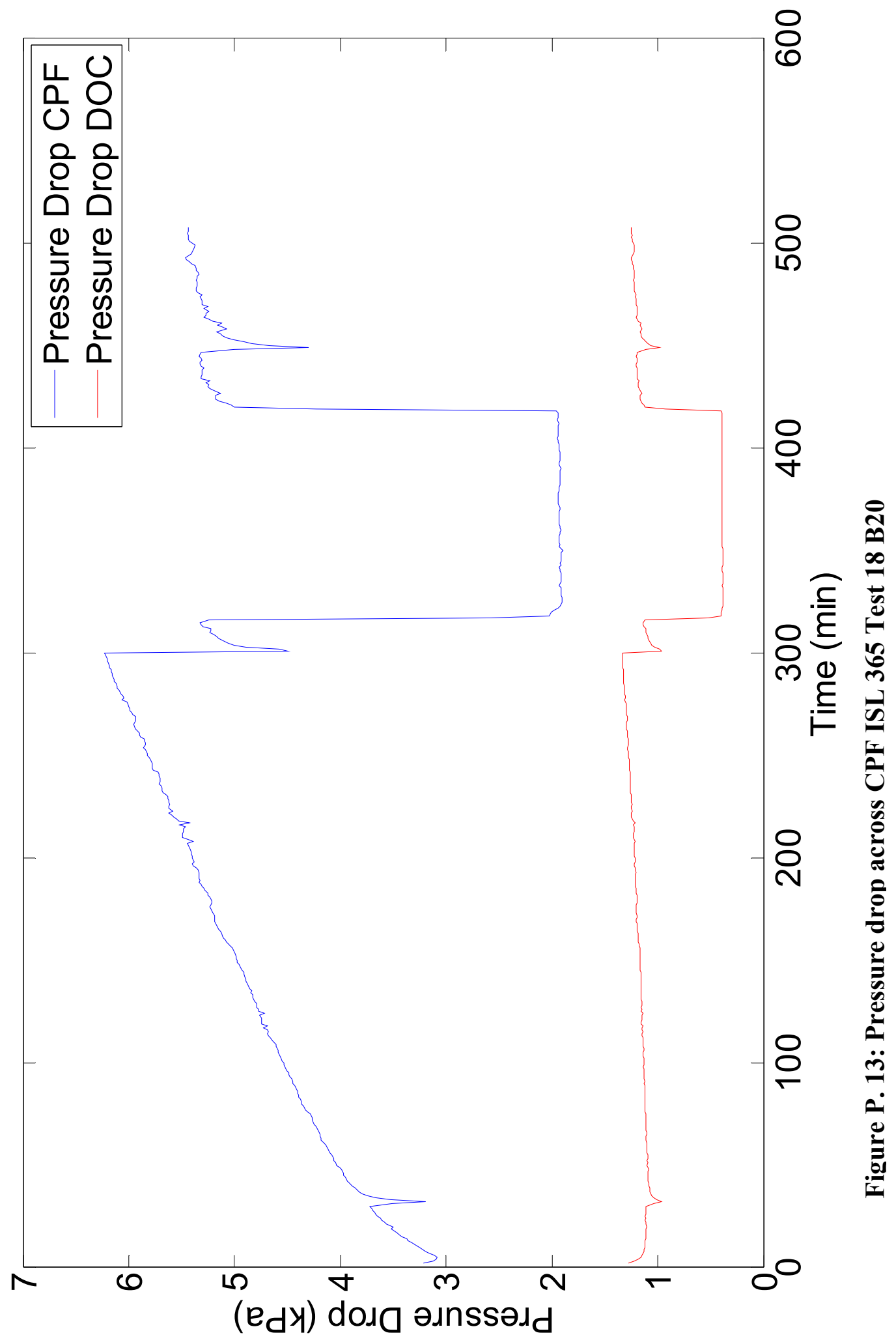




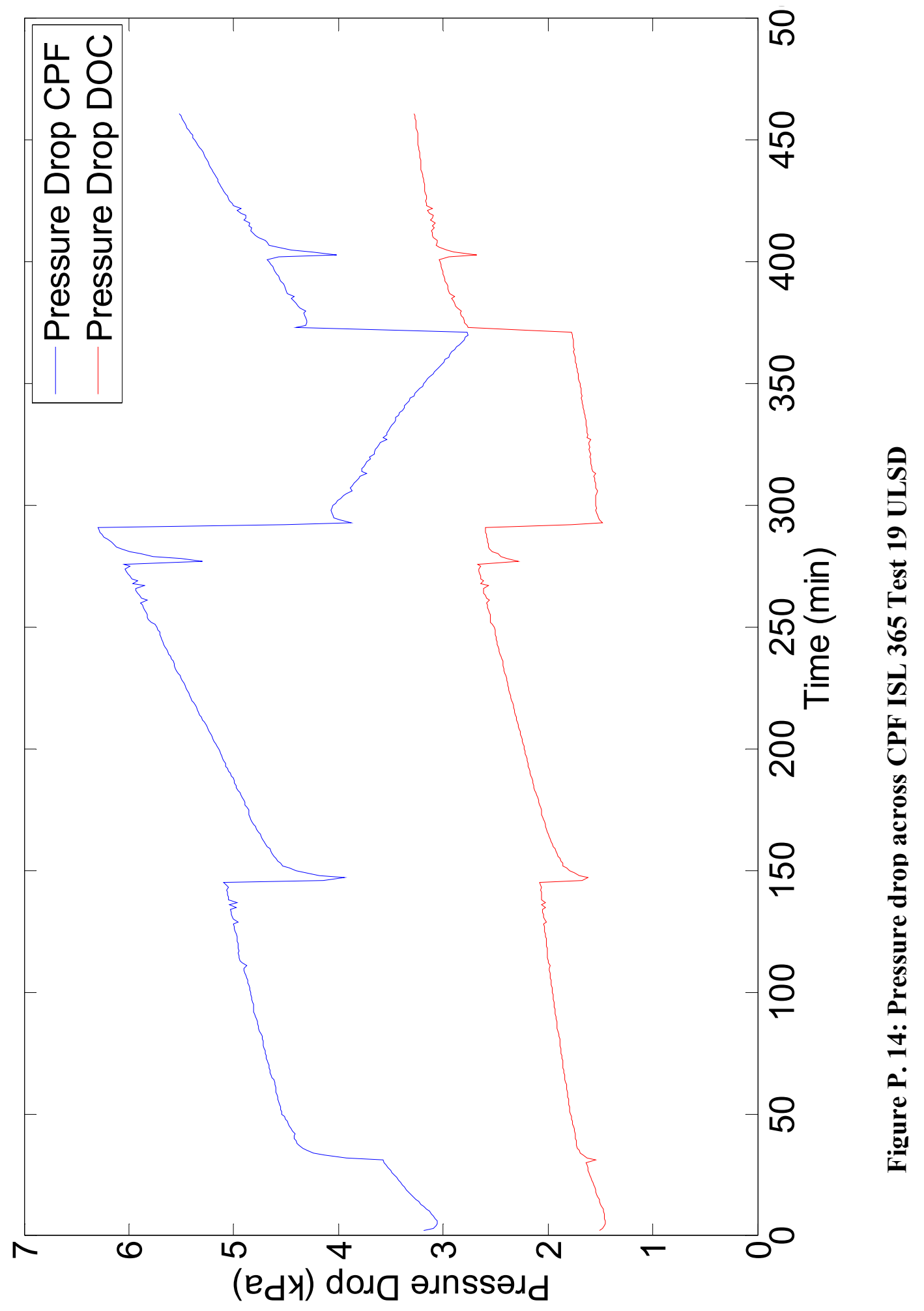




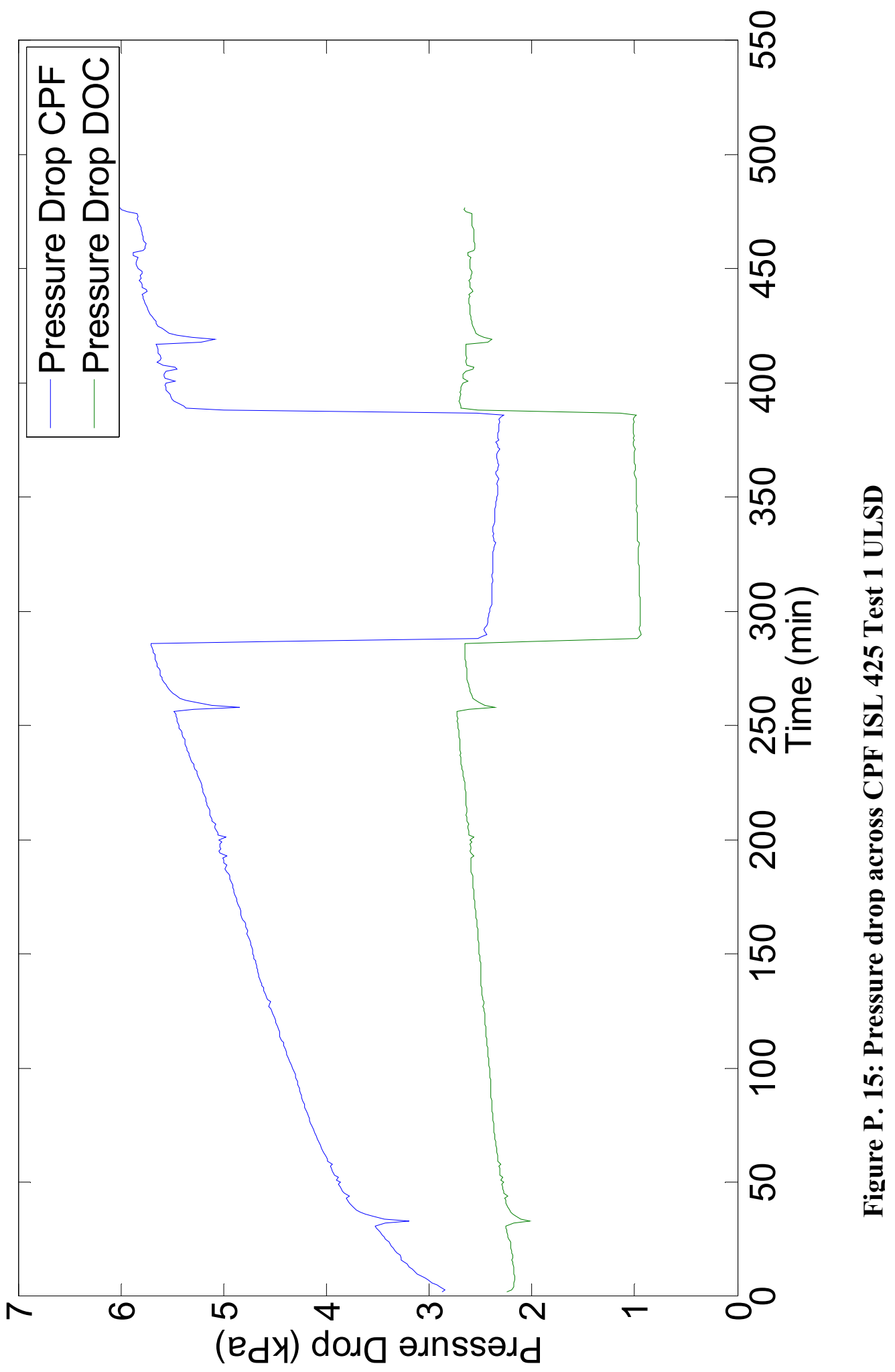




\section{Appendix Q Passive Oxidation PSD Data}
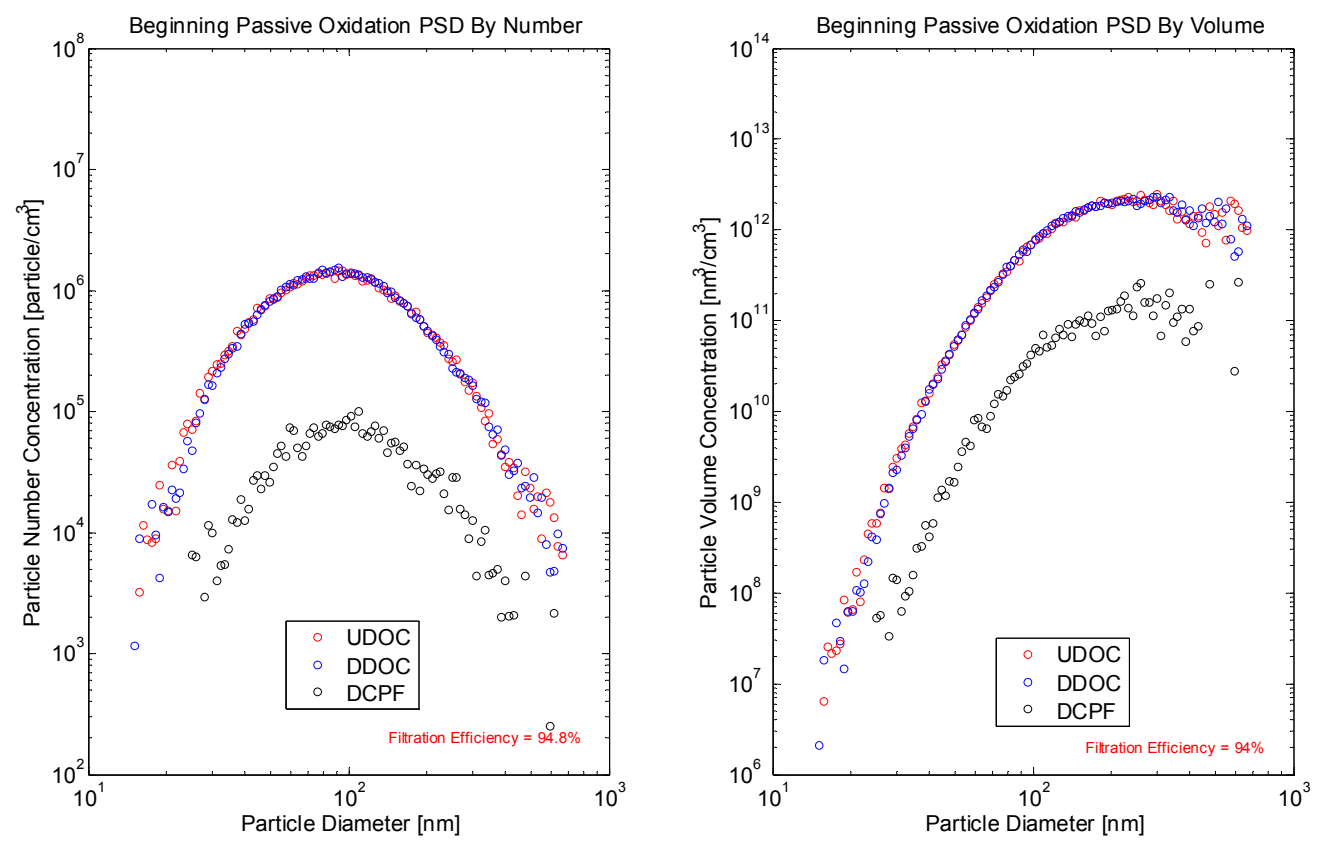

Figure Q. 1: ISL 365 B20 Test 11 beginning Passive Oxidation PSD data
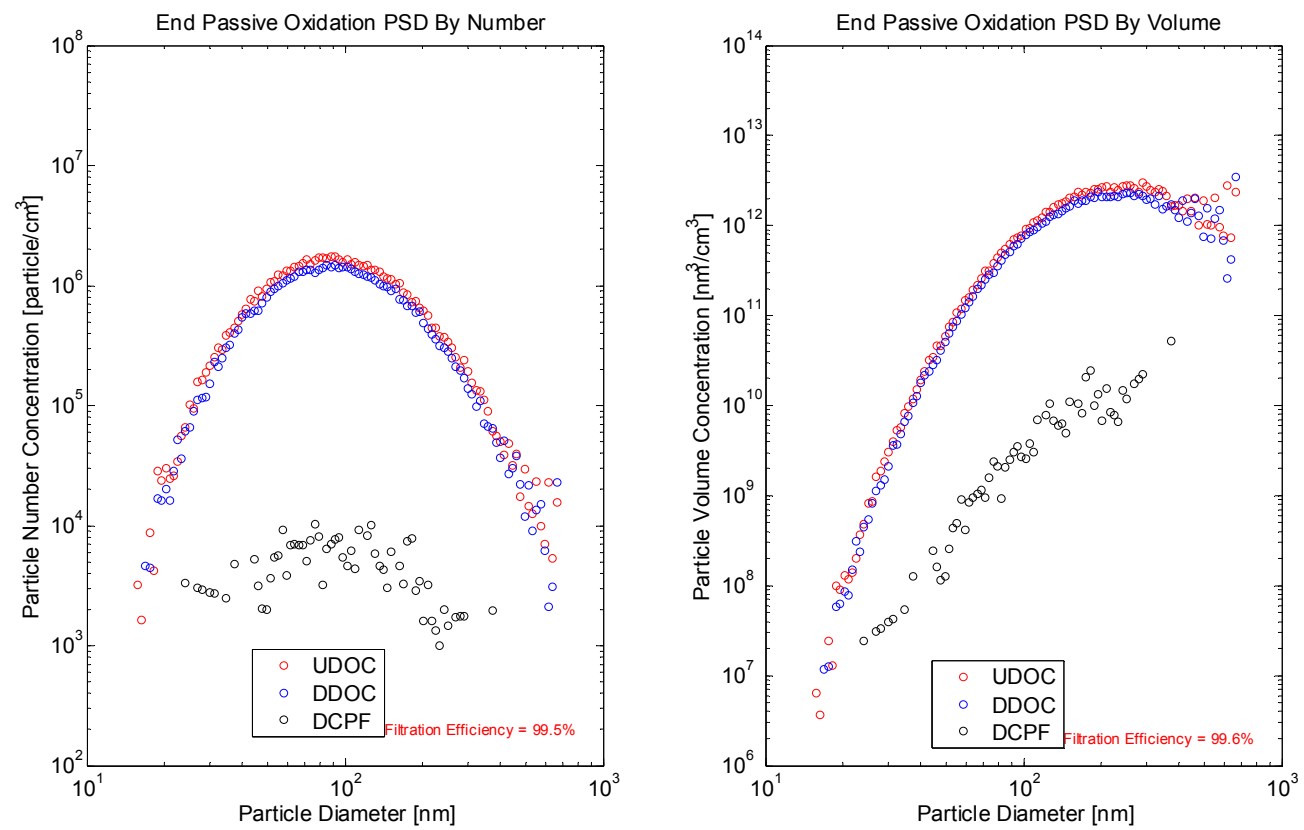

Figure Q. 2: ISL 365 B20 Test 11 end Passive Oxidation PSD data 

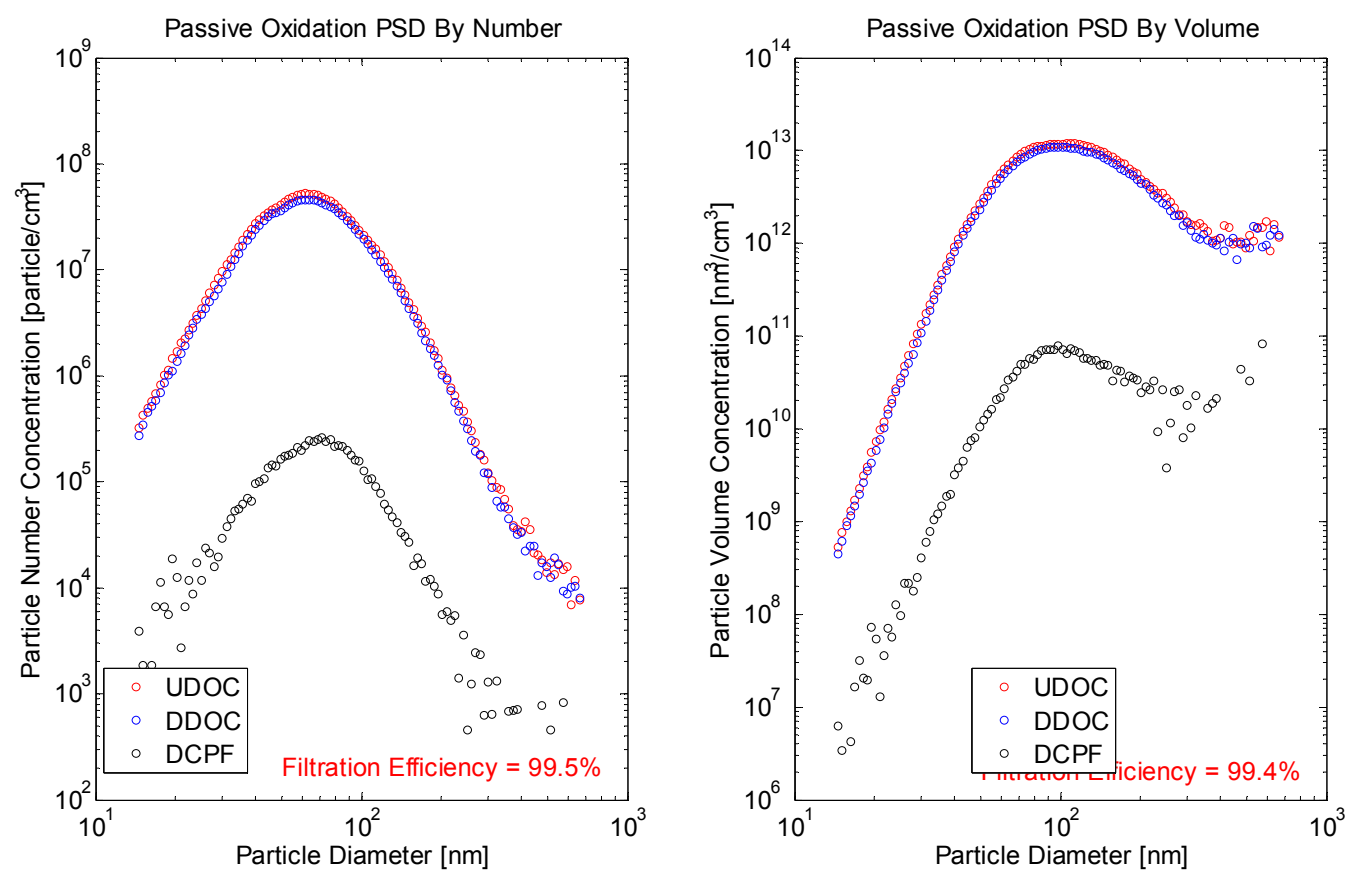

Figure Q. 3: ISL 365 B20 Test 12 Passive Oxidation PSD data (single set taken due to time)
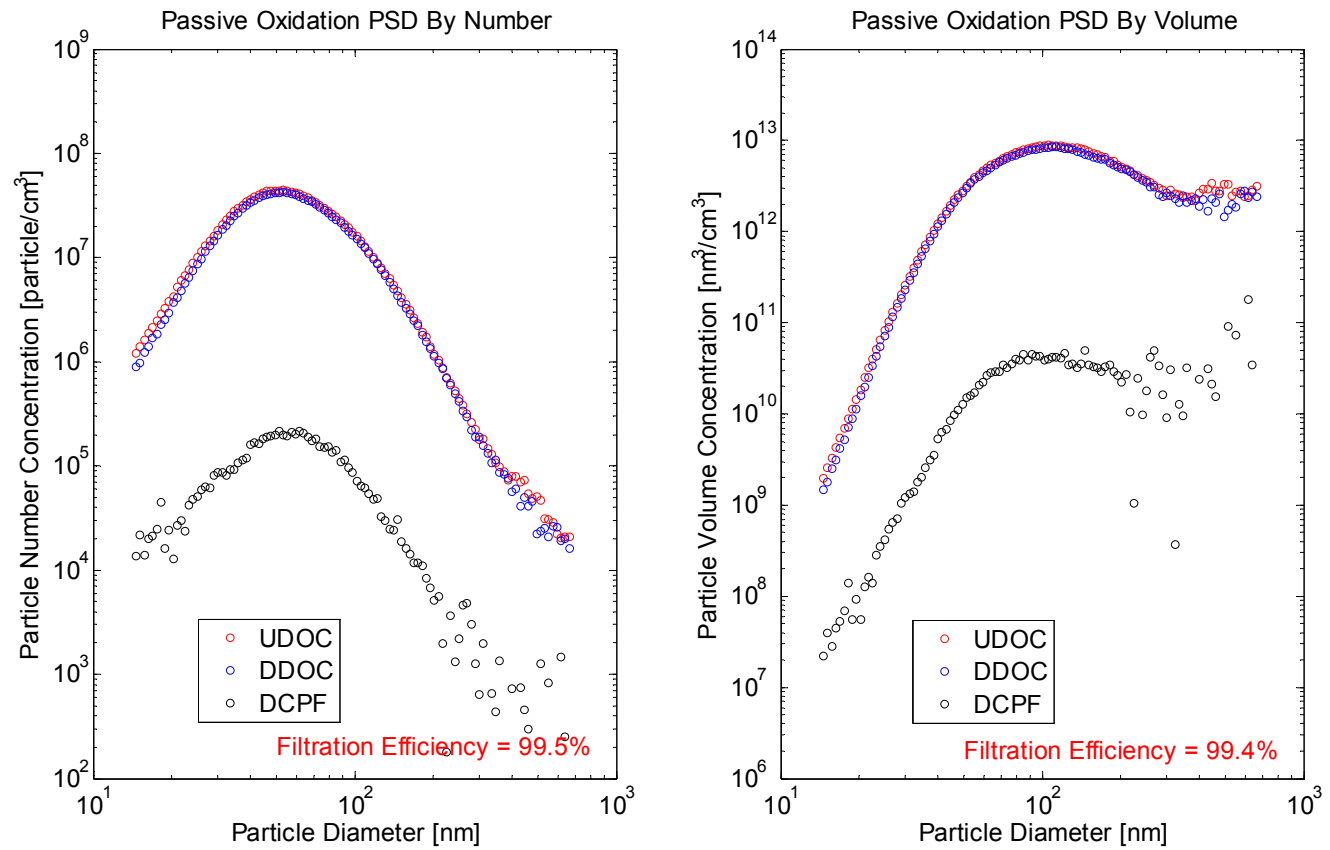

Figure Q. 4: ISL 365 B20 Test 13 Passive Oxidation PSD data (single set taken due to time) 

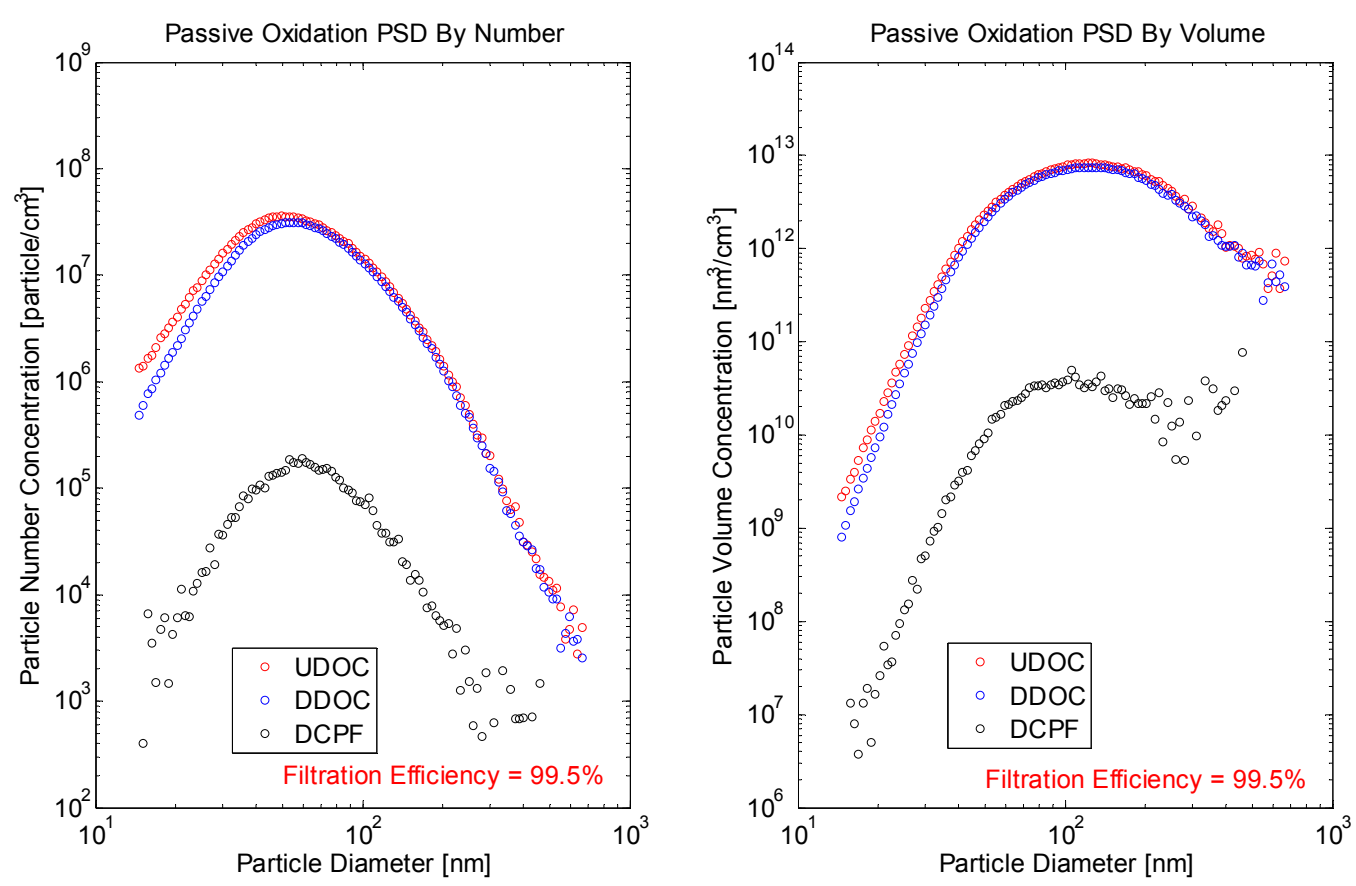

Figure Q. 5: ISL 365 B10 Test 14 end of Passive Oxidation PSD data (data collected at the beginning of Passive Oxidation was corrupted)
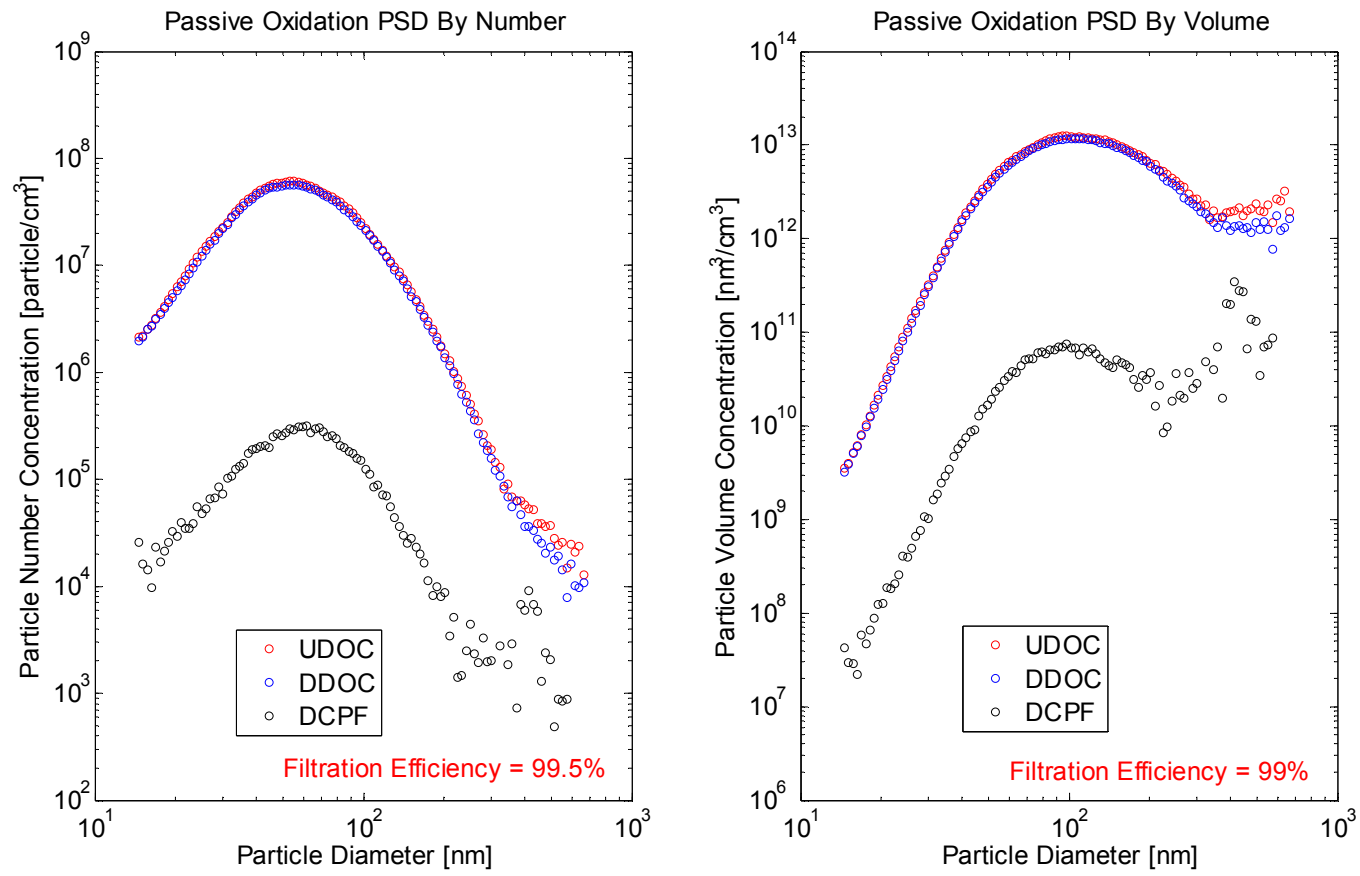

Figure Q. 6: ISL 365 B10 Test 15 Passive Oxidation PSD data 

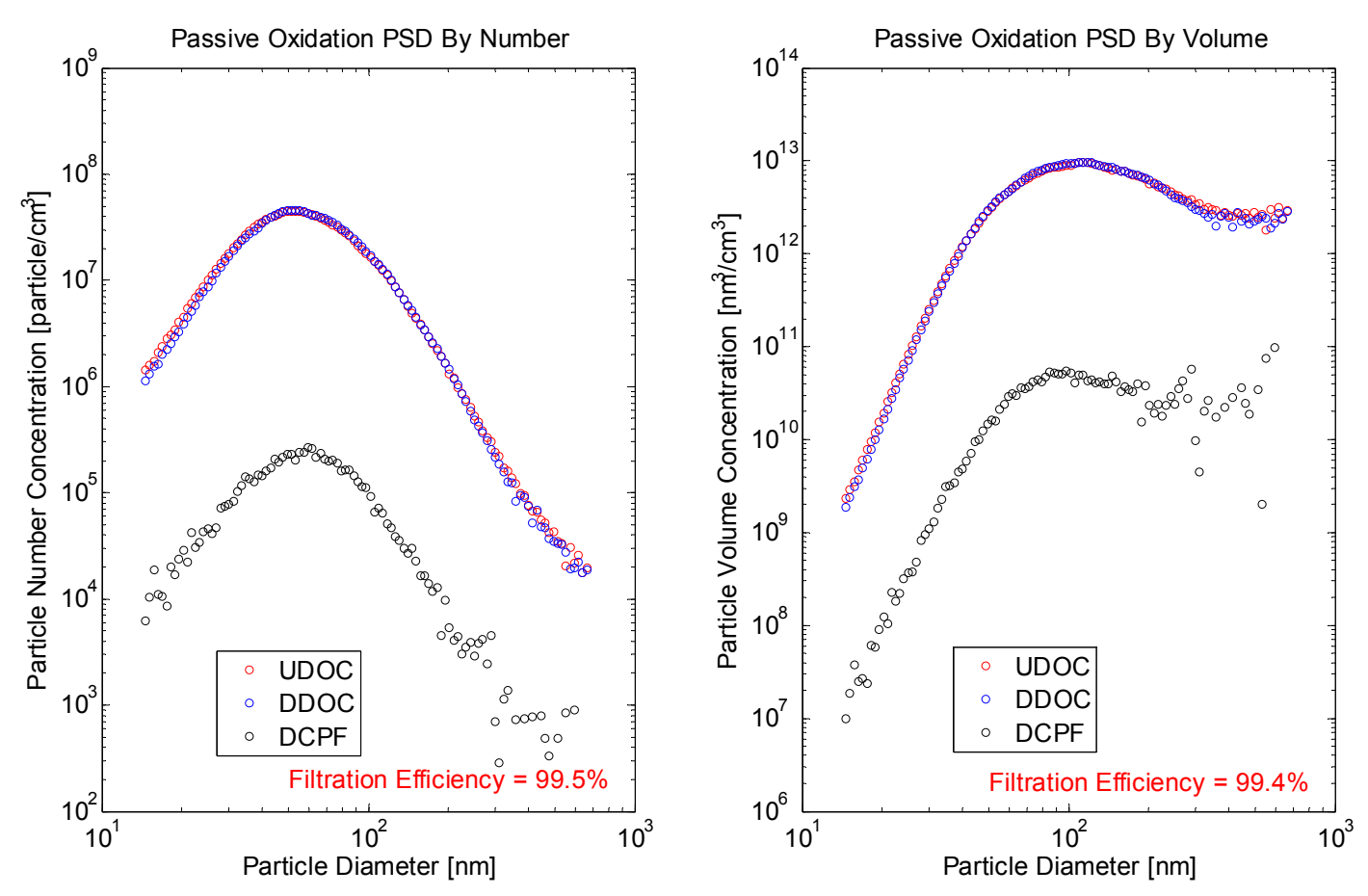

\section{Figure Q. 7: ISL 365 B10 Test 16 Passive Oxidation PSD data}
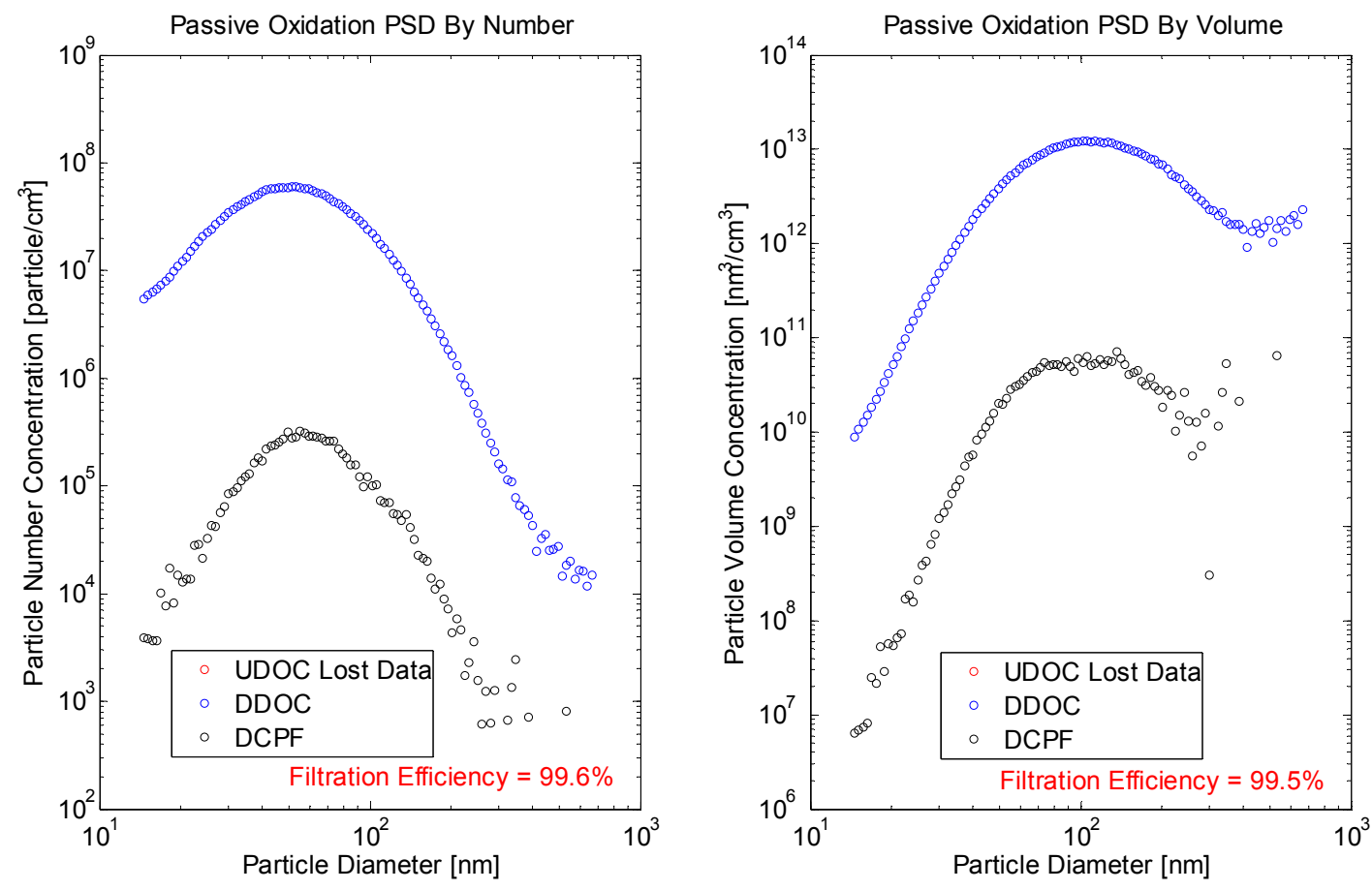

Figure Q. 8: ISL 365 B10 Test 17 Passive Oxidation PSD data 

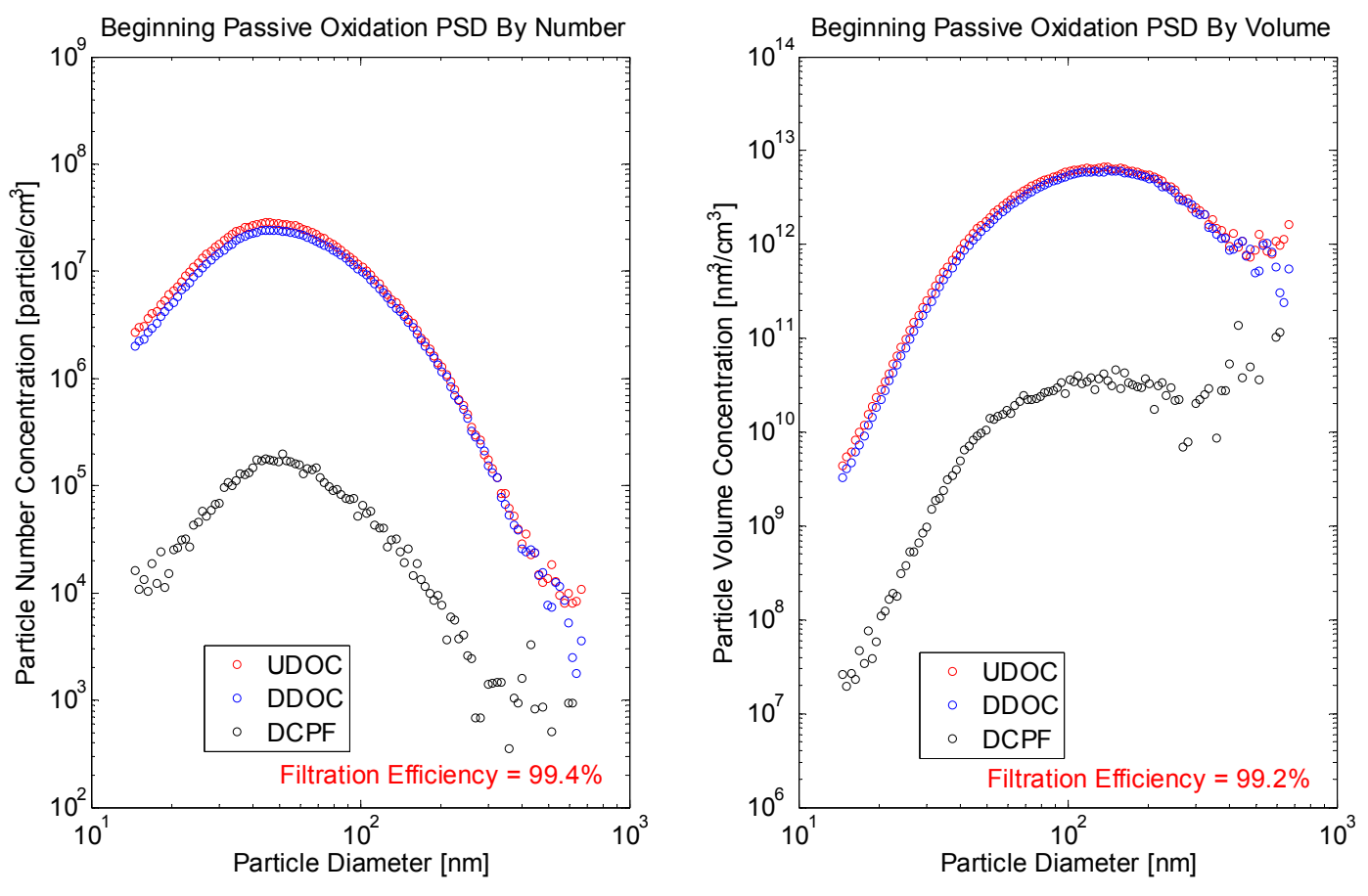

Figure Q. 9: ISL 365 B20 Test 18 beginning Passive Oxidation PSD data
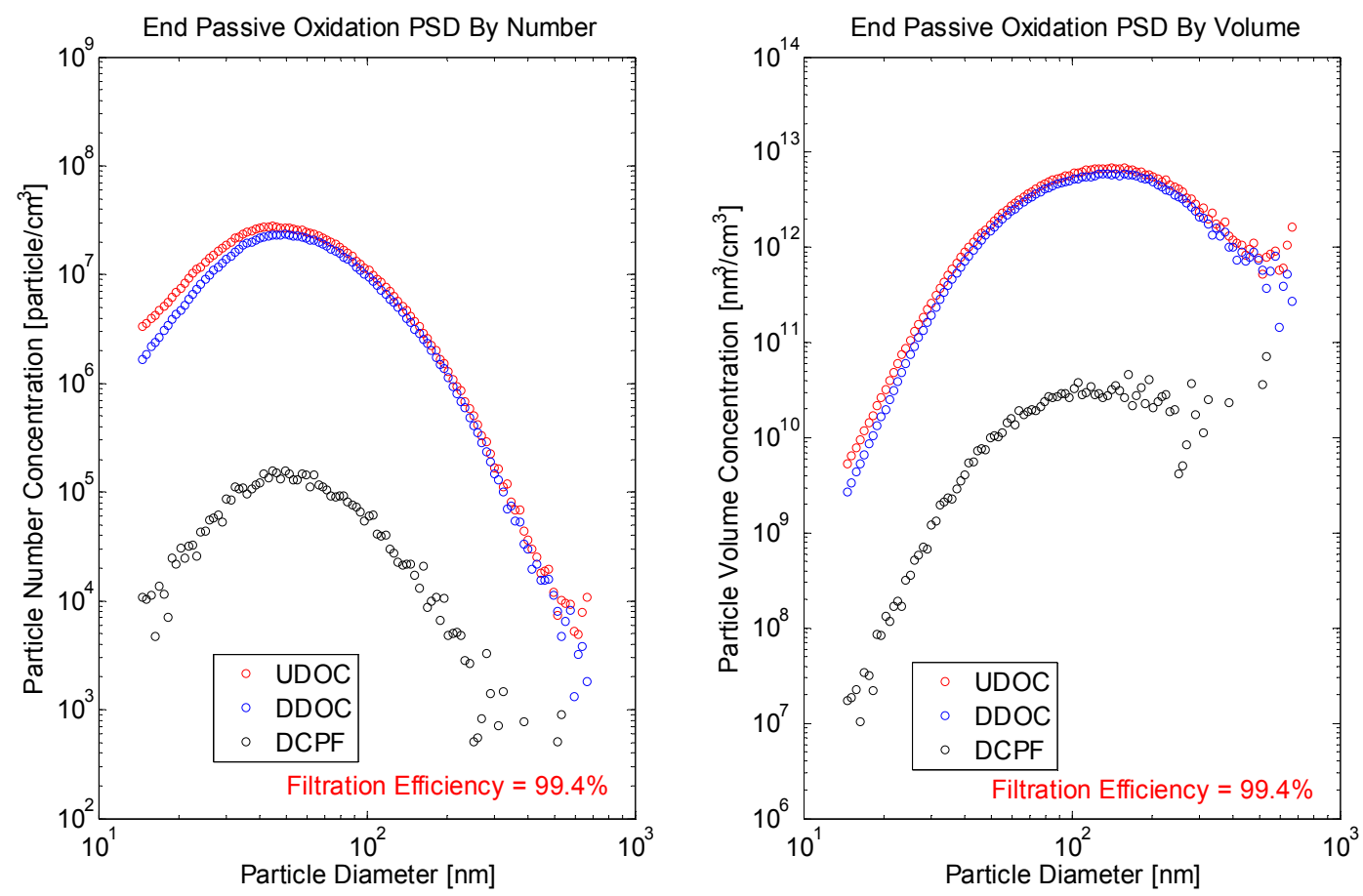

Figure Q. 10: ISL 365 B20 Test 18 end Passive Oxidation PSD data 

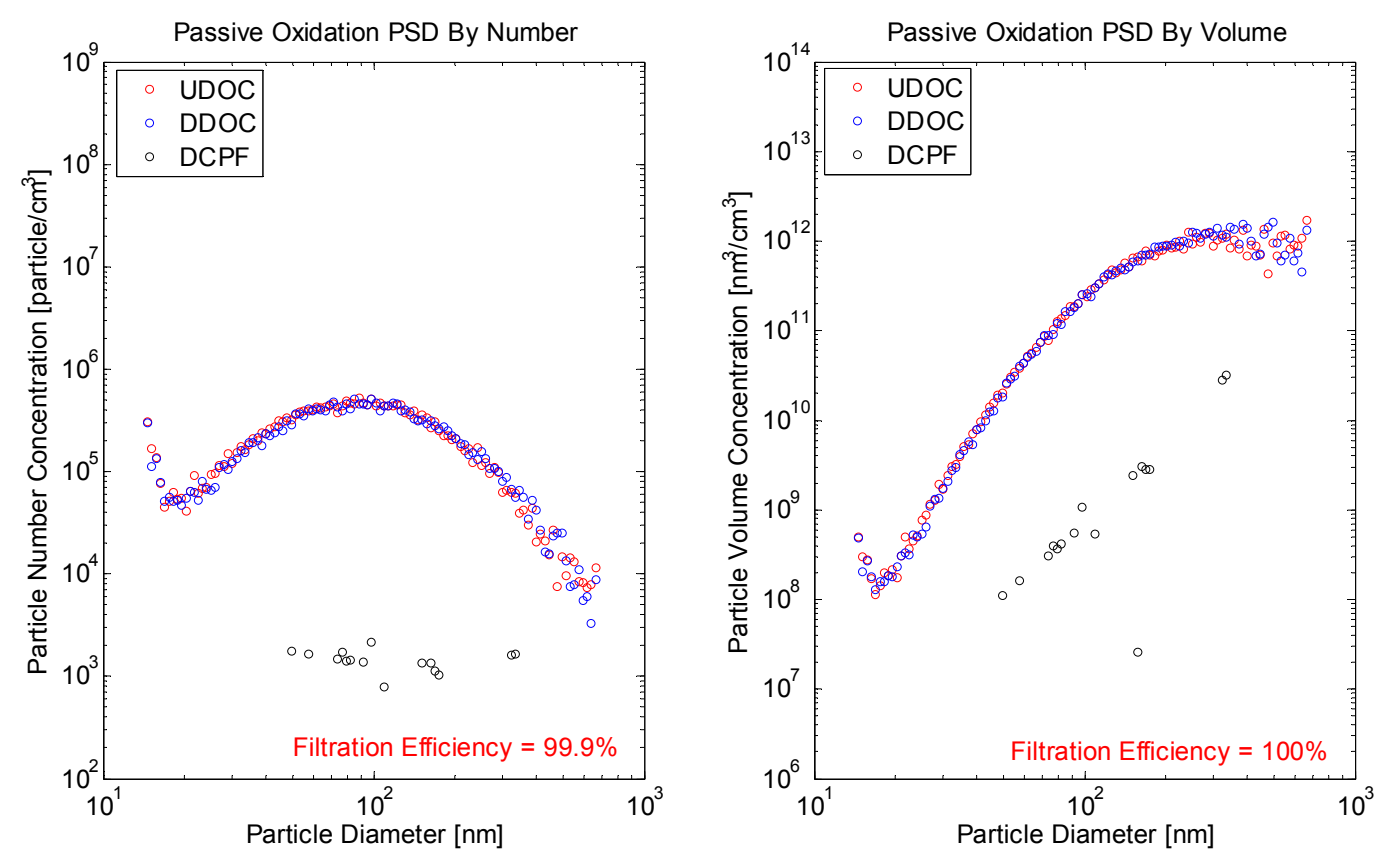

Figure Q. 11: ISL 425 Test 1 Passive Oxidation PSD data 


\section{Appendix R Quartz filter SOF Testing}

Tests were conducted with quartz, rather than glass, fiber filters so that these filters could be tested at the University of Houston. The quartz filters proved to be delicate, and while samples were collected at each engine point used during biodiesel testing, only undamaged samples collected at point $\mathrm{F}$ were chosen to be tested. Results of this testing are shown in Table R.1.

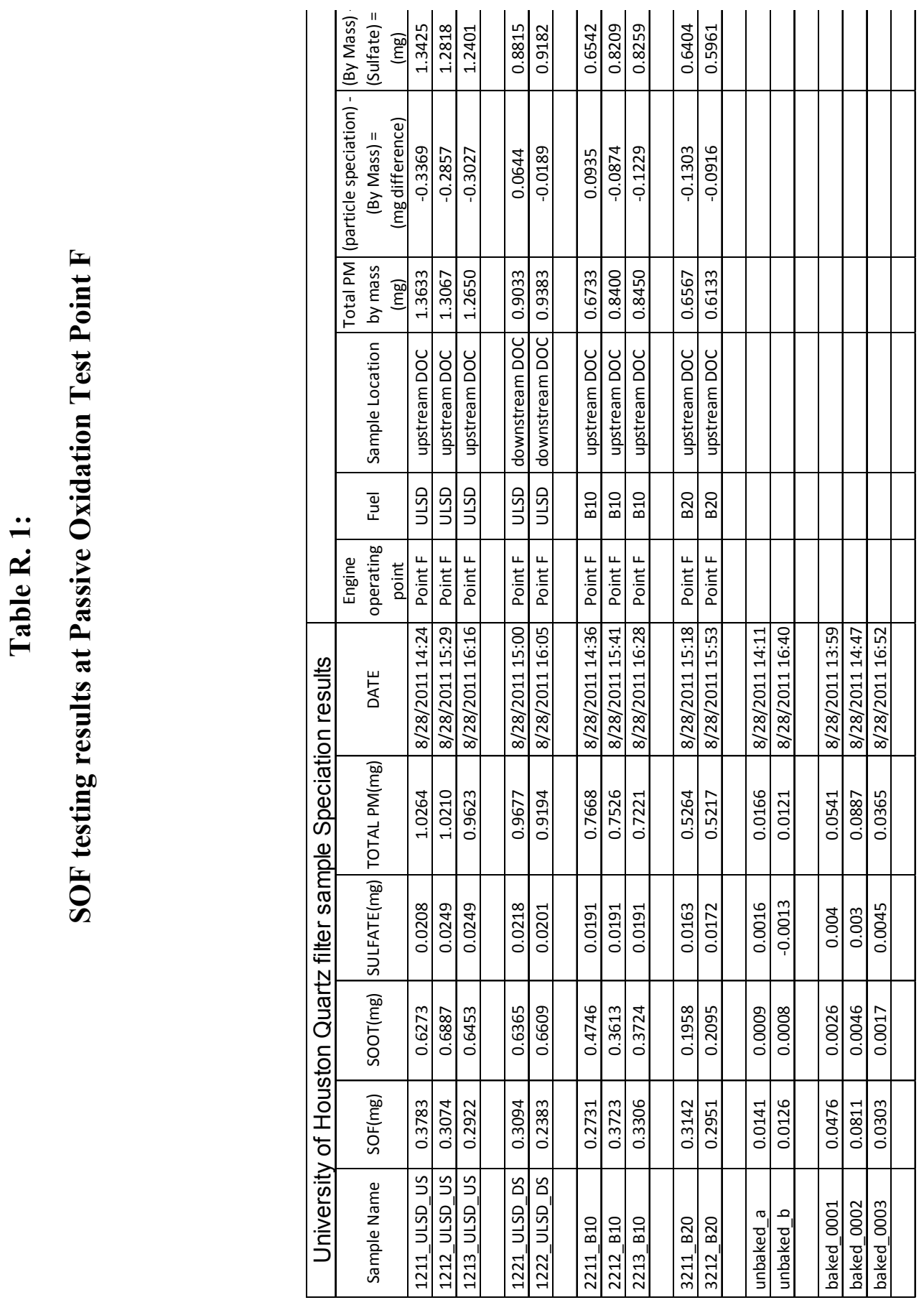



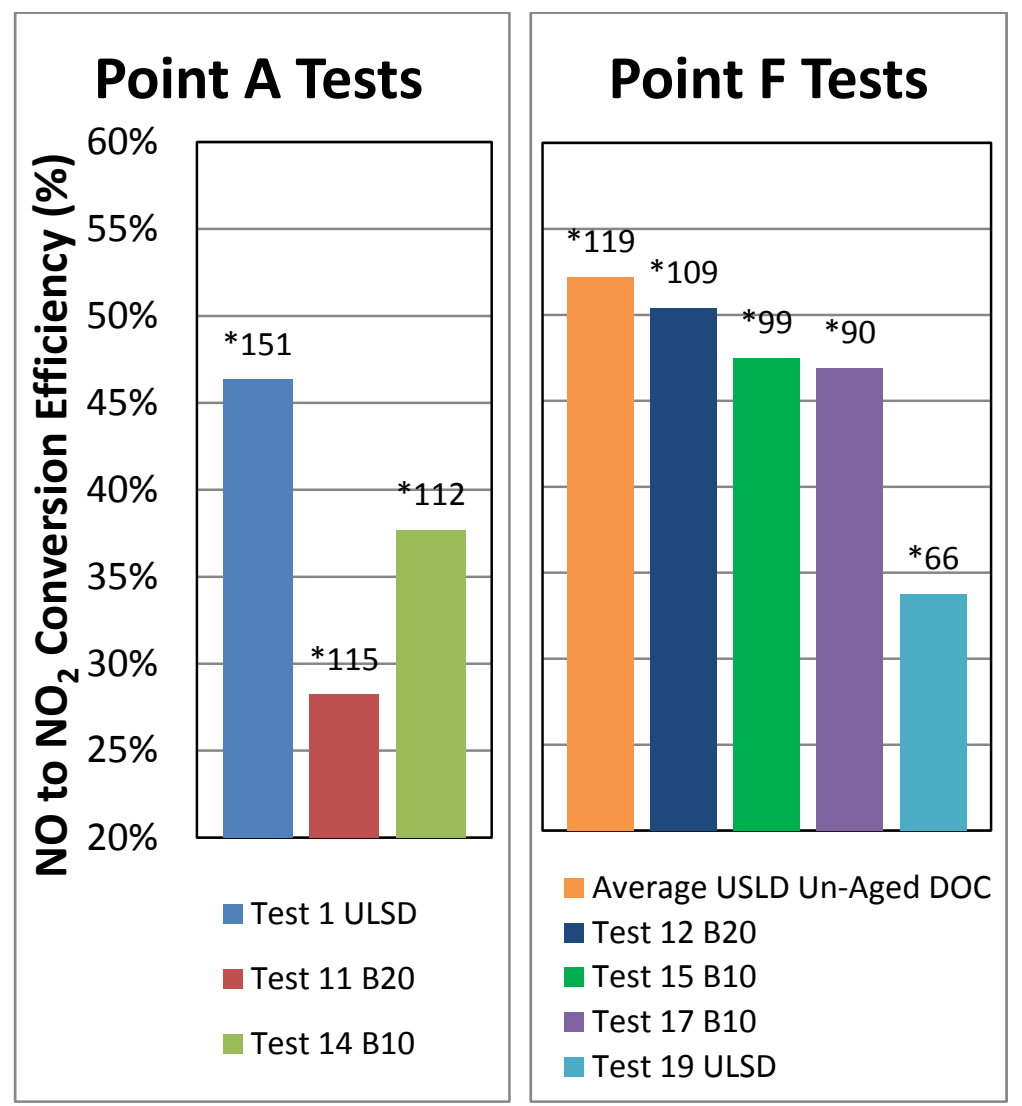

\section{Point H Tests}

*Data labels indicate ppm concentration

$\mathrm{NO}_{2}$ out of DOC

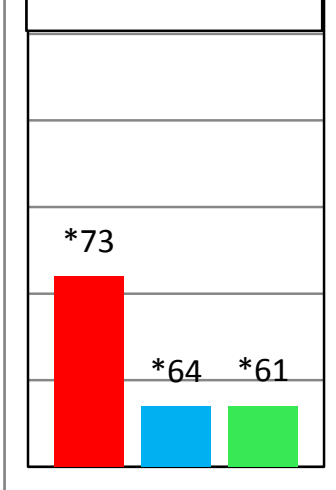

- Test 4 ULSD

- Test 13 B20

$\square$ Test 16 B10

Figure S. 1: Passive oxidation $\mathrm{NO}$ to $\mathrm{NO}_{2}$ conversion efficiencies separated by reference point and plotted chronologically left to right for each point. Emissions data from prior testing is used [2]. 


\section{Appendix T Permissions to Use Copyrighted Material}

-----Alkuperäinen viesti-----

Lähettäjä: Kenneth Shiel [mailto:klshiel@mtu.edu]

Lähetetty: 3. helmikuuta 2012 17:46

Vastaanottaja: juha; kauko; Tyler

Aihe: MTU test results from preliminary Pegasor sensor test, permission to publish in Ken Shiel's Thesis

All,

Attached is the Pegasor sensor test report which Chris recently sent. I would like to ask for permission to use this content in my thesis (This letter is for Figure 4.30).

Thanks,

Ken Shiel

Sent By juha On: February 6, 2012 2:31 AM

To: klshiel; kauko; Tyler

This is perfectly OK. Maybe you could discuss a little bit about possible differences between filter and PPS-M. I do not have an answer for this, but semivolatiles act different a different engine loads. Hop PPS-M does not measure these, but filter does.

Alos, if you could produce us nice pictures that we could use in our promotion materials would be nice. There is never enough good pictures.

Juha

Possible differences between filter and PPS-M results have been discussed in Chapter 4.6.2 
-----Alkuperäinen viesti-----

Lähettäjä: Kenneth Shiel [mailto:klshiel@mtu.edu]

Lähetetty: 14. maaliskuuta 2012 20:14

Vastaanottaja: juha.tikkanen@pegasor.fi

Aihe: Fwd: Permission to publish in Ken Shiel's Thesis

Juha,

I sent this message a few weeks ago, but maybe you missed it. Attached I have written an explanation of the PPS. Could you review this and verify that it is correct?

Also, in this explanation I have included a figure you used in your presentation to us. May I use this figure (This letter is for Figure 2.2) in my thesis?

Do you know of any technical papers that may have been written about this technology?

Thanks,

Ken Shiel

Sent By juha On: March 15, 2012 7:33 PM

To: klshiel

Perfectly OK

Juha Tikkanen, VP Sales\&Marketing, Chairman of the Board

Pegasor Oy

Hatanpään valtatie $34 \mathrm{C}$

33100 Tampere, Finand 
On Feb 20, 2012, at 5:25 PM, Kenneth Shiel<klshiel@mtu.edu> wrote:

James,

May I have permission to use this figure (This letter is for Figure 3.3) detailing the CPF thermocouple layout for my thesis. Please leave this text in your reply

Thanks,

Ken Shiel

KLShiel_Thesis_02_16_2012.docx

Sent By James Pidgeon On: February 20, 2012 5:35 PM

To: klshiel

Ken,

No problem.

JMP

Sent from my iPhone 
----- Original Message -----

From: "Kenneth Shiel" <klshiel@mtu.edu $>$

To: "Christopher Hutton" < crhutton@mtu.edu>

Sent: Monday, February 20, 2012 5:32:21 PM GMT -05:00 US/Canada Eastern

Subject: Thesis Figure

Chris,

May I have permission to use this figure detailing the DOC thermocouple layout, detailing the CPF thermocouple layout you used, and your RRo data from Stage 2 loading to be used in statistical analysis for my thesis? Please leave this text in your reply. (This letter is for Figure 3.2, Appendix A, Appendix N, and Appendix S)

Thanks,

Ken Shiel

Sent By: Christopher Hutton On: February 20, 2012 7:35 PM

To: klshiel

Ken,

Please feel free to use this figure and any other figure in your thesis that you feel is relevant to your experimental work.

Chris Hutton

Christopher Hutton

Research Engineer II

Michigan Technological University

Office: MEEM RM 913

crhutton@mtu.edu 
Kenneth Shiel<klshiel@mtu.edu>wrote:

Kiran,

May I have permission to use the attached content reference the calculation of Stage 1

PM mass retained in my thesis (This letter is for Appendix E )

Thanks,

Ken Shiel

Sent By Kiran Premchand On: February 21, 2012 10:12 PM

To: klshiel

Ken,

Yes you may. Please go ahead.

Best,

Kiran

Sent from my Android phone with K-9 Mail. Please excuse my brevity. 
Sent By klshiel On: February 21, 2012 12:49 AM

To: asappok@,MIT.EDU

Alex,

Attached are some figures that you have put into the DOE reports and explanations of how the RF-DPF sensors work and some descriptions of test results (This letter is for Figure 2.1, Figure 4.26, Figure 4.27). May I use this content in my thesis?

Thanks,

Ken Shiel

Sent By asappok On: February 27, 2012 4:34 PM

To: klshiel

Hi Ken,

Sorry for the delay. OK to include the material attached in your thesis. When will you be turning in your thesis? I started going through some of the previous data again, particularly from the bio-diesel tests, and there may be some additional results that are useful. Let me know if this would also be of interest for your thesis.

Thanks,

Alex 